US Army Corps

of Engineers

Waterways Experiment

Station

\title{
Wave Response of Kaumalapau Harbor, Lanai, Hawaii
}

\author{
Edited by Ernest R. Smith
}

Approved For Public Release; Distribution Is Unlimited 
The contents of this report are not to be used for advertising, publication, or promotional purposes. Citation of trade names does not constitute an official endorsement or approval of the use of such commercial products.

The findings of this report are not to be construed as an official Department of the Army position, unless so designated by other authorized documents. 


\title{
Wave Response of Kaumalapau Harbor, Lanai, Hawaii
}

\author{
Edited by Ernest R. Smith \\ U.S. Army Corps of Engineers \\ Waterways Experiment Station \\ 3909 Halls Ferry Road \\ Vicksburg, MS 39180-6199
}

Final report

Approved for public release; distribution is unlimited 


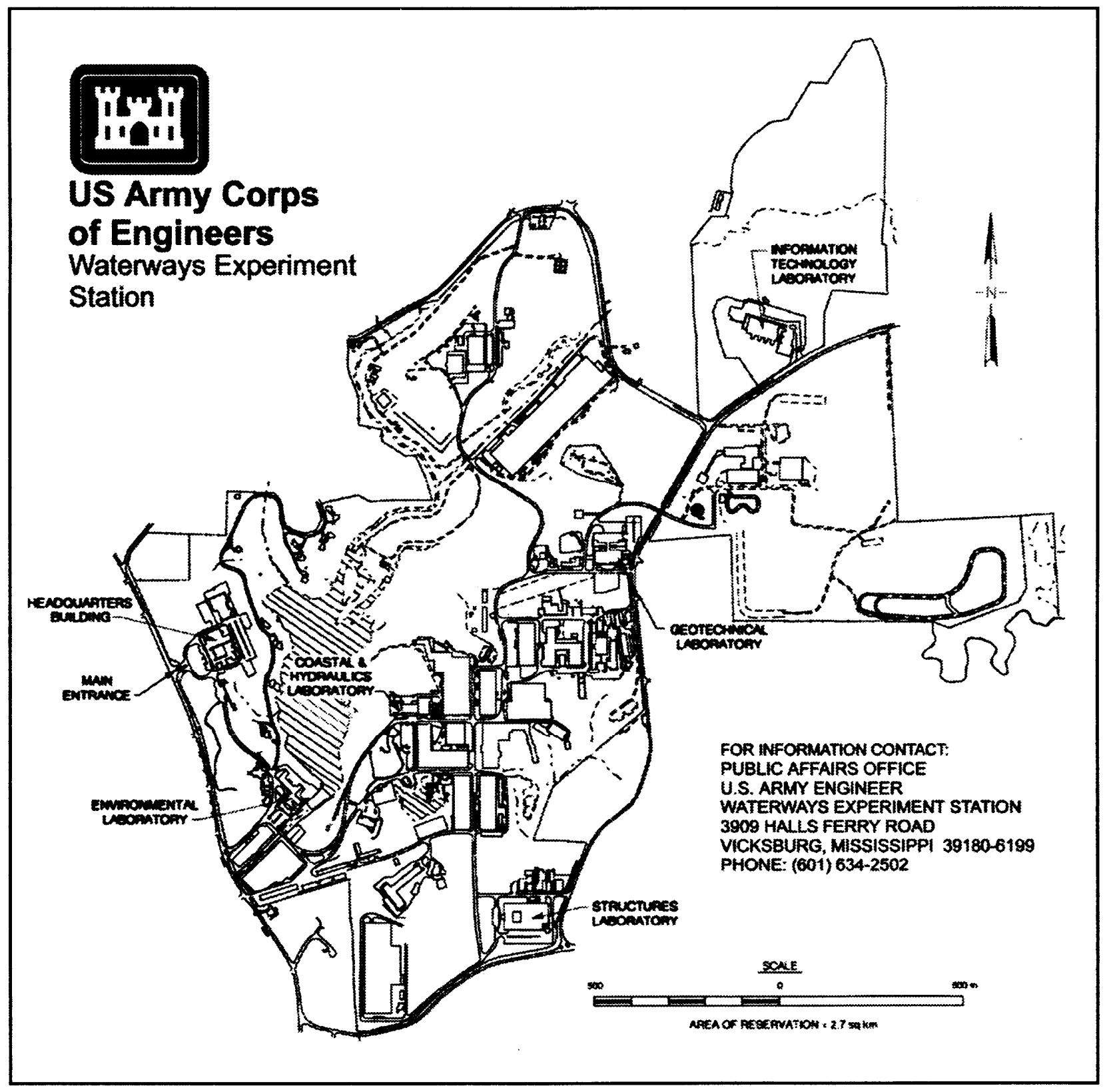

\section{Waterways Experiment Station Cataloging-in-Publication Data}

Wave response of Kaumalapau Harbor, Lanai, Hawaii / edited by Ernest R. Smith ; prepared for U.S. Army Engineer Division, Pacific Ocean.

189 p. : ill. ; $28 \mathrm{~cm}$. - (Technical report ; CHL-98-11)

Includes bibliographic references.

1. Ocean waves - Hawaii - Kaumalapau Harbor. 2. Wind waves - Hawaii - Lanai.

3. Harbors - Hydrodynamics - Mathematical models. 4. Harbors - Hawaii - Lanai. I. Smith, Ernest R. II. United States. Army. Corps of Engineers. Pacific Ocean District. III. U.S. Army Engineer Waterways Experiment Station. IV. Coastal and Hydraulics Laboratory (U.S. Army Engineer Waterways Experiment Station) V. Title. VI. Series: Technical report (U.S. Army Engineer Waterways Experiment Station) ; CHL-98-11. TA7 W34 no.CHL-98-11 


\section{Contents}

Preface $\ldots \ldots \ldots \ldots \ldots \ldots \ldots \ldots \ldots \ldots \ldots \ldots$

Summary $\ldots \ldots \ldots \ldots \ldots \ldots \ldots \ldots \ldots \ldots \ldots$ vii

Introduction $\ldots \ldots \ldots \ldots \ldots \ldots \ldots \ldots \ldots$ vii

Project Goals and Restrictions $\ldots \ldots \ldots \ldots \ldots \ldots$ vii

Wave Climate . . . . . . . . . . . . . . . . . viii

Numerical Model Studies $\ldots \ldots \ldots \ldots \ldots \ldots \ldots$ viii

Physical Model Studies $\ldots \ldots \ldots \ldots \ldots \ldots \ldots \ldots$ ix

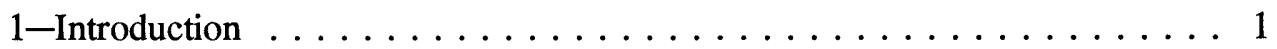

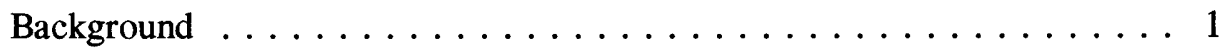

Study Location . . . . . . . . . . . . . . . . . . . 1

Harbor Operational Considerations $\ldots \ldots \ldots \ldots \ldots \ldots$

2-Wave Climate .................... 5

3-Field Wave Measurements $\ldots \ldots \ldots \ldots \ldots \ldots \ldots$

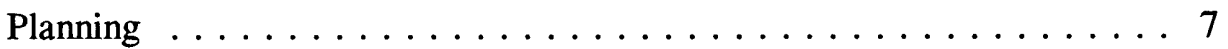

System Design $\ldots \ldots \ldots \ldots \ldots \ldots \ldots \ldots \ldots \ldots \ldots \ldots \ldots \ldots \ldots$

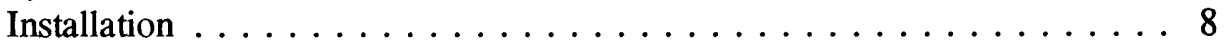

Results ...................... 9

4-Numerical Model . . . . . . . . . . . . . . . . . . . . . . . . 15

Objectives and Approach $\ldots \ldots \ldots \ldots \ldots \ldots \ldots \ldots$

Model Description . . . . . . . . . . . . . . . . 16

Simulation Procedures and Calculations $\ldots \ldots \ldots \ldots 33$

5-Harbor Response to Wind Waves and Swell . . . . . . . . . . . 38

Directional Sensitivity of the Harbor $\ldots \ldots \ldots \ldots \ldots \ldots$

Comparison of Alternatives . . . . . . . . . . . . 38

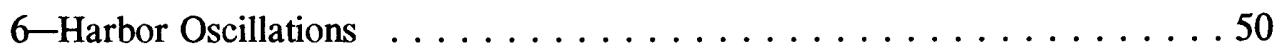


7-Physical Model Design $\ldots \ldots \ldots \ldots \ldots \ldots \ldots \ldots \ldots \ldots \ldots \ldots \ldots \ldots \ldots$

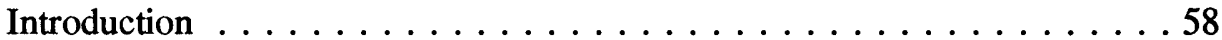

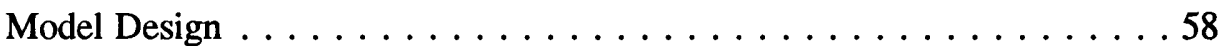

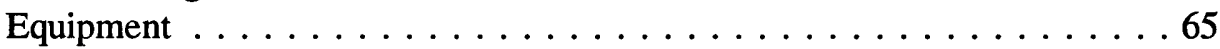

8-Physical Model Experiment Conditions . . . . . . . . . . . . 70

Still-water Levels . . . . . . . . . . . . . . . . . . . . 70

Factors Influencing Selection of Experiment Wave Characteristics . . . . 71

Harbor Layout Configurations Studied . . . . . . . . . . . . . 76

9-Physical Model Experiments and Results $\ldots \ldots \ldots \ldots \ldots$

Experiment Series $\ldots \ldots \ldots \ldots \ldots \ldots \ldots \ldots \ldots \ldots \ldots$

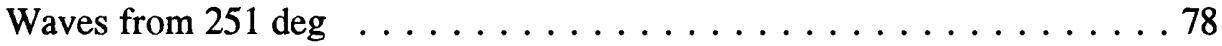

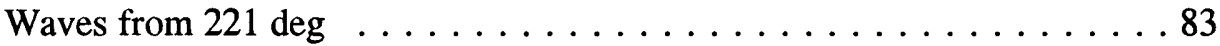

Waves from $291 \mathrm{deg} \ldots \ldots \ldots \ldots \ldots$

Summary of Results from the Three Wave Directions . . . . . . . . .91

Effectiveness of the Dogleg Breakwater Over Existing Conditions and the

Straight Breakwater Alternative . . . . . . . . . . . . . 91

Increased Harbor Usability with the Dogleg Extension . . . . . . . . . . 96

10-Three-Dimensional Stability Study . . . . . . . . . . . . . . 101

The Model . . . . . . . . . . . . . . . . . . . . . . . 101

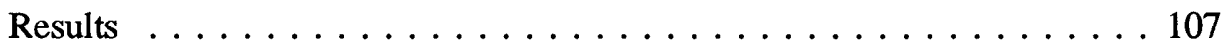

Summary . . . . . . . . . . . . . . . . 111

11-Conclusions and Recommendations $\ldots \ldots \ldots \ldots 113$

Harbor Response to Wind Waves, Swell, and Long Waves . . . . . . . . 113

Conclusions . . . . . . . . . . . . . . . . . . 113

References ........................... . . 115

Appendix A: Monthly Summaries of Prototype Data . . . . . . . . . A1

Appendix B: Three-Dimensional Stability Photographs . . . . . . . . B1

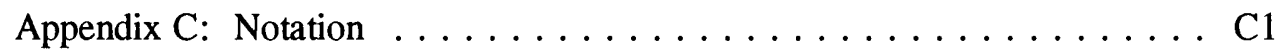

SF 298 


\section{Preface}

This study was authorized by the U.S. Army Engineer Division, Pacific Ocean (POD), and was conducted by personnel of the Coastal and Hydraulics Laboratory (CHL) of the U.S. Army Engineer Waterways Experiment Station (WES). The study was conducted during the period January 1994 through July 1995, and included a wave hindcast study, field wave measurements, and physical and numerical modeling. Ms. Helen Stupplebeen, Mr. Stanley Boc, and Mr. Pat Tom, all of POD, and Mr. Fred Nunes, State of Hawaii, oversaw progress of the study.

Technical editor for this report was Mr. Ernest R. Smith, Research Hydraulic Engineer, Coastal Structures Branch (CSB), Navigation and Harbors Division (NHD), CHL. Chapter 1, "Introduction," was prepared by Dr. Edward F. Thompson, and Ms. Lori L. Hadley, both of the Coastal Hydrodynamics Branch (CHB), NHD, CHL, and Mr. Gordon S. Harkins, Harbors and Entrances Branch (HEB), CHL. Chapter 2, "Wave Climate," was written by Dr. Jon M. Hubertz and Ms. Jane B. Payne, CHB, NHD, CHL. Chapter 3, "Field Wave Measurements," was prepared by Mr. David D. McGehee, Prototype Measurement and Analysis Branch (PMAB), Coastal Sediments and Engineering Division (CSED), CHL. Chapters 4, "Numerical Model," 5, "Harbor Response to Wind Waves and Swell," and 6, "Harbor Oscillations," were prepared by Dr. Thompson and Ms. Hadley. Chapter 7, "Physical Model Design," was prepared by Messrs. Harkins and Smith. Chapters 8, "Physical Model Experiment Conditions," and 9, "Physical Model Experiments and Results," were written by Mr. Harkins. Chapter 10, "ThreeDimensional Stability Study," was written by Mr. Smith. Chapter 11, "Summary," was prepared by Dr. Thompson, Ms. Hadley, and Messrs. Smith and Harkins. The work was performed under the direct supervision of Dr. Martin C. Miller, Chief, CHB; Mr. William L. Preslan, Chief, PMAB; Mr. Thomas W. Richardson, Chief, CSED; Mr. Dennis G. Markle, Chief, HEB; Mr. D. D. Davidson, Chief, CSB; and Mr. C. E. Chatham, Chief, NHD; and under the general supervision of Mr. Charles C. Calhoun, Jr., Assistant Director, CHL, and Dr. James R. Houston, Director, CHL. Word Processing and formatting were done by Ms. Myra E. Willis, CHL.

Liason was maintained with POD through monthly progress reports and telephone conversations during the course of the investigation. Additionally, Ms. Stupplebeen and Messrs. Boc, Tom, and Nunes visited WES to observe physical model experiments and discuss progress of the study. 
At the time of publication of this report, Director of WES was

Dr. Robert W. Whalin. Commander was COL Robin R. Cababa, EN.

The contents of this report are not to be used for advertising, publication, or promotional purposes. Citation of trade names does not constitute an official endorsement or approval of the use of such commercial products. 


\section{Summary}

\section{Introduction}

The U.S. Army Engineer Waterways Experiment Station (WES), Coastal and Hydraulics Laboratory, provided technical support to the U.S. Army Engineer Division, Pacific Ocean (POD) for the study of Kaumalapau Harbor. Kaumalapau is a privately owned small barge harbor located on the southwest coast of Lanai, Hawaii, and is the only commercial harbor serving the island. Fuel and commodities for the island's inhabitants come through this harbor. The harbor is semicircular in shape and has no distinct entrance channel. A wharf is located along the northern portion of the harbor and is protected by a 76-m- (250-ft-) long breakwater. The rubblemound breakwater has been damaged by past hurricanes and provides minimal shelter to the wharf area.

Four interrelated aspects of the study were conducted by WES; (a) review of wave hindcast data, (b) field wave gauging, (c) numerical model simulations, and (d) physical model studies.

\section{Project Goals and Restrictions}

The goal of the study was to decrease wave heights along the wharf area without adversely impacting harbor navigation. Initially, harbor pilots were contacted to ascertain their navigational needs. Although the usual criteria established for harbors is for the entrance channel to be three to ten times the boat width, at Kaumalapau, the vessel has already started to make its turn toward the wharf by the time it reaches the harbor breakwater and thus the standard convention for channel width is not applicable. The pilots stated that the harbor is so small and there is little room inside the harbor to turn so that no protective structure should encroach on the navigation channel. This criteria eliminated most protective structures, except for an extension to the existing breakwater of approximately $46 \mathrm{~m}(150 \mathrm{ft})$.

POD wanted to improve wave conditions at Kaumalapau Harbor so that the harbor's use would not be limited by wave conditions. The established project goal with end-user input, was to decrease the incident wave height of $4.6 \mathrm{~m}(15 \mathrm{ft})$ to $1.5 \mathrm{~m}(5 \mathrm{ft})$ at the wharf. 


\section{Wave Climate}

Wave conditions and southern swell information needed for numerical and physical model input were queried from Wave Information Study (WIS) results. WIS analyzed 20 years of meteorological data to predict (hindcast) wave heights every $3 \mathrm{hr}$ for 20 years by running a computer program that infers wind speed and its impact on wave generation in the open ocean. In addition to hindcast wave data, measured wind and wave data at three nondirectional National Oceanic and Atmospheric Administration (NOAA) buoys south and southwest of Kaumalapau were analyzed.

WIS data and NOAA buoys were located a sufficient distance from Kaumalapau Harbor so that wave data at the site were needed to calibrate the numerical model. Validation of a harbor model involves driving the model with measured input data, and comparing the model's output to measured response at one or more sites within the harbor. Two wave gauges were required based on preliminary results from the numerical model HARBD and logistic constraints. Data from the field measurements were used to adjust variables used in the numerical model, thus providing a calibrated and validated model.

\section{Numerical Model Studies}

The numerical model studies had four main objectives: (a) assist in optimizing placement of field wave gauges; (b) validate the model with field data; (c) maximize efficiency of physical model experiments by identifying most damaging incident wave directions and most promising harbor modification plans; and (d) evaluate harbor resonance characteristics of the final WES-recommended plan relative to the existing harbor.

To perform the wave response study for Kaumalapau Harbor, WES's numerical wave response model HARBD was used (Chen 1986, Chen and Houston 1987, Lillycrop et al. 1993, Thompson and Hadley 1995). HARBD is used in the calculation of linear wave response in harbors of arbitrary shape and depth. The model includes capabilities for modeling both long and short waves, bottom friction, and partially reflective boundaries. The model does not include wave transmission, wave overtopping, currents, wave breaking, or nonlinear effects. Diffraction around structure ends is represented as diffraction around a blunt vertical wall with a specified reflection coefficient. Despite these limitations, HARBD still was suitable for meeting the numerical modeling objectives of the Kaumalapau Harbor study.

HARBD's principal output consists of an amplification factor and phase. Amplification factors are easily interpreted and predict those wave periods that cause oscillation or tilting of the free surface which in turn make mooring of vessels difficult. Phase information is useful in long wave studies for determining relative phase differences within the harbor and interpreting harbor oscillation patterns and which mooring locations to avoid. 
HARBD studies were conducted to compare the existing and recommended harbor plan as well as evaluating alternative designs for wind waves (6-22 sec) and long-period waves $(23-500 \mathrm{sec})$. The harbor response to long-period waves was simulated to identify resonant nodes of free surface oscillation. Compared to the existing plan, resonant nodes at several locations along the wharf for the recommended plan show fewer, but generally higher, oscillations of the free surface. The model revealed that the shorter wind waves are smaller along the wharf area for the recommended plan in comparison with existing conditions.

\section{Physical Model Studies}

An undistorted, three-dimensional physical model of Kaumalapau Harbor was constructed to further evaluate harbor response to short-period waves for existing conditions and two alternative harbor layout configurations for three incident wave directions. Once the recommended configuration was defined, physical model experiments were conducted to optimize breakwater stability.

Wave response at the pier area was analyzed for three breakwater configurations. Existing breakwater conditions were evaluated first to provide a baseline against which the alternative configurations could be compared. The second breakwater configuration studied was the pre-Hurricane Ewa breakwater length of $122 \mathrm{~m}$, which extends to the edge of the navigation channel (an additional $50 \mathrm{~m}$ past existing conditions). The last alternative studied is also the preferred plan and was termed the dogleg breakwater. The last $15 \mathrm{~m}$ of the breakwater center line is aligned $30 \mathrm{deg}$ toward the inside of the harbor as measured from the center line of the straight breakwater.

Of the alternatives studied and compared to existing conditions, the dogleg breakwater provides better attenuation of short-period wave energy. The largest waves outside the harbor that will meet the $1.5-\mathrm{m}(5-\mathrm{ft})$ criterion along the wharf for the existing, straight, and dogleg breakwaters (for waves from 221 and $251 \mathrm{deg}$ measured clockwise from $\mathrm{TN})$ are 2.0, 2.1, and $2.3 \mathrm{~m}(6.5,7.0$, and $7.6 \mathrm{ft}$ ), respectively, when averaged over the two directions and numerous wave heights and periods. This does not meet the original design criteria established by the state, but these breakwaters do meet the criteria established by the end users. Further wave reduction could be met, but the breakwater would not meet the navigational criteria and economic constraints.

Increasing the breakwater length provides more protection, but care is needed to build the structure with proper armor units to ensure durability and lower maintenance costs. Armor units placed on the ends of breakwaters often are vulnerable to waves which overtop and diffract around the structure because the units are subjected to forces from the opposing direction of a two-dimensional situation. Heavier units often are required for breakwater stability on the head (seaward end) of the structure.

The design wave was specified in a reconnaissance report as a $9.8-\mathrm{sec}, 8.5-\mathrm{m}$ (27.9-ft) deepwater wave (U.S. Army Engineer District, Honolulu 1993) based upon the "worst case" hurricane passing the island. To determine a factor of safety for the structure, wave heights exceeding the design height were generated 
for 9.8- and 12-sec periods. Wave heights associated with 16-sec periods from the 221- and 251-deg directions are smaller in magnitude (limitations of the wave machine); therefore, only heights up to $H_{o}=8.5 \mathrm{~m}$ were generated for 16 -sec waves. All wave conditions were reproduced at a storm surge water level of $+1.52 \mathrm{~m}(4.98 \mathrm{ft})$ mean lower low water and a duration of $24 \mathrm{hr}$.

Experiment results revealed that: a toe trench at the shoreward end on the sea side of the breakwater was necessary to obtain stability and densely placed 18,144-kg CORE-LOCS ${ }^{\mathrm{TM}}$ (hereafter referred to as core-loc) were stable for design waves, while heavier core-locs $(31,389-\mathrm{kg})$ were required for wave heights exceeding the design condition. 


\section{Introduction ${ }^{1}$}

\section{Background}

At the request of the U.S. Army Corps of Engineers, Pacific Ocean Division (POD), the U.S. Army Engineer Waterways Experiment Station's (WES) Coastal and Hydraulics Laboratory carried out a wave response study for Kaumalapau Harbor, Lanai, Hawaii. Kaumalapau Harbor, Lanai's main commercial harbor, is being studied for development. It is protected from the open ocean by a single rubble-mound breakwater.

The breakwater, particularly the seaward end, has suffered damage from previous storms. Most recent damage was caused by Hurricane Iniki and winter storm waves in February 1993. In its present configuration, the most seaward $22.9 \mathrm{~m}(75 \mathrm{ft})$ of breakwater length has been reduced to a submerged mound. The mound extends south and slightly seaward from the existing breakwater head. The shallowest depth over the submerged breakwater head is approximately $3.6 \mathrm{~m}$ $(12 \mathrm{ft})$.

There is concern that the existing breakwater does not provide adequate protection of the harbor from approaching ocean waves. Wave action in the vicinity of the main dock is the primary concern. Difficult wave conditions are reported to occur during the winter season, particularly during high energy swell from the north.

\section{Study Location}

Kaumalapau Harbor is located in a small embayment along the south central part of the west coast of the island of Lanai (Figure 1). The general exposure is to the west. The northwest lobe of Lanai shelters the site from the north and northnorthwest. The entrance to Kaumalapau Harbor is formed by a rocky point on the south side and the main Kaumalapau breakwater on the north side (Figure 2). Navigation lights are located on the breakwater tip and the point south of the harbor.

\footnotetext{
${ }^{1}$ Written by Edward F. Thompson, Lori L. Hadley, and Gordon S. Harkins.
} 


\section{Hawaiian Islands}

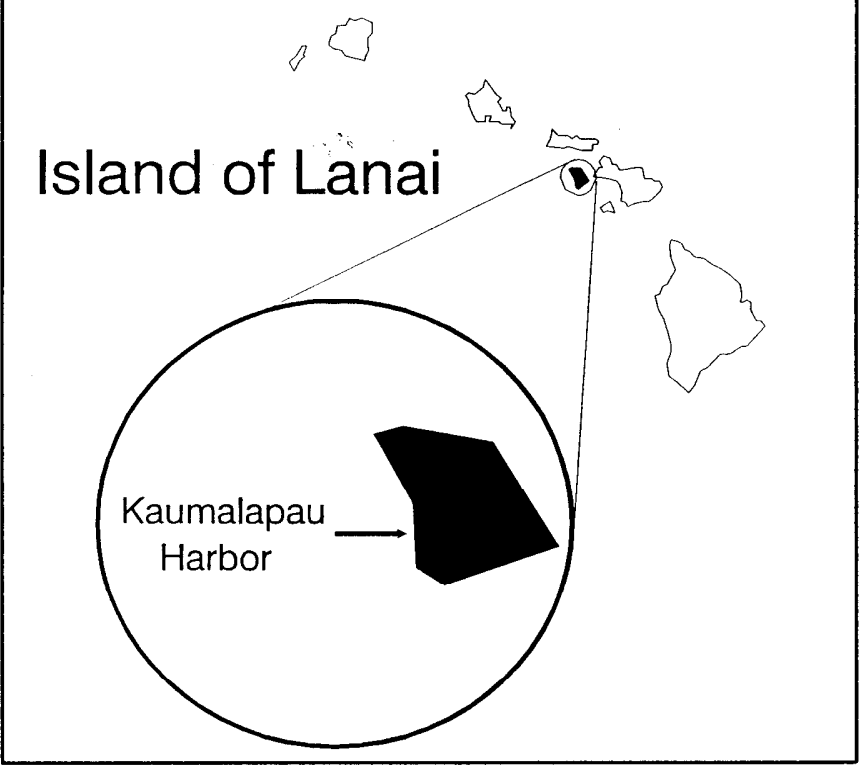

Figure 1. Study location

The harbor entrance is a $183-\mathrm{m}-(600-\mathrm{ft}-)$ wide opening into a semi-protected, $40,500-\mathrm{m}^{2}(10$-acre) berthing area. Water depths in the berthing area range from 9.1 to $15.2 \mathrm{~m}$ ( 30 to $50 \mathrm{ft}$ ). The rubble-mound breakwater is approximately $76.2 \mathrm{~m}$ $(250 \mathrm{ft})$ long with a crest elevation of about $3.0 \mathrm{~m}(10 \mathrm{ft})$. Commercial operations occur along a single $121.9-\mathrm{m}(400-\mathrm{ft})$ wharf in the lee of the breakwater. The wharf is concrete atop a rock base. The wharf face is concrete down to about the waterline and pile supported under water. Behind the piles is a nearly vertical rock face.

Kaumalapau Harbor is Lanai's main commercial harbor. Lanai's second harbor of note is a small boat harbor at Manele Bay, on the southeast coast. Primary cargos at Kaumalapau have traditionally been outbound pineapples and inbound supplies needed for people and operations involved in pineapple farming. Pineapple farming on Lanai has virtually ended, and facilities for recreation and tourism are developing. Kaumalapau Harbor will continue to be the critical sea link between Lanai's residents and visitors and the rest of the world.

Most of the shoreline of Kaumalapau Harbor consists of rocky cliffs. Water depth over the harbor is generally between 6.1 and $15.2 \mathrm{~m} \mathrm{(20} \mathrm{and} 50 \mathrm{ft})$. A stream discharges into Kaumalapau Harbor in the center of the eastern shore of the embayment. The bottom is shallow and gently sloped in the vicinity of the stream outlet. Bottom material in the harbor is generally sand with some rocky features near the shore and in the east-central part of the embayment. 


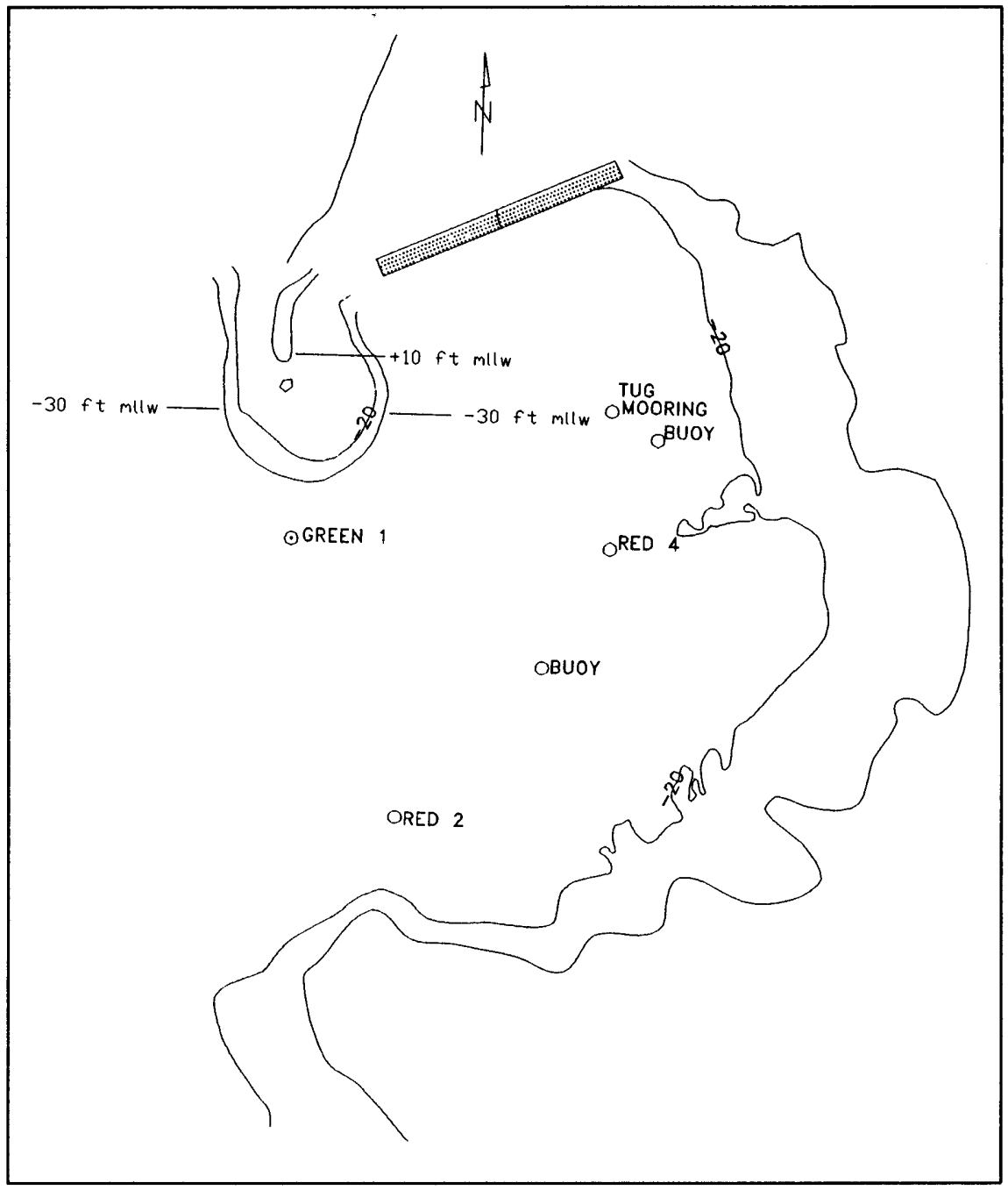

Figure 2. Kaumalapau Harbor

\section{Harbor Operational Considerations}

Before the study commenced, the harbor end users - Sause Brothers (fuel barge operators) and Young Brothers (container ship owners) were contacted to ascertain their operational and navigational needs. Kaumalapau is a small harbor and the first stipulation imposed by the harbor pilots was that no protective structure should encroach into the existing navigation channel. Kaumalapau is unique in that the embayment is very narrow. The distance from the $6.1-\mathrm{m}(20-\mathrm{ft})$ depth contour along the shoreline adjacent to the cliff walls to the $20-\mathrm{m}(65.6-\mathrm{ft})$ depth contour of the existing breakwater is approximately $150 \mathrm{~m}(500 \mathrm{ft})$. The navigation channel is indicated by the navigation buoys shown in Figure 2.

The largest vessel calling at Kaumalapau Harbor is a fuel barge with a length of $83 \mathrm{~m}(272 \mathrm{ft})$, a beam width of $23 \mathrm{~m}(76 \mathrm{ft})$, and a draft of $5.3 \mathrm{~m}(17.4 \mathrm{ft})$. The fuel 
barge is accompanied by two tugs, which are $30.5 \mathrm{~m}(100 \mathrm{ft})$ in length. The tugs operate on the same side of the barge and the combined width of the three vessels is approximately $30.5 \mathrm{~m}(100 \mathrm{ft})$.

Container barges call on the harbor on a regular basis. These vessels are $69 \mathrm{~m}$

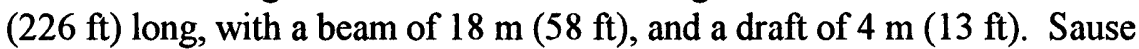

Brothers has indicated that the fuel barge requires smaller wave conditions than the container barge for safe navigation and mooring.

The operational condition established by POD, after discussion with the end users, was for $1.5-\mathrm{m}(4.9-\mathrm{ft})$ wave heights or less at the wharf when $4.6-\mathrm{m}(15.1-\mathrm{ft})$ waves are present outside the harbor. These waves were not linked to a specific direction or wave period. 


\section{Wave Climate ${ }^{1}$}

A large-scale physical model of the harbor was constructed by WES to optimize needed modifications to the existing harbor. Wave conditions required to drive the model were requested from the Wave Information Study (WIS). Measured wind and wave data at three nondirectional National Oceanic and Atmospheric Administration (NOAA) buoys south and southwest of Kaumalapau were analyzed to supplement WIS data.

Statistical products (percent occurrence tables and wave rose diagrams) describing hindcast results at WIS stations 34 and 35 were extracted from the WIS Pacific Phase I final report (1986), and guidance for the use of the products was provided. A similar statistical analysis was performed with measured data from NOAA buoys 51002,51003 , and 51005 (Figure 3). Because these buoys do not measure wave direction, recorded wind direction data were used to estimate wave direction.

Results from two Pacific Phase I hindcast stations indicated that, for the 20 years hindcast, the mean wave height is near $2.5 \mathrm{~m}(8.2 \mathrm{ft})$. The largest significant wave height is $6.7 \mathrm{~m}(22.0 \mathrm{ft})$, and the mean peak period is $9.2 \mathrm{sec}$. A total of 58,440 cases were analyzed, and 99 percent of the waves came from the north-northwest through north to north-northeast, meaning that only 1 percent or less came from directions that would affect Kaumalapau. This result is explained by the shape of the WIS Pacific Phase I grid, which allows only a small amount of energy from the south and west of Hawaii to come into the hindcast grid.

Analysis of measurements from three nondirectional NOAA buoys near Hawaii supplements WIS hindcast data. Occurrence of waves from south and west of Kaumalapau is estimated using observations from a wind direction window (180to 315-deg azimuth). Occurrences of total observations for buoys 51002, 51003, and 51005 from that window are $1.6,3.7$, and 7.0 percent, respectively. Summer swell (only 0.1 or 0.2 percent of total observations) is isolated by limiting the occurrences to April through September and wave period to $12.5 \mathrm{sec}$ or more. Total wave observations are classified by height and period, as is swell for all seasons and summer swell for all directions. Wave height maximums are $6.2 \mathrm{~m}$ $(20.3 \mathrm{ft})$ for buoy $51002,6.8 \mathrm{~m}(22.3 \mathrm{ft})$ for buoy 51003 , and $5.4 \mathrm{~m}(17.7 \mathrm{ft})$ for buoy 51005 for the individual period of record.

\footnotetext{
${ }^{1}$ Written by Jane B. Payne and John M. Hubertz.
} 


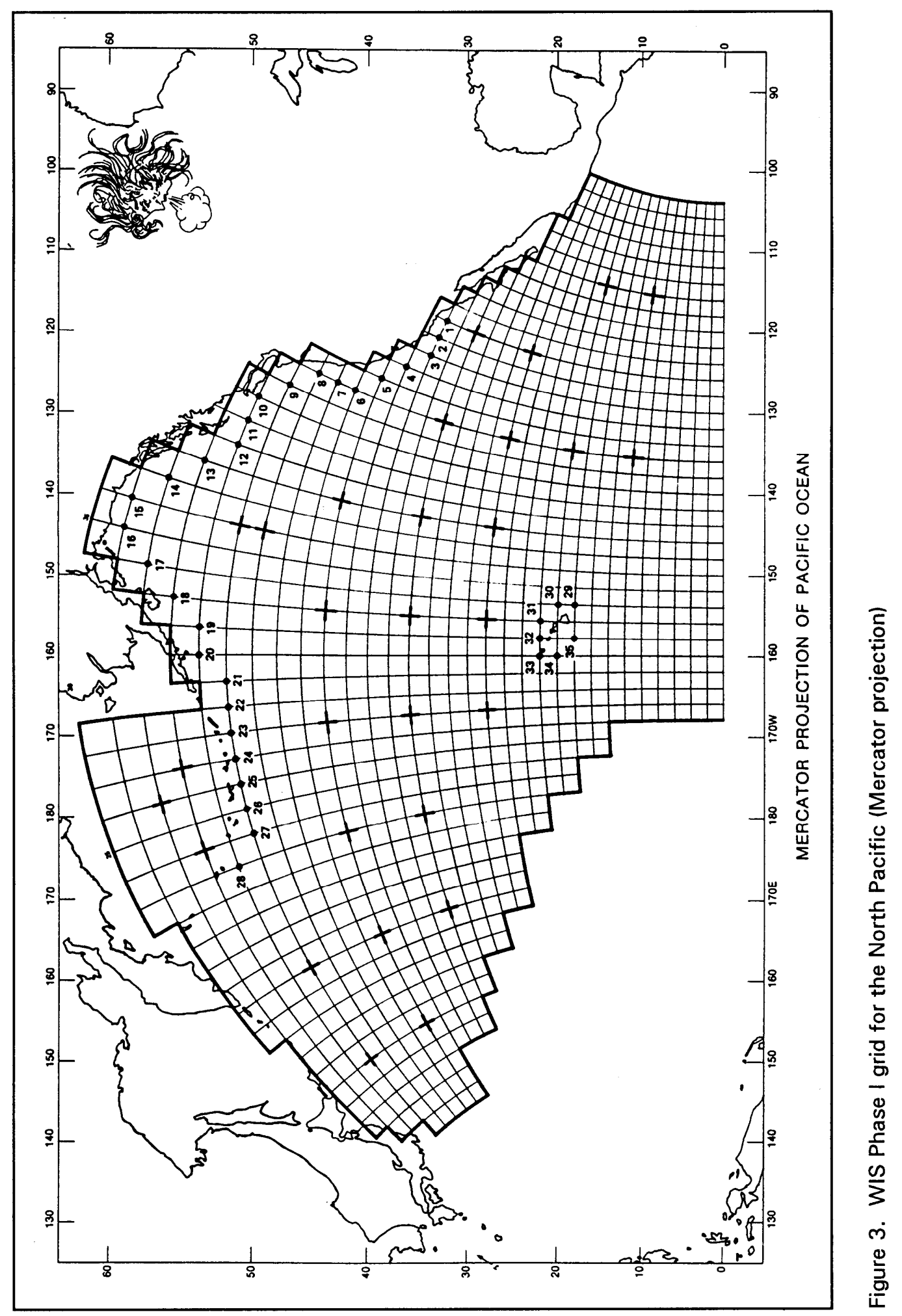




\section{Field Wave Measurements ${ }^{1}$}

\section{Planning}

Wave measurements were made at Kaumalapau Harbor to provide data to validate numerical (HARBD) and physical models of the harbor response to incident wave energy. (A secondary objective was validation of the structure stability model. Since it would require measurements of an event of sufficient magnitude to cause quantifiable damage to the structure, this objective was not expected to be met during a limited-duration study.) Validation of a harbor model involves driving the model with measured input data, and comparing the model's output to the measured response at one or more sites within the harbor. Planning the measurement program requires specifying the location, duration, and type of data collected. Ideally, incident measurements coincide with the outer boundary of the model, and there are sufficient interior measurements to define the spatial variability within the harbor. It is desirable to continue measurements long enough to obtain a broad range of incident conditions - up to or exceeding design conditions. Finally, the types of data (wave energy, wave direction, currents, etc.) and the range of frequencies measured will equal or exceed the requirements of the model. Practically, fiscal, logistic, or schedule limits will constrain the measurement plan.

A minimum of two sites was required; one for incident conditions, and one for harbor response. Wave gauge placement was based on preliminary (uncalibrated) results from HARBD and logistic constraints. Both the numerical and physical models include water level, incident wave energy, frequency, and direction as input, and the preliminary HARBD results showed the harbor response was sensitive to incident wave direction. The available budget only permitted installation of nondirectional wave gauges. Funds from other programs were anticipated to support a directional wave gauge in deep water, west of Lanai, at some point during the study.

While depths at outer boundaries of the models ranged from about 29 to $45.7 \mathrm{~m}$ (95.1 to $150 \mathrm{ft}$ ) mean lower low water (mllw), instrumental (pressure attenuation factor) and installation (divers' bottom times) constraints limited gauge depths to a maximum of about $21 \mathrm{~m}$. A site between the toe of the breakwater head and the entrance channel met the depth constraint and provided some protection from the

\footnotetext{
${ }^{1}$ Written by David D. McGehee.
} 
risk of damage from tow bridles. However, measurements at this site will contain some reflected energy; in fact, the HARBD results showed the entire model domain was affected by reflected energy from the breakwater and/or the interior of the harbor. Because of the steep shoreline, an "incident only" wave measurement would require a gauge on the order of miles offshore. For the single interior gauge, a position on the wharf is obviously of most interest from an operations viewpoint. The middle to western section of the wharf was recommended by the HARBD results, since it showed unexpected amplification for the longer wind waves (swell), and contained fewer nodes for harbor oscillation than the eastern end.

\section{System Design}

Potential damage from large waves, vessel traffic, and vandalism made bottommounted pressure sensors the best sensor choice. Oscillating quartz transducers (ParosScientific) were used in PVC pressure housings. The transducers were sampled at $1 \mathrm{~Hz}$, which is sufficient to permit measurement of wind-wave energy up to $0.5 \mathrm{~Hz}$. While continuous sampling is desirable, limitations of memory and battery power prescribe a discrete sampling scheme. Both sensors were sampled for $2,048 \mathrm{sec}$ every hour. When conditions were mild (significant wave height below $1.5 \mathrm{~m}(4.9 \mathrm{ft}))$ sampling was reduced to 4 -hr intervals.

Two data capture modes were used: telemetry to WES, to monitor system performance and ensure recovery of transmitted data in the event of catastrophic damage to the system; and internal storage, to retain data for later recovery in the event of loss of the telemetry link. The telemetry link included a double-armored, 0.01-m-diam electro-mechanical cable from the transducer to a WES-designed Remote Terminal Unit (RTU), and a modem (Hayes Smart-modem 1200) connected to a commercial telephone line. Data were retrieved daily through automatic dial-up and connection by the mainframe computer at WES. The RTU contained a $256-\mathrm{Kb}$ buffer to hold data for short-duration (3 days) interruptions in the recovery. In the event of longer-term failure of the telemetry link, a $12-\mathrm{Mb}$ multi-channel data logger (Woods Hole Instruments) was located onshore. The RTU and sensors were normally powered by $110-\mathrm{V} \mathrm{AC}$ shore power. An independent battery pack would operate the sensors and data logger (but not the RTU and modem) for 6 months in the event of power loss.

\section{Installation}

The system was installed during 10 through 13 January 1994. The incident gauge (HI01) was clamped about $0.3 \mathrm{~m}(1 \mathrm{ft})$ off the bottom onto a $0.05-\mathrm{m}-(0.17$ $\mathrm{ft}$ )-diam pipe pile that had been jetted $3 \mathrm{~m}$ into the sand bottom in approximately 
$21 \mathrm{~m}(68.9 \mathrm{ft})$ of water. ${ }^{1}$ The gauge was positioned by divers relative to the toe of

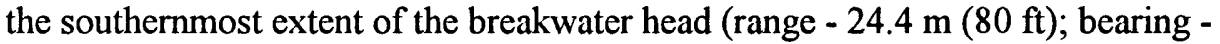
$30 \mathrm{deg}$ ) and the mooring weight of channel buoy number 1 (range $-30.5 \mathrm{~m}(100 \mathrm{ft}$ ); bearing - $70 \mathrm{deg}$ ). The interior gauge (HI02) was clamped at the outer face of the wharf to pile No. 23 , or $36.9 \mathrm{~m}(121 \mathrm{ft})$ east from the west end of the wharf. The water depth in front of the wharf was about $6.4 \mathrm{~m}(21 \mathrm{ft})$, and the transducer was placed about $1.5 \mathrm{~m}(4.9 \mathrm{ft})$ above the bottom (Figure 4).

The armored cables from the transducers were hand-placed by divers along the toe of the breakwater and/or adjacent to the outer row of pilings, specifically to avoid disturbance by marine operations. The cable is sufficiently dense that it tends to self-scour several inches into a sand bottom after a few hours. Both cables exited the water at the eastern end of the wharf. As protection against topside operations, the cables were encased in $0.05-\mathrm{m}$ - (0.17-ft-) diameter schedule 40 galvanized pipe conduit from below the waterline, across the wharf, up the vertical rock cliff at the east end of the harbor, and across the top of the cliff into an existing compressor/utility building (Figure 4). The RTU and other electronics were mounted inside this building in a weatherproof enclosure. Power and telephone connections were made at the building.

\section{Results}

Data collection commenced on 16 January 1994, and continued through September 1994. The system failed on 29 March when a short circuit in the power supply to the sensors caused a protective fuse to blow. The short occurred when the cable to HIO I was cut during harbor operations by a barge mooring weight. The system was diagnosed and $\mathrm{HIO} 2$ brought back on line on 8 April; the cable to HIO1 was repaired on 28 April. The system operated essentially without interruption through September. Additional funds for continued operation were unavailable, so the gauges were placed in an inactive mode - data were collected, but not analyzed; no data quality assurance was conducted, and no system maintenance was performed. The system ceased operation on 8 December 1994.

Summaries of significant wave height and peak period are provided as monthly plots in Appendix A (Figures Al through A 18). Energy spectra and reduced wave parameters from each observation are saved in a database and are available to POD and WES researchers upon request.

Wave conditions were not very energetic over the course of the study. The mean incident wave height was $0.5 \mathrm{~m}(1.6 \mathrm{ft})$. The largest wave occurred in January, with

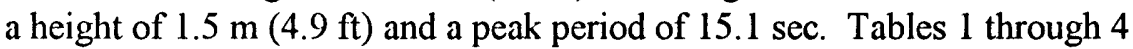
summarize the data from the two gauges. The deepwater directional wave gauge, funded by another project, was installed about $22 \mathrm{~km}$ (13.7 miles) west of Lanai at

\footnotetext{
${ }^{1}$ Though mean depths can be obtained from the pressure signals, accurate depth data require correction of the measurements with atmospheric pressure data. Adjustment of the depth information to a common datum, such as mllw or National Geodetic Vertical Datum involves significant additional analysis and/or measurements. This report does not include water depth information.
} 
$20.45 \operatorname{deg} \mathrm{N}, 157.13 \mathrm{deg} \mathrm{W}$ on 6 December 1994, providing just 2 days of overlap before the system ceased operation. The data logger for the harbor gauges has been removed, but the remainder of the system is still in place.

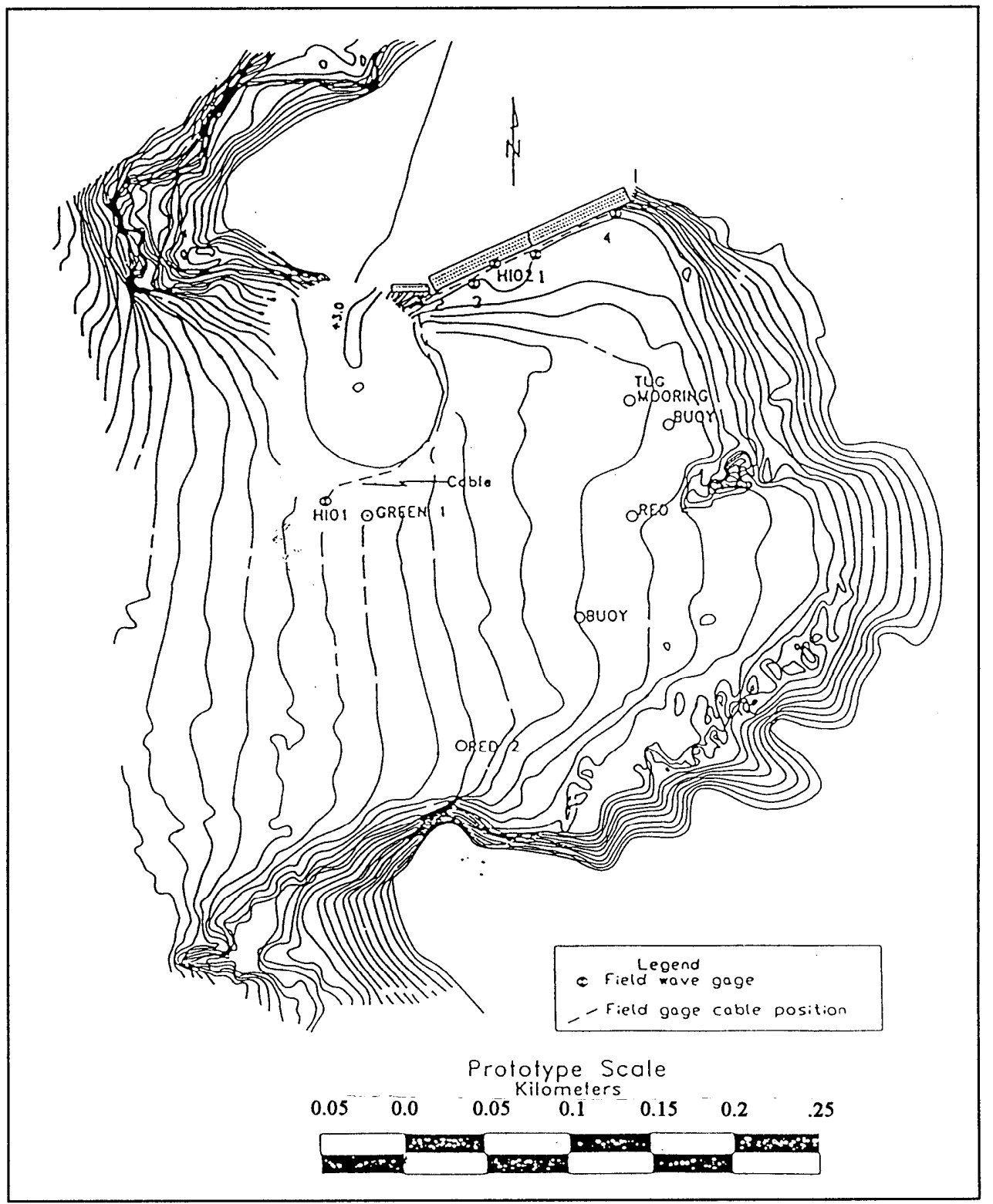

Figure 4. Location of prototype wave gauges 


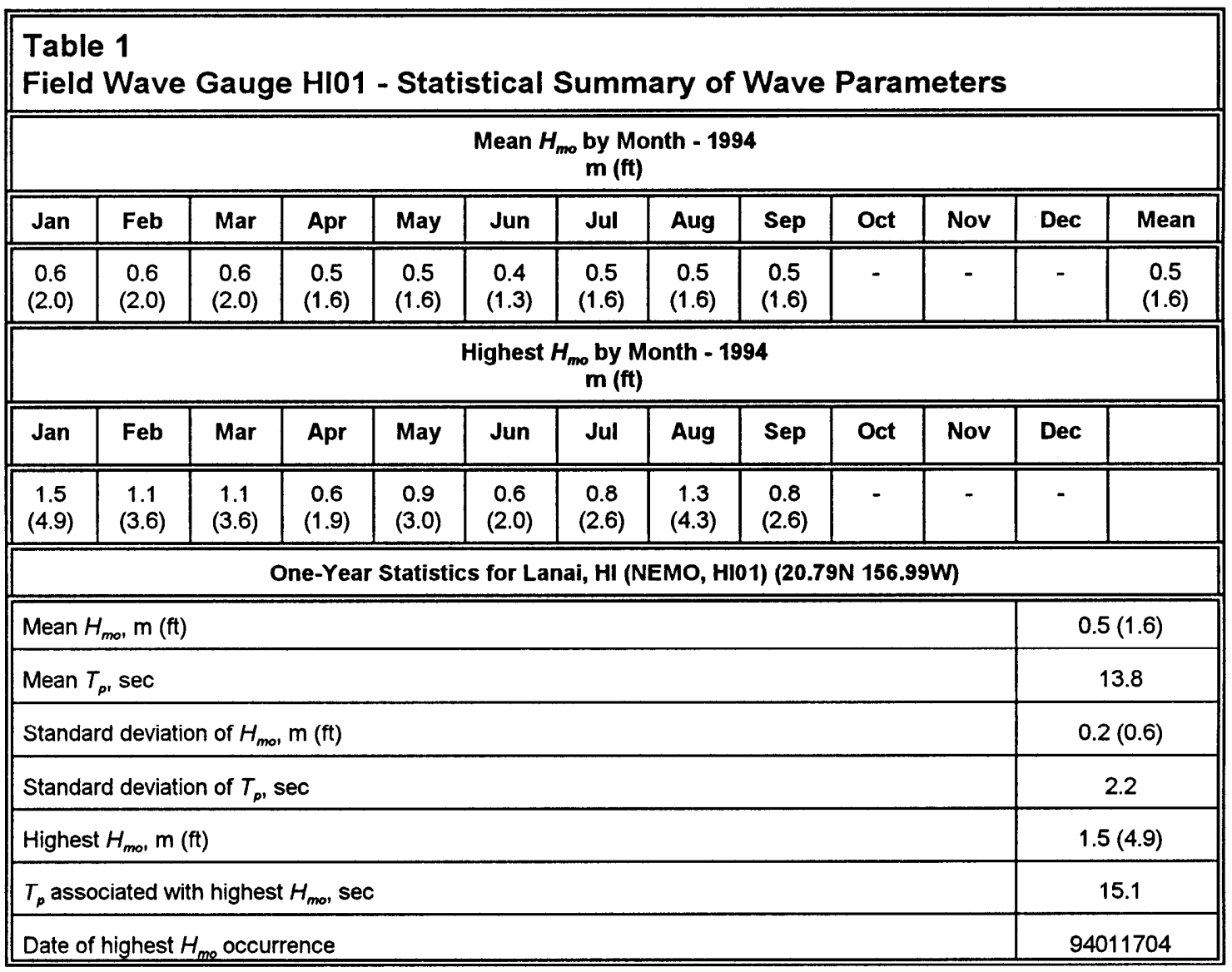




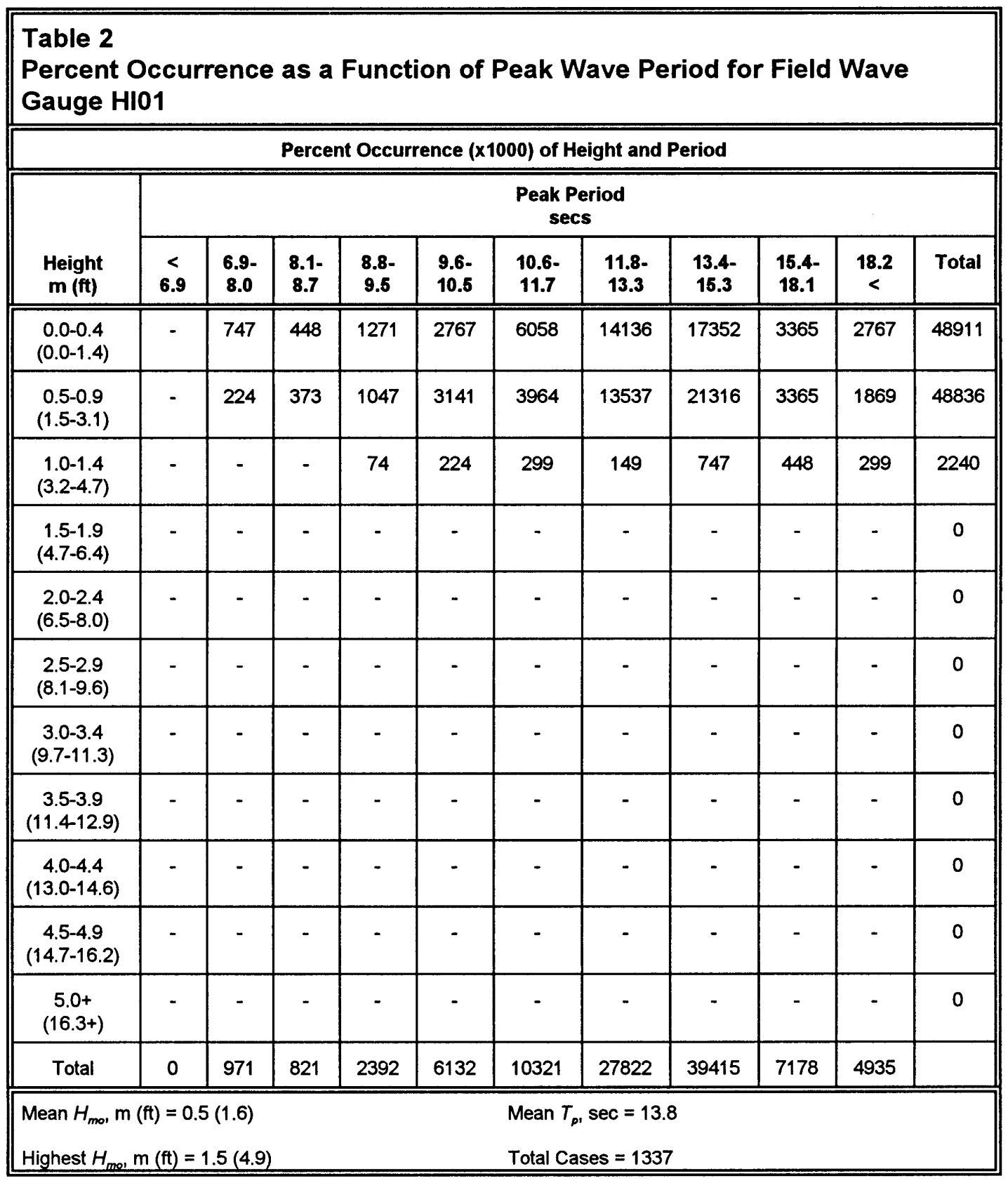




\section{Table 3}

Field Wave Gauge HIO2 - Statistical Summary of Wave Parameters

\begin{tabular}{||c|c|c|c|c|c|c|c|c|c|c|c|c|}
\hline \multicolumn{10}{|c|}{$\begin{array}{c}\text { Mean } H_{m o} \text { by Month - } 1994 \\
\mathbf{m}(\mathrm{ft})\end{array}$} \\
\hline \hline Jan & Feb & Mar & Apr & May & Jun & Jul & Aug & Sep & Oct & Nov & Dec & Mean \\
\hline \hline $\begin{array}{c}0.4 \\
(1.3)\end{array}$ & $\begin{array}{c}0.5 \\
(1.6)\end{array}$ & $\begin{array}{c}0.4 \\
(1.3)\end{array}$ & $\begin{array}{c}0.4 \\
(1.3)\end{array}$ & $\begin{array}{c}0.4 \\
(1.3)\end{array}$ & $\begin{array}{c}0.4 \\
(1.3)\end{array}$ & $\begin{array}{c}0.4 \\
(1.3)\end{array}$ & $\begin{array}{c}0.5 \\
(1.6)\end{array}$ & $\begin{array}{c}0.5 \\
(1.6)\end{array}$ & - & - & - & $\begin{array}{c}0.4 \\
(1.3)\end{array}$ \\
\hline \hline
\end{tabular}

Highest $H_{m o}$ by Month - 1994 $\mathrm{m}$ (ft)

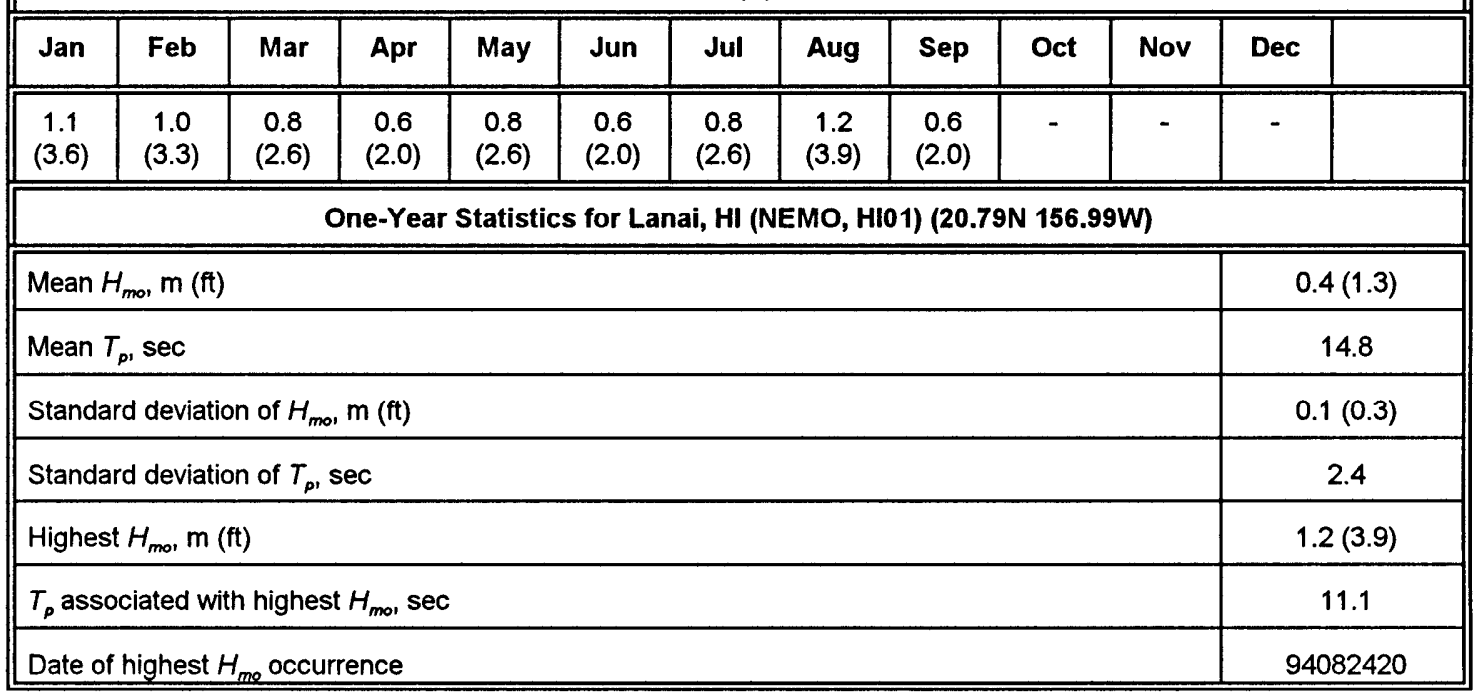




\begin{tabular}{|c|c|c|c|c|c|c|c|c|c|c|c|}
\hline \multicolumn{12}{|c|}{$\begin{array}{l}\text { Table } 4 \\
\text { Percent Occurrence as a Function of Peak Wave Period for Field Wave } \\
\text { Gauge } \mathrm{HIO2}\end{array}$} \\
\hline \multicolumn{12}{|c|}{ Percent Occurrence $(x 1000)$ of Height and Period } \\
\hline \multirow[b]{2}{*}{$\begin{array}{l}\text { Height } \\
m(f t)\end{array}$} & \multicolumn{11}{|c|}{$\begin{array}{c}\text { Peak Period } \\
\text { secs }\end{array}$} \\
\hline & $\begin{array}{c}< \\
6.9\end{array}$ & $\begin{array}{l}6.9- \\
8.0\end{array}$ & $\begin{array}{l}8.1- \\
8.7\end{array}$ & $\begin{array}{l}8.8- \\
9.5\end{array}$ & $\begin{array}{l}9.6- \\
10.5\end{array}$ & $\begin{array}{l}10.6- \\
11.7\end{array}$ & $\begin{array}{l}11.8- \\
13.3\end{array}$ & $\begin{array}{l}13.4- \\
15.3\end{array}$ & $\begin{array}{l}15.4- \\
18.1\end{array}$ & $\stackrel{18.2}{<}$ & Total \\
\hline $\begin{array}{c}0.0-0.4 \\
(0.0-1.4)\end{array}$ & 207 & - & 69 & 1243 & 6772 & 7049 & 7740 & 27228 & 14858 & 10158 & 75324 \\
\hline $\begin{array}{c}0.5-0.9 \\
(1.5-3.1)\end{array}$ & - & - & - & 483 & 1105 & 898 & 1658 & 8845 & 7947 & 3455 & 24391 \\
\hline $\begin{array}{c}1.0-1.4 \\
(3.2-4.7)\end{array}$ & - & - & - & - & 69 & - & - & 69 & 69 & 69 & 276 \\
\hline $\begin{array}{c}1.5-1.9 \\
(4.7-6.4)\end{array}$ & - & - & - & - & - & - & - & - & - & - & 0 \\
\hline $\begin{array}{c}2.0-2.4 \\
(6.5-8.0)\end{array}$ & - & - & - & - & - & - & - & - & - & - & 0 \\
\hline $\begin{array}{r}2.5-2.9 \\
(8.1-9.6)\end{array}$ & - & - & - & - & - & - & - & - & - & - & 0 \\
\hline $\begin{array}{c}3.0-3.4 \\
(9.7- \\
11.3)\end{array}$ & - & - & - & - & - & - & - & - & - & - & 0 \\
\hline $\begin{array}{c}3.5-3.9 \\
(11.4 \\
12.9)\end{array}$ & - & - & - & - & - & - & - & - & - & - & 0 \\
\hline $\begin{array}{c}4.0-4.4 \\
(13.0- \\
14.6)\end{array}$ & - & - & - & - & - & - & - & - & - & - & 0 \\
\hline $\begin{array}{c}4.5-4.9 \\
(14.7- \\
16.2)\end{array}$ & - & - & - & - & - & - & - & - & - & - & 0 \\
\hline $\begin{array}{c}5.0+ \\
(16.3+)\end{array}$ & - & - & - & - & - & - & - & - & - & - & 0 \\
\hline Total & 207 & 0 & 69 & 1726 & 7946 & 7947 & 9398 & 36142 & 22874 & 13682 & \\
\hline \multicolumn{6}{|c|}{ Mean $H_{m o}, \mathrm{~m}(\mathrm{ft})=0.4(1.3)$} & \multicolumn{6}{|c|}{ Mean $T_{p,} \sec =14.8$} \\
\hline
\end{tabular}




\section{Numerical Model ${ }^{1}$}

\section{Objectives and Approach}

The numerical model study had four main objectives:

a Assist in optimizing the placement of field wave gauges.

b. Validate the model with field data.

c. Maximize efficiency of physical model experiments by identifying the most promising harbor modification plans and most damaging incident wave directions.

d. Evaluate harbor oscillation characteristics of the final WES-recommended plan relative to the existing harbor.

The first objective was met with a fast-track modeling effort which evaluated the existing harbor response to both short waves (periods between 6 and $22 \mathrm{sec}$ ) and long waves (periods between 23 and $500 \mathrm{sec}$ ). Once field gauges were in place and operating, field records with relatively high wave energy were used for model validation. Following validation, nine alternative harbor plans were defined and investigated. Upon selection of the final harbor plan, harbor response to long waves was reevaluated, including comparison with existing conditions.

The numerical model, HARBD, is the standard WES tool for numerical harbor wave studies. The model includes the following assumptions:

a. No wave transmission through the breakwater.

b. No wave overtopping of structures.

c. Structure crest elevations above the water surface cannot be studied or optimized.

${ }^{1}$ Written by Edward F. Thompson and Lori L. Hadley. 
d. Currents in the channel cannot be evaluated.

$e$. Wave breaking effects in the entrance and harbor cannot be considered.

f. No nonlinear effects are considered.

g. Diffraction around structure ends is represented by diffraction around a blunt vertical wall with specified reflection coefficient.

Despite limitations imposed by the above assumptions, HARBD is considered suitable for meeting the numerical modeling objectives of the Kaumalapau Harbor study.

The harbor wave response model is presented in the following section, including a general description of the HARBD model and implementation of the model at Kaumalapau Harbor. Validation was accomplished with eight high wave cases selected from available field data. The final section of this chapter describes the numerical simulation procedures and calculations.

As part of the simulation procedures, a suite of incident wave conditions must be specified at the seaward boundary of the area covered by HARBD. Often the incident short waves are determined by consideration of offshore wave climate and wave transformation when propagating over nearshore bathymetry. This step was not included in the Kaumalapau Harbor study. Instead, the full range of possible incident wind wave and swell conditions was represented in the incident waves studied. A broad range of long wave conditions was also studied to identify possible harbor resonant responses.

Results for wind waves and swell are presented in Chapter 5. Harbor oscillation results are presented in Chapter 6 . The presentation focuses on wave conditions in the vicinity of the main dock, but results over the full harbor area also are given.

\section{Model Description}

\section{Model formulation}

The numerical wave model HARBD is a steady-state hybrid element model used in the calculation of linear wave response in harbors of varying size and depth (Chen 1986, Chen and Houston 1987, Lillycrop and Thompson 1995). Originally developed for use with long-period waves (Chen and Mei 1974), HARBD has since been adapted to include capabilities for modeling wind waves and swell (Houston 1981), bottom friction, and partially reflective boundaries (Chen 1986). The model is based on a linearized mild slope equation. An overview of the model and its applications is given by Thompson and Hadley (1995).

The HARBD model has been shown to perform satisfactorily in comparison to analytic solutions and laboratory data for a variety of wind wave and swell cases 
(Houston 1981; Crawford and Chen 1988; Thompson, Chen, and Hadley 1996) and long-wave cases (Chen 1986; Chen and Houston 1987; Houston 1981; Thompson, Chen, and Hadley 1993). As a result, it has been used with confidence in both long-wave and short-wave studies. Long-wave studies have included harbor oscillations (Thompson and Hadley 1994b; Briggs et al. 1994; Briggs, Lillycrop, and McGehee 1992; Mesa 1992; Sargent 1989; Weishar and Aubrey 1986; Houston 1976) and tsunamis (Farrar and Houston 1982, Houston and Garcia 1978, Houston 1978). Wind wave and swell studies include Thompson and Hadley (1994a, 1994b); Lillycrop et al. (1993); Lillycrop and Boc (1992); Lillycrop, Bratos, and Thompson (1990); Kaihatu, Lillycrop, and Thompson (1989); Farrar and Chen (1987); Clausner and Abel (1986); and Bottin, Sargent, and Mize (1985).

The HARBD model covers in detail a domain including the harbor and a portion of the adjacent nearshore area (Figure 5). This domain is bounded by a 180 -deg semicircle in the water region seaward of the harbor entrance $(\partial \mathrm{A}$ in Figure 5) and the land-water interface along the shoreline and harbor $(\partial \mathrm{C}$ in Figure 5). The region defined by these boundaries is denoted Region A. If possible, the semicircle radius should be at least twice the wavelength of the longest incident wave to be modeled (using a typical water depth within the semicircle). Also, the semicircle should encompass any complex offshore bathymetry which strongly influences waves entering the harbor. In general, the semicircle should be as large as practical constraints on grid size and resolution will allow.

The area outside the semicircle is treated as a semi-infinite region which extends from a straight coastline seaward to infinity (Region B). This region is assumed to have a constant water depth and no bottom friction.

Assuming linear, regular waves propagating over mild slope in arbitrary water depth, Chen (1986) derived the governing equation as

$$
\nabla \cdot\left(\lambda c c_{g} \nabla \phi\right)+\frac{\omega^{2} c_{g}}{c} \phi=0
$$

where

$$
\begin{aligned}
\nabla & =\text { horizontal gradient operator } \\
\lambda & =\text { complex bottom friction factor } \\
c & =\text { wave phase speed } \\
c_{g} & =\text { wave group speed } \\
\phi & =\text { velocity potential } \\
\omega & =\text { angular frequency }
\end{aligned}
$$

This equation is identical to Berkhoff's (1972) equation except for addition of the bottom friction factor $\lambda$. The factor $\lambda$, which is a complex number with magnitude greater than zero and less than or equal to one, is specified as

\footnotetext{
${ }^{1}$ For convenience, symbols and abbreviations are listed in the notation (Appendix C).
} 


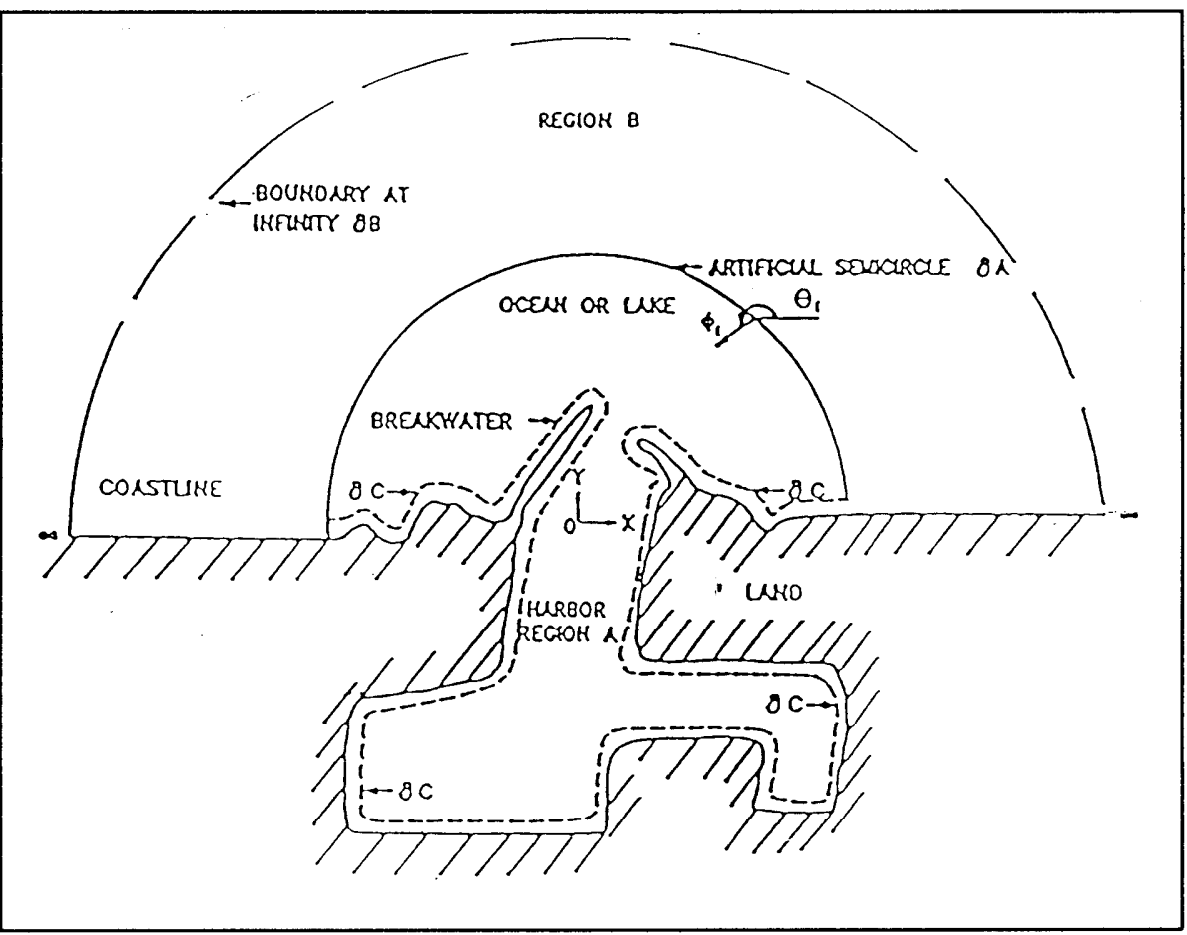

Figure 5. Representation of HARBD domain

$$
\lambda=\frac{1}{1+\frac{i \beta a_{i}}{d \sinh \kappa d} e^{i \gamma}}
$$

where

$$
\begin{aligned}
& i=(-1)^{1 / 2} \\
& \beta=\text { dimensionless bottom friction coefficient that can vary in space } \\
& a_{i}=\text { incident wave amplitude } \\
& d=\text { water depth } \\
& \kappa=\text { wave number } \\
& \gamma=\text { phase shift between stress and flow velocity }
\end{aligned}
$$

The bottom friction factor is a factor tending to reduce local velocities proportionately through the relationships

$$
\begin{aligned}
& u=\lambda \frac{\partial \phi}{\partial x} \\
& v=\lambda \frac{\partial \phi}{\partial y}
\end{aligned}
$$


where

$u, v=$ local horizontal velocity components

$x, y=$ horizontal coordinates

Boundary conditions are specified in Regions $A$ and $B$. At the solid boundary $\partial C$, a reflection/absorption boundary condition is used similar to the impedance condition in acoustics. The condition is specified as

$$
\frac{\partial \phi}{\partial n}-\alpha \phi=0
$$

with

$$
\alpha=i \kappa \frac{1-K_{r}}{1+K_{r}}
$$

where

$n=$ unit normal vector directed into the solid region

$K_{r}=$ reflection coefficient of the boundary

Values of $K_{r}$ for wind waves and swell are normally chosen based on the boundary material and shape. General guidelines for $K_{r}$ can be assembled from laboratory and field data (Thompson, Chen, and Hadley 1996). In wind wave and swell studies, $K_{r}$ is generally chosen to be consistent with this guidance. Effects such as slope, permeability, relative depth, wave period, breaking, and overtopping can be considered in selecting values within these fairly wide ranges. For long-wave studies, $K_{r}$ is generally set equal to 1.0 , representing full reflection.

The second boundary condition is imposed in the far region (Region $B$ ) at infinity. It requires that the scattered wave, defined as the difference between the total wave and incident wave, behave as a classical outgoing wave at infinity. This radiation condition may be expressed as

$$
\lim _{r \rightarrow \infty} \sqrt{r}\left(\frac{\partial}{\partial r}-i \mathrm{\kappa}\right) \phi^{s}=0
$$

where

$$
\begin{array}{ll}
r & =\text { radial polar coordinate } \\
\phi^{s} & =\text { velocity potential of the scattered wave } \\
\partial \quad & =\text { partial differential symbol }
\end{array}
$$

The complete boundary value problem is specified by Equations 1, 4, and 6 . A hybrid element method is employed to solve the boundary value problem. A conventional finite element grid is developed and solved in Region $A$. The triangular elements allow detailed representation of harbor features and 
bathymetry within Region $A$. An analytical solution with unknown coefficients in a Hankel function series is used to describe Region $B$. For a given grid, short wave period simulations (relatively large values of $\kappa$ ) require more terms than long-period simulations to adequately represent the series. A variational principle with a proper functional is established such that matching conditions are satisfied along $\partial A$. Details are given by Chen (1986) and Lillycrop and Thompson (1995).

Experience with the model has indicated that the element size $\Delta x$ and local wavelength $L$ should be related by

$$
\Delta x \leq \frac{L}{6}
$$

Typically, harbor domains include some shallow areas in which many elements would be needed to satisfy the constraint in Equation 7. In practice, Equation 7 is at least satisfied in the harbor channel and basin depths. If additional elements can be accomodated, it is generally preferred to extend the semicircle further seaward rather than to greatly refine shallow harbor regions.

Input information for HARBD must be carefully assembled. In addition to developing the finite element grid to suit HARBD requirements, a number of parameters must be specified. Critical input parameters and ranges of typical values are summarized in Table 5 .

\begin{tabular}{|c|c|c|c|}
\hline \multicolumn{4}{|c|}{$\begin{array}{l}\text { Table } 5 \\
\text { Critical HARBD Input Parameters and Ranges of Typical Values }\end{array}$} \\
\hline \multirow{2}{*}{ Parameter } & \multirow{2}{*}{ Where Specified } & \multicolumn{2}{|c|}{ Typical Values } \\
\hline & & Short Waves & Long Waves \\
\hline Bottom friction, $\beta$ & Every element & 0.0 & $0.0-0.1$ \\
\hline Boundary reflection, $K$ & Every element on solid boundary & $0.0-1.0$ & 1.0 \\
\hline Coastline reflection, $K_{r, \text { coost }}$ & Single value & 1.0 & 1.0 \\
\hline $\begin{array}{l}\text { Depth in infinite region, } \\
d_{\text {tat }}\end{array}$ & Single value & \multicolumn{2}{|c|}{ Between avg. \& max. on semicircle } \\
\hline $\begin{array}{l}\text { Number of terms in } \\
\text { Hankel function series }\end{array}$ & Single value & $8-100^{1}$ & 8 \\
\hline
\end{tabular}

The principal output information available from HARBD consists of amplification factor and phase at each node. These are defined as 


$$
\begin{aligned}
A_{\text {amp }} & =\left|\frac{a}{a_{i}}\right|=\left|\frac{H}{H_{i}}\right|=|\phi| \\
\theta & =\tan ^{-1}\left[\frac{\operatorname{Im}\{\phi\}}{\operatorname{Re}\{\phi\}}\right]
\end{aligned}
$$

where

$$
\begin{aligned}
A_{\text {amp }} & =\text { amplification factor } \\
a, a_{i} & =\text { local and incident wave amplitudes } \\
H, H_{i} & =\text { local and incident wave heights } \\
\theta & =\text { phase relative to the incident wave } \\
\operatorname{Im}\{\phi\} & =\text { imaginary part of } \phi \\
\operatorname{Re}\{\phi\} & =\text { real part of } \phi
\end{aligned}
$$

Amplification factors are easily interpreted. Phases are helpful in viewing wind wave and swell propagation characteristics and in interpreting standing wave patterns. In long-wave applications, phases prove useful for determining relative phase differences within the harbor, interpreting harbor oscillation patterns, and identifying potentially troublesome nodal areas.

\section{Spectral adaptation}

Often the model is used to approximate irregular wind wave and swell behavior, as in physical model experiments with irregular waves and all field cases. More realistic numerical model simulations can be obtained by linearly combining HARBD results from a range of regular wave frequencies in the irregular wave spectrum. Regular wave results are weighted to properly represent the desired spectral distribution of energy. The concept of linear superposition of weighted regular wave results also can be extended to include directional spreading in the spectrum to be simulated.

Spectral adaptation of the HARBD model is done as a post-processing step using the standard, regular wave output from the model. For a given incident wave direction, HARBD is run for a number of wave periods spread between the shortest period satisfying the grid resolution constraint of Equation 7 and the longest swell period of interest.

Spectral post-processing is based on the assumption that a consistent spectral form can be applied at every node. This major assumption provides the basis for a workable, reasonable spectral weighting which improves on the traditional regular wave approach. The JONSWAP spectral form was chosen (Hasselmann et al. 1973). The JONSWAP spectrum is specified as (U.S. Army Corps of Engineers 1989)

$$
S\left(f_{i}\right)=\frac{\alpha g^{2}}{(2 \pi)^{4} f_{i}^{5}} e^{a} \gamma^{b}
$$


where

$$
S\left(f_{i}\right) \quad=\text { spectral energy density at frequency } f_{i}
$$

The parameters $a$ and $b$ are given by the following relationships

$$
\begin{gathered}
a=\frac{-1.25}{f_{i} T_{p}^{4}} \\
b=e^{\frac{-1}{2 \sigma^{2}}\left(f_{i} T_{p}-1\right)^{2}} \\
\sigma=0.07 \quad \text { for } f_{i} \leq f_{p} \\
=0.09 \text { for } f_{i} \geq f_{p}
\end{gathered}
$$

where

$$
\begin{aligned}
T_{p} & =\text { peak spectral period } \\
f_{p} & =\text { peak spectral frequency }=\frac{1}{T_{p}}
\end{aligned}
$$

Parameters $\alpha$ and $\gamma$ are calculated as

$$
\begin{aligned}
\alpha & =157.9 \epsilon^{2} \\
\gamma & =6614 \epsilon^{1.59} \\
\epsilon & =\frac{H_{s}}{4 L_{p}}
\end{aligned}
$$

where

$H_{s}=$ significant wave height

$L_{p}=$ wavelength for waves at peak frequency

The parameter $\epsilon$ is a significant wave steepness. The parameter $\gamma$, called the peak enhancement factor, controls the sharpness of the spectral peak. 
Although the JONSWAP spectrum was developed primarily for actively growing wind waves, it can be used to approximate any single-peaked spectrum, including old swell which has travelled a great distance from the generation area, by appropriate choice of $\gamma$ (e.g. Goda 1985) (Table 6).

Spectral post-processing begins with specification of the desired $H_{s}, T_{p}$, and $\gamma$

\begin{tabular}{|c|c|}
\hline $\begin{array}{l}\text { Table } 6 \\
\text { Guidance fo } \\
\text { Choosing Y }\end{array}$ & \\
\hline Wave Condition & $y$ \\
\hline Growing sea & 3.3 \\
\hline Old swell & $8-10$ \\
\hline
\end{tabular}
and the arrays of HARBD amplification factors. A refined JONSWAP spectrum is computed with 1,000 points, where the $f_{i}$ 's in Equation 9 are

$$
f_{1}=0.5 * f_{p}, f_{2}=0.502 * f_{p}, f_{3}=0.504 * f_{p}, \ldots, f_{1000}=2.498 * f_{p}
$$

The number of wave periods computed with HARBD is always much smaller than 1,000 , typically less than 20 . These periods, converted to frequency (reciprocal of period), can be used to define bands in the JONSWAP spectrum. Bands are bounded by the midpoints between HARBD computational frequencies. The highest and lowest frequency bands are assumed to be centered on the highest and lowest HARBD computational frequencies, respectively. A weighting factor for each HARBD-defined band is computed by summing values from the refined JONSWAP spectrum which fall within the band and normalizing by the total spectral energy.

$$
w_{k}=\frac{\sum_{i=N_{k 1}}^{N_{k 2}} S\left(f_{i}\right)}{\sum_{i=1}^{1000} S\left(f_{i}\right)}
$$

where

$$
\begin{aligned}
w_{k}= & \text { weighting factor for } k^{\prime} \text { th HARBD computational frequency } \\
N_{k 1}= & \text { index of lowest JONSWAP frequency, } f_{i} \text {, satisfying } f_{i}>\frac{f_{k-1}+f_{k}}{2} \\
N_{k 2}= & \text { index of highest JONSWAP frequency, } f_{i} \text {, satisfying } f_{i}<\frac{f_{k}+f_{k+1}}{2} \\
f_{k-1}, f_{k} f_{k+1}= & (k-1)^{\prime} \text { 'th, } k^{\prime} \text { th, and }(k+1)^{\prime} \text { 'th HARBD computational frequencies, } \\
& \text { with } f_{k-1}<f_{k}<f_{k+1}
\end{aligned}
$$

Though not shown in the equation, the weighting factor also includes fractional energy interpolated across JONSWAP frequencies bracketing the two end points of each HARBD band. 
The effective amplification factor at each node is computed as

$$
\left(A_{\text {amp }}\right)_{e f f}=\sqrt{\sum_{k=1}^{N_{T}} w_{k} A_{a m p}^{2}\left(f_{k}\right)}
$$

where

$$
\begin{aligned}
\left(A_{\text {amp }}\right)_{\text {eff }} & =\text { effective }, \text { or spectral, amplification factor at a node } \\
A_{\text {amp }}\left(f_{k}\right) & =\text { nodal amplification factor for HARBD computational frequency } f_{k} \\
\text { NT } & =\text { number of HARBD computational wave periods }
\end{aligned}
$$

\section{Finite element grids}

The finite element numerical grid depicting existing conditions at Kaumalapau Harbor was created using WES's finite element grid development software (Turner and Baptista 1993) (Figure 6). The grid covers the entire Kaumalapau Harbor embayment and extends somewhat seaward from the bay entrance. The land boundary was digitized from a NOAA nautical chart. Grid element size is based on the criteria of six elements per wavelength (the minimum recommended resolution with HARBD) for a 6-sec wave in a $2.7-\mathrm{m}$ (9-ft) water depth. Depths over virtually the entire embayment exceed $2.7 \mathrm{~m}(9 \mathrm{ft})$. For the longer period waves, the grids give a high degree of resolution. Grid characteristics are summarized in Table 7.

The radius of the seaward semicircle is $303 \mathrm{~m}(995 \mathrm{ft})$. This is equivalent to 0.9 and 5.4 wavelengths for the longest and shortest short wave periods considered, assuming a representative water depth of $27.4 \mathrm{~m}(90 \mathrm{ft})$. The semicircle size and location were chosen to include the breakwater, the large shoal north of the breakwater, and the point and shoal area south of the harbor entrance. The semicircle extends sufficiently far seaward to cover the most important nearshore bathymetry.

Bathymetric data were obtained from NOAA hydrographic chart 19351.

Digitized depths were transferred onto the finite element grid using the WES grid software package. A contour plot of bathymetry is given in Figure 7.

Reflection coefficients $K_{r}$ are needed for all solid boundaries. For the short wave simulations, $K_{r}$ values were estimated from existing Corps of Engineers guidance, photos from a recent site visit by WES personnel, and past experience. The solid boundary was divided into eight zones and a reflection coefficient was 


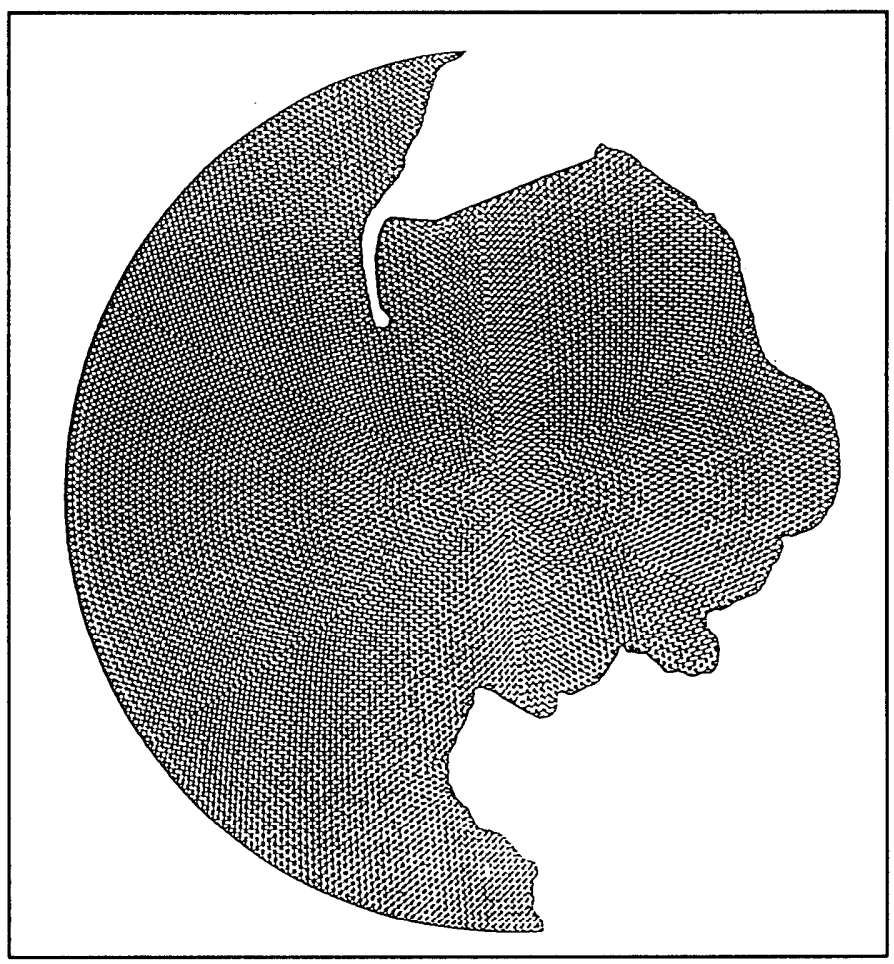

Figure 6. Grid of existing harbor

\begin{tabular}{||l|l|l|l|l|l||}
\hline \hline \multicolumn{2}{||l}{$\begin{array}{l}\text { Table } 7 \\
\text { Grid Sizes }\end{array}$} & $\begin{array}{l}\text { Length } \\
\text { of Typical } \\
\text { Element } \\
\text { m (ft) }\end{array}$ \\
\hline \hline \multirow{2}{*}{ Breakwater Layout } & \multicolumn{2}{|l||}{ Number of: } & \multicolumn{4}{l||}{$\begin{array}{l}\text { Semicircle } \\
\text { Boundary } \\
\text { Nodes }\end{array}$} & $\begin{array}{l}\text { Solid } \\
\text { Boundary } \\
\text { Nodes }\end{array}$ & Elements & Nodes & & $4.9(16.1)$ \\
\hline \hline Existing & 17,376 & 8,929 & 285 & 196 & $4.9(16.1)$ \\
\hline Straight Extension & 17,364 & 8,927 & 296 & 196 & $4.9(16.1)$ \\
\hline Dogleg Extension & 17,355 & 8,924 & 296 & 196 & $4.9(16.1)$ \\
\hline Southern Breakwater & 17,350 & 8,927 & 307 & 196 & $4.9(16.1)$ \\
\hline $\begin{array}{l}\text { WES-recommended } \\
\text { Plan }\end{array}$ & 17,396 & 8,945 & 297 & 196 & \\
\hline
\end{tabular}




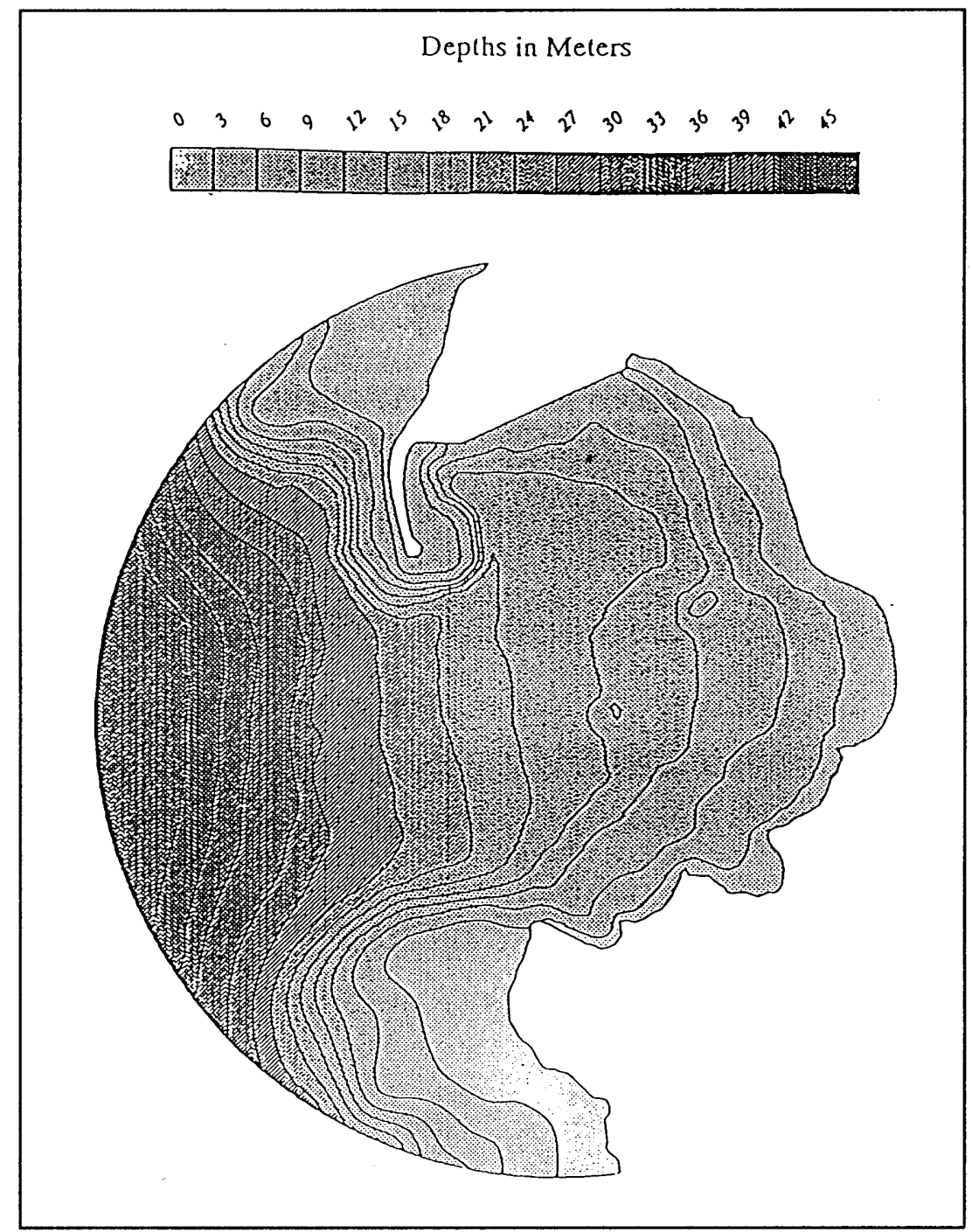

Figure 7. Bathymetry

estimated for each zone (Figure 8). Reflection coefficients ranged from 0.2 for the shallow sandy area around the stream outlet to 0.5 for the exposed cliff areas along much of the embayment to 0.8 along the wharf face. Other parameter values used in the numerical model are summarized in Table 8 .

Different parameters are used for the long-wave simulations. The reflection coefficient was set to 1.0 for all boundaries, since long waves generally reflect very well from a coastal boundary. Long waves are more affected by bottom friction than short waves, so a value of $\beta$ greater than zero is appropriate. The value of $\beta$ is best determined by calibration with field data. However, data records in this study are too short to provide reliable long-wave information. An accurate value for $\beta$ is not critical to objectives of the study, and a default value of $\beta=0$ was used. This and other parameters are summarized in Table 8. 


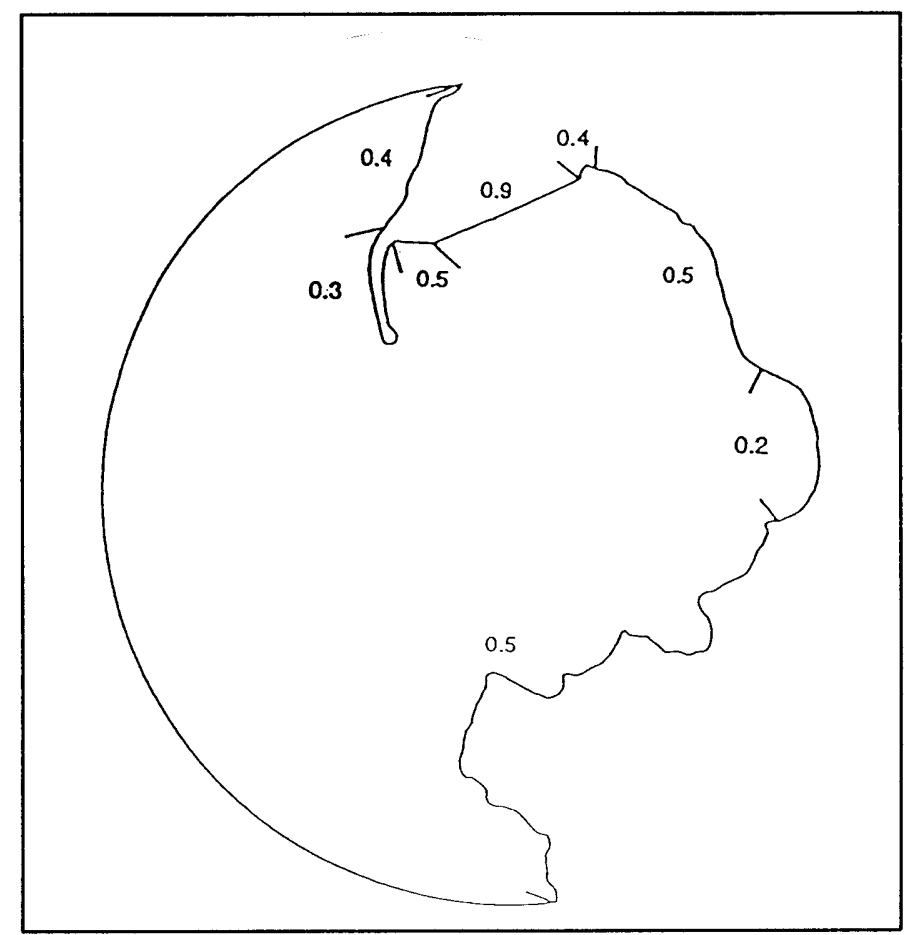

Figure 8. Wave reflection coefficient values, short waves

\begin{tabular}{|c|c|c|}
\hline \multicolumn{3}{|c|}{$\begin{array}{l}\text { Table } 8 \\
\text { Parameter Values Used in HARBD }\end{array}$} \\
\hline \multirow{2}{*}{ Parameter } & \multicolumn{2}{|l|}{ Value } \\
\hline & Short Waves & Long Waves \\
\hline Bottom friction, $\beta$ & 0.0 & 0.0 \\
\hline Coastline reflection, $K_{u \text { coast }}$ & 1.0 & 1.0 \\
\hline Depth in infinite region, $d_{t a r}$ & $38.4 \mathrm{~m}(126 \mathrm{ft})$ & $38.4 \mathrm{~m}(126 \mathrm{ft})$ \\
\hline
\end{tabular}

Nine plans for modifying the harbor were defined after a study team review meeting with sponsors (Table 9). The plans involved three breakwater modifications, including a breakwater at the southern end of the harbor embayment and two alternatives for extending the existing breakwater. During physical model experiments, a final WES-recommended plan was developed. The existing harbor grid was modified to represent the alternative breakwater configurations (Figures 9 through 12). Grid characteristics for each of the four breakwater configurations are included in Table 7. 


\begin{tabular}{||l|l|l|l|l|l|l|l|l|l|l||}
\hline \hline $\begin{array}{l}\text { Table 9 } \\
\text { Harbor Alternatives for Numerical Modeling }\end{array}$ \\
\hline \hline Feature
\end{tabular}

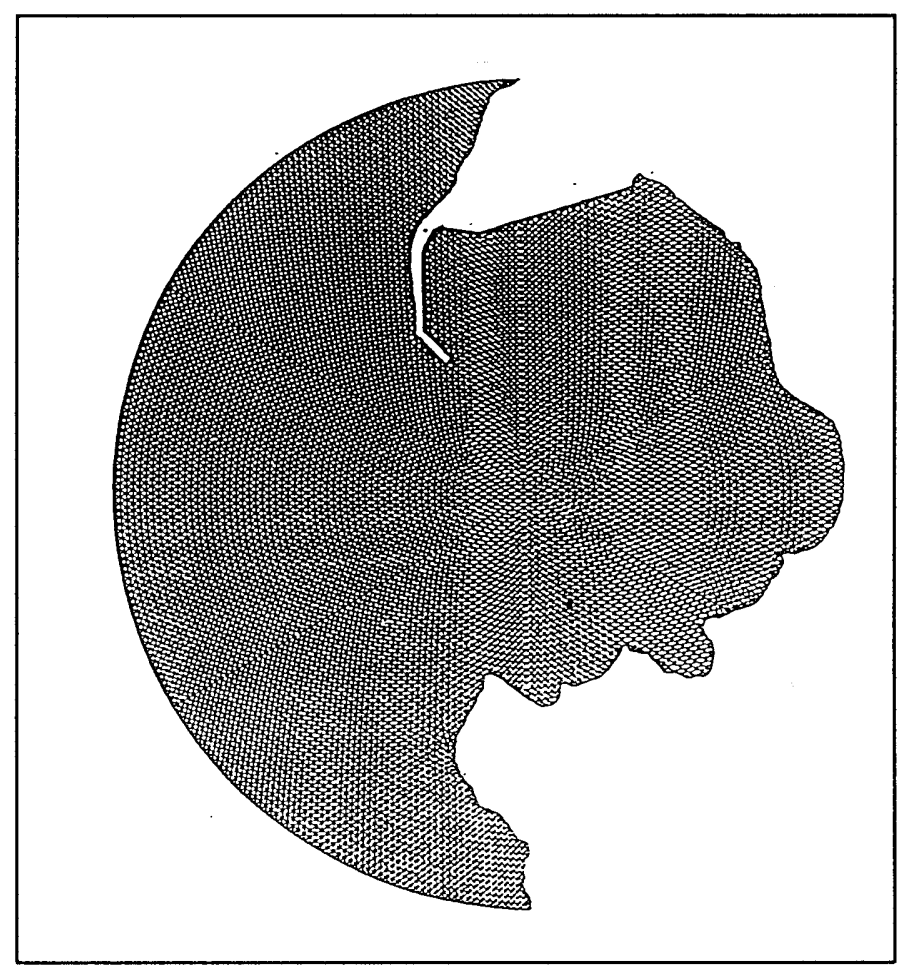

Figure 9. Grid with dogleg breakwater extension 


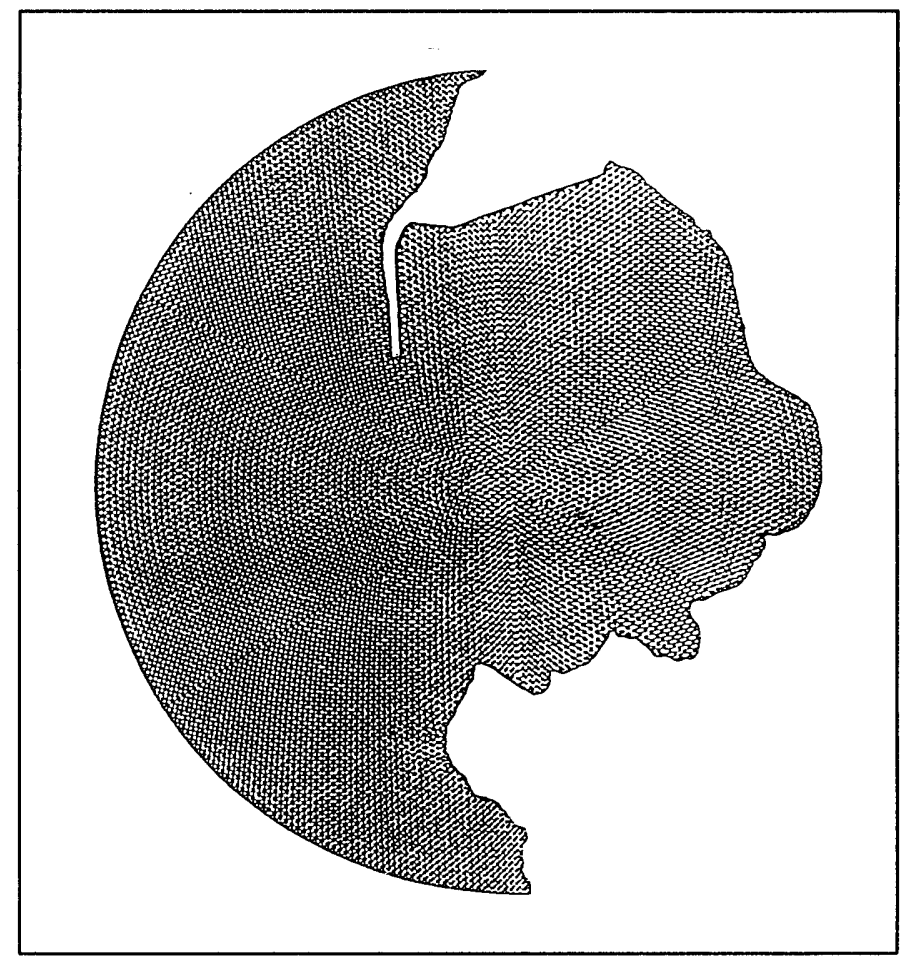

Figure 10. Grid with straight breakwater extension

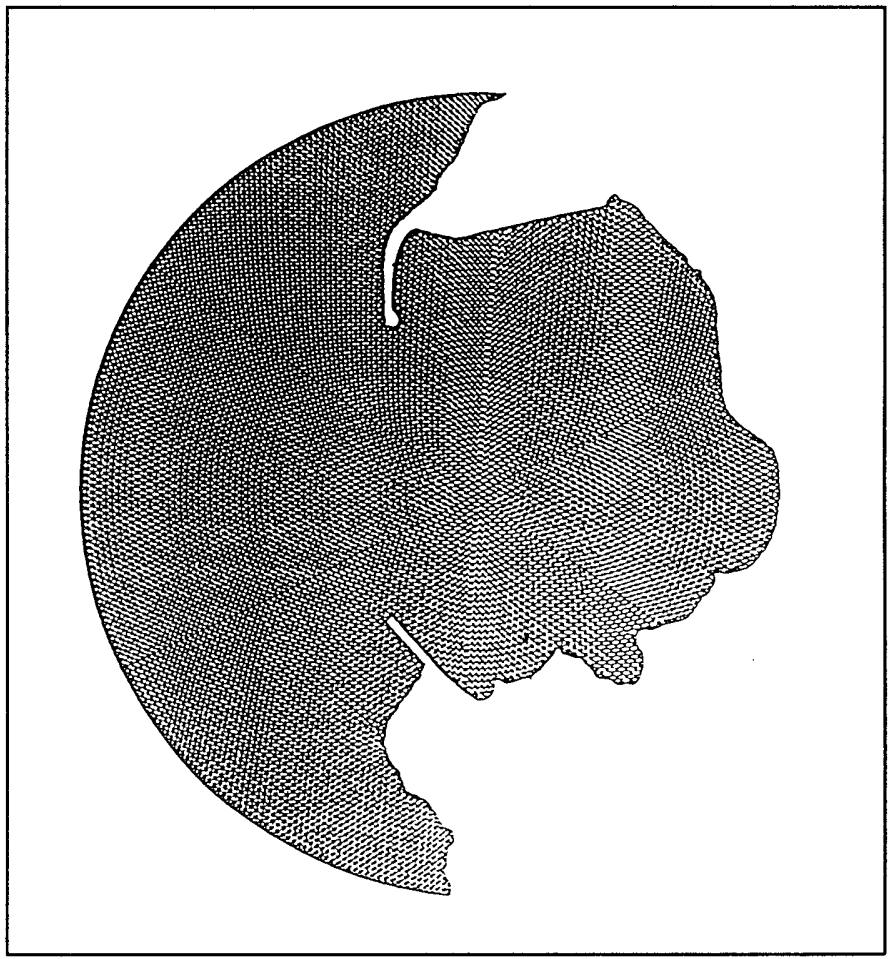

Figure 11. Grid with south breakwater addition 


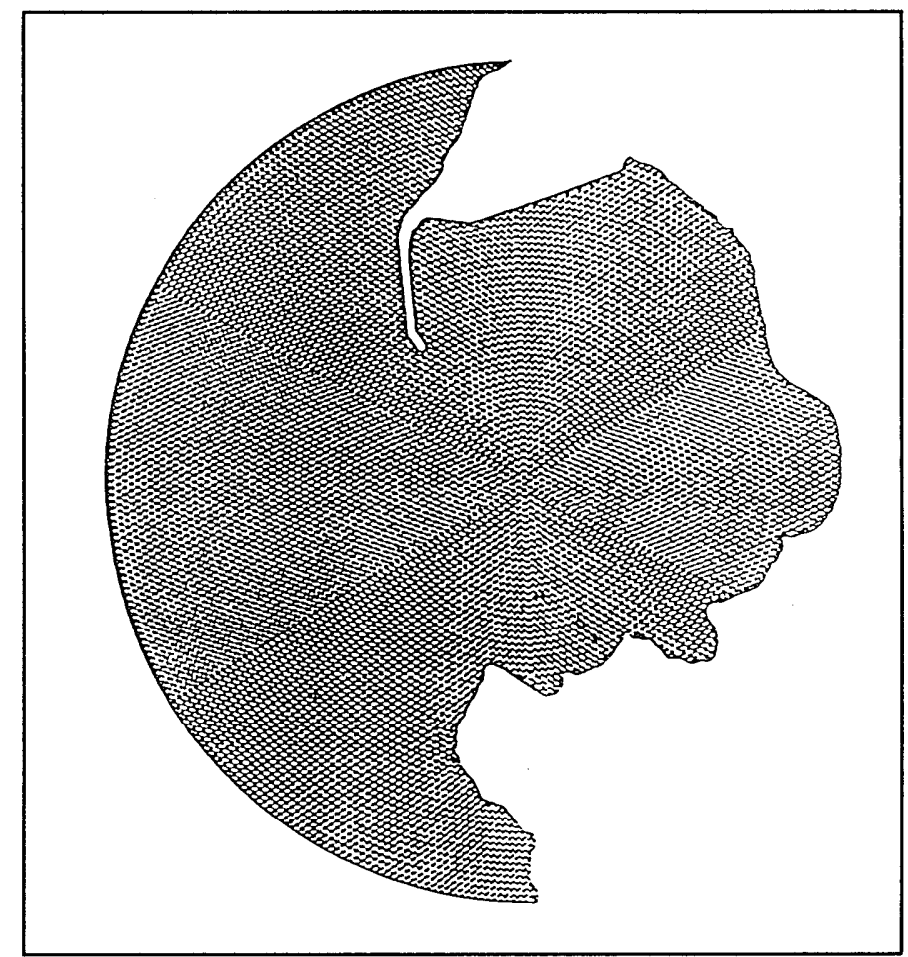

Figure 12. Grid of WES-recommended plan

The harbor modifications studied include combinations of the following:

a. $45.7-\mathrm{m}(150-\mathrm{ft})$ dogleg extension to the existing breakwater, angled into the harbor.

b. $45.7-\mathrm{m}(150-\mathrm{ft})$ straight extension to the existing breakwater.

c. 61-m (200-ft) rubble-mound breakwater, extending northwest from the southern corner of the harbor entrance.

d. Addition of wave absorber along the northeast portion of the harbor shore.

$e$. Addition of wave absorber along the northernmost portion of the northeast harbor shore.

f. Addition of wave absorber along the southeast portion of the harbor shore.

The addition of wave absorber was simulated by reducing the value of the shortwave reflection coefficient to $K_{r}=0.2$ over the affected area. Absorber was simulated over large segments of the harbor boundary to assess the maximum potential effect of this type of modification (Figure 13). 


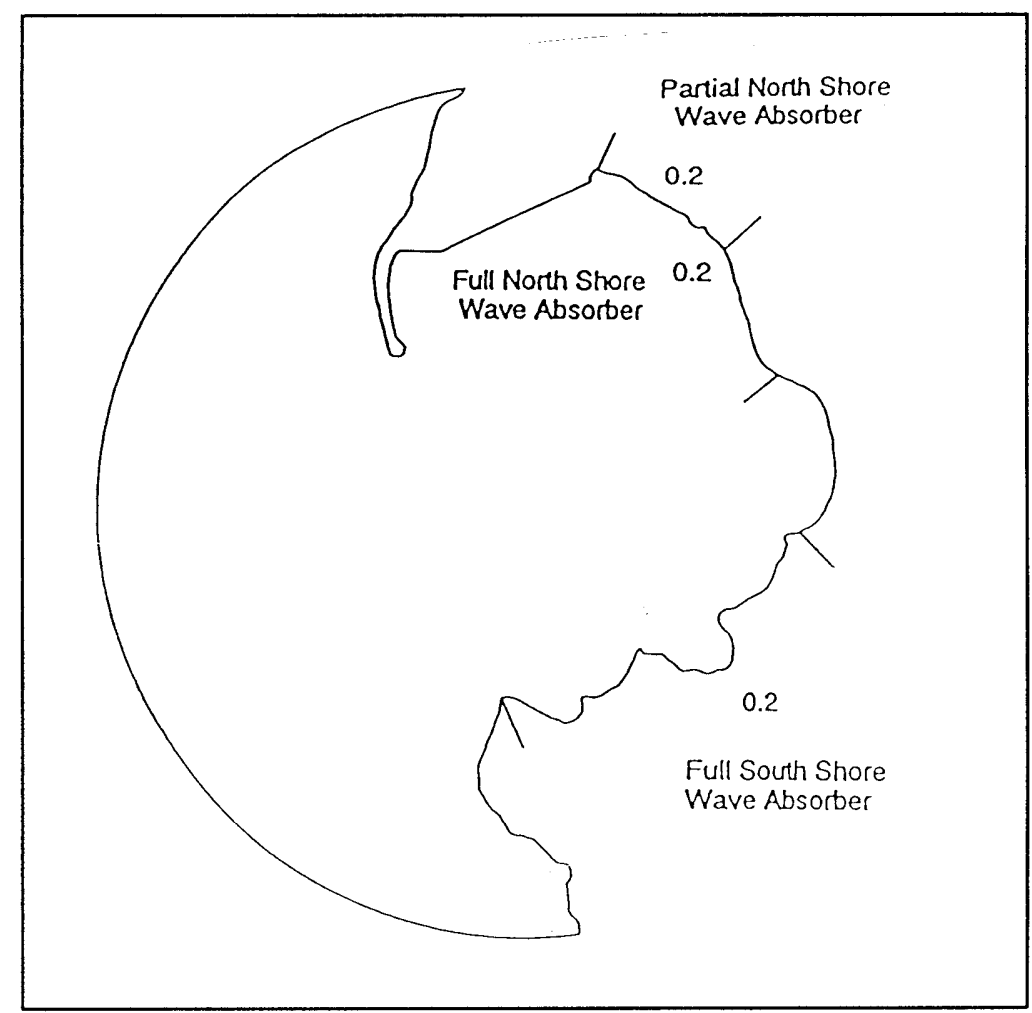

Figure 13. Wave reflection coefficient values for wave absorber simulations, short waves

\section{Validation}

The availability of field data at Kaumalapau Harbor allowed a validation test of the numerical harbor response model. Validation was confined to short-wave cases. The field records were not suited to long-wave validation, and validation was not essential for meeting the comparative objectives of the long-wave study.

Field validation of a short-wave model is inherently difficult, typically including uncertainties about some aspects of incident waves, bathymetry, and construction underneath wharves and piers and inside breakwaters (which affects harbor boundary locations and reflection coefficients). Even when the structure is known, the effective reflection coefficient can rarely be estimated with precision. Despite the impossibility of getting a highly accurate and controlled field validation experiment, field data are valuable for a rough validation to ensure that the model, with parameter values within the range of reasonable choices given the particular site, gives results consistent with measurements.

Five events occurred during the winter of 1994 in which $H_{m 0}$ at the outside gauge exceeded $1 \mathrm{~m}$. One or two records within each of these events was selected for HARBD simulation (Table 10). The main criteria for selection are that $H_{m 0}$ and $T_{p}$ at Kaumalapau Harbor and mean wave direction from the NOAA buoy north of the island of Molokai (Gauge 51026) are relatively stable for at least a few hours 


\begin{tabular}{||l|l|l|l||}
\hline \hline $\begin{array}{l}\text { Table 10 } \\
\text { Summary of Field Cases for Model Validation }\end{array}$ \\
\hline \hline Date & $\begin{array}{l}\text { Hour } \\
\text { GMT }\end{array}$ & $\begin{array}{l}\text { Wave Period } \\
\text { Sec }\end{array}$ & $\begin{array}{l}\text { Wave Direction } \\
\text { Deg }\end{array}$ \\
\hline 17 Jan 94 & 1200 & 15.1 & 300 \\
\hline 31 Jan 94 & 0800 & 19.7 & 325 \\
\hline 31 Jan 94 & 1200 & 18.3 & 325 \\
\hline 24 Feb 94 & 1200 & 11.1 & 320 \\
\hline 27 Feb 94 & 0400 & 17.1 & 301 \\
\hline 27 Feb 94 & 0800 & 17.1 & 301 \\
\hline 11 Mar 94 & 1200 & 15.1 & 300 \\
\hline 12 Mar 94 & 1200 & 12.8 & 329 \\
\hline
\end{tabular}

preceding the selected record and the spectral shape is single peaked if possible. These criteria help to ensure that $H_{m 0}$ and $T_{p}$ are well-defined and that the JONSWAP spectral form imposed on the numerical model results is at least qualitatively correct. All five of the events also appeared as high wave events in the Molokai buoy measurements. This observation, coupled with the climatological predominance of winter storm events from northerly directions, strongly implies that the waves at Kaumalapau were coming from the northwest. Some exploratory HARBD runs were done using incident wave directions on either end of the reasonable bounds at Kaumalapau, consistent with a northerly approach and sheltering by the northwest tip of Lanai. Since results were only mildly sensitive to incident direction, the actual direction reported from the Molokai buoy (which fell within the reasonable bounds at Lanai) was used in the final HARBD runs. Frequency-dependent amplification factors from the HARBD runs were weighted based on the energy levels in a JONSWAP spectrum. Appropriate $T_{p}$ and spectral shape parameters were used to establish the weightings.

Reflection coefficient at the wharf is a key model parameter in comparing to measurements at mid-wharf. The wharf face is a concrete deck supported by concrete piles. Under the wharf, within about 2 to $3 \mathrm{~m}$ (6.6 to $9.8 \mathrm{ft}$ ) landward of the wharf face, is a rough vertical wall of solid rock. It was estimated that a reflection coefficient between 0.6 and 0.9 would be representative of the wharf. Initially $K_{r}=$ 0.9 was used to be conservative.

The ratio of $H_{m 0}$ 's at the inner and outer harbor gauges was compared to amplification factor ratio at the same locations from HARBD runs using the spectral approach. The numerical model results showed a tendency to overestimate wave conditions at the wharf. Runs were repeated with wharf reflection coefficient adjusted to 0.8 and 0.6 . A reflection coefficient of 0.8 gave satisfactory, unbiased results (Figure 14). The figure also indicates the location of the data cloud when the reflection coefficient at the wharf is set to 0.6 and 0.9 , excluding for clarity the 


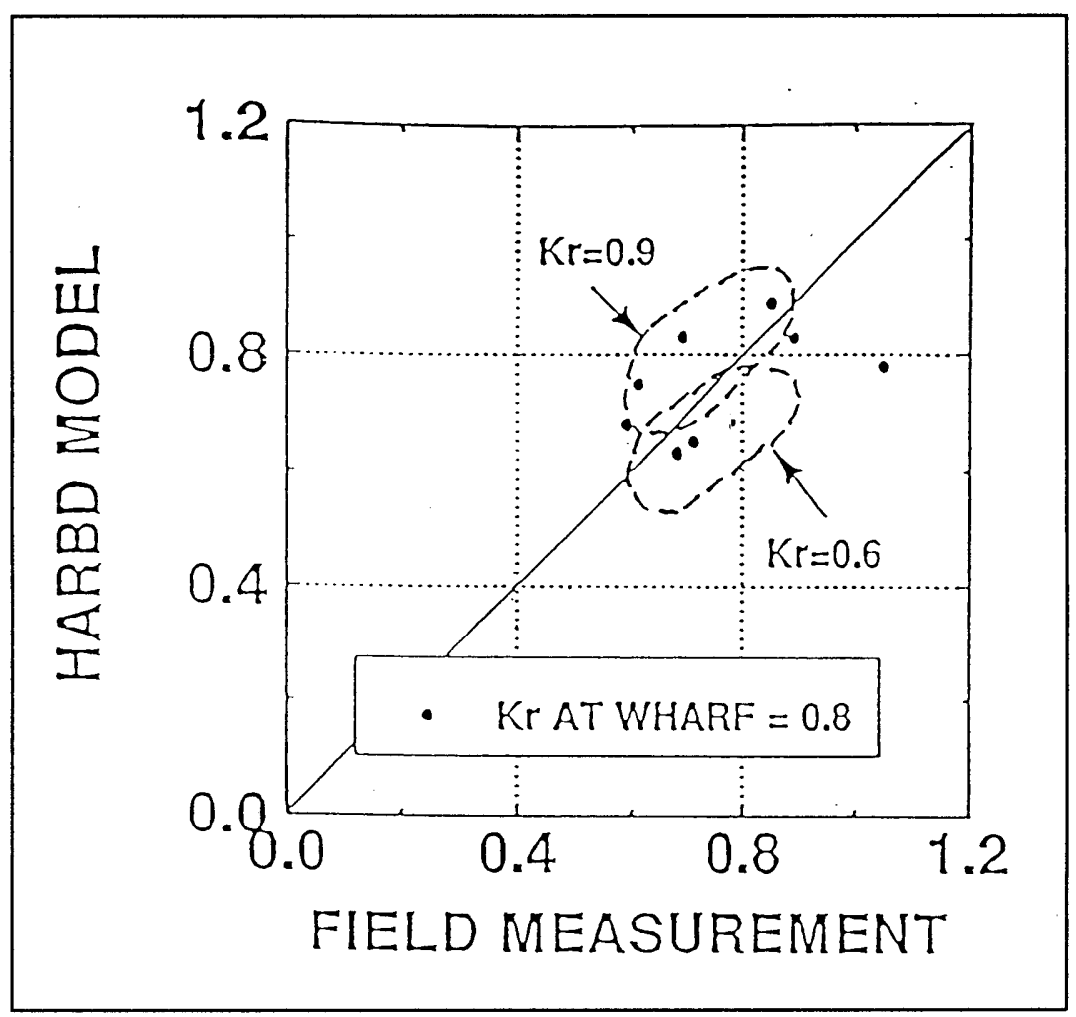

Figure 14. Model validation

single point for which the field ratio was greater than 1.0. The best-fitting reflection coefficient, 0.8 , is very reasonable for this wharf structure, and the field validation is considered successful.

Varying reflection coefficient along the wharf significantly affected wave estimates at the wharf, but the effect was very localized. Areas away from the immediate wharf area were relatively unchanged. Similar localized changes appeared when boundary reflection coefficients were varied as part of the short wave simulations of harbor modification alternatives (Chapter 5).

\section{Simulation Procedures and Calculations}

\section{Incident wave conditions}

A range of short-and long-wave conditions incident to the Kaumalapau Harbor breakwater and embayment was considered. A full range of wave periods and directions which could cause damaging waves inside the harbor was included. 
The short wave periods and approach directions considered are given in Table 11. The shortest wave period represents a local storm condition which, based on local experience, can generate waves of concern within the harbor. The longest period represents a very long swell condition. Directions were chosen to include all likely approach directions to the harbor entrance. Numerical simulation directions were reckoned in 10-deg increments relative to the straight-in approach direction (261.5-deg azimuth, rounded to $261 \mathrm{deg}$ for determining calculation directions ). Incident wave directions and the angular orientation of the seaward semicircular model boundary are illustrated in Figure 15.

Not all of the incident short wave conditions listed in the table were considered in every set of simulations. Directional sensitivity tests of the existing harbor included HARBD calculations with all of the listed wave periods and all of the listed directions. Directional sensitivity then was evaluated for spectra with $T_{p}$ values of 8,10 , 16 , and $18 \mathrm{sec}$, representative of storm and swell conditions at the site.

For comparing alternatives, HARBD was run with the full set of short wave periods for each simulation and a representative set of directions, chosen after consideration of the directional sensitivity test results. The numerical simulation directions were the 201-, 221-, 251-, 291-, and 315-deg azimuth. The 315-deg direction was used in place of $321 \mathrm{deg}$ to represent a more realistic northerly limit on incident wave direction. Alternatives were evaluated for spectra with $T_{p}$ values of 10 and $16 \mathrm{sec}$.

Wave heights and probabilities of occurrence, which also generally are needed in harbor studies, were not necessary in this study. The objectives of the study were to assess harbor characteristics for various harbor layouts, but did not include the estimation of wave climate inside the harbor. Hence, an estimate of local wave climate was not essential. Since the numerical model used is linear, the results for each incident wave period and direction can be taken as representative for any nonbreaking wave height. 


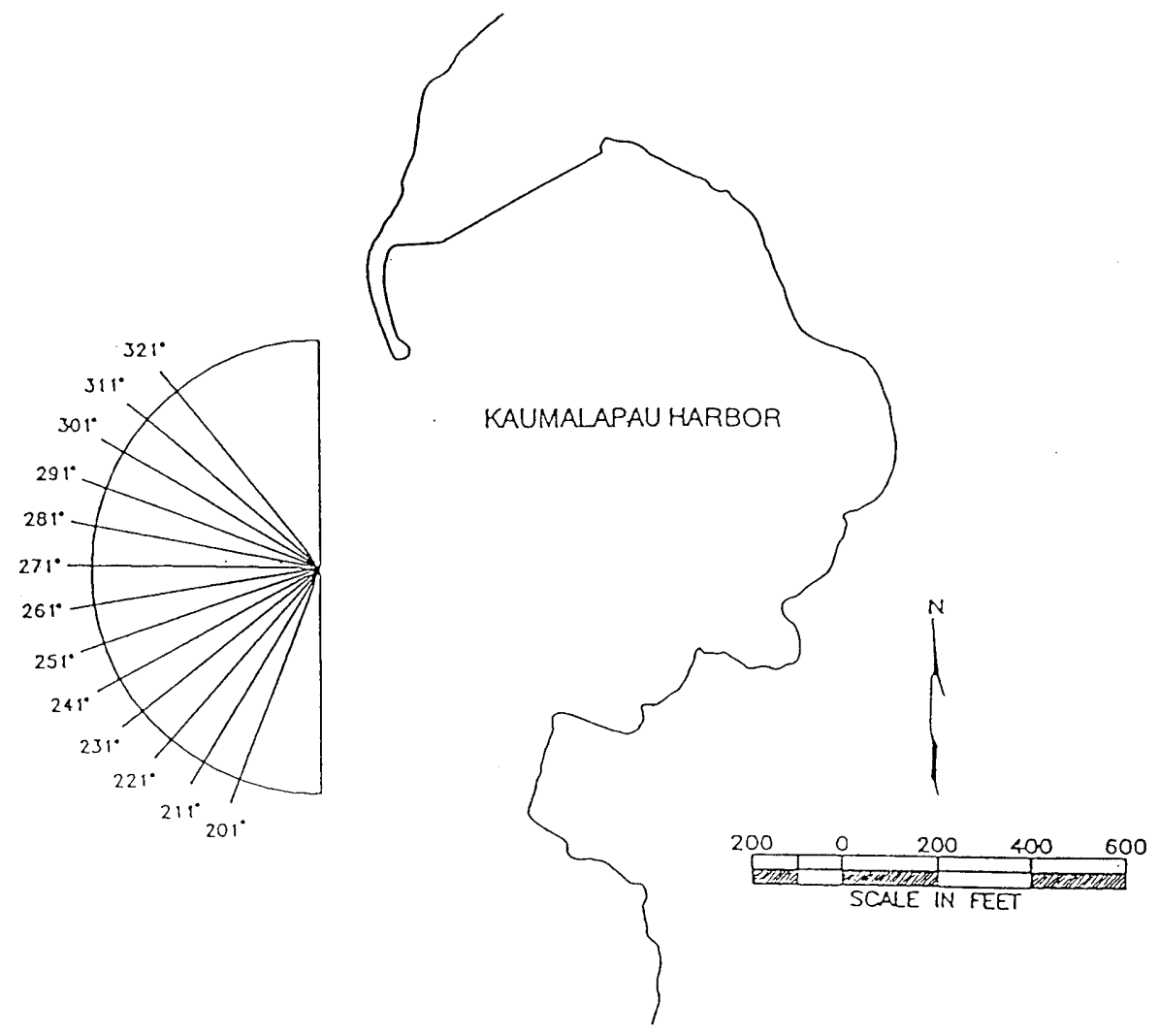

Figure 15. Incident wave directions

Incident long-wave conditions considered are given in Table 12. A fine resolution in wave frequency was used over the full range of possible resonant conditions to ensure that all important peaks were identified. A total of 202 periods were considered. Only one approach direction is included, since past studies have indicated that harbor response is relatively insensitive to incident long-wave direction. This direction represents a wave directly approaching the harbor entrance from deep water.

One water level was used in the simulations. The tide range at Kaumalapau Harbor is relatively small, with a mean range of $0.46 \mathrm{~m}(1.5 \mathrm{ft})$. A high-water condition corresponding to the mean high-water tide level was selected because highwave conditions are often accompanied by some-

\begin{tabular}{|l|l|}
\hline \multicolumn{2}{|l|}{$\begin{array}{l}\text { Table } 12 \\
\text { Summary of } \\
\text { Incident Long Wave } \\
\text { Conditions }\end{array}$} \\
\hline $\begin{array}{l}\text { Wave } \\
\text { Period } \\
\text { sec }\end{array}$ & $\begin{array}{l}\text { Wave Direction } \\
\text { deg azimuth }\end{array}$ \\
\hline 22.0 & 261.5 \\
\hline 22.3 & \\
\hline 22.6 & \\
\hline$\ldots$ & \\
\hline $\begin{array}{l}1 \\
513.0\end{array}$ & \\
\hline $\begin{array}{l}1 \\
\text { Frequency increments are } \\
0.0001 \mathrm{~Hz} \text { for periods of } 22- \\
82 \text { sec and } 0.00006 \mathrm{~Hz} \text { for } \\
\text { periods of } 83-513 \text { sec. }\end{array}$ \\
\hline
\end{tabular}


what elevated water levels. Mean high water at Kaumalapau Harbor is $+0.52 \mathrm{~m}$ $(+1.7 \mathrm{ft}) \mathrm{mllw}$.

\section{Calculation of spectra}

All numerical model simulation results for Kaumalapau Harbor are based on spectral post-processing of the initial HARBD runs. This approach requires, first, that HARBD be run with the range of wave periods to be considered in the spectral calculations. Second, values of peak wave period $T_{p}$, corresponding to the peak spectral frequency, and spectral peak enhancement factor $\gamma$ must be specified. The $T_{p}$ values were chosen to represent wind wave and swell conditions at the harbor, as discussed in the section "Incident Wave Conditions."

Values for $\gamma$ were approximated by relating the guidance in Table 6 to $T_{p}$ values (Table 13). High-energy waves, of concern for harbor design, with $T_{p}$ up to $10 \mathrm{sec}$ were assumed to be growing seas, and $\gamma$ was set to 3.3. Waves with $T_{p}$ equal to $16 \mathrm{sec}$ and $18 \mathrm{sec}$ were treated as swell. As swell $T_{p}$ increases, the swell is expected to have an increasingly peaked spectrum. However, a value of $\gamma=8$ was considered representative of the two swell periods considered.

\section{Output basins}

In order to get special coverage of areas

\begin{tabular}{|l|l|}
\hline \hline \multicolumn{2}{||l|}{\begin{tabular}{l} 
Table 13 \\
Approximate \\
Relationship \\
Between $T_{\rho}$ and $V$ \\
\hline \hline $\begin{array}{l}T_{p} \\
\text { sec }\end{array}$
\end{tabular}} \\
\hline \hline 8 & $Y$ \\
\hline 10 & 3.3 \\
\hline 16 & 3.3 \\
\hline 18 & 8 \\
\hline
\end{tabular}
where harbor traffic would most likely be affected by wave conditions, 11 output locations or "basins" were selected in the approach to the main wharf (basins 5 through 7 and 11), the main wharf (basins 1through 4), and peripheral areas (basins 8 through 10) (Figure 16). Basins 1 and 5 coincide with field wave gauge locations. A basin is a small cluster of elements over which the HARBD response is averaged to give a more representative output. Each basin in this study contains 41 to 54 elements. At each of these locations, HARBD output information was saved in addition to the detailed output at nodes. 


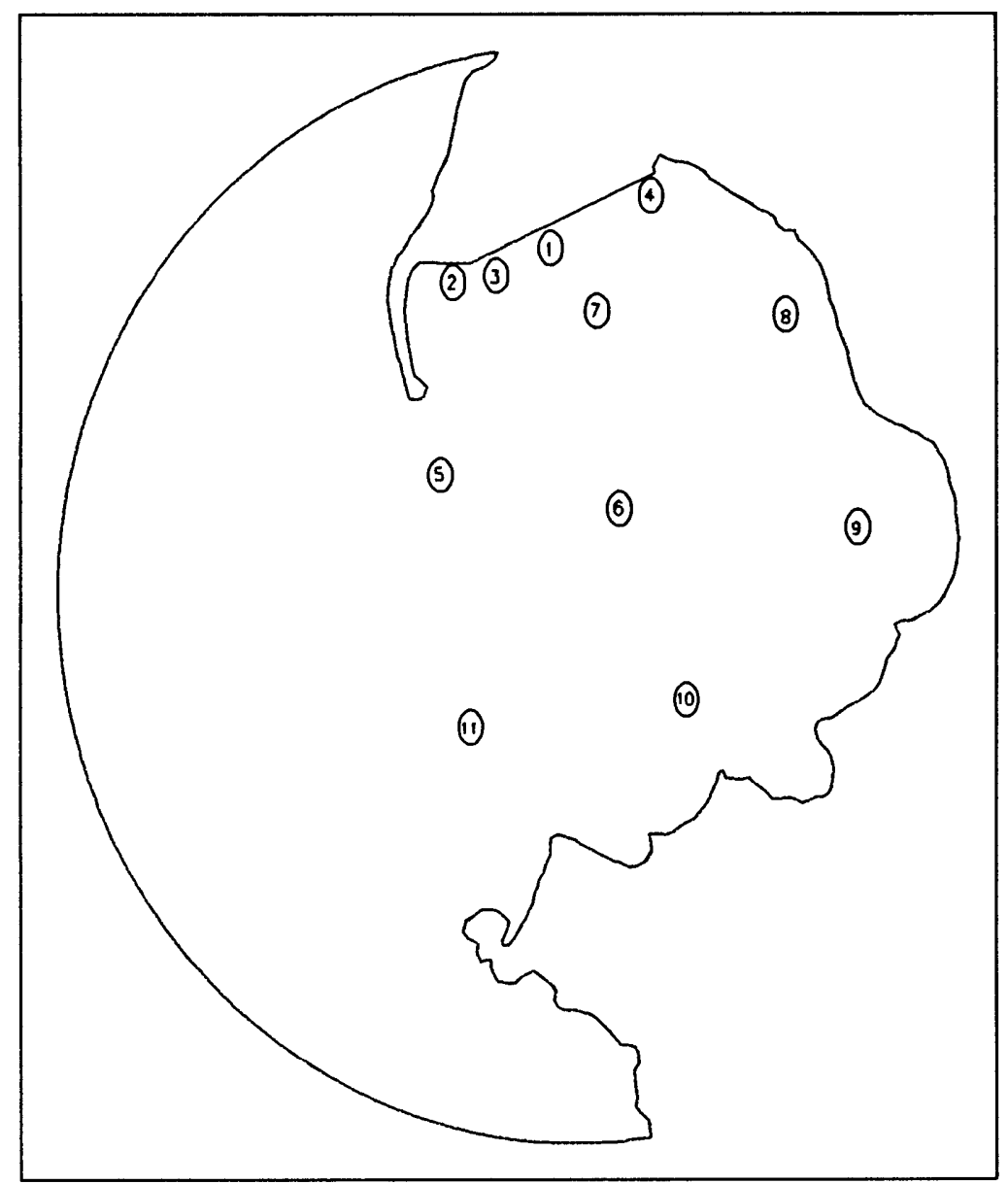

Figure 16. Output basins 


\section{Harbor Response to Wind Waves and Swell ${ }^{1}$}

Numerical model studies of the harbor response to wind waves and swell were directed toward increasing the efficiency and decreasing the time and cost for physical model experiments.

\section{Directional Sensitivity of the Harbor}

Large wavemakers were used to generate unidirectional irregular waves in the physical model. To change the incident wave direction, the wavemakers had to be physically moved and side training walls relocated, a time-consuming and expensive operation. For practical reasons, only three incident directions could be considered. To assure that the directions were representative of the most damaging harbor conditions, a directional sensitivity study was performed with the HARBD model for incident $T_{p}$ values of 8, 10, 16, and $18 \mathrm{sec}$ (Figures 17 through 20).

Figures 17 and 18 indicate that shorter period waves at the wharf have a tendency to be high (relative to incident waves) when coming from a southerly direction, though the directional response for 8-sec waves also peaks around a northerly approach direction of $281 \mathrm{deg}$. Since the wharf is most directly exposed to waves from the southwest, a strong response to southerly waves is not surprising. For the longer period swell, the peak directional response shifts more toward the direct approach to the harbor of 251 to $261 \mathrm{deg}$ (Figures 19 and 20).

\section{Comparison of Alternatives}

Nine different harbor modification alternatives were defined by the Kaumalapau Harbor study team for exploratory investigation, as discussed earlier. Alternatives were assessed with the numerical model. Physical model experiment plans were streamlined based on conclusions from the numerical model simulations.

\footnotetext{
${ }^{1}$ Written by Edward F. Thompson and Lori L. Hadley.
} 


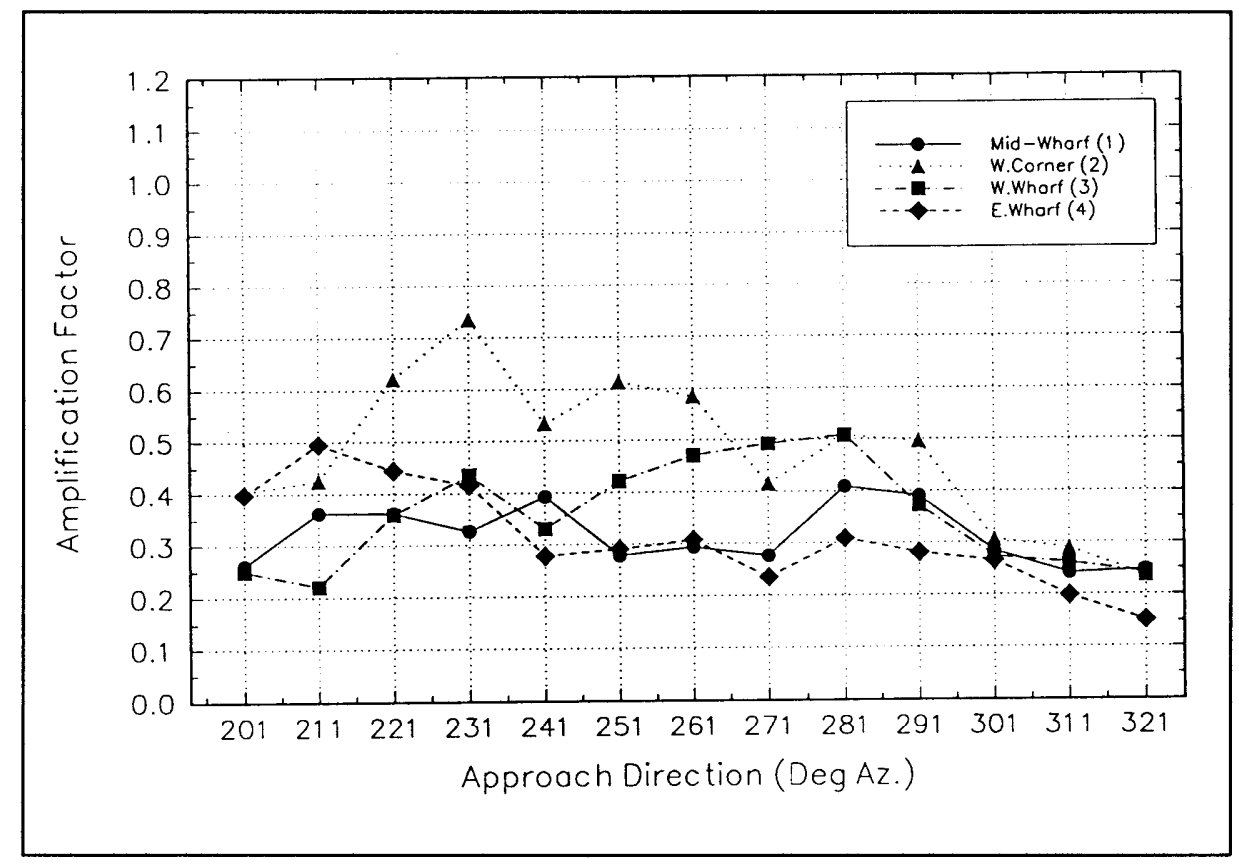

Figure 17. Amplification factor sensitivity to wave direction, $T_{p}=8 \mathrm{sec}$

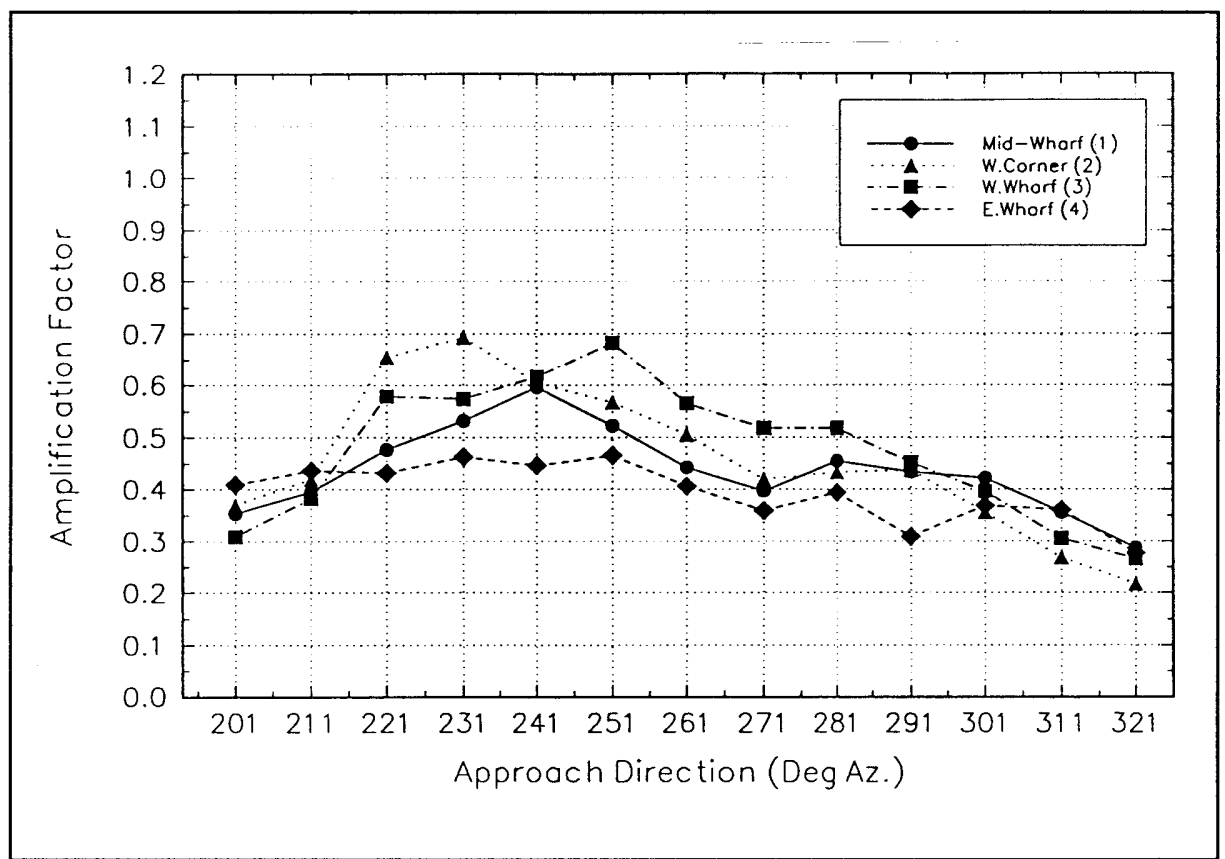

Figure 18. Amplification factor sensitivity to wave direction, $T_{p}=10 \mathrm{sec}$ 


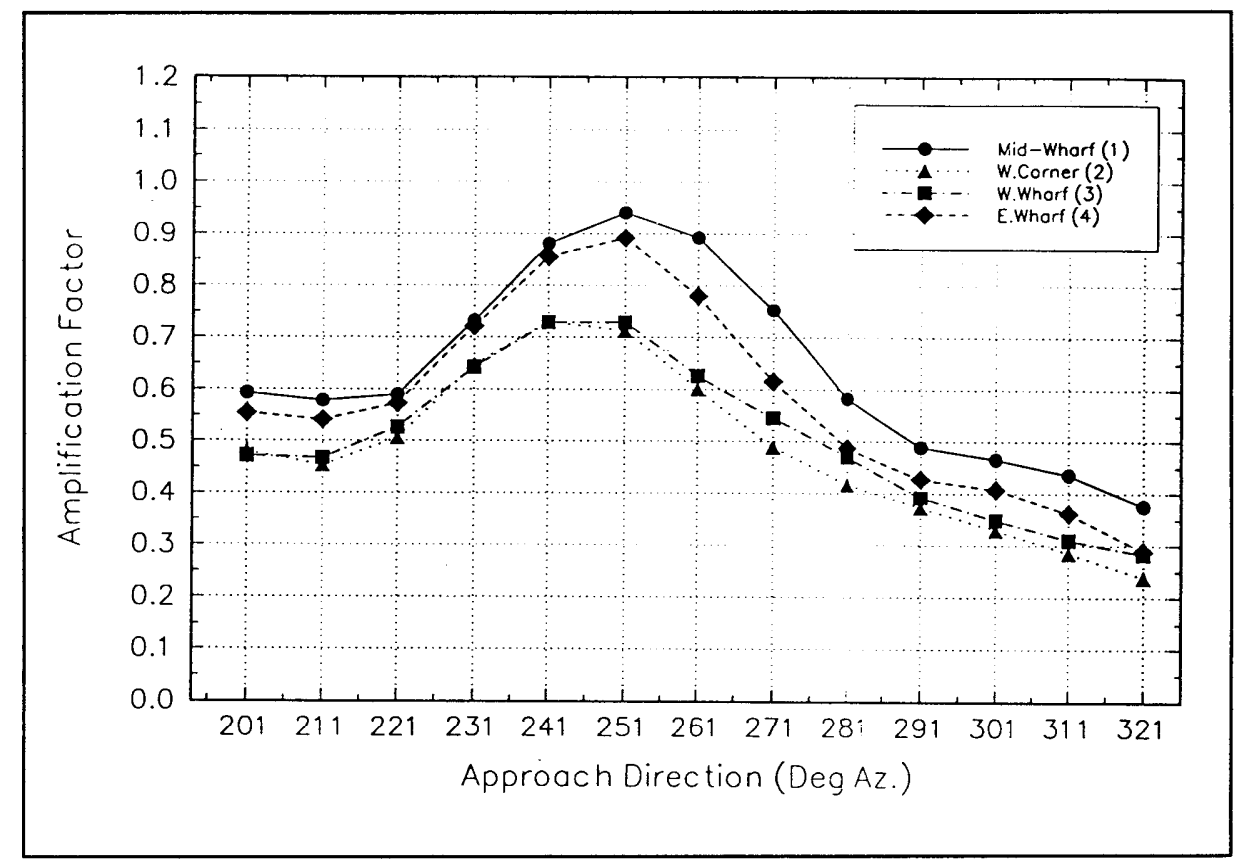

Figure 19. Amplification factor sensitivity to wave direction, $T_{p}=16 \mathrm{sec}$

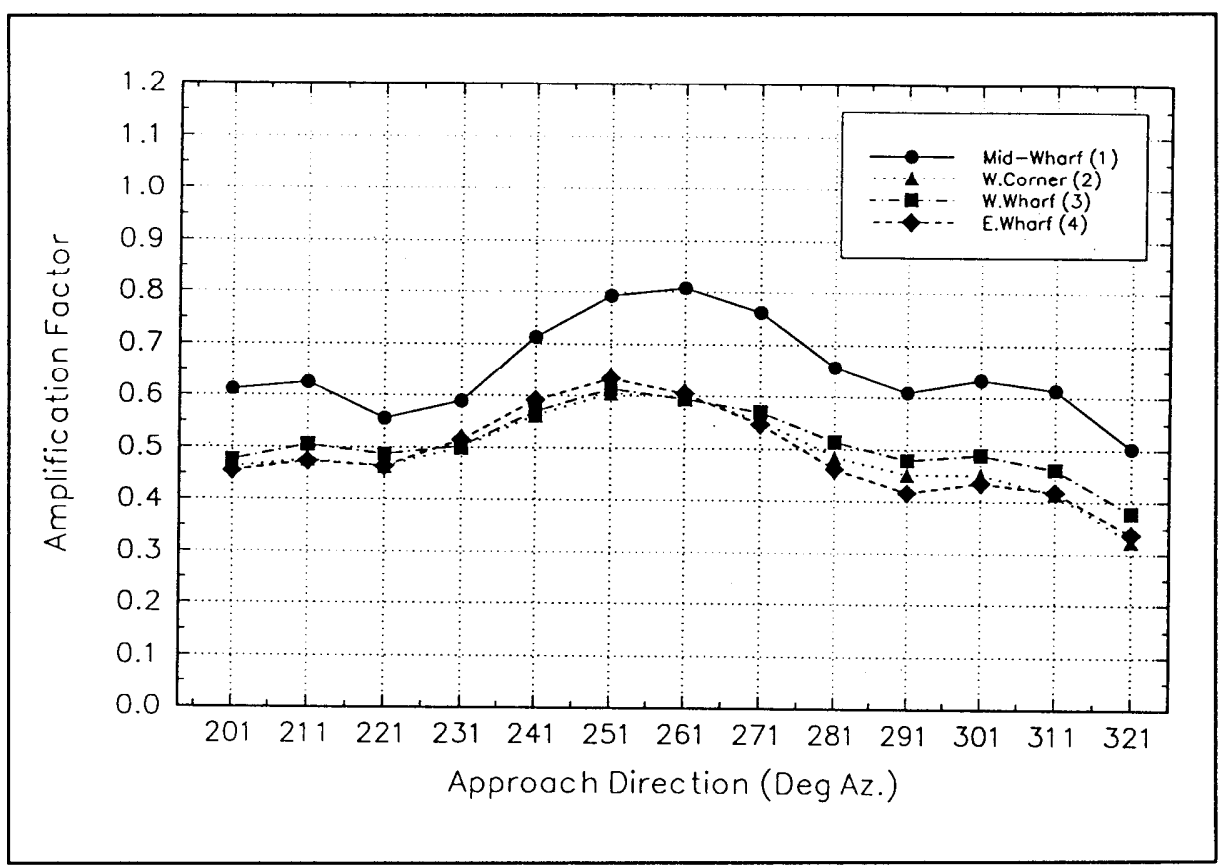

Figure 20. Amplification factor sensitivity to wave direction, $T_{p}=18 \mathrm{sec}$ 
Proposed modifications were evaluated in terms of wave height in the alternative plan relative to wave height in the existing harbor at three locations along the main wharf (Basins 1, 3, and 4). Relative wave heights were plotted against wave approach direction for each harbor alternative. The two peak wave periods considered, 10 and $16 \mathrm{sec}$, are representative of wind wave and swell conditions at Kaumalapau Harbor. Results for the dogleg breakwater extension are given in Figures 21 and 22 . The addition of the dogleg extension significantly reduces wave heights within the harbor. Waves with 10 -sec periods approaching from the northwest were particularly affected, resulting in wave heights 43 to 74 percent of those in the existing harbor. The same wave condition approaching from the west and southwest was reduced, but to a lesser degree, resulting in wave heights 60 to 98 percent those in the existing harbor. A single case of increased amplification occurred at the east end of the main wharf (Basin 4) for an incident wave direction of $221 \mathrm{deg}$.

Longer period swell (Figure 22) also showed a marked decrease in wave height with the addition of the dogleg extension, but with greater consistency through all incident directions. For waves approaching between 315 and $201 \mathrm{deg}$, wave heights along the main wharf ranged between 65 and 80 percent of those in the existing harbor.

The addition of wave absorber along the northeast or south shore of the harbor had little effect on wave heights at the wharf. In all cases involving wave absorbers, the average reduction in wave height along the wharf was no greater than 10 percent. Although wave absorbers had little impact on the wharf area, they did reduce wave heights in a very localized area immediately adjacent to the absorbing shore.

Similar results for the straight breakwater extension are shown in Figures 23 and 24. For 10-sec waves approaching from the northwest, the addition of the straight breakwater extension without further modification gives wave heights along the pier between 45 and 71 percent of those within the existing harbor. The same waves approaching from the southwest show wave heights that are between 61 and 113 percent those with the existing harbor, where values greater than 100 percent represent an increase in wave amplification. Longer period swell shows less directional sensitivity, giving a more focussed range of wave heights between 69 and 90 percent of those for existing harbor conditions.

Based on results for dogleg modifications, wave absorber was added only along the north shore for straight breakwater designs. Again the average reduction in wave height along the pier did not exceed 10 percent.

In order to isolate effects of the wave absorber on harbor response, absorber combinations with the existing breakwater were also evaluated (Figures 25 and 26). Results show that wave heights along the pier are reduced by no more than 11 percent for all cases where wave absorber was present. Also, the addition of a south breakwater had little effect on wave heights along the pier, showing a maximum reduction in height of 19 percent with an average reduction of approximately 2 percent. 


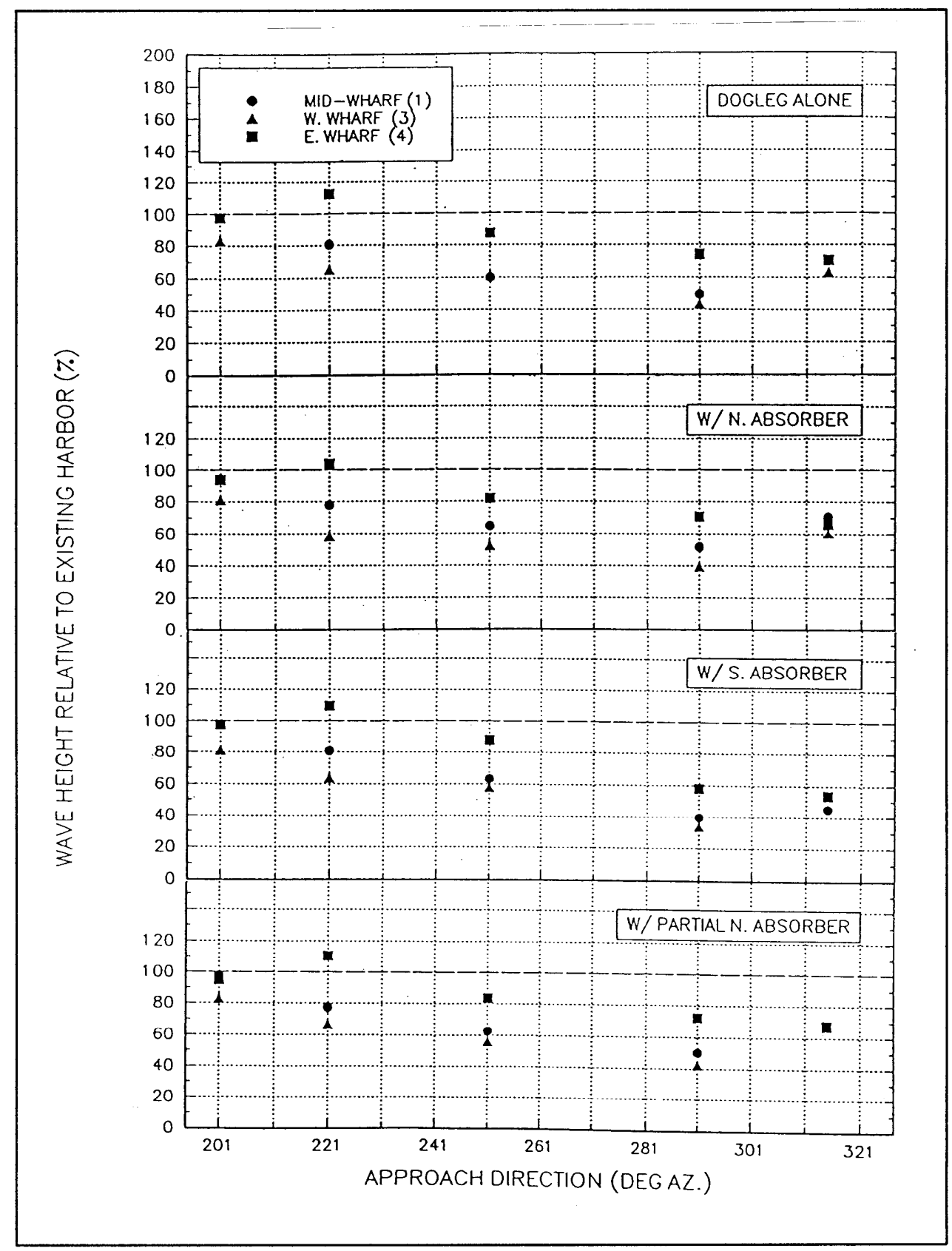

Figure 21. Wave height relative to existing harbor, dogleg breakwater extension, $T_{p}=10 \mathrm{sec}$ 


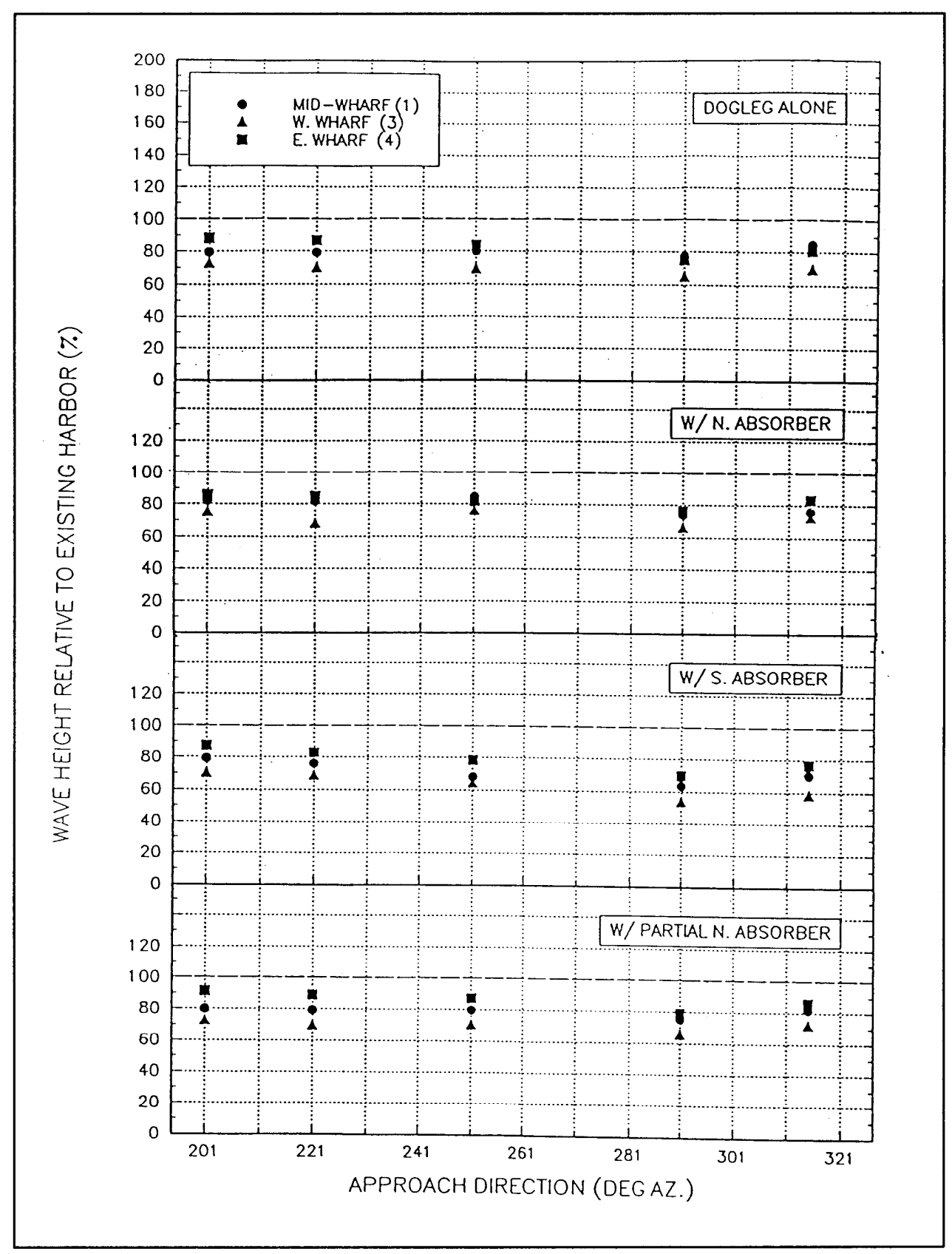

Figure 22. Wave height relative to existing harbor, dogleg breakwater extension, $T_{p}=16 \mathrm{sec}$ 


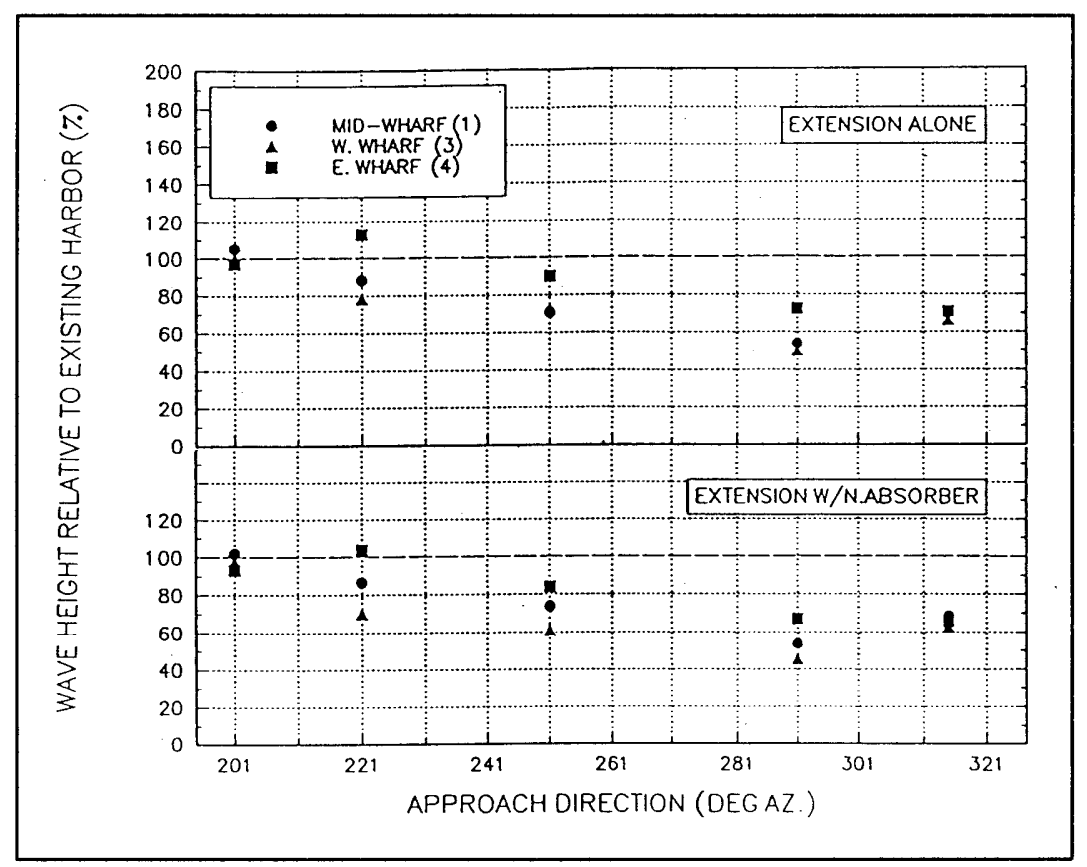

Figure 23. Wave height relative to existing harbor, straight breakwater extension, $T_{p}=10 \mathrm{sec}$

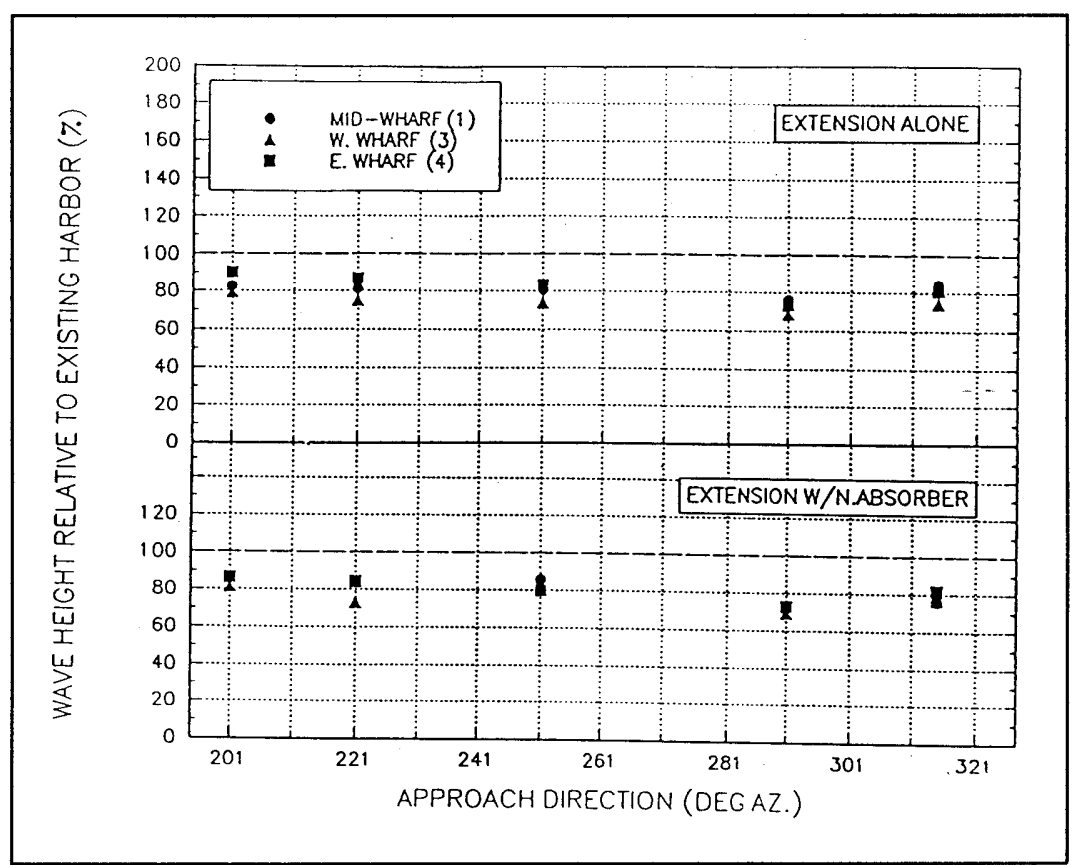

Figure 24. Wave height relative to existing harbor, straight breakwater extension, $T_{p}=16 \mathrm{sec}$ 


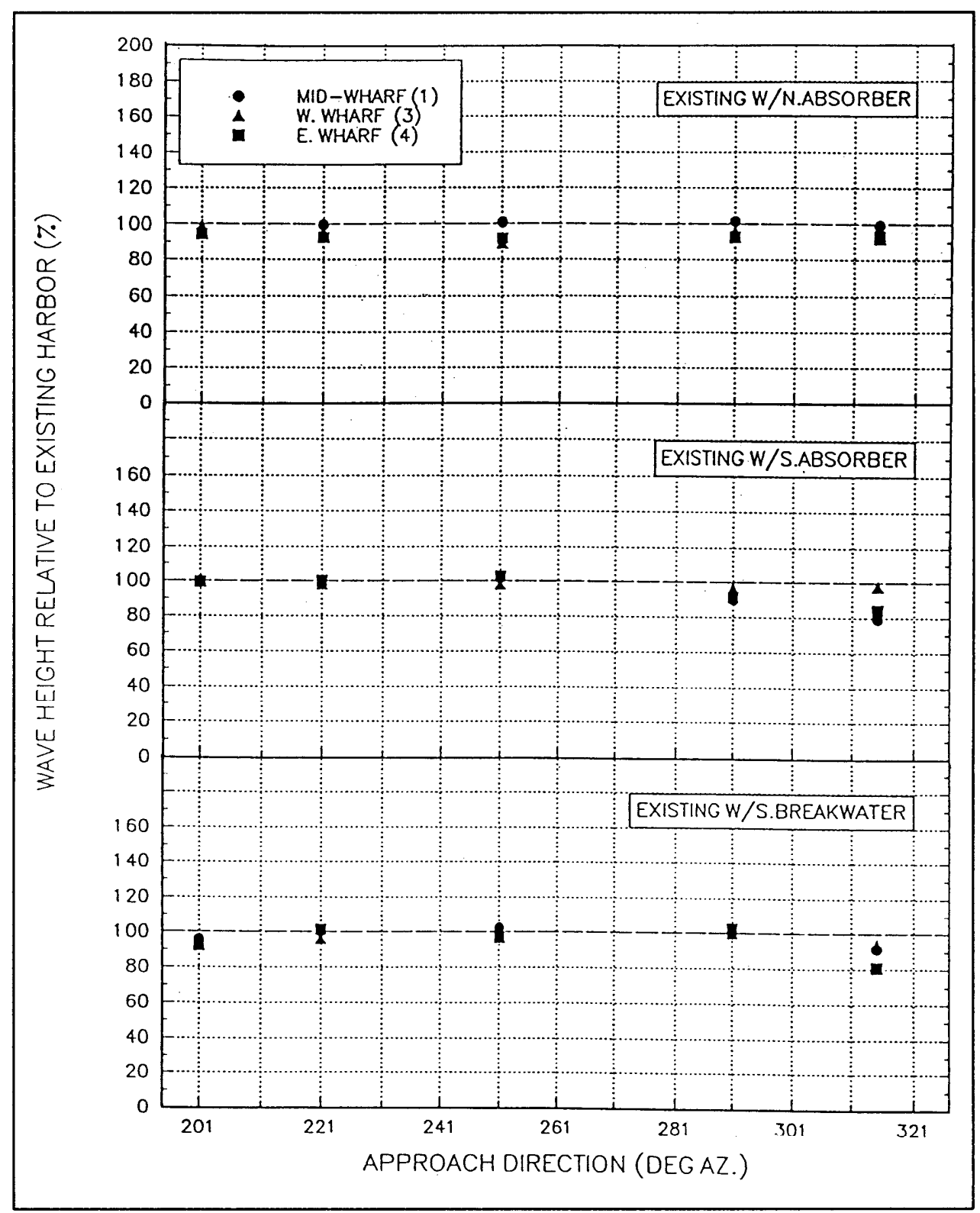

Figure 25. Wave height relative to existing harbor, existing breakwater, $T_{p}=$ $10 \mathrm{sec}$ 


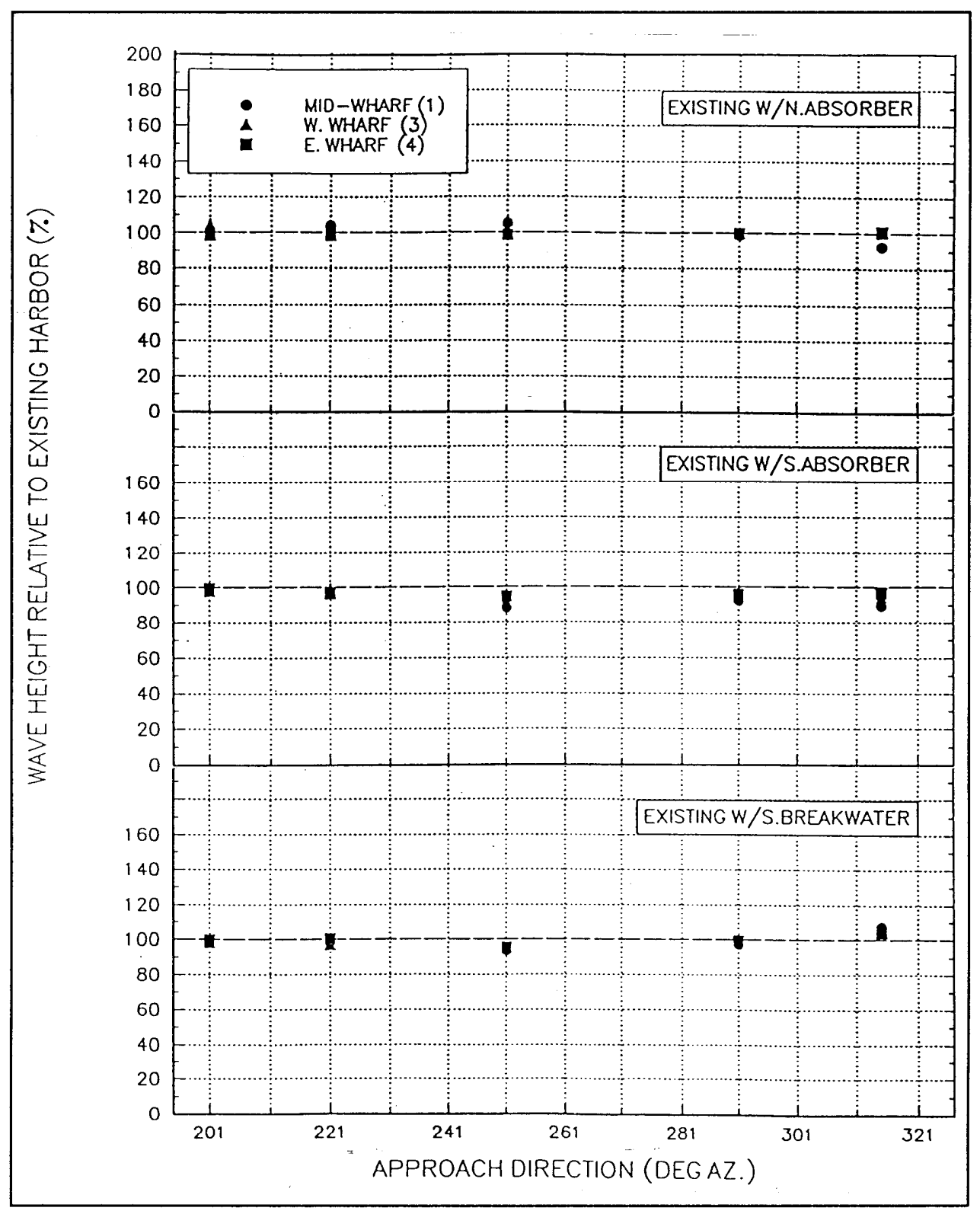

Figure 26. Wave height relative to existing harbor, existing breakwater, $T_{p}=$ $16 \mathrm{sec}$ 
Amplification factor contour plots illustrate the effect of each of the breakwater alternatives on waves entering the harbor (Figures 27 and 28). The effect of the wave absorber along the northeast shore also is illustrated.

In summary, the numerical model simulations of harbor alternatives indicate that a $45.7-\mathrm{m}(150-\mathrm{ft})$ extension to the existing breakwater will reduce short wave heights at the wharf to about 60 to 80 percent of those in the existing harbor. The dogleg breakwater extension is a little more effective than the straight extension for reducing wave action at the wharf. Wave absorbers along the northeast or south shores of the embayment have minimal impact on wave heights at the wharf. 


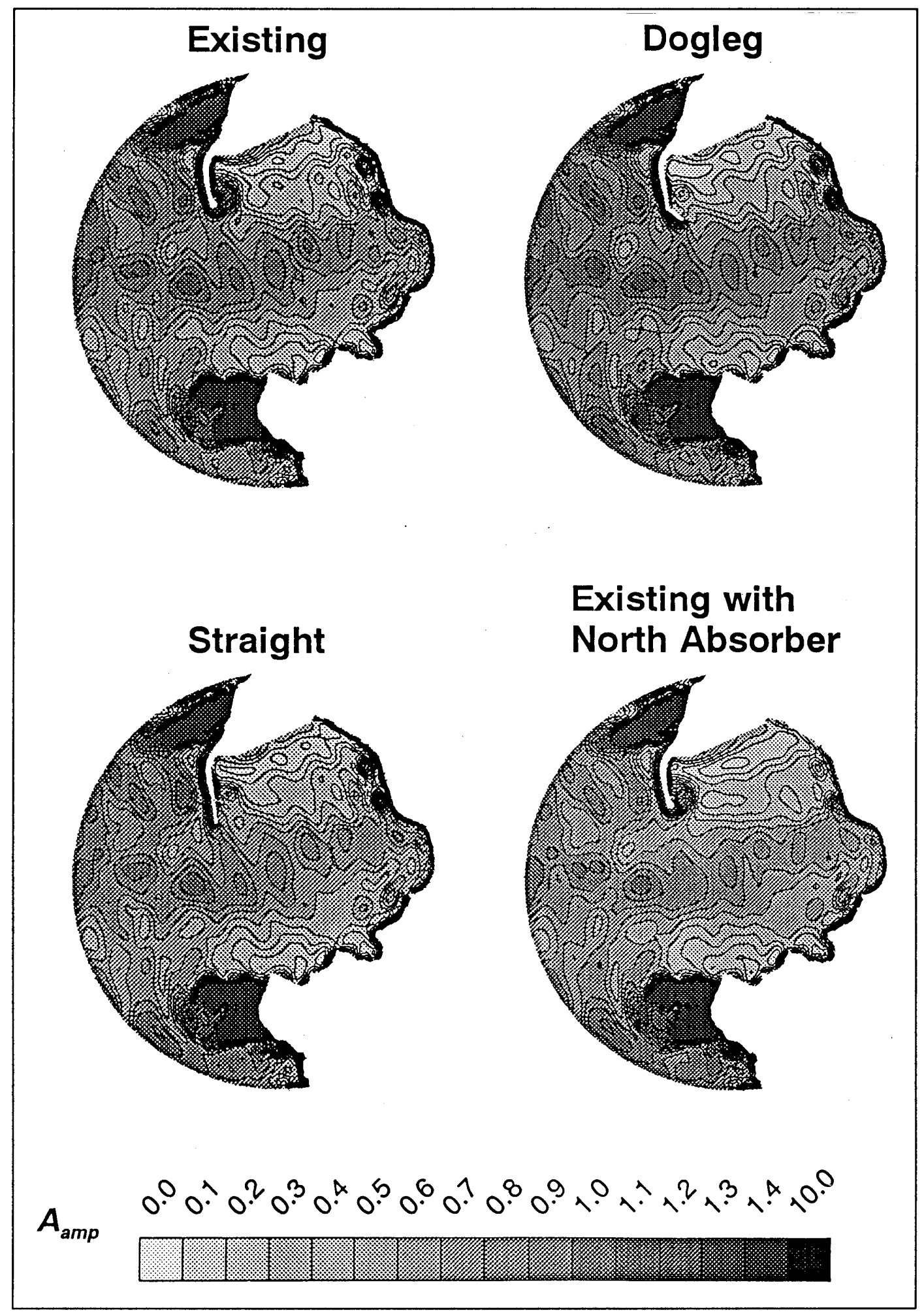

Figure 27. Amplification factor contours, 251-deg incident direction, $T_{p}=10 \mathrm{sec}$ 


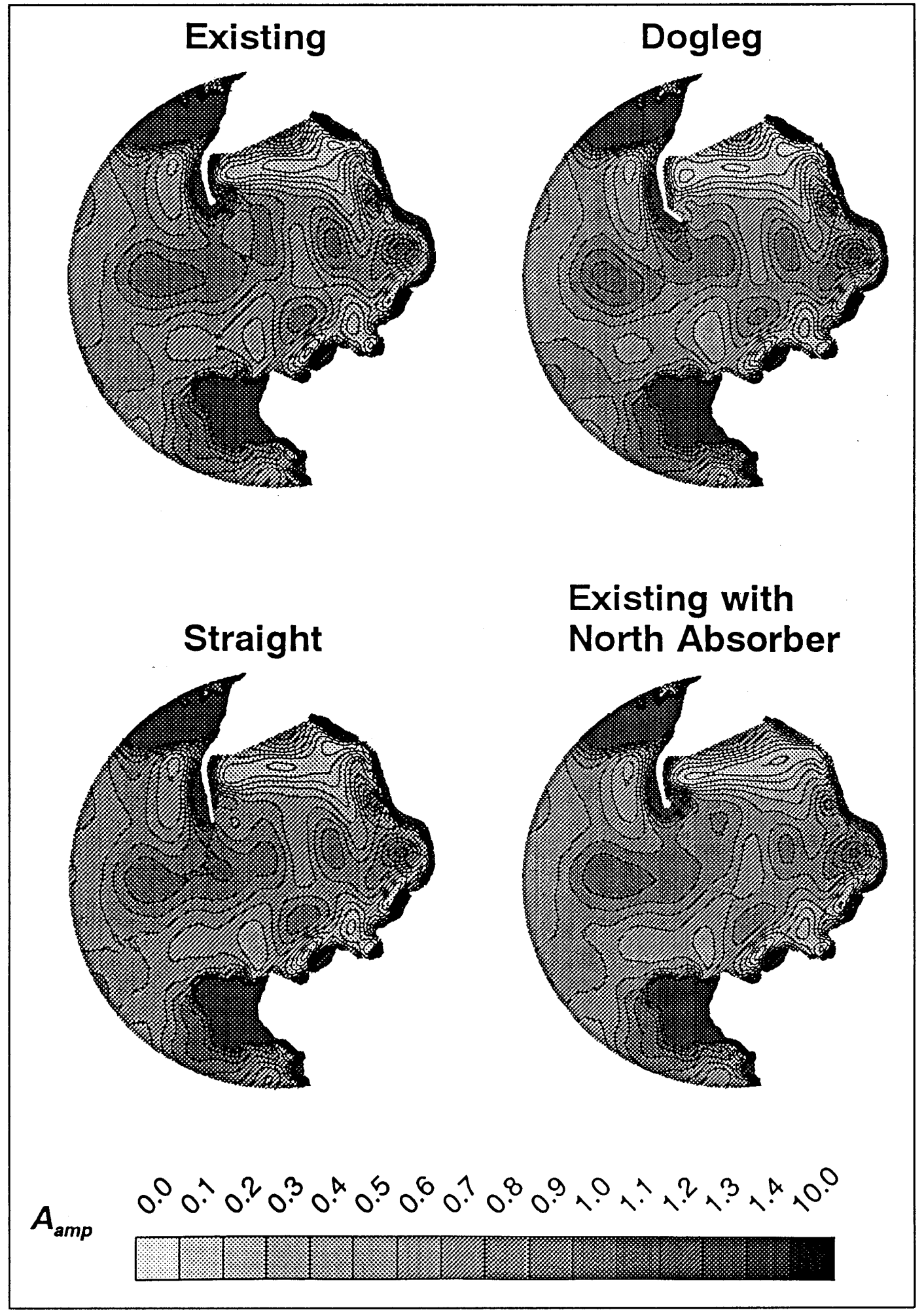

Figure 28. Amplification factor contours, 251-deg incident direction, $T_{p}=16 \mathrm{sec}$ 


\section{Harbor Oscillations'}

To evaluate harbor resonance characteristics, the HARBD numerical model was run for the existing harbor and the WES-recommended plan. Incident longwave periods ranged from 23 to $513 \mathrm{sec}$ in very fine increments, as discussed in Chapter 4. These simulations were included because modifications to a harbor can potentially lead to increased operational problems due to harbor oscillations.

Amplification factors in the existing harbor along the wharf, Basins 1 through 4 (Figure 16), are shown as a function of wave frequency in Figure 29. Some frequencies produce a strong resonant amplification, with peak amplification factors between approximately 5 and 30 . Many of the same resonant frequencies appear at all four basins, though the strength of amplification can vary considerably between basins. Similar resonant frequencies are indicated at the other basins with few exceptions (not shown).

Amplification factors in the WES-recommended alternative plan along the wharf also show strong resonance at some frequencies (Figure 30). The lowest frequency resonance, at $0.00615 \mathrm{~Hz}$, is similar to that in the existing harbor. However, the other resonant peaks generally differ from the existing harbor results in both magnitude and frequency. The WES-recommended plan shows fewer, but generally higher, resonant peaks than the existing harbor.

Amplification factor and phase contour plots for the six highest resonant peaks show oscillation patterns in the existing harbor. In the amplification factor plots, areas of high amplification are evident as darker shades of gray (Figure 31). Corresponding phase contours are shown in Figure 32. In a pure standing wave, the phase values are constant between nodes and they shift $180 \mathrm{deg}$ across a node. Areas in which phase contours are tightly bunched indicate nodal areas. Velocities and particle excursions at nodes are relatively large and vertical motions are relatively small. Thus, nodal lines in Figure 32 coincide with low amplification factors in Figure 31. The phase plots also indicate areas of the harbor which rise and fall together during the resonant condition (same gray shade). Thus, the oscillation patterns can be interpreted.

\footnotetext{
${ }^{1}$ Written by Edward F. Thompson and Lori L. Hadley.
} 


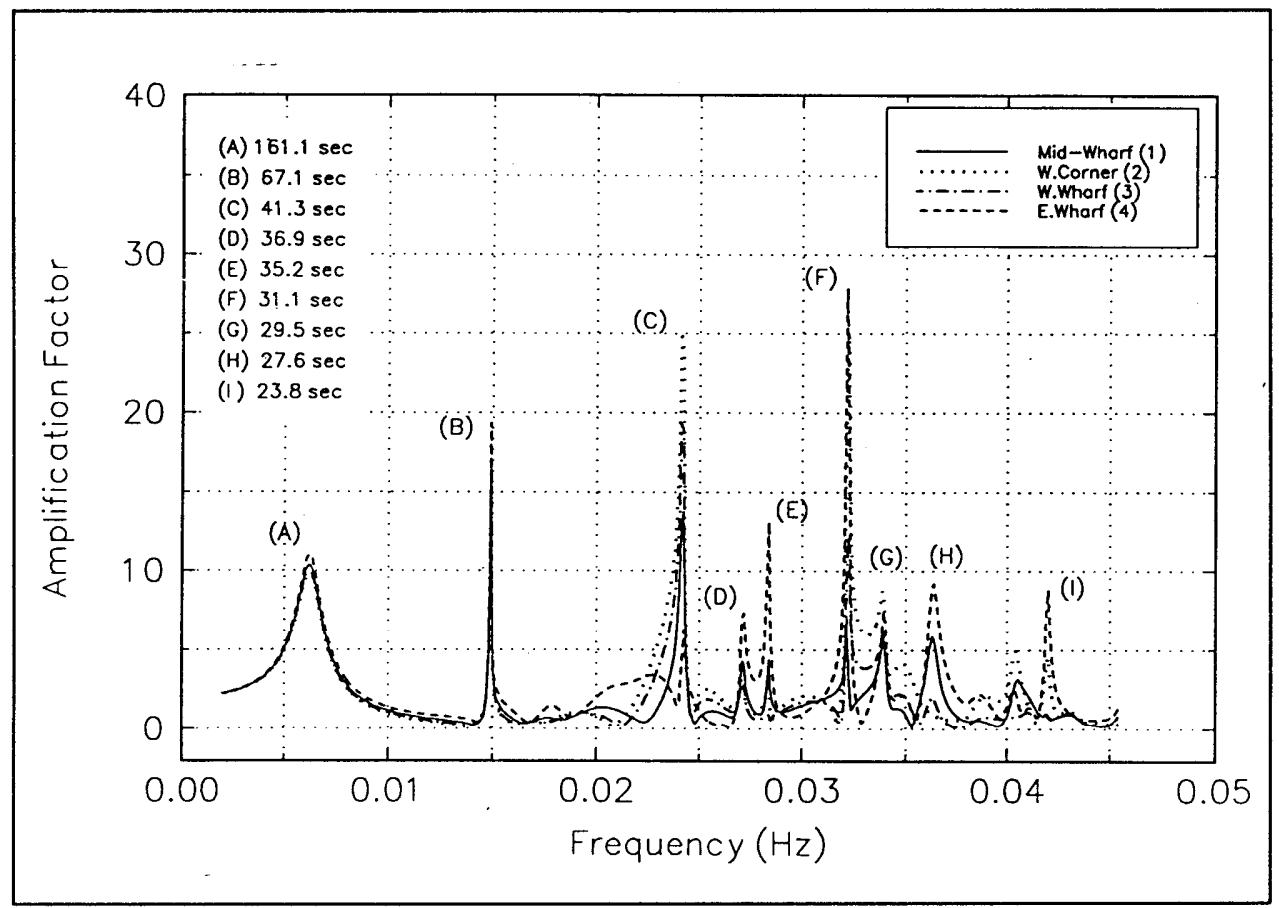

Figure 29. Long wave response, existing harbor

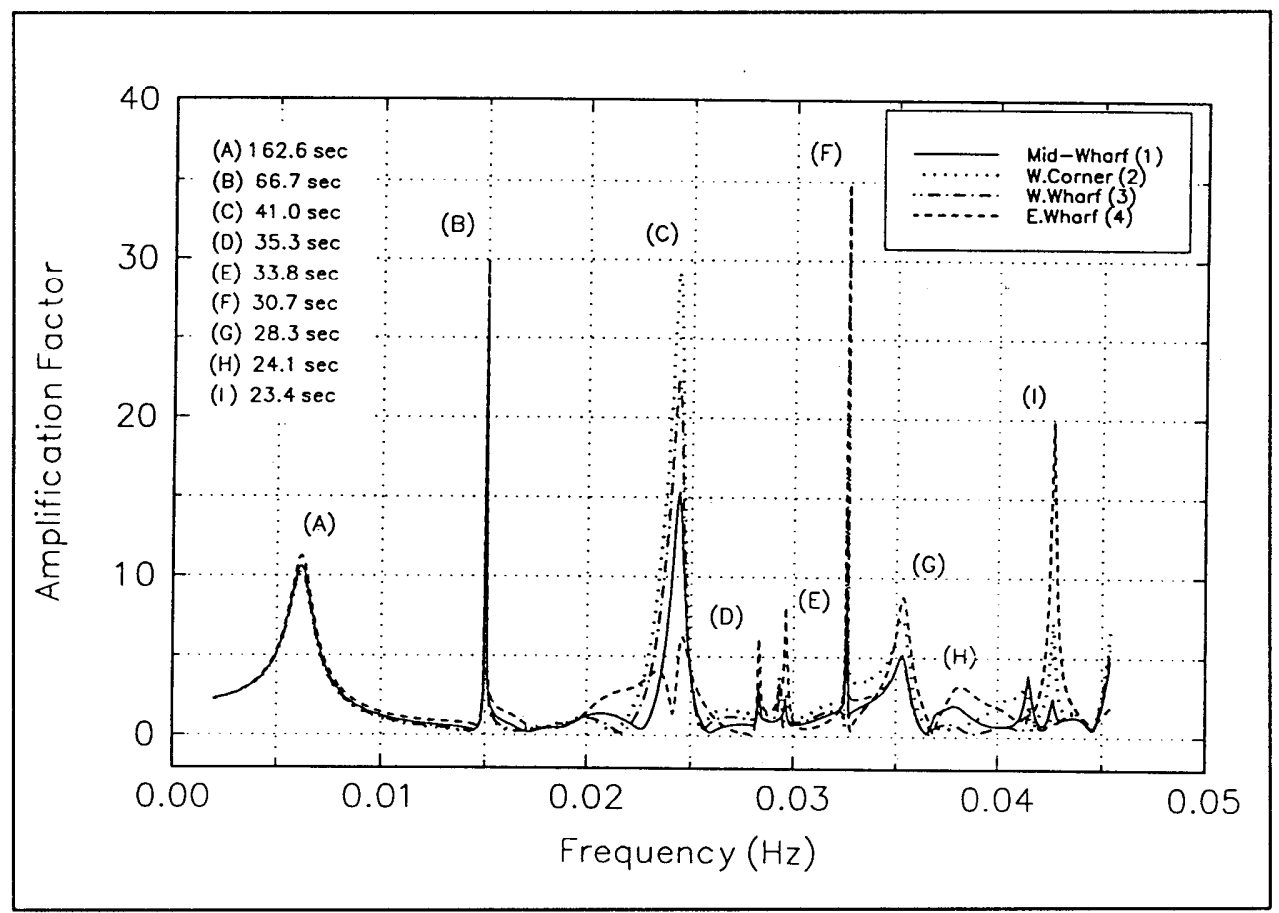

Figure 30. Long wave response, WES-recommended plan 


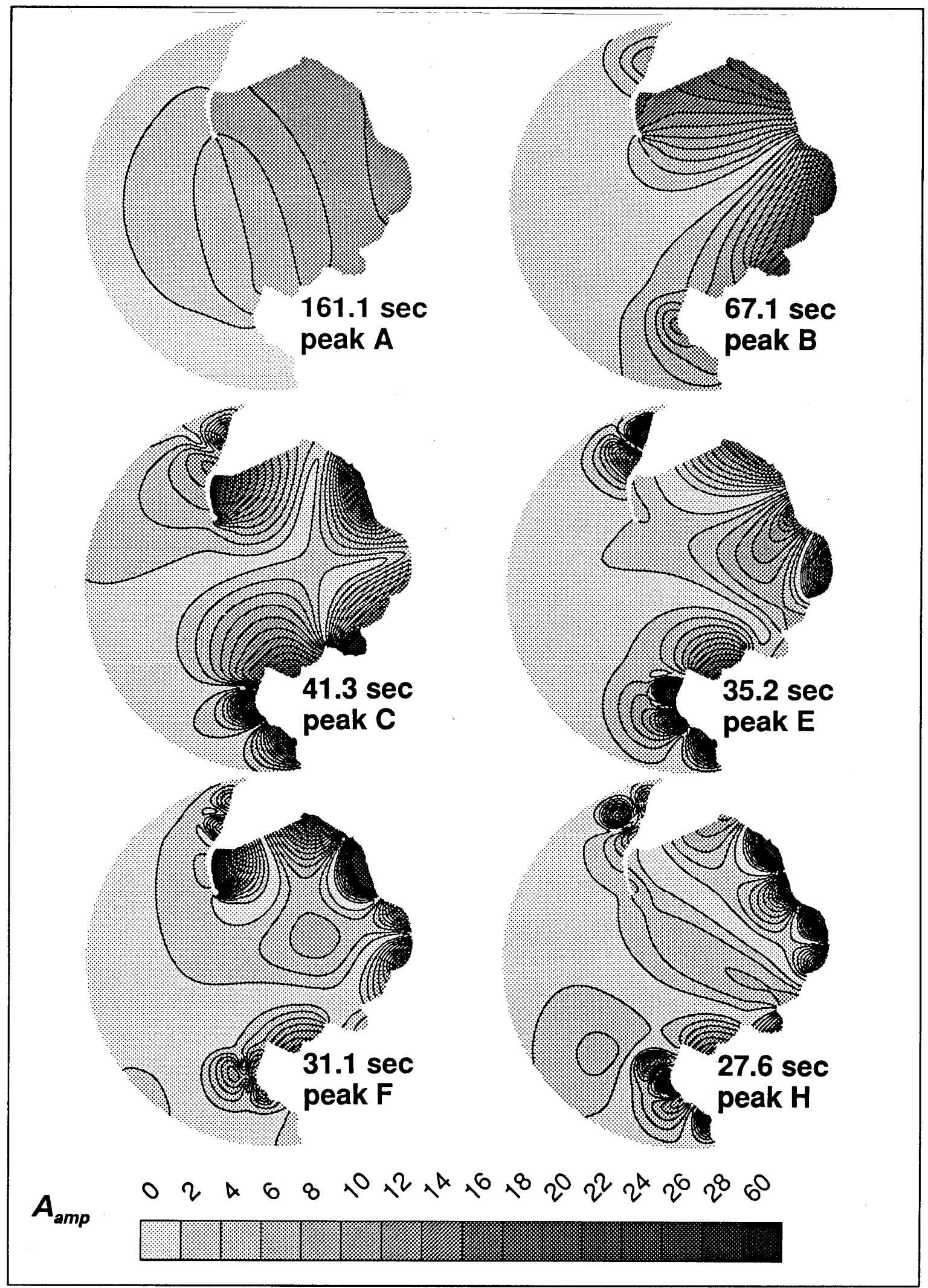

Figure 31. Resonant long wave amplification factor contours, existing harbor 


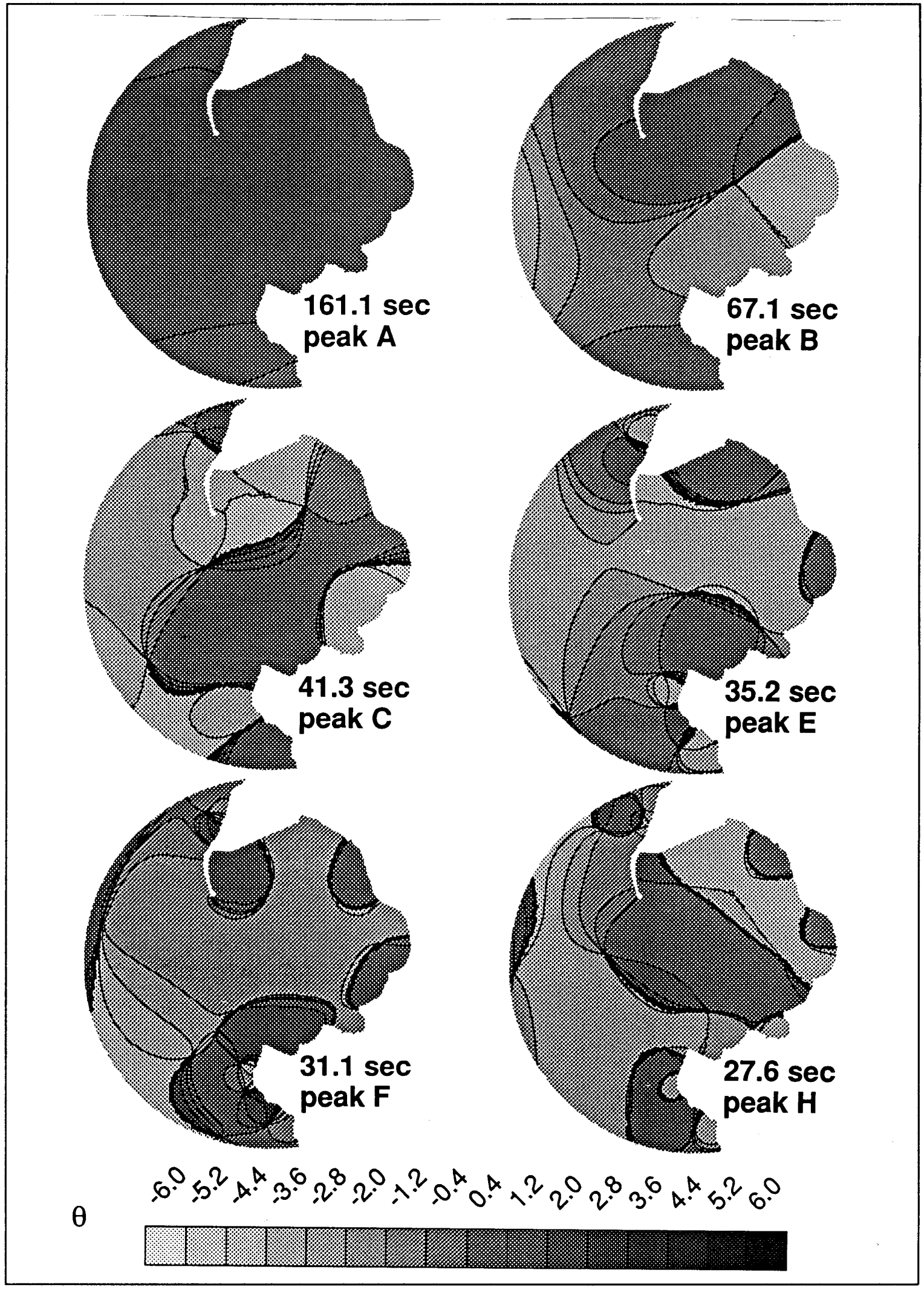

Figure 32. Resonant long-wave phase contours, existing harbor 
From the figures, it is clear that peak $A$ at $161.1 \mathrm{sec}$ represents the Helmholtz (or grave) mode of oscillation, in which the entire harbor rises and falls in unison. The phase value is constant over the whole embayment. The 67.1-sec resonant period, peak $B$, represents a simple rocking oscillation between the north and southeast areas of the harbor. A single nodal line runs across the harbor in a northeast-southwest direction. The shorter period oscillations are more complex patterns, though they generally indicate a strong nodal area at or near the wharf and a strong amplification west of the west wharf end and/or just east of the east wharf end. The elbow at the intersection of the breakwater and the wharf and the northeast corner of the harbor appear to be natural antinodes for long-wave resonance. Peaks $D$ and. $G$, which are not included in the figures, are weaker resonances, in which the north end of the embayment acts in phase and there are no nodal lines intersecting the wharf. The peak I resonance (not shown) is an interesting pattern similar to that shown below for peak I in the WES-recommended plan.

Amplification factor and phase contour plots for resonant peaks in the WESrecommended plan show similar oscillation patterns for peaks $A, B, C, E$, and $F$ (Figures 33 and 34). The stronger amplifications for the peak $B, C$, and $F$ cases (relative to the existing harbor) can be attributed to the greater constriction of the harbor by the longer breakwater in the WES-recommended plan. There is no strong resonance in the WES-recommended plan comparable to peak $H$ in the existing harbor, and the pattern for peak $I$ is included instead. The peak $I$ resonance shows an interesting nodal pattern which nearly intersects the western part of the wharf.

The long-wave amplification factors shown here should be viewed as conservatively high for several reasons. Wave reflection coefficient at all solid boundaries was set to 1.0. Bottom friction was set to 0.0. Also, the breakwater is represented as a solid barrier; but for harbor oscillation wave periods, significant energy may be transmitted through it.

A more quantitative comparison between the existing harbor and the WESrecommended alternative plan can be obtained by averaging amplification factors across the entire range of long-wave frequencies. The root-mean-square (RMS) amplification factor was computed for each plan (Table 14). The RMS is used because squared amplification factors are indicative of wave energy, a more relevant basis for comparison than wave height. The WES-recommended plan gives a higher RMS amplification factor than the existing harbor at all four basin locations along the wharf. As might be expected, the biggest increase between plans ( 20 percent) is at the western basins, closest to the breakwater. Differences between the existing and WES-recommended plans may be exaggerated because of the very high, narrow resonant peaks. Experience at other harbors has shown that such narrow peaks are often strongly attenuated when bottom friction is added to the model. Repetition of the Kaumalapau Harbor runs with a representative value of bottom friction was beyond the scope of this study. 


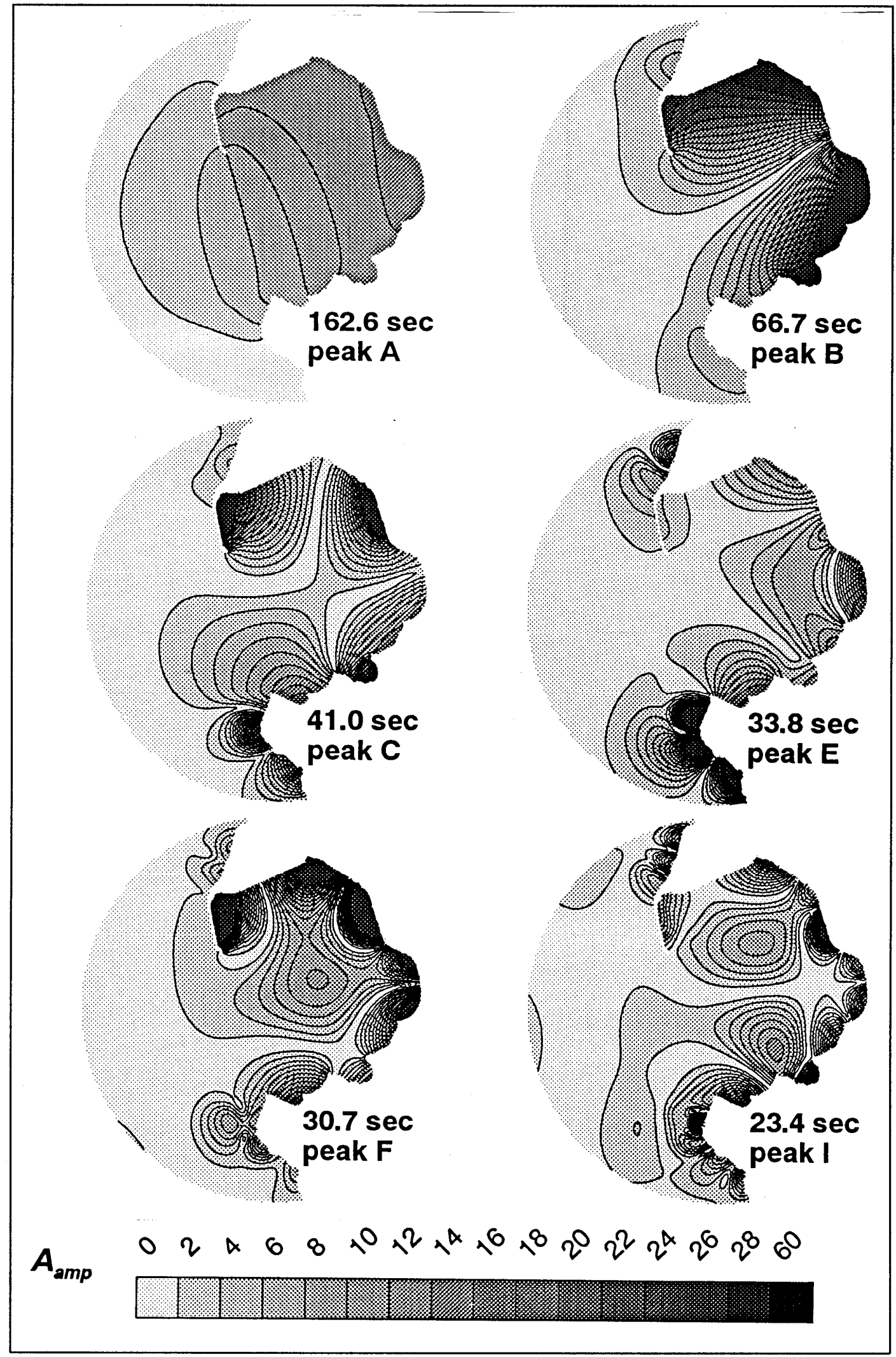

Figure 33. Resonant long-wave amplification factor contours, WES-recommended plan 


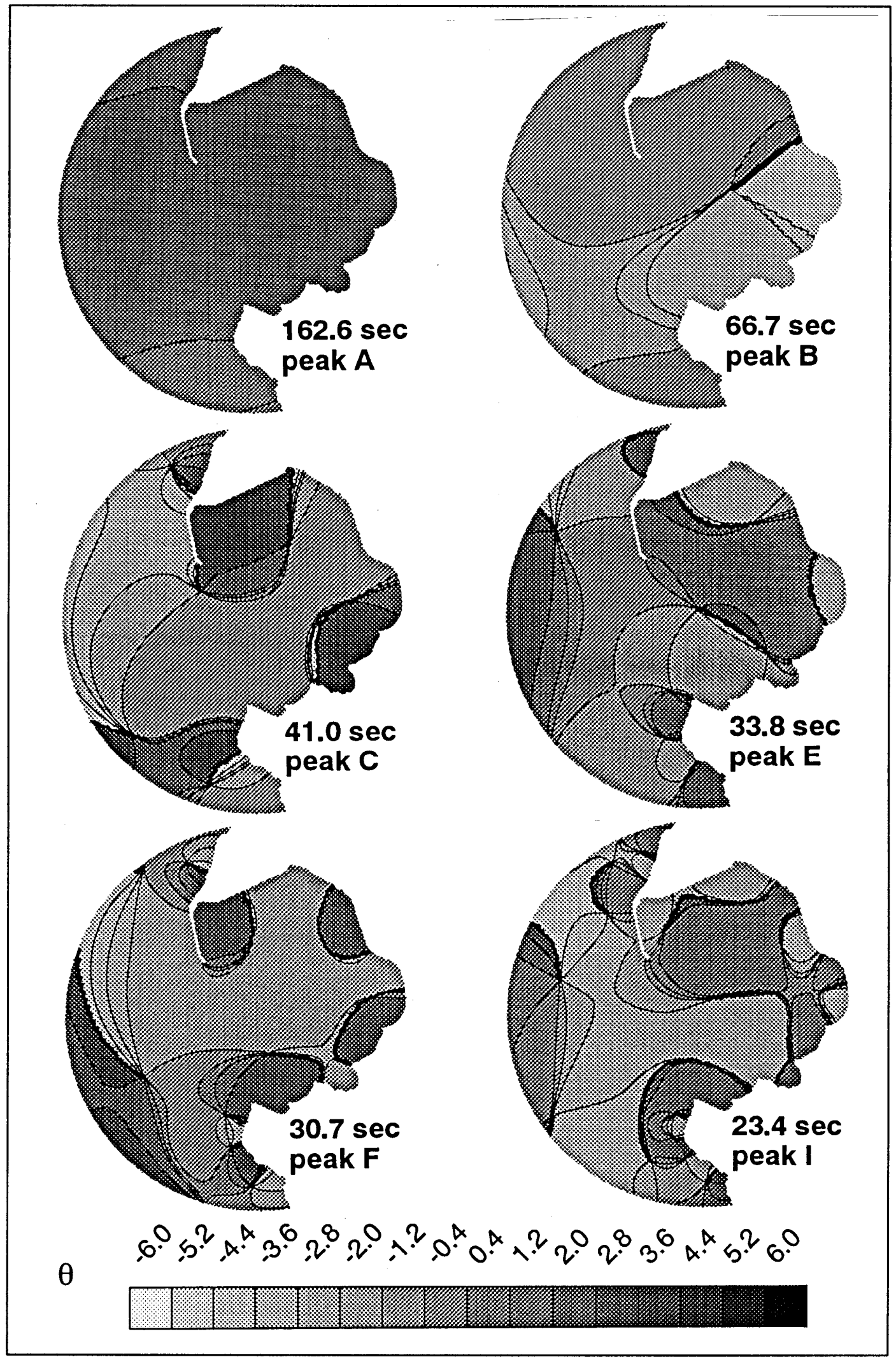

Figure 34. Resonant long-wave phase contours, WES-recommended plan 


\begin{tabular}{|c|c|c|c|}
\hline \multicolumn{4}{|c|}{$\begin{array}{l}\text { Table } 14 \\
\text { Comparison of Long Wave Response in Existing and WES-Recommended } \\
\text { Harbor Plans }\end{array}$} \\
\hline \multirow[t]{2}{*}{ Basin } & \multicolumn{3}{|c|}{ RMS Amplification Factor } \\
\hline & $\begin{array}{l}\text { Existing } \\
\text { Harbor }\end{array}$ & WES-Recommended Plan & $\begin{array}{l}\text { Percent Difference } \\
\text { (WES Plan - Existing) }\end{array}$ \\
\hline 1 (Mid-Wharf) & 3.13 & 3.49 & +12 \\
\hline 2 (W. Corner) & 4.13 & 4.94 & +20 \\
\hline 3 (W. Wharf) & 3.33 & 3.98 & +20 \\
\hline 4 (E. Wharf) & 3.95 & 4.18 & +6 \\
\hline
\end{tabular}

Although the WES-recommended plan is prone to stronger oscillations than the existing harbor, it seems likely that the differences will have little operational significance. Even with the WES-recommended plan, the harbor is quite open. Thus the level of wind wave and swell energy at the wharf will continue to be fairly high (by typical harbor standards). Wind waves and swell can be expected to continue as a primary operational concern which will probably outweigh any practical problems due to increased oscillations. 


\section{Physical Model Design ${ }^{1}$}

\section{Introduction}

An undistorted, three-dimensional physical model of Kaumalapau Harbor, Hawaii, was constructed to evaluate harbor response to short-period waves for a prebreakwater configuration, existing conditions, and two alternative breakwater configurations. Only the straight and dogleg alternative configurations were built, because the other alternative harbor plans studied in the numerical model did not perform satisfactorily. The physical model then was used to "fine tune" design the two preferred plans. The physical model also was used to investigate and optimize stability of the breakwater configuration which provided the best reduction in wave energy at the pier.

\section{Model Design}

\section{Model scaling}

The Kaumalapau physical model was constructed at an undistorted linear scale of $1: 49$, model to prototype. This scale was chosen based upon the following factors:

a. Size of the physical model which can accurately reproduce the necessary wave patterns within physical limitations imposed by basin size and hardware constraints.

$b$. Depth of water necessary to generate realistic waves without excessive scale effects and the ability to generate the size of hurricane waves needed.

c. Available CORE-LOC ${ }^{\mathrm{TM}}$ (hereafter referred to as core-loc) and dolos sizes.

d. Model construction costs.

\footnotetext{
${ }^{1}$ Written by Gordon S. Harkins and Ernest R. Smith.
} 
Following selection of the linear scale, the model was designed and operated in accordance with Froude's model law (Stevens et al. 1942). The scale relations used for design and operation of the model are shown in Table 15.

\begin{tabular}{|c|c|c|c|}
\hline \multicolumn{4}{|c|}{$\begin{array}{l}\text { Table } 15^{1} \\
\text { Model-Prototype Scale Relations (1:49 scale) }\end{array}$} \\
\hline \multirow[t]{2}{*}{ Characteristic } & \multirow{2}{*}{$\begin{array}{l}\text { Dimension } \\
l\end{array}$} & \multicolumn{2}{|c|}{$\begin{array}{l}\text { Scale Relations } \\
\text { Model:Prototype }\end{array}$} \\
\hline & & $l_{r}=$ & $1: 49$ \\
\hline Area & $l^{2}$ & $a_{r}=$ & 1:2401 \\
\hline Volume & $l^{3}$ & $v_{r}=$ & 1:117649 \\
\hline Time & $l^{1 / 2}$ & $t_{r}=$ & $1: 7$ \\
\hline Velocity & $\nu t$ & $v_{r}=$ & $1: 7$ \\
\hline Discharge & $l^{3} / t$ & $q_{r}=$ & $1: 16807$ \\
\hline
\end{tabular}

The physical model covered approximately $0.3 \mathrm{sq} \mathrm{km}$ and extended vertically from $-29 \mathrm{~m}(-95 \mathrm{ft})$ to $+8 \mathrm{~m}(26.2 \mathrm{ft}) \mathrm{mllw}$ contour in the prototype (Figure 35$)$. The $+8-\mathrm{m}(+26.2-\mathrm{ft})$ contour was chosen to avoid overtopping on to the top of the model. However, water splashed on to the overbank under extreme hurricane conditions.

\section{Construction}

The model was designed using detailed bathymetric and topographic data and constructed with sand fill and a concrete cap (Figure 36). In the vicinity of the existing breakwater, the model was constructed in a pre-breakwater configuration. This first configuration allowed the determination of the design wave heights for model armor unit selection. The existing and two alternative breakwater configurations then were built above the pre-breakwater contours as described below.

\section{Breakwater design}

The proposed breakwater rehabilitation was designed to withstand storms from the South Pacific with minimal repairs. The crest elevation was to be raised to $+6.1 \mathrm{~m}(+20 \mathrm{ft})$ mllw with a $6.1-\mathrm{m}$-wide ( 20 -ft-wide) crown consisting of a cast-inplace concrete ribcap. The proposed length of the structure was $91.4 \mathrm{~m} \mathrm{(300} \mathrm{ft).} \mathrm{It}$ was desired to use existing breakwater material as a foundation and core for the proposed breakwater. 


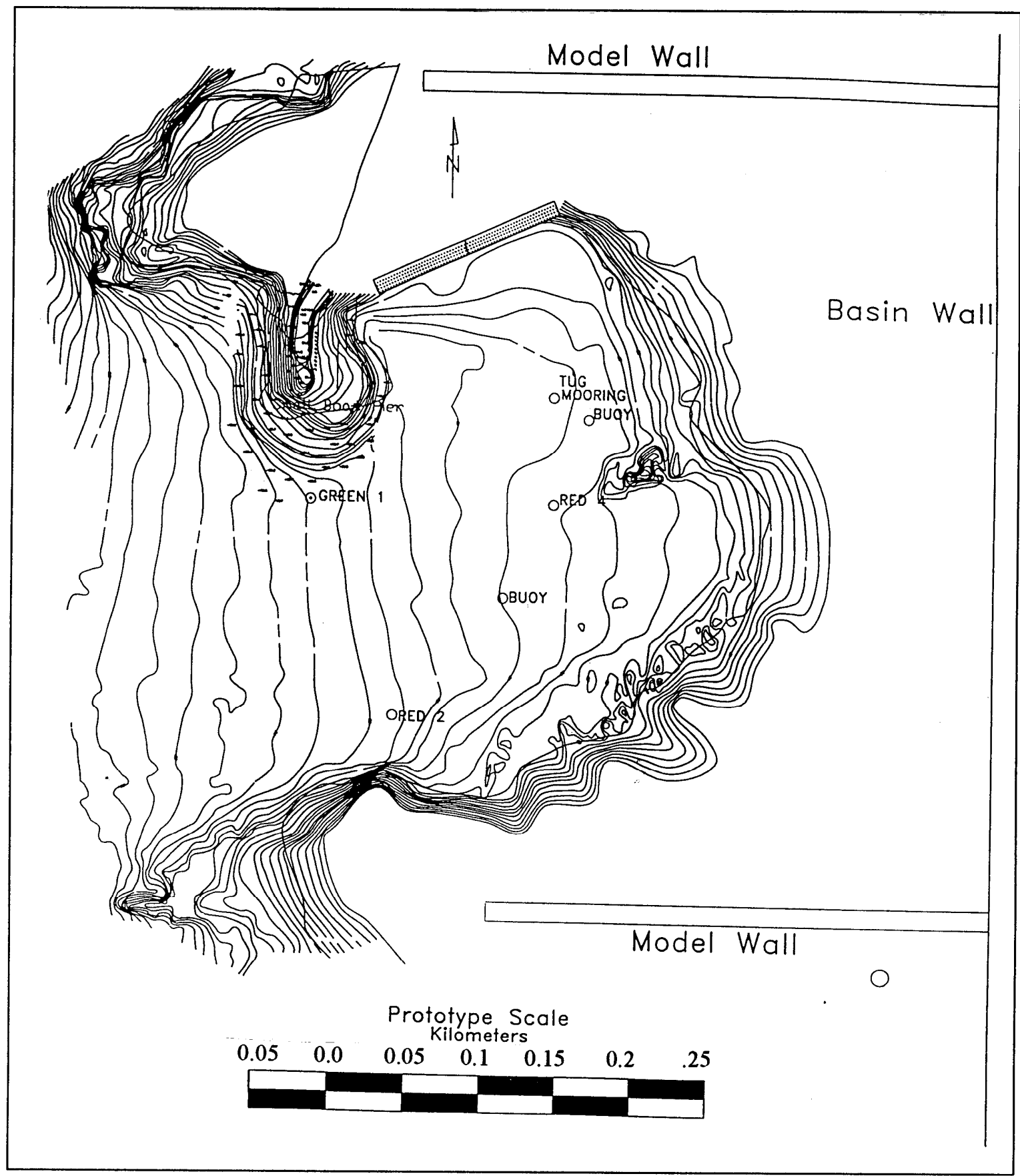

Figure 35. Physical model layout 


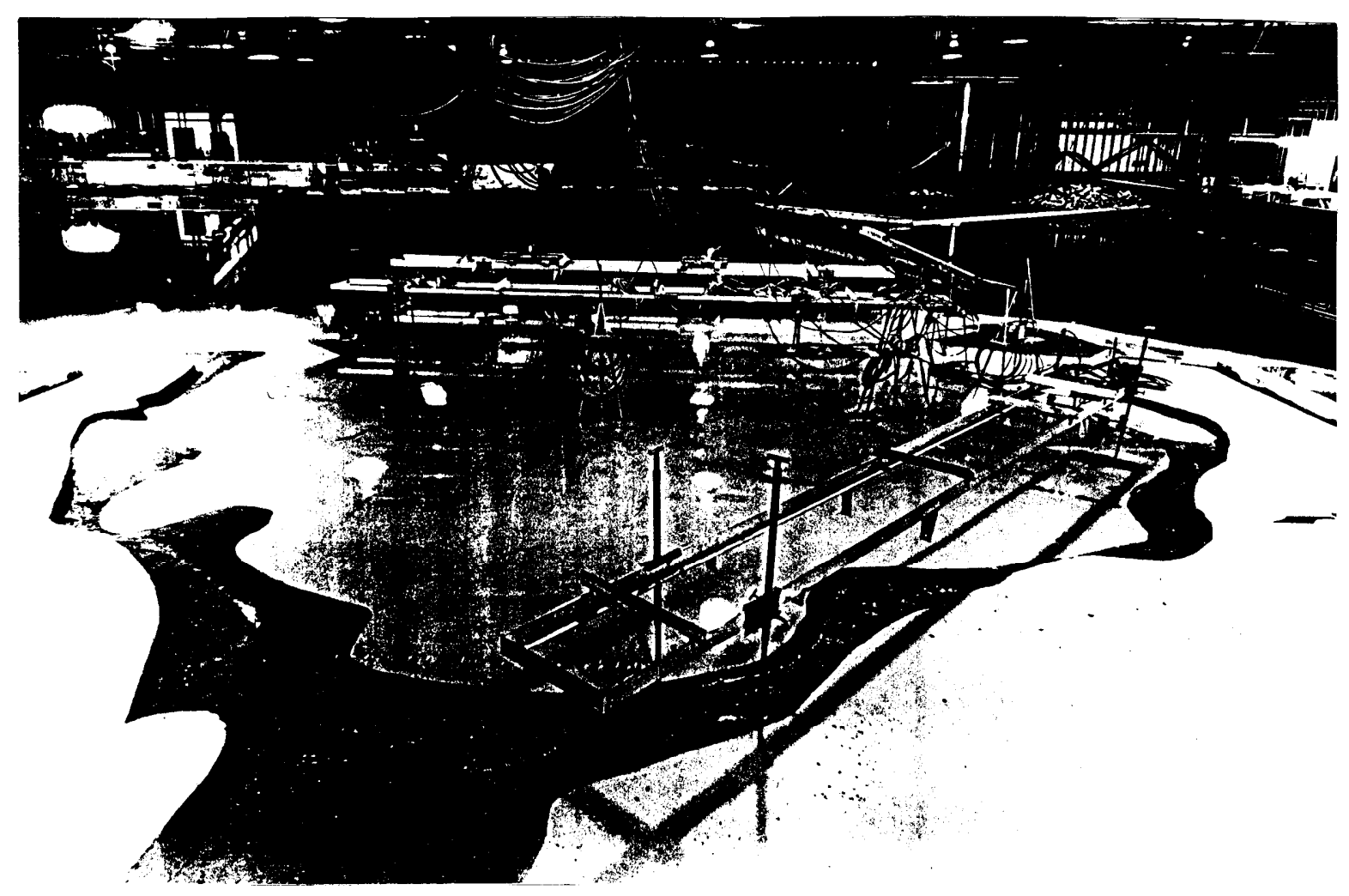

Figure 36. Photograph of physical model

Cross section design. The proposed breakwater consisted of an armor layer constructed of core-locs, an underlayer, and, where necessary, a core. It was necessary in certain locations to excavate material from the existing breakwater to place the armor layer and underlayer. This excavated material was used as a base near the end of the proposed structure. Core material was added only in locations where it was required to raise the elevation of the existing breakwater to the bottom elevation of the underlayer.

The design wave height specified by the U.S. Army Engineer District (USAED), Honolulu (1993) was a deepwater wave height $H_{o}$ of $8.5 \mathrm{~m}(28 \mathrm{ft})$ or wave height at the structure $H_{d}$ of $7.2 \mathrm{~m}(23.6 \mathrm{ft})$. Core-loc size for the armor layer was calculated using the stability equation of Hudson (1958):

$$
W_{a}=\frac{\gamma_{a} H_{d}^{3}}{K_{d}\left(S_{a}-1\right)^{3} \cot \theta}
$$

in which $W_{a}$ is the weight of an individual armor unit, $\gamma_{o}$ is the specific weight of an individual armor unit, $K_{d}$ is the stability coefficient, $S_{a}$ is the specific gravity of an individual armor unit or stone relative to the water in which it is placed, $S_{a}=\gamma_{a} / \gamma_{w}$ 
in which $\gamma_{w}$ is the specific weight of water, and $\theta$ is the angle of the structure slope measured from horizontal in degrees.

The water depth at the breakwater exceeds $1.5 H_{d}(10.8 \mathrm{~m}, 35.4 \mathrm{ft})$. Therefore, core-loc was placed according to Engineer Manual 1110-2-2904 ("Design of Breakwaters and Jetties") (U.S. Army Corps of Engineers 1986) to a bottom elevation of $-10.8 \mathrm{~m}(-35.4 \mathrm{ft}) \mathrm{mllw}$.

Straight alignment. Figures 37 and 38 show cross sections of the proposed breakwater superimposed with the existing structure at selected stations. The seaside slope of the proposed structure extended past the existing structure at the toe for stations seaward of Station $0+25$. This indicates that fill material was required to support the structure sea side at these stations. However, sufficient material exists on the structure lee side. To make efficient use of existing material, cross sections requiring fill on the sea side were offset to the lee side to allow a minimum sea-side toe shelf of $1.5 \mathrm{~m}(5 \mathrm{ft})$. Figure 39 shows a plan view of the existing structure and points indicating the minimum centerline location for each station to avoid sea-side fill placement. An adjusted centerline was drawn, shown as a dashed line in Figure 39, that maintained the minimum toe shelf distance and provided a straight breakwater alignment. Little existing material is present between Station $2+25$ and the terminus of the proposed structure. Therefore, fill, obtained from the structure leeside, was required to provide a base for the breakwater in this region. A cross section at Station 2+00 of the revised straight breakwater alignment is shown in Figure 40, and a plan view sketch is shown in Figure 41.

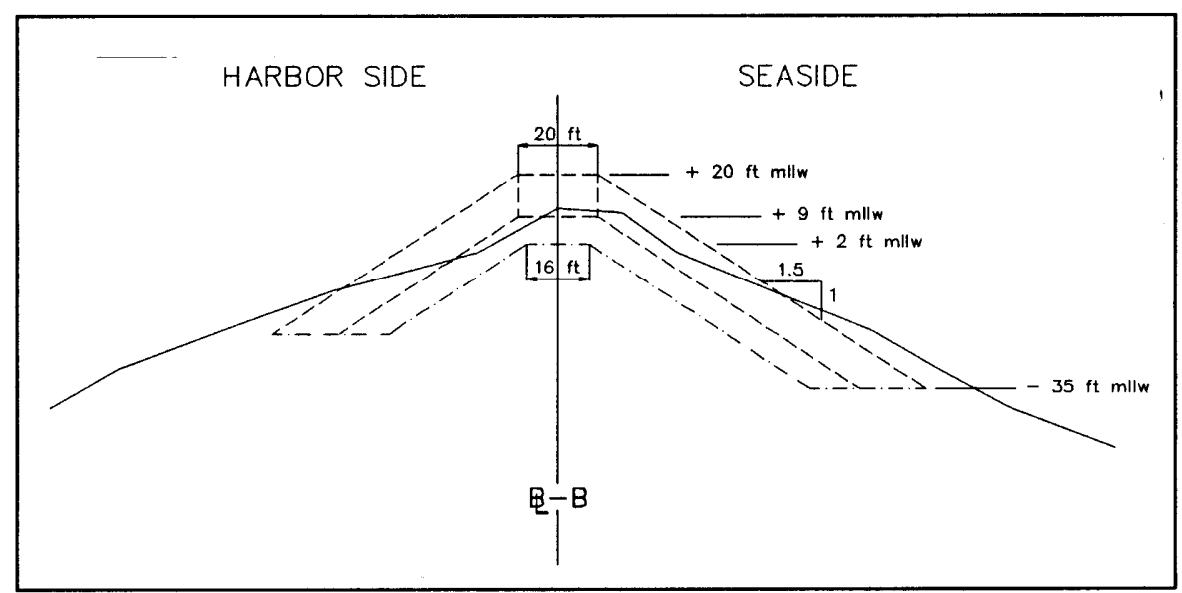

Figure 37. Cross section of proposed structure at existing structure center line, Station $0+00$ 


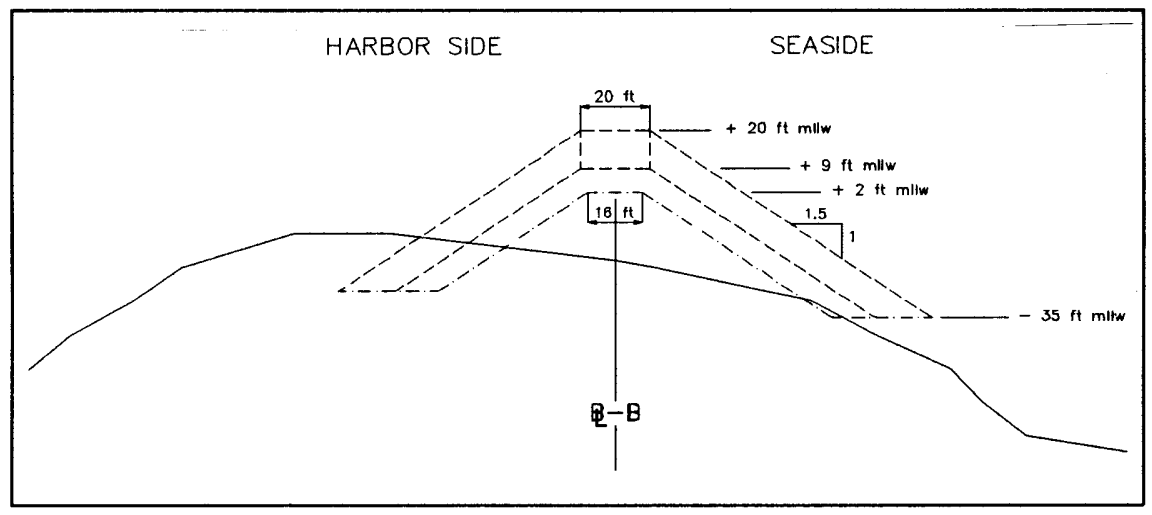

Figure 38. Cross section of proposed structure at existing breakwater center line, Station $2+00$

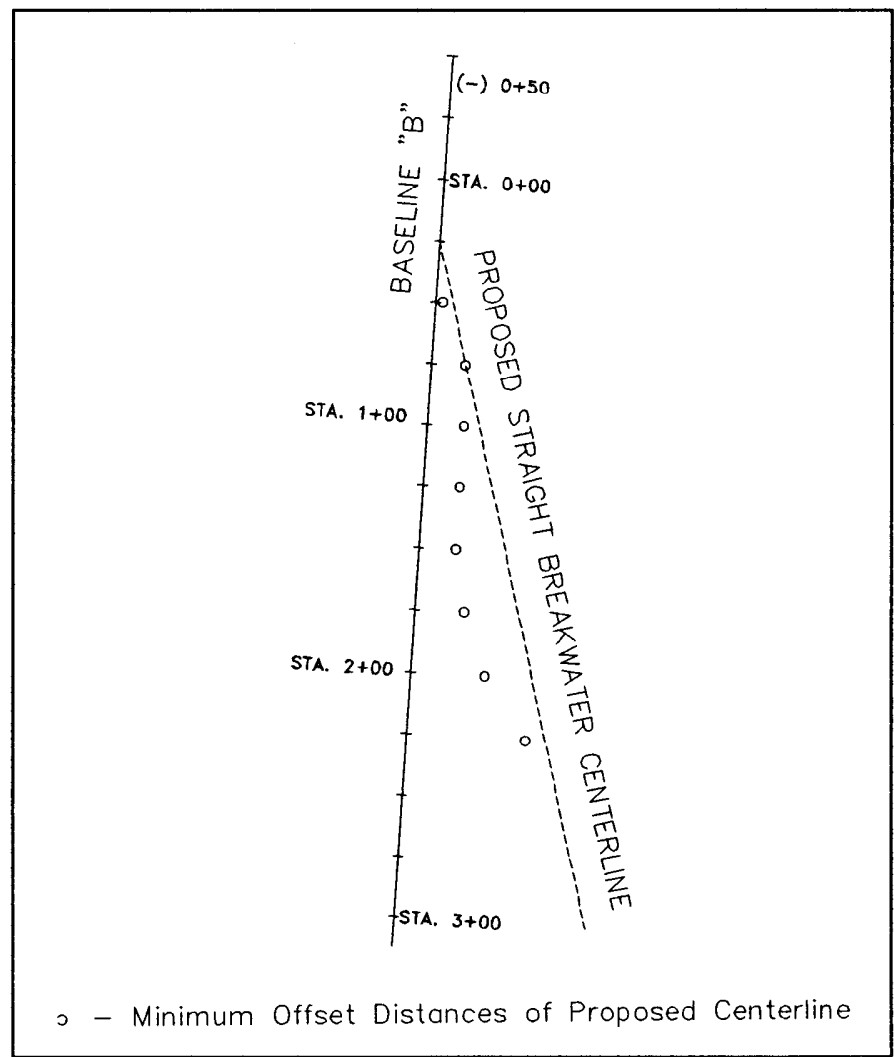

Figure 39. Minimum center line offset distances and revised centerline for straight breakwater 


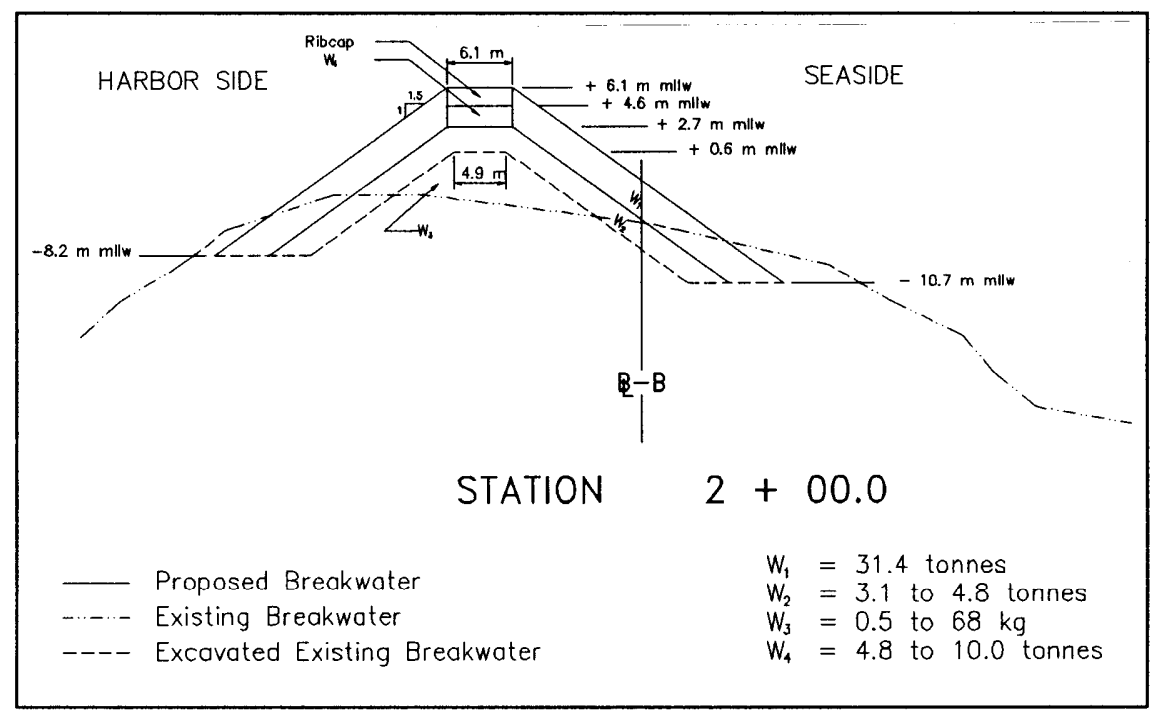

Figure 40. Cross section of proposed breakwater at revised center line, Station $2+00$

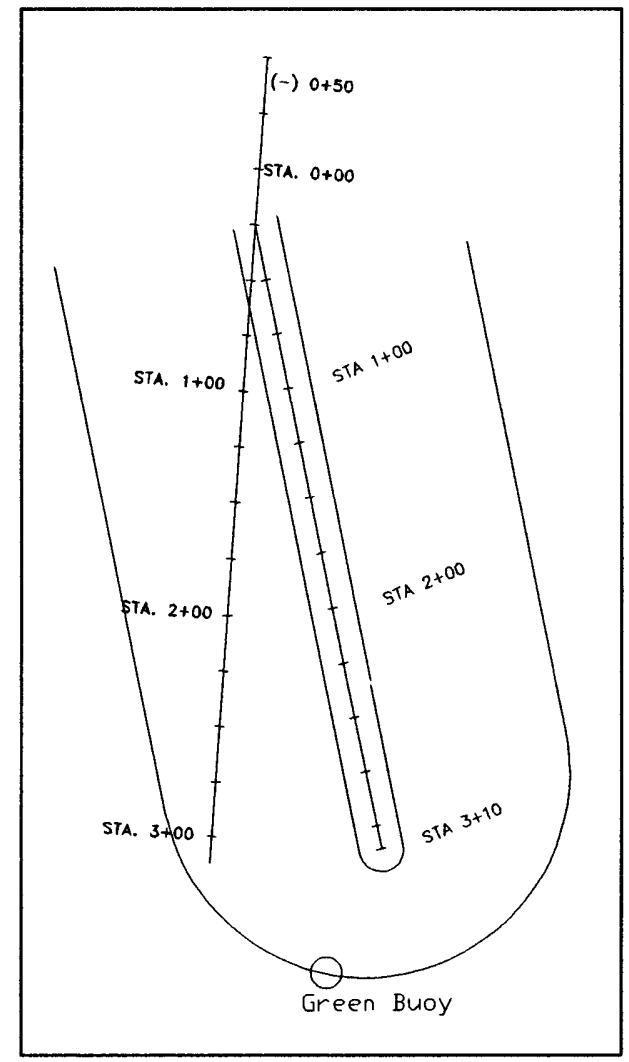

Figure 41. Sketch of straight breakwater configuration (Plan 3) 
Dogleg alignment. An alternative to the straight breakwater alignment was a dogleg configuration. The breakwater head position was limited by a navigational buoy and the harbor basin. A configuration was developed that provided the maximum protection within the constraints of navigation. The dogleg portion consisted of $11.9 \mathrm{~m}$ ( $39 \mathrm{ft})$ of the seaward portion of the structure. The dogleg originated at

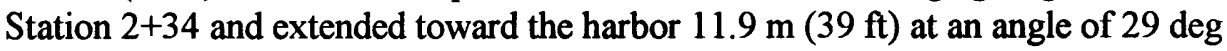
with the straight alignment center line (45 deg with the original center line, Figure 42).

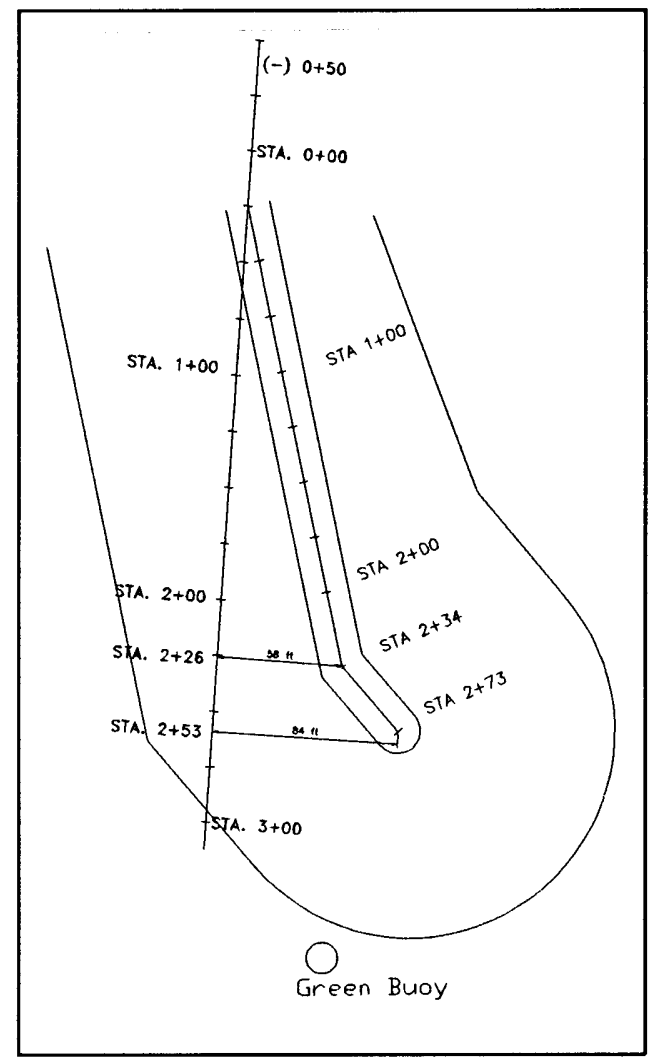

Figure 42. Sketch of dogleg breakwater configuration (Plan 4)

\section{Equipment}

\section{Wave generators}

Two wavemakers were connected to provide a $9.1-\mathrm{m}-(30-\mathrm{ft}-)$ wide crest width. This corresponds to the prototype width of approximately $457.2 \mathrm{~m}(1,500 \mathrm{ft})$, which is the same order of magnitude as the harbor entrance. The wavemakers used in this study were hydraulically powered, piston wavemakers. They were capable of making waves from one direction (i.e., unidirectional) at a time. To generate waves from different directions, the wavemakers were physically reoriented. 
Heights of waves generated from a wavemaker are a function of the water depth at the wavemaker. To generate waves of significant height and to minimize spurious wave components, the wave machines were located in the prototype depth of $-29 \mathrm{~m}(-95 \mathrm{ft})$.

The wavemakers were computer controlled and generated irregular waves. Irregular waves have varying wave height and period and provide more realistic sea conditions than monochromatic waves.

\section{Wave gauges}

Parallel wire capacitance wave gauges were used to measure and record model wave heights. Output of gauges is directly proportional to their submergence depth in water and calibration curves for each wave gauge were recorded each morning, by automatically stepping wave rods throughout the water column over 11 steps. Two wave gauge configurations were used throughout model experiments.

The first configuration, called the pre-breakwater configuration, is shown in Figure 43. This wave gauge configuration utilized 15 gauges and was used to calibrate the waves and to determine wave heights along the center line of the prebreakwater configuration. Gauges were numbered to correspond with the numerical model basin locations (Figure 16). Gauge locations labeled 1 through 7 correspond with the basin locations labeled identically. Gauges 1 through 4 were the principal gauges of interest and were located along the main pier with gauge 2 located closest to the breakwater, and gauges 3 and 1 in the center of the pier, and gauge 4 farthest from the breakwater. Gauge 5 was located in the center of the mouth of the bay. Gauge 7 was located approximately $100 \mathrm{~m}(330 \mathrm{ft})$ from the pier and gauge 8 was positioned $30 \mathrm{~m}(100 \mathrm{ft})$ from the pier and $50 \mathrm{~m}(160 \mathrm{ft})$ from the base of the cliff wall to quantify reflection of wave energy off the near-vertical walls. If numerical model results had indicated that wave absorbers were effective, then this gauge would have been used to determine changes between cases with a wave absorber versus those without a wave absorber. Gauge 9 corresponds to basin location 11 and initially was going to be used to measure incident wave height for one of the preliminary plans for a jetty located along the south side of Kaumalapau Harbor. Results from this plan were not satisfactory and were not continued beyond numerical model studies. Gauges 10 through 13 were located along the center line of the existing breakwater location. The model was in a pre-breakwater configuration, so that the gauges were located above an assumed bottom depth which would correspond to the depth present before the breakwater was built. These gauges were positioned over the center line of the breakwater and were used to define maximum wave height occurring along the breakwater. Gauges 14 and 15 were used to calibrate the incoming wave heights and are located in a depth of $-29 \mathrm{~m}$ $(-95 \mathrm{ft})$ mllw.

The second wave gauge layout was used during studies of the alternative breakwater configurations and can be seen in Figure 44. Gauges 1 through 7 were not moved from the first wave gauge configuration except for the fifth gauge. The fifth gauge was located in two adjacent positions labeled 5 and $55^{\prime}$. The location of 


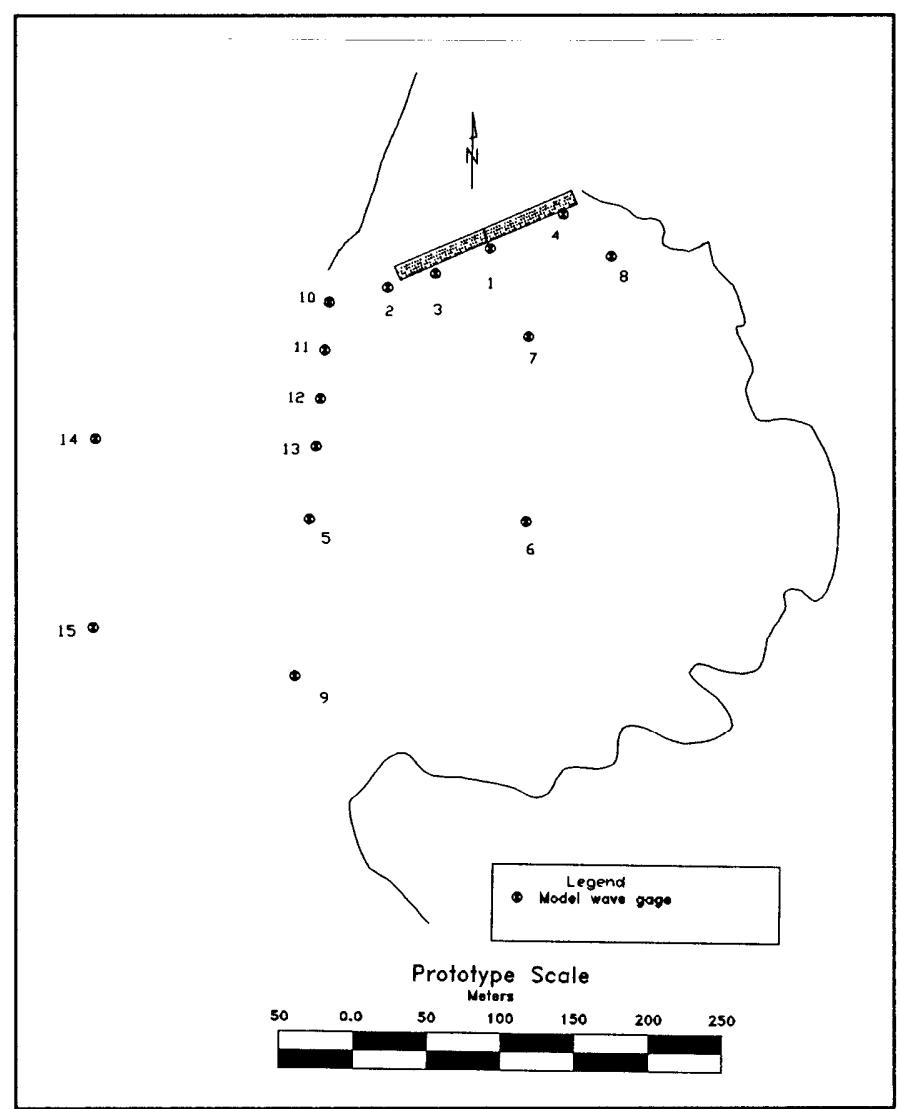

Figure 43. Wave gauge configuration 1 for studies of pre-breakwater conditions

gauge 5 corresponds to the numerical model basin location. For ease in building and removing the straight and dogleg breakwater, the fifth gauge was repositioned slightly seaward of its initial position and relabelled 5 ' to distinguish its second position. The fifth gauge was positioned at location $5^{\prime}$ whenever the straight or dogleg extensions were in place. Gauges 6 through 8 correspond to the numerical model basin locations. Gauge 9 was positioned seaward of the small cobble pocket beach. At one point, developers were going to build a man-made sand beach and gauge 9 was located in this position to quantify the incident wave heights to the shoreline. There was also talk of building a floating private marina in the vicinity of gauge 10. Gauge 11 was located at the numerical model basin location No. 11 .

Gauge 12 was located seaward of the breakwater to quantify incident wave heights. Gauges 13 and 14 were used to measure the incident wave heights.

\section{Computer support}

Wave machine signal generation, wave machine control, and data collection were performed on a Digital Equipment Corporation MicroVax computer. This process consists of converting a digital control signal to an analog voltage which is sent simultaneously to the hydraulic controllers of the wave machine. Wave gauge 


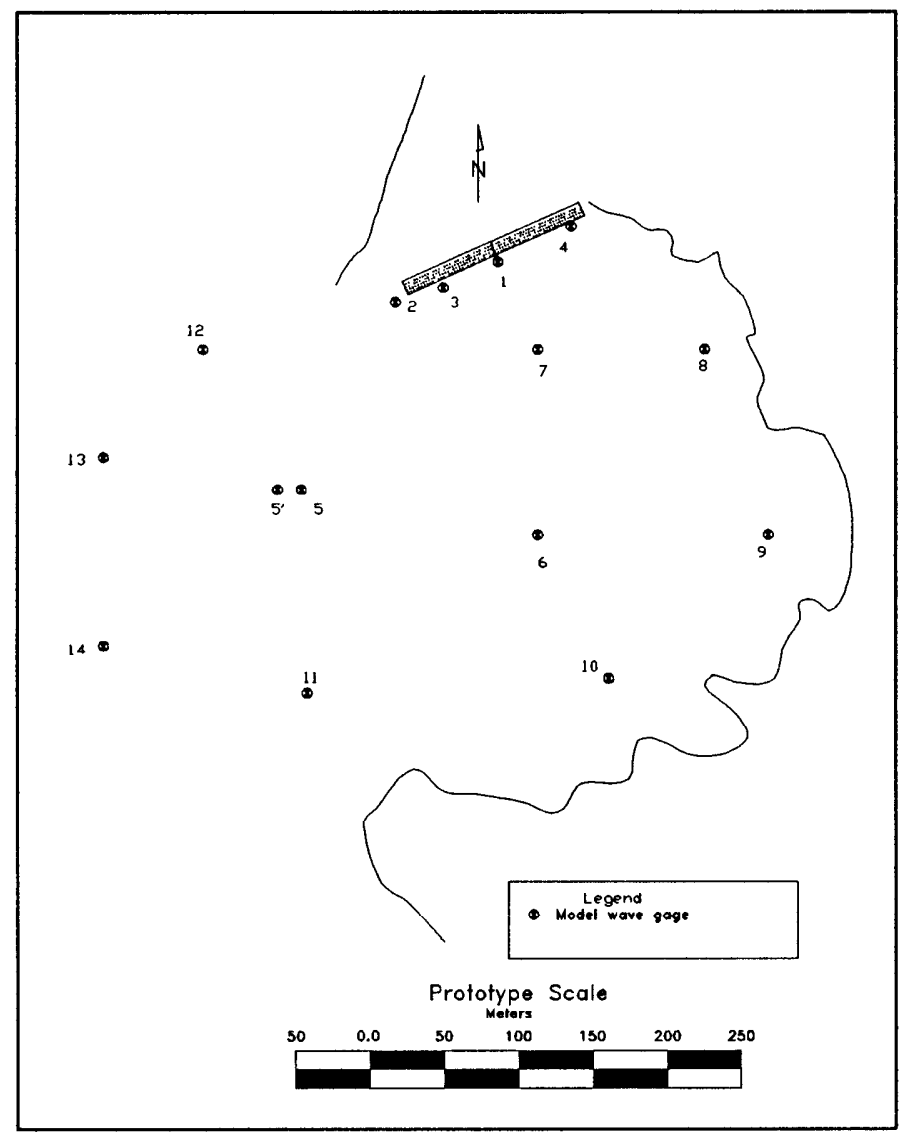

Figure 44. Wave gauge configuration 2 for studies of existing and alternative harbor plans

calibration and preliminary data analysis were also conducted on the MicroVax computer.

\section{Wave absorbing material}

Rolls of fiber wave absorber measuring $1.2 \mathrm{~m}(4 \mathrm{ft})$ wide and $0.6 \mathrm{~m}(2 \mathrm{ft})$ high were positioned behind the wavemakers to absorb waves generated from the back of the wave paddles. Behind the rolls of fiber wave absorbing material, $2-\mathrm{kg}(5-\mathrm{lb})$ to $15-\mathrm{kg}(30-\mathrm{lb})$ stones on a 1:2 (vertical:horizontal) slope up to $1.5 \mathrm{~m}(5 \mathrm{ft})$ in height were positioned adjacent to the back wall. This sloping structure further reduced wave energy that would have reflected off the vertical basin walls.

Fiber wave absorber material was positioned around the perimeter of the model in front of the wave machines at the water surface to absorb reflections off the Kaumalapau model. 


\section{Guide vanes}

In nature, storms that generate wave events are large in size and can propagate over long distances affecting large portions of the coastline. Finite length wavemakers, however, have end effects. To minimize end effects, aluminum barriers called guide vanes measuring $3 \mathrm{~m}(10 \mathrm{ft})$ long by $1.5 \mathrm{~m}(5 \mathrm{ft})$ tall and approximately $0.5 \mathrm{~cm}(0.25 \mathrm{in}$.) wide were positioned at both ends of the wave machine to contain the wave energy generated by the wavemakers. These guide vanes limit the wave diffraction effects that occur at the ends of the wave paddles and also contain the wave energy, providing a more uniform wave elevation incident to the model study area. 


\section{Physical Model Experiment Conditions $^{1}$}

\section{Still-water Levels}

Still-water levels (swl's) for wave action models are selected so that various wave-induced phenomena that are dependent on water depths are accurately reproduced in the model. These phenomena include refraction, diffraction, and overtopping of harbor structures.

In most cases, for the following reasons, it is desirable to select a model swl that closely approximates the higher prototype water levels:

a. The maximum amount of wave energy reaching a coastal area normally occurs during the higher water phase of the local tidal cycle.

b. Most storms moving onshore are characteristically accompanied by a higher water level due to wind, tide, and shoreward mass transport.

c. The selection of a high swl helps minimize model scale effects due to viscous bottom friction.

d. When a high swl is selected, a model investigation tends to yield more conservative results.

The Hawaiian Islands experience two high and two low tides daily. The tides are semidiurnal with pronounced diurnal inequalities. Tidal data representative at the site are shown in Table 16 (USAED, Honolulu 1993):

${ }^{1}$ Written by Gordon S. Harkins. 


\begin{tabular}{|c|c|}
\hline \multicolumn{2}{|c|}{$\begin{array}{l}\text { Table } 16 \\
\text { Kaumalapau Tidal Data }\end{array}$} \\
\hline Tide Description & $\begin{array}{c}\text { Elevation } \\
m \text { (ft) }\end{array}$ \\
\hline Highest tide (estimated) & $+1.06(+3.5)$ \\
\hline Mean higher high water & $+0.67(+2.2)$ \\
\hline Mean high water & $+0.52(+1.7)$ \\
\hline Mean tide level & $+0.29(+0.95)$ \\
\hline Mean low water & $+0.06(+0.2)$ \\
\hline Mean lower low water & $0.0(0.0)$ \\
\hline Lowest tide (estimated) & $-0.3(-1.0)$ \\
\hline
\end{tabular}

Swl's of $0.67 \mathrm{~m}(2.2 \mathrm{ft})$ and $1.52 \mathrm{~m}(5.0 \mathrm{ft})$ mllw were selected by POD for use in experiments of Kaumalapau Harbor. The $0.67-\mathrm{m}(2.2-\mathrm{ft})$ value was representative of mean higher high water ( $\mathrm{mhhw}$ ) and was used during operational wave condition experiments from the various directions. The $1.52-\mathrm{m}(5.0-\mathrm{ft})$ level consisting of an astronomical tide of $1.06 \mathrm{~m}(3.5 \mathrm{ft})$, a water level rise due to a reduction in atmospheric pressure of $0.43 \mathrm{~m}(1.4 \mathrm{ft})$, and a water level rise due to a storm surge of $0.03 \mathrm{~m}(0.1 \mathrm{ft})$, was used during experiments of severe storm wave conditions associated with passage of the design hurricane.

\section{Factors Influencing Selection of Experiment Wave Characteristics}

In planning the physical model experimental program for Kaumalapau Harbor, it was necessary to select heights, periods, and directions for the experimental waves that would allow realistic study of the two proposed alternative breakwater configurations based upon typical wave conditions and the design hurricane waves as seen at the site. WIS data were available to the southwest of the site and provided the primary means of determining wave height and period. Wave direction was determined from the WIS data and numerical modeling results. Since explicit wave criteria for reduction in wave heights at the wharf were not known, typical waves found at Kaumalapau were examined. Hurricane waves were used in the breakwater stability studies.

\section{Wave refraction}

When waves move into water of gradually decreasing depth, transformations take place in all wave characteristics except wave period (to the first order of approximation). The most important transformations with respect to the selection of experimental wave characteristics for the study are the changes in wave height and direction of travel due to the phenomenon referred to as wave refraction. When the refraction coefficient $\left(K_{r}\right)$ is determined, it is multiplied by the shoaling coefficient $\left(K_{s}\right)$, which gives a conversion factor for transforming deepwater wave heights to shallow-water values. The shoaling coefficient, a function of wave 
length and water depth, can be obtained from the Shore Protection Manual (1984). The change in wave height and direction may be determined by using the numerical Regional Coastal Processes Wave Transformation Model (RCPWAVE) developed by Ebersole, Cialone, and Prater (1986).

Due to the very deep water levels just offshore of Kaumalapau Harbor, a wave refraction analysis was not deemed essential. Deepwater waves generally begin refracting at a depth of about one half their wave length (deepwater wave length $L_{o}$ is defined as $g T^{2} / 2$ ). A wide range of wave conditions was studied in the model. Waves were generated in the $-29-\mathrm{m}(-95-\mathrm{ft})$ model pit. From this point, the model contours refracted the wave trains to the shore.

\section{Wave and storm data selected}

Prevailing winds in the Hawaiian Islands are the northeasterly trade winds, which occur approximately 90 to 95 percent of the time during the summer months (May-October), and 55 to 65 percent of the time between November and April, with speeds of 16 to $32 \mathrm{~km} / \mathrm{hr}$ (10 to $20 \mathrm{mph}$ ). Storm conditions generally result when a breakdown of the trade wind circulation occurs, which is relatively infrequent.

Three classes of disturbances produce major storms in Hawaii: cold fronts, low-pressure passages, and true tropical storms or hurricanes. Cold fronts, which occur during the winter months, cause spotty rainfall and gusty winds. Lowpressure passages result in heavy rain, sometimes with strong winds. A lowpressure storm type known as a "kona" storm usually occurs during the winter months, and is associated with strong and persistent southerly winds and intense rainfall on the south and western shores of the islands. Hurricanes, classified as storms with wind speeds greater than $119 \mathrm{~km} / \mathrm{hr}(74 \mathrm{mph})$, are infrequent, but historical records reveal that several have passed over the island of Lanai.

Measured prototype wave data covering a sufficiently long duration from which to base a comprehensive statistical analysis of deepwater wave conditions for the Kaumalapau Harbor area were not available. However, statistical wave hindcast estimates representative of this area were obtained from the WIS studies, which include a 20-year hindcast period (1956 to 1975). The hindcast (Corson et al. 1986) was obtained at WIS Station 34 (20.00 deg north, 160.00 deg west) and Station 35 (17.99 deg north, $157.90 \mathrm{deg}$ west) in the North Pacific Ocean southwest of the island of Lanai. The WIS data do not include waves generated by hurricanes or southern hemisphere swell conditions.

Hurricane wave conditions were provided in Kaumalapau Harbor Navigation Improvements Island of Lanai, Hawaii - Reconnaissance Report (USAED, Honolulu 1993), which defined the design conditions as a deepwater significant wave height of $8.5 \mathrm{~m}(27.9 \mathrm{ft})$ with a 9.8-sec period based upon numerical model predictions. This was assuming a worst case Hawaiian hurricane approaching from the south to southwest direction. 


\section{Wave selection}

The unidirectional wave machines were positioned in three directions to reproduce and encompass the typical wave climate at Kaumalapau Harbor. Results from the WIS data and model results provided by HARBD on the sensitivity of the harbor to wave direction were used to determine the wave maker positioning. Waves approaching from 221, 251, and 291 deg referenced to north were chosen. Figure 45 shows the wavemaker positions and the wave directions chosen. The wave period and wave height for each direction were chosen through a review of the data from the WIS Stations 34 and 35 described earlier. The combined number of occurrences from the two stations bracketed by direction can be seen in Table 17. The total number of occurrences from both WIS stations is 116,880 .

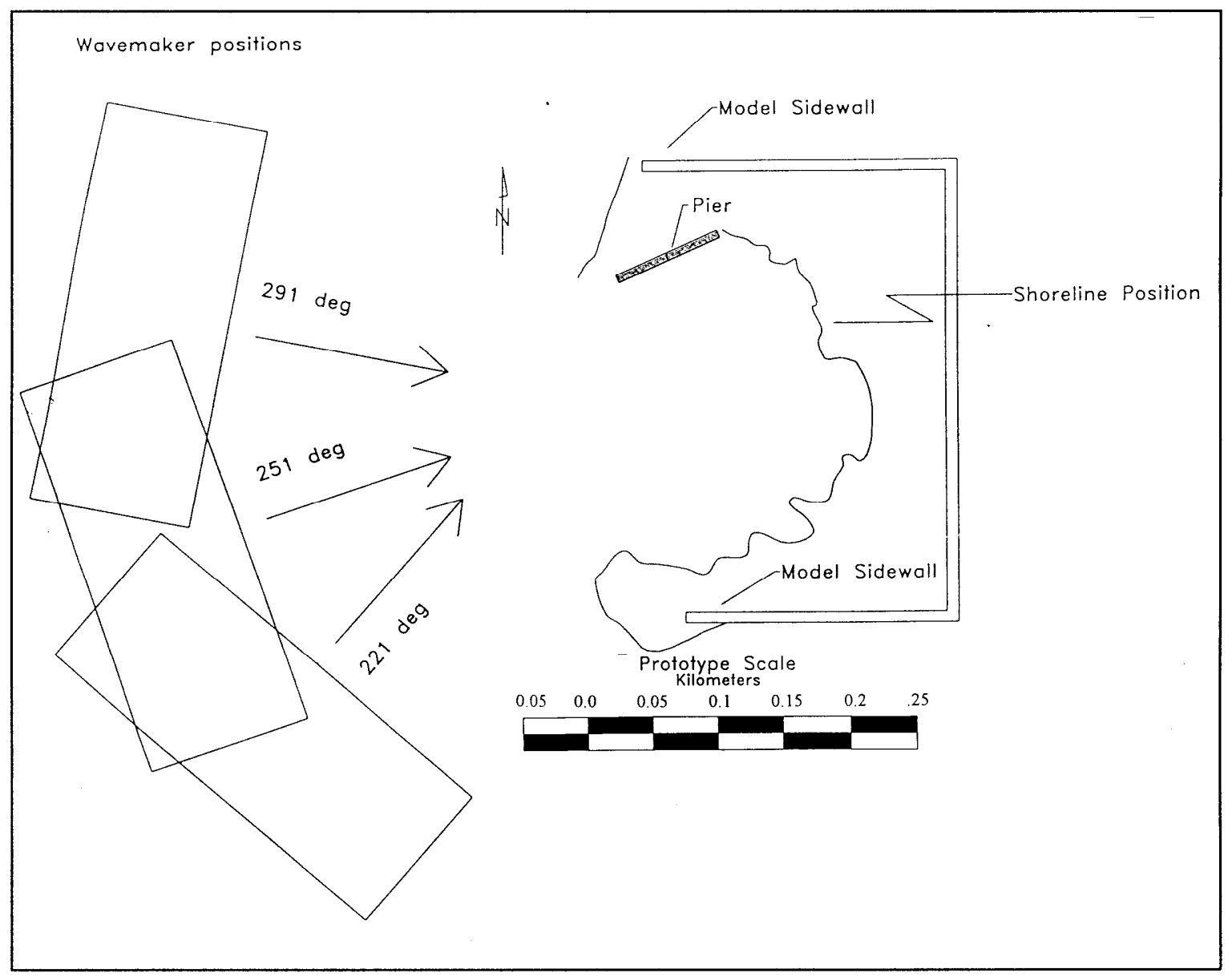

Figure 45. Incident wave directions for physical model studies 


\begin{tabular}{|c|c|c|c|c|c|c|c|c|c|}
\hline \multicolumn{10}{|c|}{$\begin{array}{l}\text { Table } 17 \\
\text { Combined Number of Occurrences for the Two WIS Stations }\end{array}$} \\
\hline $\begin{array}{c}\text { Wave } \\
\text { Dir } \\
\text { Bins } \\
\text { deg }\end{array}$ & $\begin{array}{c}\text { Rep. } \\
\text { Mean } \\
\text { Wave } \\
\text { Dir }\end{array}$ & $\begin{array}{c}T_{p} \\
\text { sec }\end{array}$ & \multicolumn{7}{|c|}{$\underset{\text { (ft) }}{\mathrm{H}_{\text {mo, }}} \mathbf{m}$} \\
\hline \multirow[t]{9}{*}{$\begin{array}{l}206- \\
235\end{array}$} & \multirow[t]{9}{*}{221} & & $\begin{array}{c}<1 \\
(<3.2)\end{array}$ & $\begin{array}{c}1-2 \\
(3.2-6.6)\end{array}$ & $\begin{array}{c}2-3 \\
(6.6-9.8)\end{array}$ & $\begin{array}{c}3-4 \\
(9.8-13.1)\end{array}$ & $\begin{array}{c}4-5 \\
(13.1-16.4)\end{array}$ & $\begin{array}{c}5-6 \\
(16.4-19.7)\end{array}$ & $\begin{array}{c}>6 \\
(>19.7)\end{array}$ \\
\hline & & $<7$ & 0 & 0 & 5 & 0 & 0 & 0 & 0 \\
\hline & & $7-9$ & 0 & 0 & 10 & 15 & 7 & 0 & 0 \\
\hline & & $9-11$ & 0 & 0 & 0 & 3 & 3 & 10 & 0 \\
\hline & & 11.13 & 0 & 0 & 1 & 1 & 0 & 0 & 0 \\
\hline & & $13-15$ & 0 & 0 & 0 & 0 & 0 & 0 & 0 \\
\hline & & $15-17$ & 0 & 0 & 0 & 0 & 0 & 0 & 0 \\
\hline & & $17-19$ & 0 & 0 & 0 & 0 & 0 & 0 & 0 \\
\hline & & $>19$ & 0 & 0 & 0 & 0 & 0 & 0 & 0 \\
\hline \multirow[t]{9}{*}{$\begin{array}{l}235- \\
270\end{array}$} & \multirow[t]{9}{*}{251} & & $\begin{array}{c}<1 \\
(<3.2)\end{array}$ & $\begin{array}{c}1-2 \\
(3.2-6.6)\end{array}$ & $\begin{array}{c}2-3 \\
(6.6-9.8)\end{array}$ & $\begin{array}{c}3-4 \\
(9.8-13.1)\end{array}$ & $\begin{array}{c}4-5 \\
(13.1-16.4)\end{array}$ & $\begin{array}{c}5-6 \\
(16.4-19.7)\end{array}$ & $\begin{array}{c}>6 \\
(>19.7)\end{array}$ \\
\hline & & $<7$ & 9 & 0 & 11 & 0 & 0 & 0 & 0 \\
\hline & & $7-9$ & 0 & 0 & 22 & 23 & 5 & 1 & 0 \\
\hline & & $9-11$ & 0 & 0 & 1 & 5 & 1 & 2 & 1 \\
\hline & & $11-13$ & 0 & 0 & 13 & 10 & 0 & 0 & 0 \\
\hline & & $13-15$ & 0 & 0 & 1 & 8 & 3 & 0 & 0 \\
\hline & & $15-17$ & 0 & 0 & 0 & 0 & 0 & 0 & 0 \\
\hline & & $17-19$ & 0 & 0 & 0 & 0 & 0 & 0 & 0 \\
\hline & & $>19$ & 0 & 0 & 0 & 0 & 0 & 0 & 0 \\
\hline \multirow[t]{9}{*}{$\begin{array}{l}270- \\
310\end{array}$} & \multirow[t]{9}{*}{290} & & $\begin{array}{c}<1 \\
(<3.2)\end{array}$ & $\begin{array}{c}1-2 \\
(3.2-6.6)\end{array}$ & $\begin{array}{c}2-3 \\
(6.6-9.8)\end{array}$ & $\begin{array}{c}3-4 \\
(9.8-13.1)\end{array}$ & $\begin{array}{c}4-5 \\
(13.1-16.4)\end{array}$ & $\begin{array}{l}5-6 \\
(16.4-19.7)\end{array}$ & $\begin{array}{c}>6 \\
(>19.7)\end{array}$ \\
\hline & & $<7$ & 0 & 0 & 8 & 1 & 0 & 0 & 0 \\
\hline & & $7-9$ & 0 & 6 & 26 & 24 & 18 & 1 & 0 \\
\hline & & $9-11$ & 0 & 94 & 162 & 31 & 4 & 1 & 2 \\
\hline & & $11-13$ & 0 & 7 & 934 & 424 & 33 & 1 & 0 \\
\hline & & $13-15$ & 0 & 0 & 662 & 1894 & 991 & 175 & 8 \\
\hline & & $15-17$ & 0 & 0 & 0 & 0 & 0 & 0 & 0 \\
\hline & & $17-19$ & 0 & 0 & 0 & 21 & 24 & 26 & 39 \\
\hline & & $>19$ & 0 & 0 & 0 & 0 & 0 & 0 & 0 \\
\hline
\end{tabular}


Using the WIS data above, POD agreed to the wave conditions shown in Table 18 for the harbor wave action portion of the study. Incident direction and significant wave height $\left(H_{m 0}\right)$ are defined at $-29 \mathrm{~m}(-95 \mathrm{ft})$ mllw. These waves were reproduced at the $0.67-\mathrm{m}(2.2-\mathrm{ft}) \mathrm{swl}$.

\begin{tabular}{|c|c|c|}
\hline \multicolumn{3}{|c|}{$\begin{array}{l}\text { Table } 18 \\
\text { Physical Model Wave Conditions Chosen }\end{array}$} \\
\hline $\begin{array}{c}\text { Wave Direction' } \\
\text { deg }\end{array}$ & $\begin{array}{c}\text { Wave Period } \\
\text { sec }\end{array}$ & $\begin{array}{c}\mathrm{H}_{\mathrm{m0}} \text { Wave Height' } \\
\mathrm{m}(\mathrm{ft})\end{array}$ \\
\hline \multirow[t]{6}{*}{221} & 8.0 & $2.5(8.2), 3.5(11.5), 4.5(14.8)$ \\
\hline & 10.0 & $2.5(8.2), 5.5(18.0)$ \\
\hline & 12.0 & $1.5(4.9), 2.5(8.2), 3.5(11.5)$ \\
\hline & 14.0 & $1.5(4.9), 2.5(8.2), 3.5(11.5)$ \\
\hline & 16.0 & $1.5(4.9), 2.5(8.2), 3.5(11.5)$ \\
\hline & 20.0 & $1.5(4.9), 2.5(8.2)$ \\
\hline \multirow[t]{6}{*}{251} & 8.0 & $2.5(8.2), 3.5(11.5), 4.5(14.8)$ \\
\hline & 10.0 & $\begin{array}{l}2.5(8.2), 4.5(14.8), 5.0(16.4), 5.5 \\
(18.0), 6.0(19.7)\end{array}$ \\
\hline & 12.0 & $2.5(8.2), 3.5(11.5)$ \\
\hline & 14.0 & $3.5(11.5)$ \\
\hline & 16.0 & $3.5(11.5)$ \\
\hline & 20.0 & $1.5(4.9), 2.5(8.2)$ \\
\hline \multirow[t]{4}{*}{291} & 8.0 & $2.5(8.2), 3.5(11.5), 4.5(14.8)$ \\
\hline & 10.0 & $2.5(8.2), 3.5(11.5)$ \\
\hline & 12.0 & $2.5(8.2), 3.5(11.5), 4.5(14.8)$ \\
\hline & 14.0 & $\begin{array}{l}2.5(8.2), 3.5(11.5), 4.5(14.8), 5.5 \\
(18.0)\end{array}$ \\
\hline
\end{tabular}

Ocean waves consist of waves of more than one height and period. To reproduce typical ocean waves, spectral seas were reproduced in the physical model. A spectral parameter called the groupiness parameter was adjusted to simulate how far the waves had traveled from the generating source. The groupiness of waves is important for long-period swell waves (wave periods from 12 to $25 \mathrm{sec}$ ) that have traveled from distant generating sources. This type of phenomenon is important for both southern and northern swell.

The signals used to control the wave paddles were calibrated by comparing the target $\mathrm{H}_{m 0}$ wave height versus the measured $\mathrm{H}_{m 0}$ wave height at gauges 14 and 15 (Figure 43). A gain factor was applied to the spectra and the waves were rerun and 
reanalyzed. Table 19 shows the target and reproduced wave height comparisons for a selection of experimental wave conditions.

\begin{tabular}{|c|c|c|}
\hline $\begin{array}{l}\text { Table } 19 \\
\text { Target Vesus } \\
251 \mathrm{deg}\end{array}$ & ave Heigh & s from \\
\hline & & \\
\hline $\begin{array}{c}\text { Wave Period } \\
\text { sec }\end{array}$ & Target & Measured \\
\hline 8 & $2.5(8.2)$ & $2.5(8.2)$ \\
\hline 8 & $3.5(11.5)$ & $3.4(11.2)$ \\
\hline 8 & $4.5(14.8)$ & $4.4(14.4)$ \\
\hline 10 & $2.5(8.2)$ & $2.5(8.2)$ \\
\hline 10 & $6.0(19.7)$ & $6.0(19.7)$ \\
\hline 10 & $5.5(18.0)$ & $5.5(18.0)$ \\
\hline 10 & $5.0(16.4)$ & $4.9(16.1)$ \\
\hline 10 & $4.5(14.8)$ & $4.4(14.4)$ \\
\hline 12 & $2.5(8.2)$ & $2.5(8.2)$ \\
\hline 12 & $3.5(11.5)$ & $3.5(11.5)$ \\
\hline 14 & $3.5(11.5)$ & $3.3(10.8)$ \\
\hline 16 & $3.5(11.5)$ & $3.2(10.5)$ \\
\hline 20 & $1.5(4.9)$ & $1.5(4.9)$ \\
\hline 20 & $25(8.2)$ & $25(8.2)$ \\
\hline
\end{tabular}

\section{Harbor Layout Configurations Studied}

Four harbor layout configurations were studied in the physical model. Plan 1 was the pre-breakwater condition, which was used to determine appropriate core-loc armor unit sizes based upon the measured wave height along the assumed existing breakwater center line. Wave response at the pier area was analyzed for the remaining three breakwater configurations, Plans 2-4 shown in Figure 46. The figure shows the $+3-\mathrm{m}(10-\mathrm{ft})$ contour of the existing structure, the $+6-\mathrm{m}(20-\mathrm{ft})$ contour of the straight and dogleg breakwater and the $-9-\mathrm{m}(30-\mathrm{ft})$ contour of each structure. The existing breakwater condition, Plan 2, was evaluated first to provide a baseline against which the alternative configurations could be compared. The second breakwater configuration studied was called the straight breakwater (Plan 3). This was referred to as the pre-Ewa breakwater with a length of $122 \mathrm{~m}(400 \mathrm{ft})$ as shown in Figure 41. The last alternative studied was termed the dogleg breakwater, Plan 4. For Plan 4, the last $15 \mathrm{~m}(49.2 \mathrm{ft})$ of the breakwater center line was aligned 30 deg towards the inside of the harbor as measured from the center line of the straight breakwater as shown in Figure 42. 


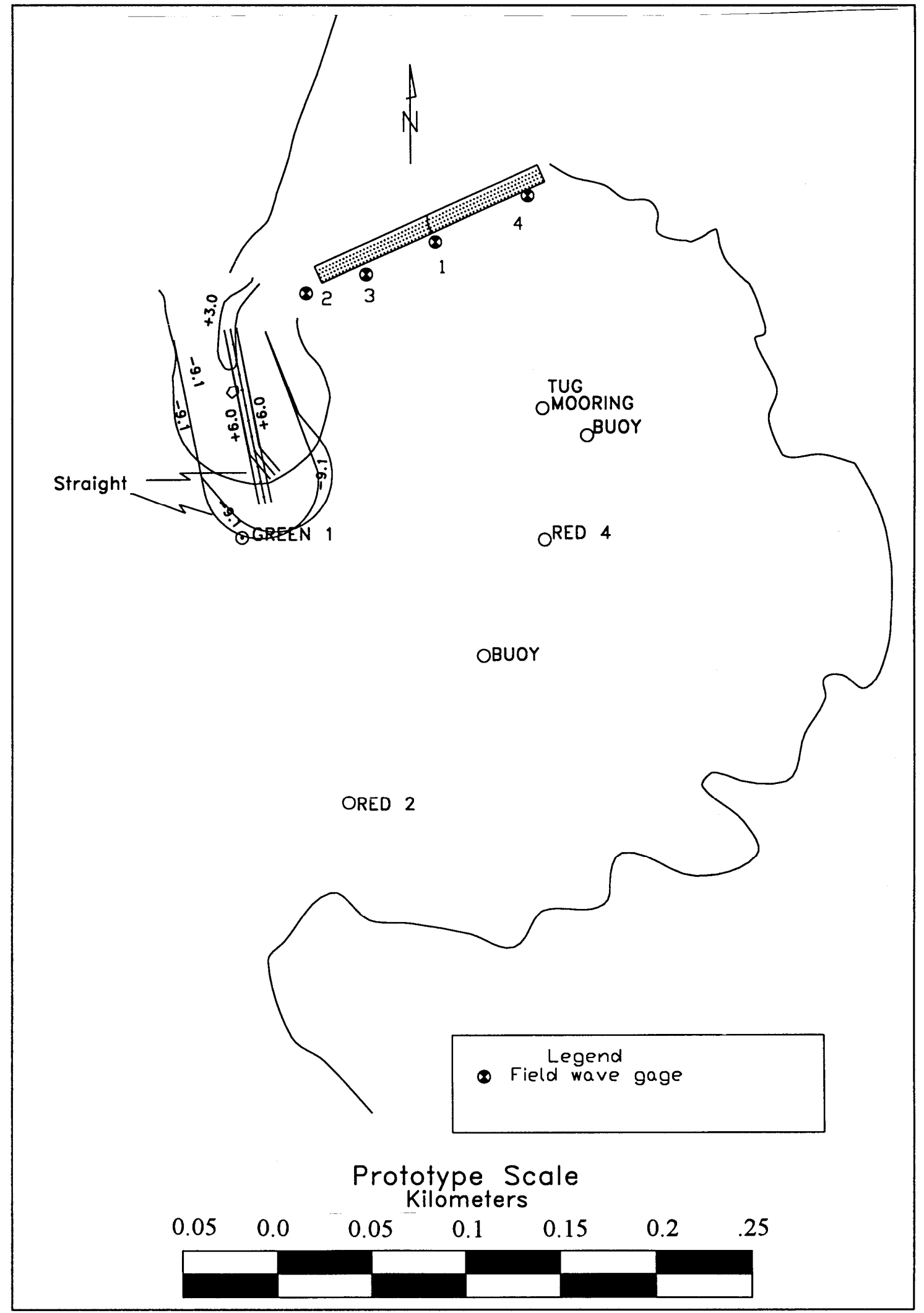

Figure 46. Plan view of breakwater crest and $-9.1 \mathrm{~m}$ depth contour of existing, straight and dogleg breakwater 


\section{Physical Model Experiments and Results ${ }^{1}$}

\section{Experiment Series}

Based upon the numerical model results, three wave directions were simulated in the physical model. The first wave direction analyzed was for waves approaching the harbor directly, $251 \mathrm{deg}$. This direction was thought to provide the highest waves that would impact the breakwater and was used for the prebreakwater experiment series. Results from this direction were thought to provide a good indication of the merits of the two proposed breakwater configurations. The wave machines were moved to the southerly direction and experiments on existing conditions (Plan 2), straight (Plan 3), and dogleg (Plan 4) breakwaters were performed. Experiments were conducted only for existing conditions and the dogleg breakwater plan for waves from $291 \mathrm{deg}$. Results from the other two directions indicated that the dogleg breakwater was a better alternative than the straight breakwater.

\section{Waves from $251 \mathrm{deg}$}

\section{Breakwater results}

Results for the existing, straight, and dogleg breakwater configurations are given in Tables 20,21, and 22, respectively. The results show a minimal reduction in deepwater wave height, especially for the longer period wind wave conditions.

Results for the 8-, 12-, and 20-sec, $2.5-\mathrm{m}$ (8.2-ft) waves are shown graphically in Figure 47. The gauges are arranged in order of increasing distance from the breakwater. Results for the straight or dogleg breakwater do not satisfy the design criteria established by POD for all wave conditions. The criteria was a $4.7-\mathrm{m}$ (15-ft) offshore wave height reduced to $1.5 \mathrm{~m}(4.9 \mathrm{ft})$ inside the harbor. The existing breakwater condition reduces a $2.5-\mathrm{m}(8.2-\mathrm{ft})$ offshore wave height to less than $1.5 \mathrm{~m}(4.9 \mathrm{ft})$ for only the 8 -sec wave period. For the 12 - and $20-\mathrm{sec}$ waves,

\footnotetext{
${ }^{1}$ Written by Gordon S. Harkins.
} 


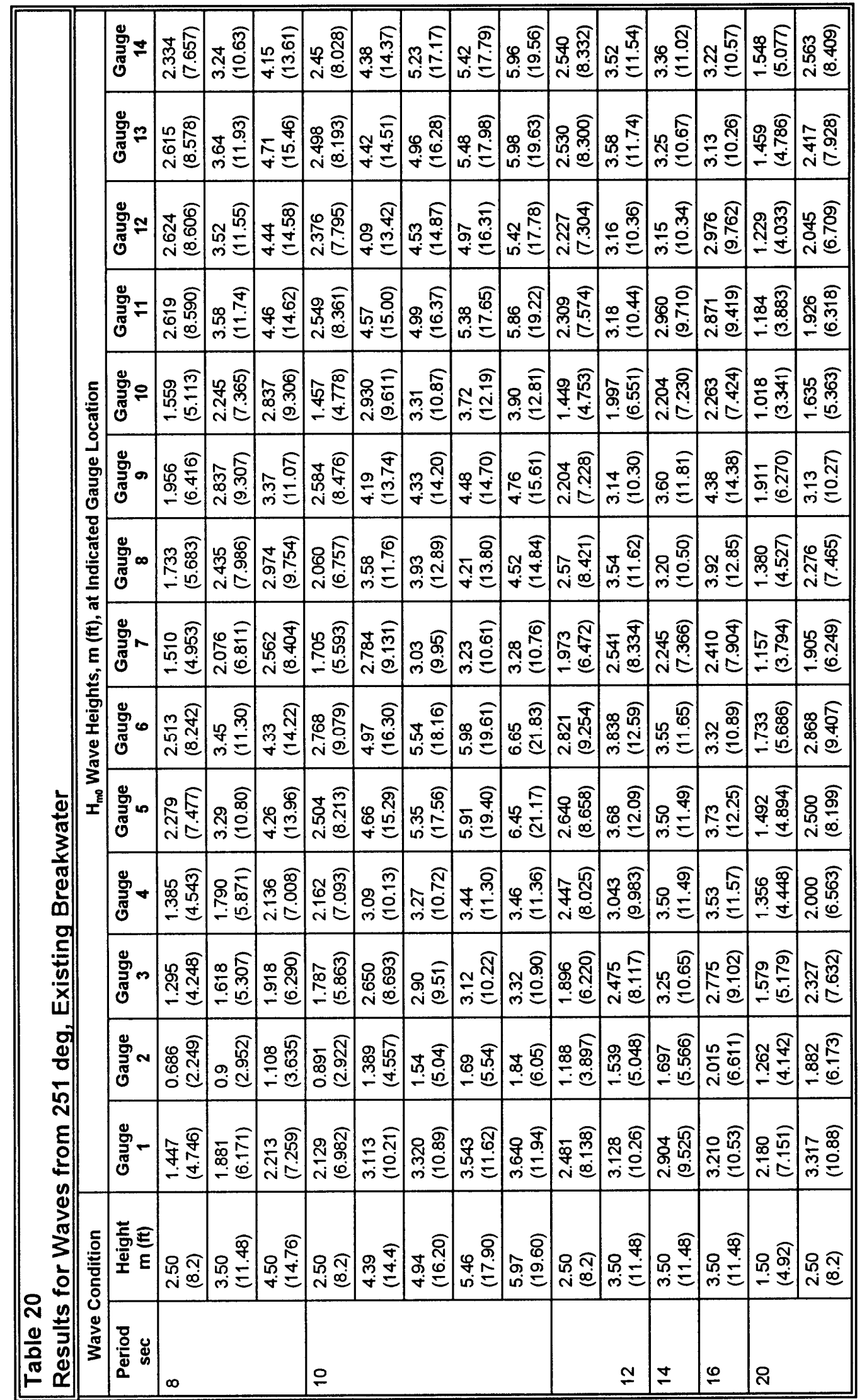




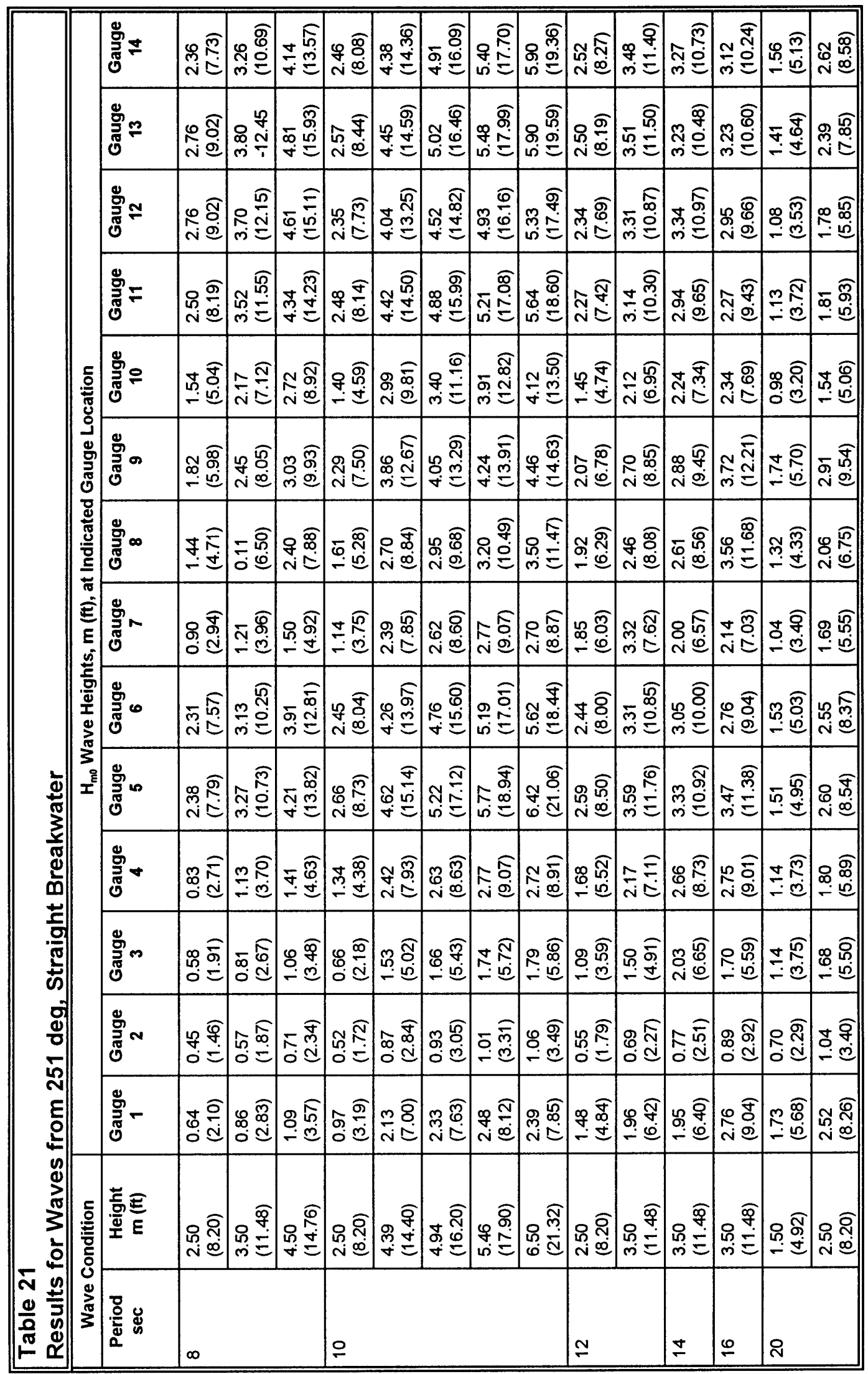




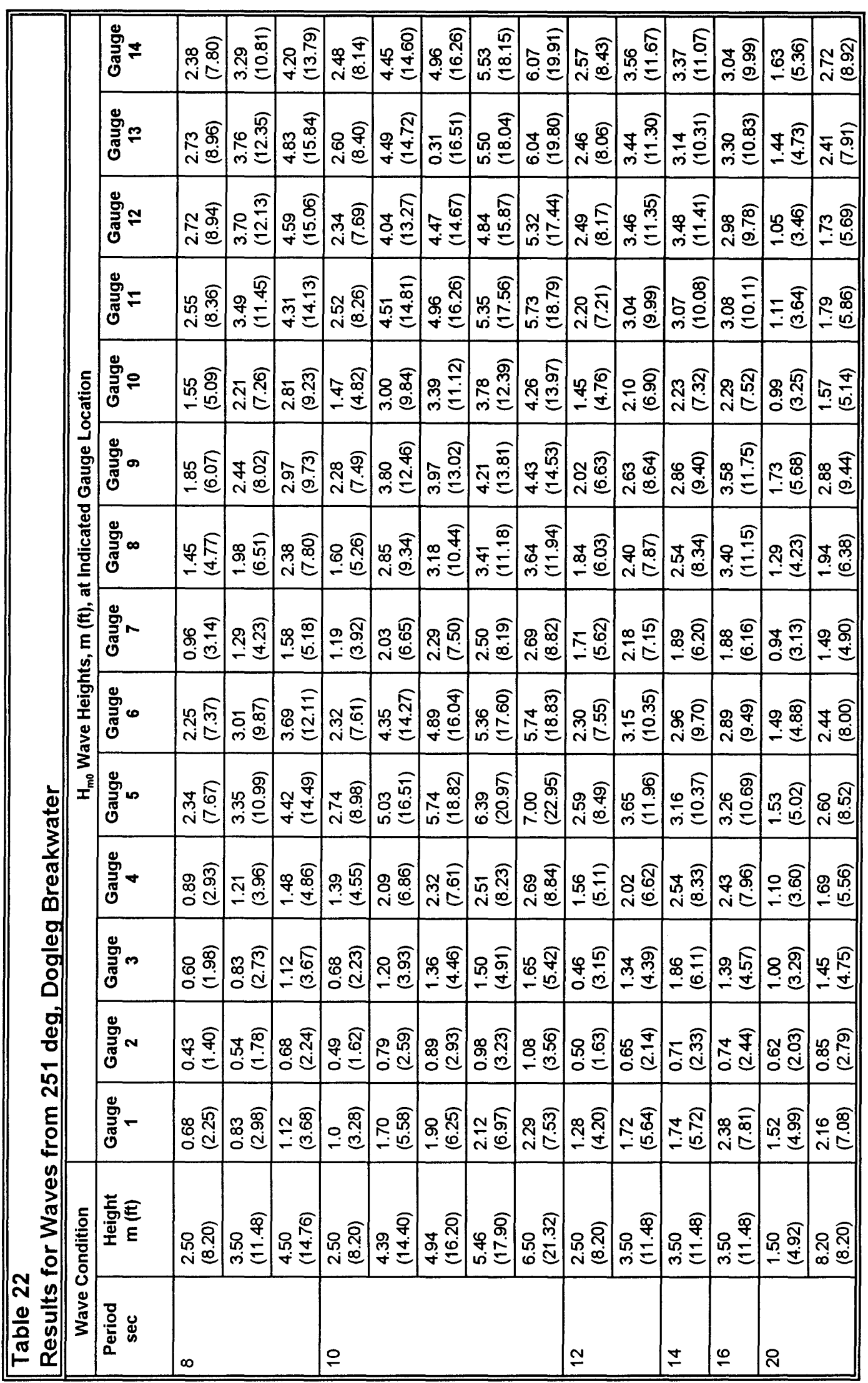



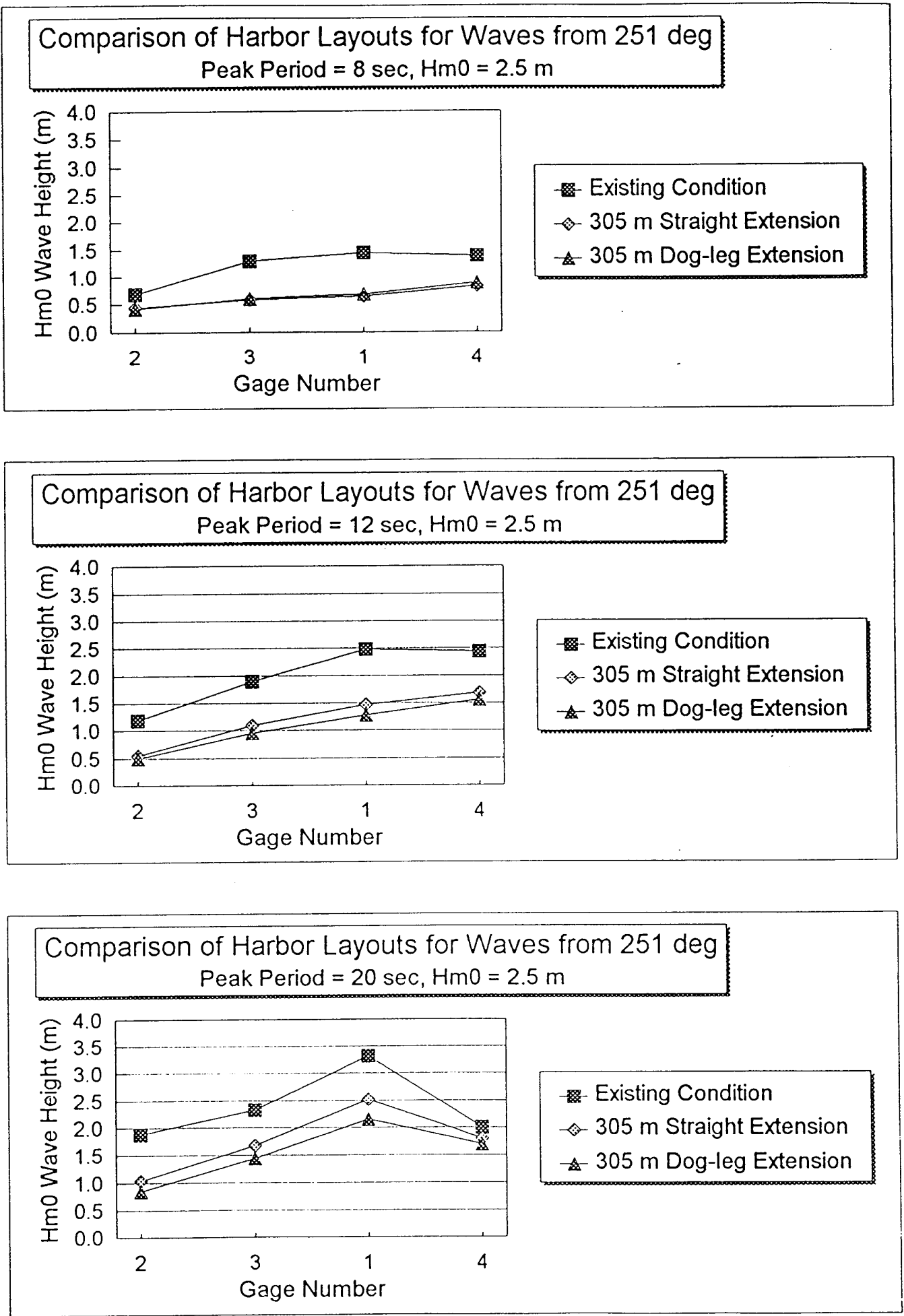

Figure 47. Comparison of existing conditions with the two alternative layout configurations waves from $251 \mathrm{deg}$ 
the wave height is only less than $1.5 \mathrm{~m}(4.9 \mathrm{ft})$ at gauge 2 for the 12 -sec wave period. Longer-period waves are only minimally affected by the straight or dogleg breakwater. However, results are significantly better than for existing conditions. One might notice the high wave height at gauge 1 for the 20 -sec wave condition, which is higher than the deepwater incident condition. This appears to be due to the close proximity of the gauge to the near vertical wall below the pier area. Near a purely reflective structure, the wave height can be twice as high as the incident wave height. For shorter period waves, this phenomenon was not present, indicating that these waves were not affected by the wall and the distance to the wall relative to the wavelength was long enough that doubling of the wave height was not realized. It also might indicate that a standing wave pattern is being created. For the higher wave heights, the results at the pier are correspondingly higher.

The differences between the straight and dogleg extensions become more obvious for the longer period waves. For the $20-\mathrm{sec}$ waves, the wave height at the pier for the dogleg breakwater is on average 12 percent less than the straight breakwater with an 18-percent maximum difference and a 5-percent minimum difference for gauges 1 through 4 .

\section{Waves from $221 \mathrm{deg}$}

The wave machines were reoriented to the 221-deg direction. Results for the existing, straight, and dogleg configurations are shown in Tables 23, 24, and 25, respectively. Results for 8-, 12-, and 20-sec waves are shown in Figure 48. The shorter, 8 -sec waves with a $2.5-\mathrm{m}(8.2-\mathrm{ft})$ deepwater wave height are reduced on the average by a factor of two. The deepwater wave height is reduced by a factor of five at gauge 2 . Although gauge 4 is located farthest from the breakwater, the maximum wave height occurs at gauge 1 for $12-$ and $20-\mathrm{sec}$ waves. Refraction of the waves as they enter the harbor and reflection from the sidewalls under the pier is greater at gauge 1. For the 8- and 12-sec waves, both proposed plans show improvements over existing conditions. However, results with 20 -sec waves differ little between the three plans. The design criteria of a $1.5-\mathrm{m}(4.9-\mathrm{ft})$ wave or lower at the pier is not realized for waves from $221 \mathrm{deg}$. All plans provide only limited sheltering for waves from the 221-deg wave direction for the 12- and 20-sec waves.

\section{Waves from $291 \mathrm{deg}$}

The wave machines were moved for simulation of waves from $291 \mathrm{deg}$. Results for the existing conditions and the dogleg configuration are given in Tables 26 and 27 , respectively. For waves from $29 \mathrm{I} \mathrm{deg}$, the straight breakwater had been eliminated as a possible alternative and experiments on this configuration were not conducted. Unlike the first two directions, the 20 -sec wave was not a typical wave condition from this direction and thus a shorter, 14-sec wave was generated, and results are shown in Figure 49. The pier area is sheltered by both the existing and dogleg breakwater for waves from $291 \mathrm{deg}$. An increased reduction in wave height of the dogleg breakwater over existing conditions at gauges 3 and 4 is shown in Tables 26 and 27 . However, there is not a substantial difference at gauge 2 . 


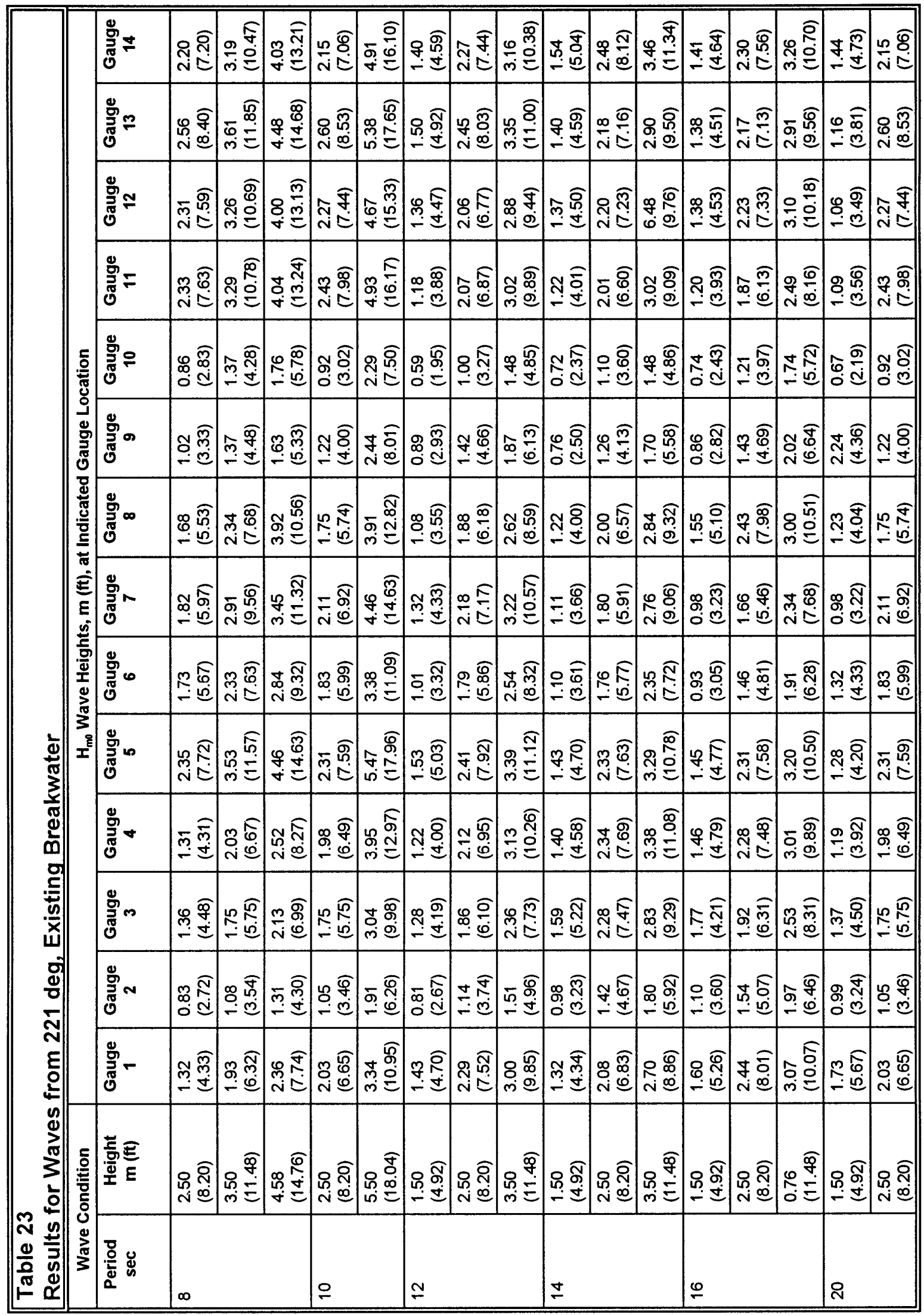




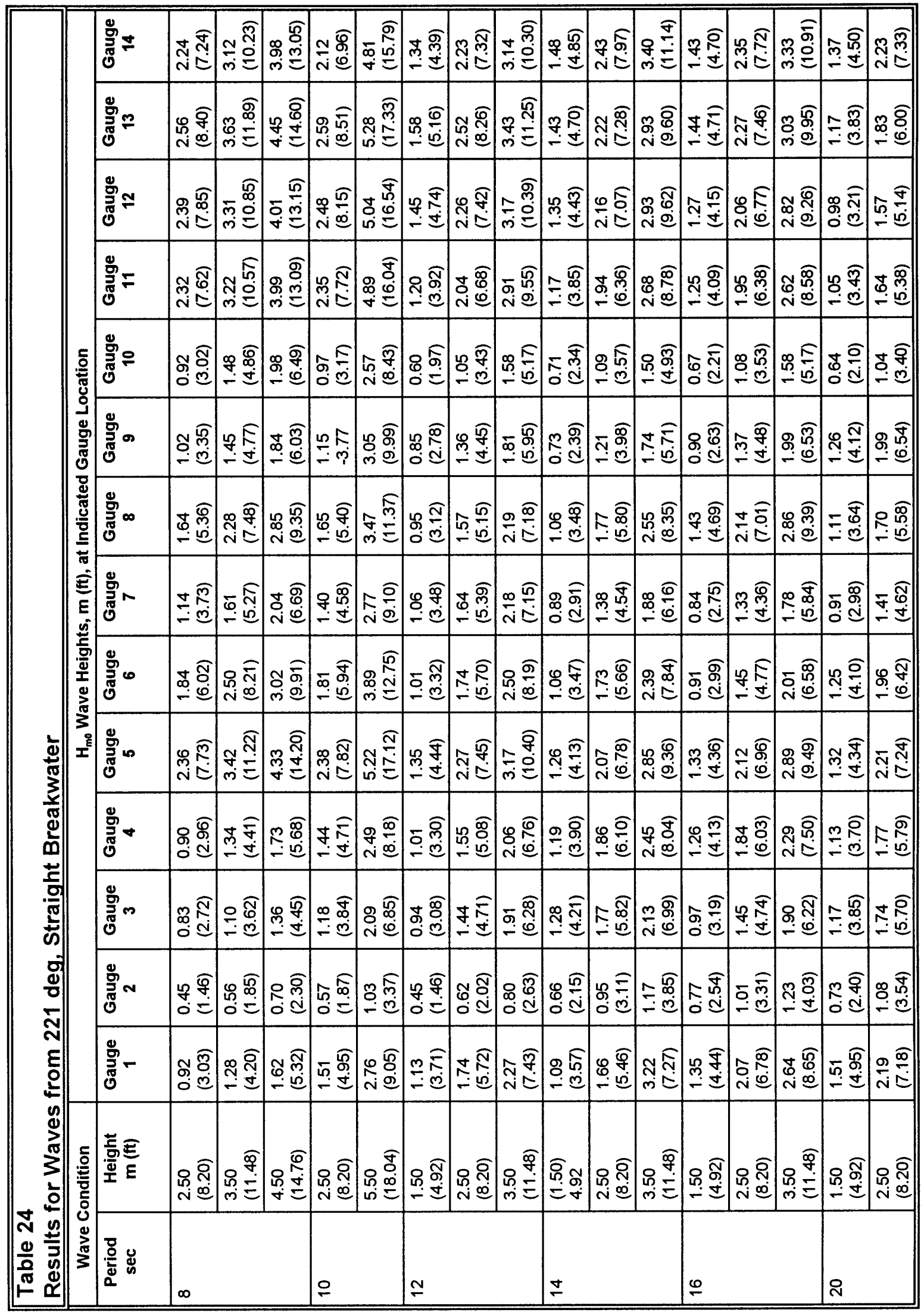




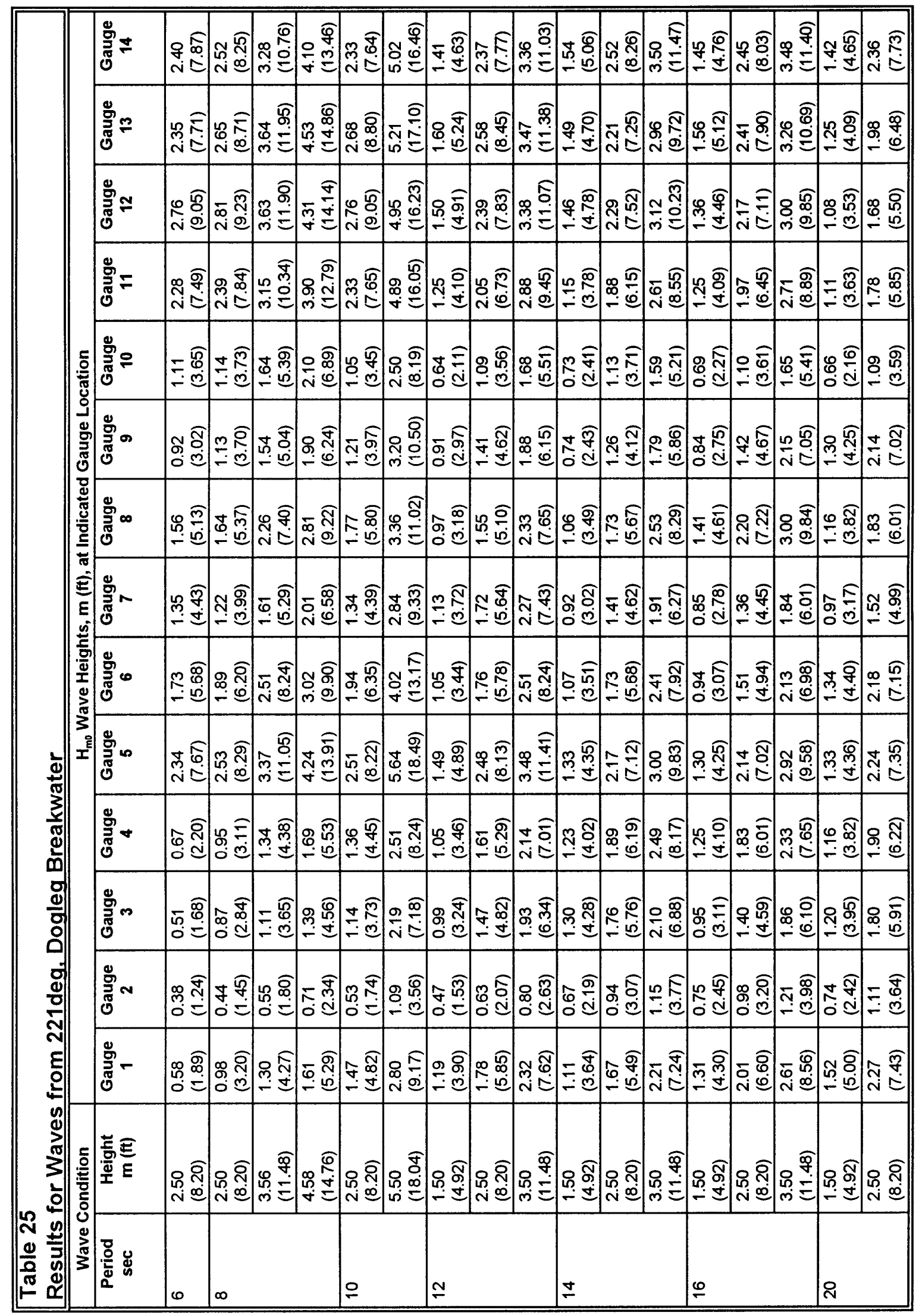




\section{Comparison of Harbor Layouts for Waves from $221 \mathrm{deg}$ Peak Period $=8 \mathrm{sec}, \mathrm{Hmo}=2.5 \mathrm{~m}$}

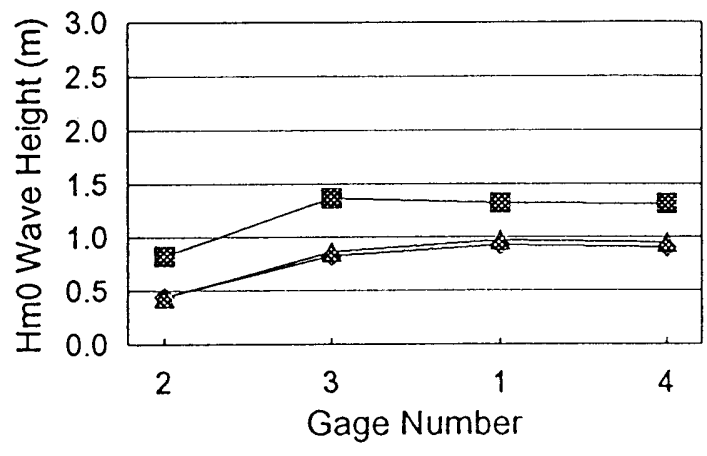

Existing Condition - $305 \mathrm{~m}$ Straight Extension « $305 \mathrm{~m}$ Dog-leg Extension

Comparison of Harbor Layouts for Waves from 221 deg

Peak Period $=12 \mathrm{sec}, \mathrm{Hm0}=2.5 \mathrm{~m}$

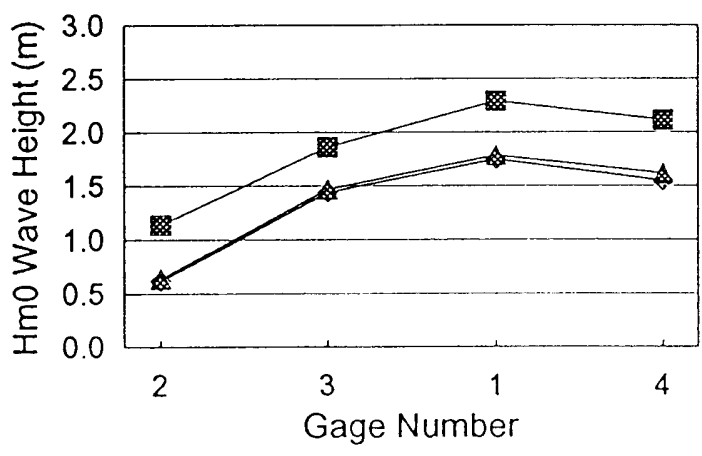

Existing Condition

ه $305 \mathrm{~m}$ Straight Extension

$\$ 305 \mathrm{~m}$ Dog-leg Extension

Comparison of Harbor Layouts for Waves from $221 \mathrm{deg}$

Peak Period $=20 \mathrm{sec}, \mathrm{Hmo}=2.5 \mathrm{~m}$

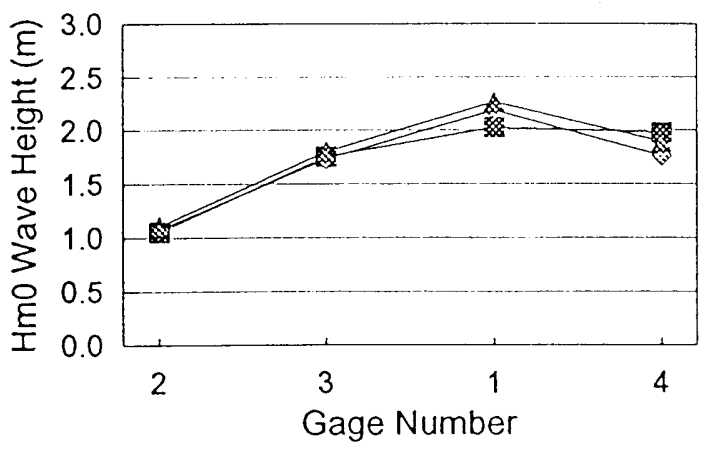

Existing Condition

- $305 \mathrm{~m}$ Straight Extension

$\$ 305 \mathrm{~m}$ Dog-leg Extension

Figure 48. Comparison of existing conditions with the two alternative layout configurations for waves from $221 \mathrm{deg}$ 


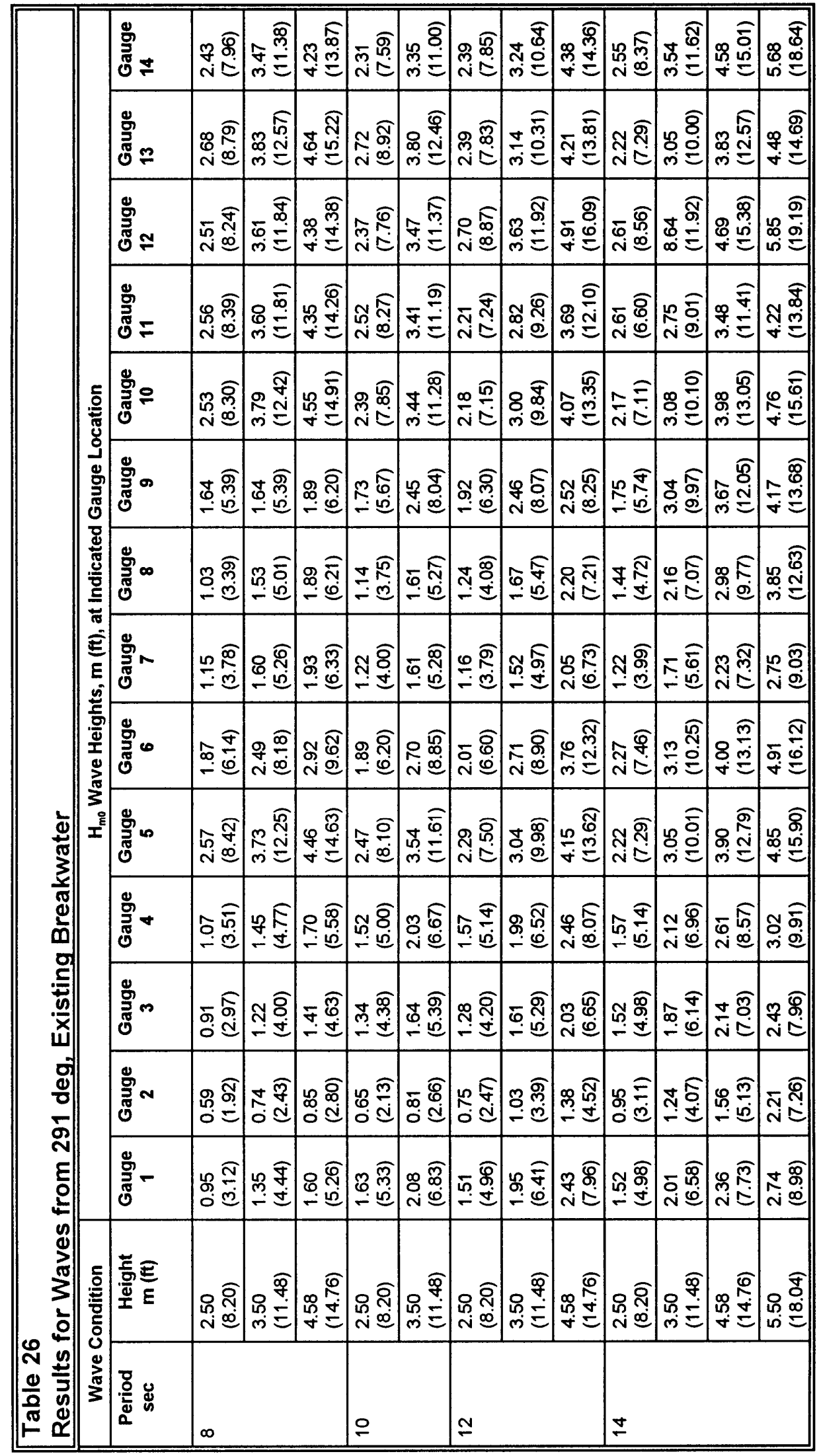




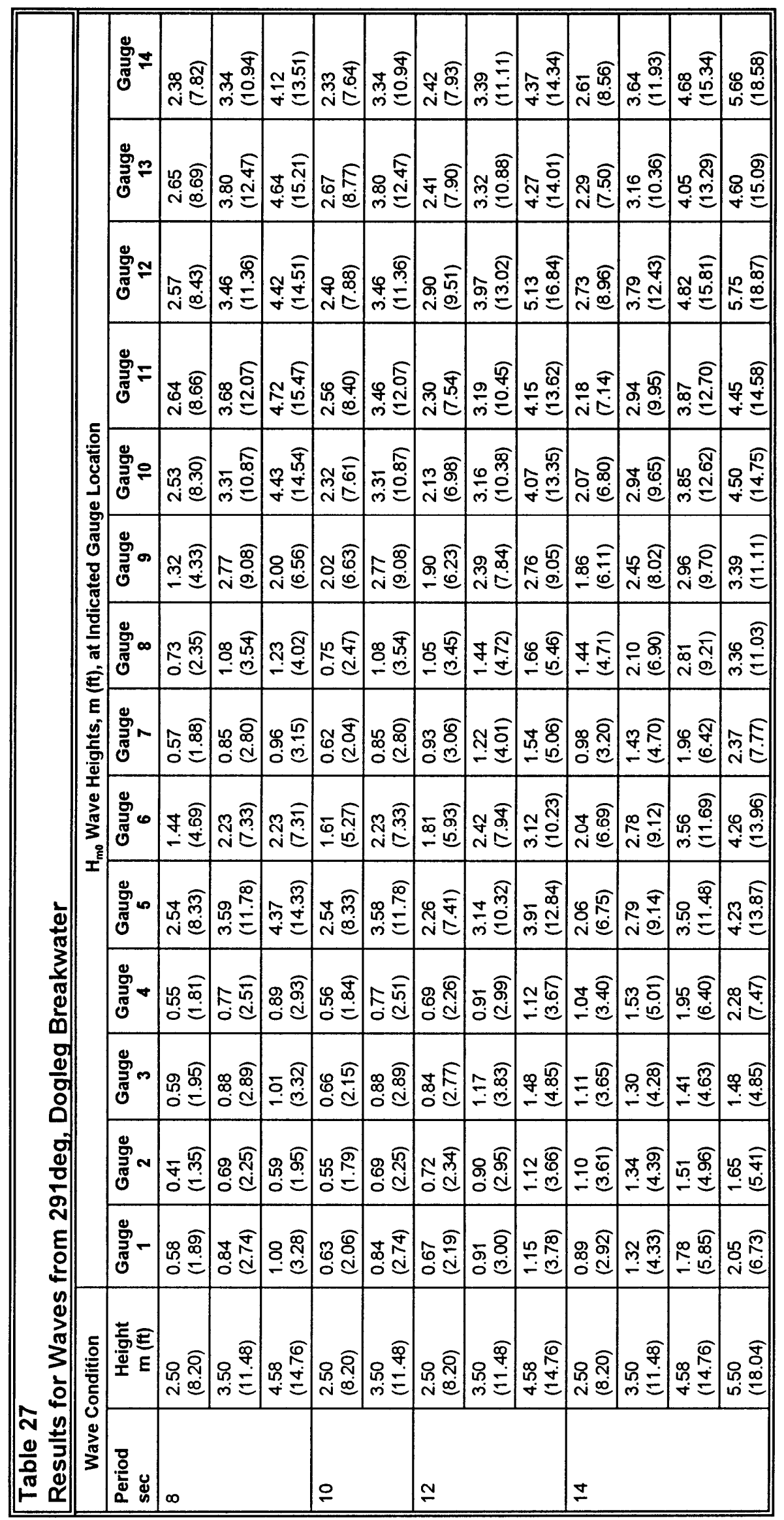




\section{Comparison of Harbor Layouts for Waves from $291 \mathrm{deg}$ \\ Peak Period $=8 \mathrm{sec}, \mathrm{Hm0}=2.5 \mathrm{~m}$}

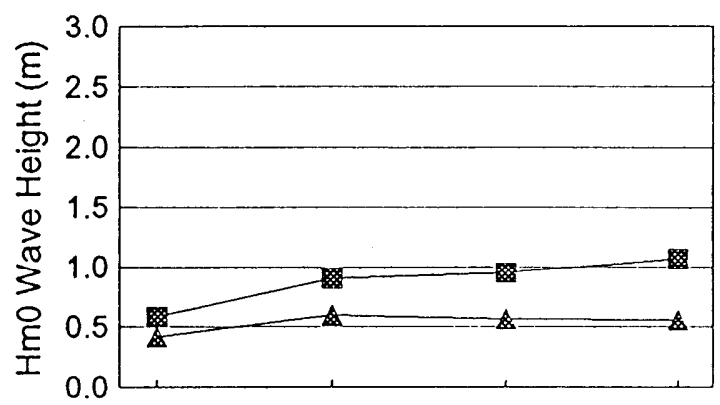

Existing Condition

« $305 \mathrm{~m}$ Dog-leg Extension

Gage Number

\section{Comparison of Harbor Layouts for Waves from 291 deg}

Peak Period $=12 \mathrm{sec}, \mathrm{Hmo}=2.5 \mathrm{~m}$

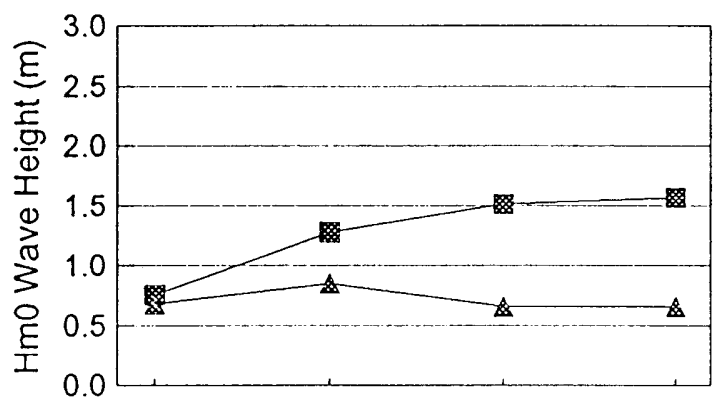

- Existing Condition

$\triangle 305 \mathrm{~m}$ Dog-leg Extension

Gage Number

\section{Comparison of Harbor Layouts for Waves from $291 \mathrm{deg}$ \\ Peak Period $=14 \mathrm{sec}, \mathrm{Hm0}=2.5 \mathrm{~m}$}

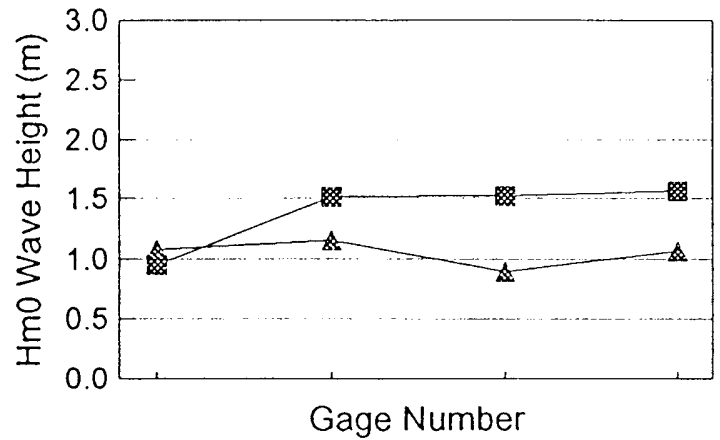

Existing Condition

\ 305 m Dog-leg Extension

Gage Number

Figure 49. Comparison of existing conditions with the two alternative layout configurations for waves from $291 \mathrm{deg}$ 


\section{Summary of Results from the Three Wave Directions}

Figures 47 through 49 show the importance of wave direction, period, distance from the breakwater, and breakwater configuration on measured wave heights along the pier for a $2.5-\mathrm{m}(8.2-\mathrm{ft})$ deepwater incident wave. Wave heights at the pier are

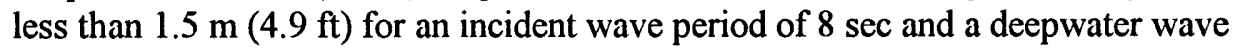
height of $2.5 \mathrm{~m}(8.2 \mathrm{ft})$ for the three directions studied and the three breakwater configurations constructed. From $291 \mathrm{deg}$, the wave height along the pier also was

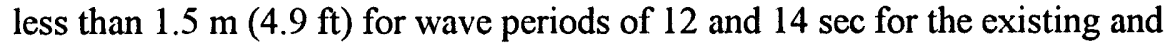
dogleg breakwaters for an incident wave height of $2.5 \mathrm{~m}(8.2 \mathrm{ft})$. The dogleg breakwater provided increased reduction of wave heights. For a $2.5-\mathrm{m}(8.2-\mathrm{ft})$ wave from $251 \mathrm{deg}$, the wave height along the pier was less than $1.5 \mathrm{~m}(4.9 \mathrm{ft})$ for $12-\mathrm{sec}$ waves for the straight and dogleg breakwaters, but not for existing conditions. For

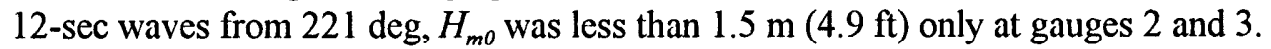
Only gauge 2 showed wave heights less than $1.5 \mathrm{~m}(4.9 \mathrm{ft})$ for 20 -sec waves from 251 and $221 \mathrm{deg}$ ).

Obviously, the criteria established by POD for a $4.7-\mathrm{m}$ (15.5-ft) deepwater wave height not to exceed $1.5 \mathrm{~m}(4.9 \mathrm{ft})$ at the pier were not met by the alternatives studied. However, the results indicate that both the straight and dogleg extensions decrease the wave height at the pier compared to existing conditions. The dogleg extension provides slightly better results over the straight breakwater, especially for the longer period waves from $251 \mathrm{deg}$.

\section{Effectiveness of the Dogleg Breakwater Over Exist- ing Conditions and the Straight Breakwater Alter- native}

To summarize the effectiveness of the dogleg breakwater, two normalizing techniques were used. The first and simplest technique, termed the transmission coefficient, normalizes the wave heights at the pier by the deepwater wave height or simply

$$
A^{\prime} \frac{H_{i}}{H_{o}}
$$

where $H_{i}$ is the wave height at the $\mathrm{i}^{\text {th }}$ gauge location and $H_{o}$ is the average wave height at gauges 13 and 14, the deepwater wave height. This technique is used when showing the results for a single plan. If the result is less than unity, then there is a reduction in wave height at the pier in comparison with the deepwater wave height. If the wave height is amplified at the pier, the value would be greater than unity. To simplify the results, all runs for a particular period were averaged and one result for each wave period is shown. The results for the dogleg breakwater are 
shown in Figures 50 through 52 for the three incident wave directions. The graphs show the transmission coefficient of the deepwater wave height for gauges located along the pier area (see Figure 44).

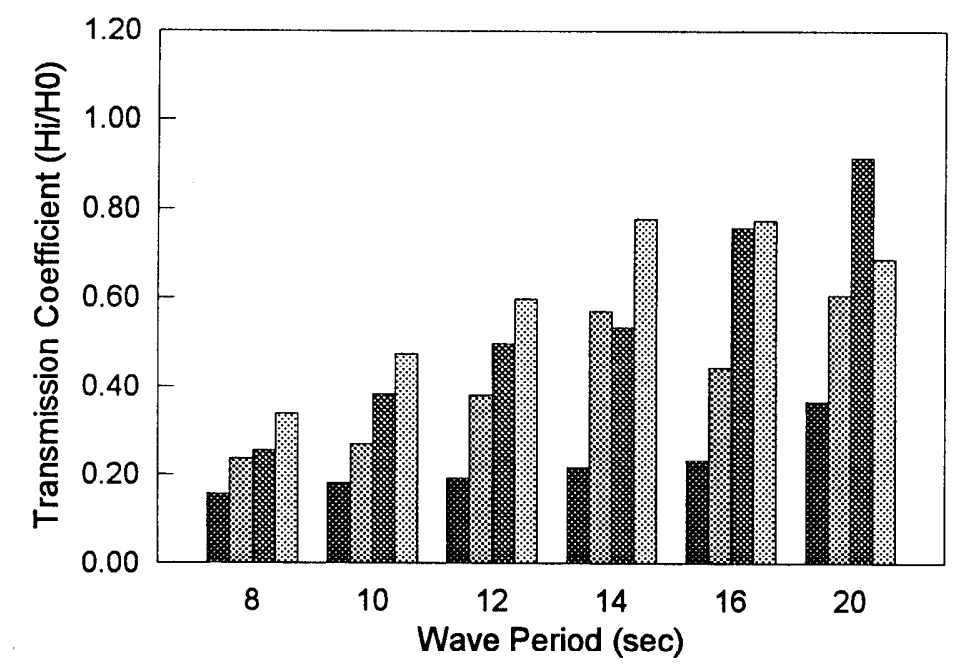

Gauge 2

Gauge 3

Gauge 1

: Gauge 4

Figure 50. Period-averaged deepwater wave height transmission coefficient for waves from $251 \mathrm{deg}$ with dogleg breakwater

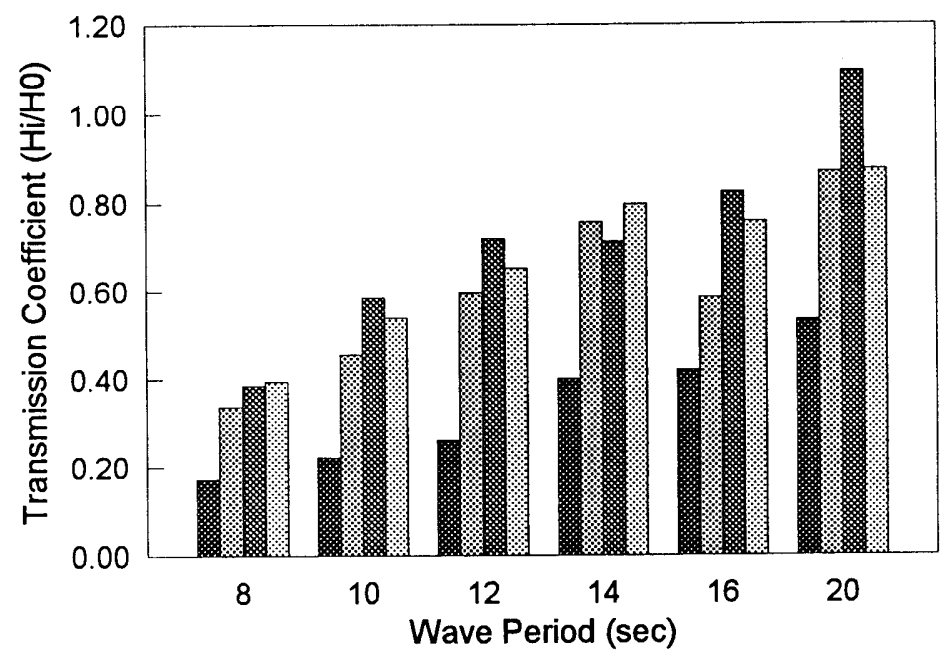

Gauge 2

a․ Gauge 3

Gauge 1

… Gauge 4

Figure 51. Period-averaged deepwater wave height transmission coefficient for waves from $221 \mathrm{deg}$ with dogleg breakwater 


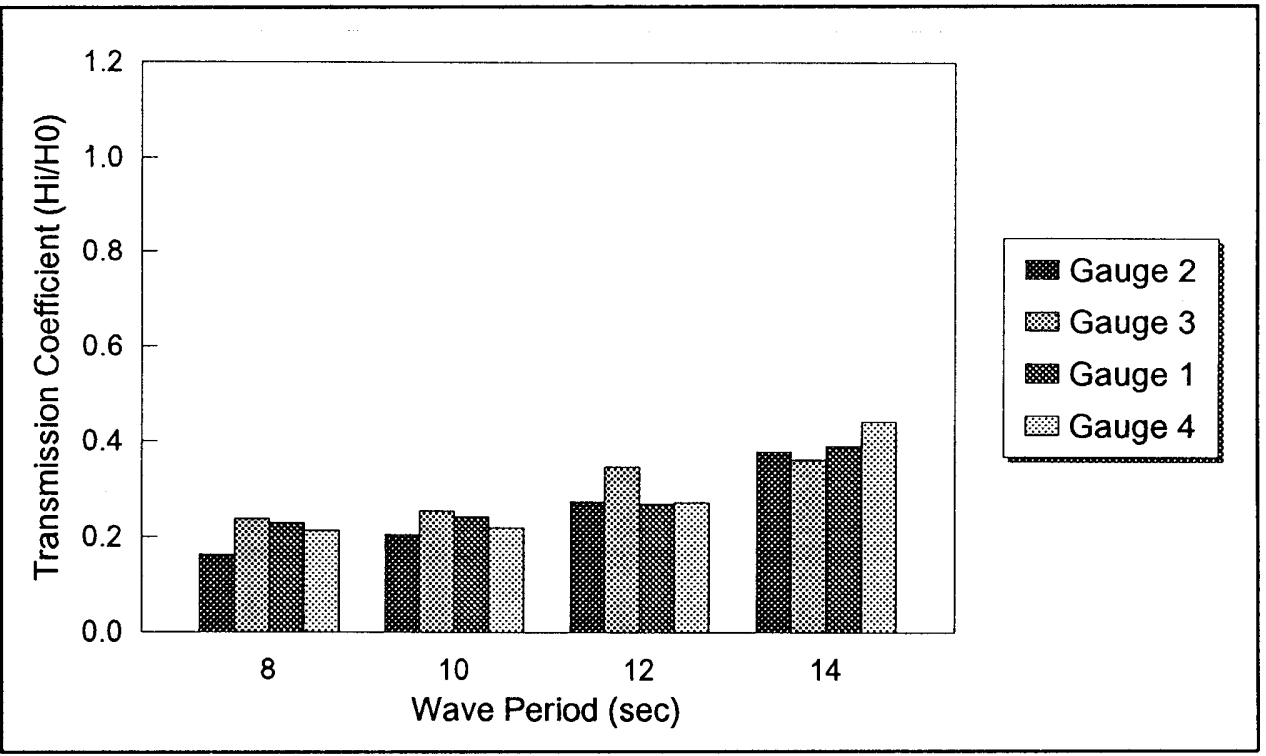

Figure 52. Period-averaged deepwater wave height transmission coefficient for waves from 291 deg with dogleg breakwater

Model results, showing the transmission coefficient, are summarized in Table 28. The table is divided into the three directions with typical wave periods associated with each direction. The transmission coefficient and maximum wave height at the $29-\mathrm{m}(95-\mathrm{ft})$ depth that produces a $1.5-\mathrm{m}$ (4.9-ft) average wave height along the pier is also given. Averaging was used to summarize the results for gauges 1-4 for varying wave heights for a particular wave period and direction. For example, for existing conditions for an 8-sec wave period for waves from $221 \mathrm{deg}$ the transmission coefficients are shown in Table 29.

The maximum wave height, Table 28 , at the $29-\mathrm{m}(95-\mathrm{ft})$ depth was calculated by dividing $1.5 \mathrm{~m}(4.9 \mathrm{ft})$ by the transmission coefficient. This number provides the shipping companies an idea of the maximum deepwater wave height for a given wave direction and period that will provide an average $1.5-\mathrm{m}(4.9-\mathrm{ft})$ wave height along the pier. Another useful way to use this chart is to calculate the wave height along the pier given incident wave height, period, and direction from which waves are approaching the harbor in deep water. For existing conditions, given a 6-m (19.7-ft) wave height, 8 -sec period from $221 \mathrm{deg}$, the average wave height along the pier is $3 \mathrm{~m}(9.8 \mathrm{ft})$, conditions that would be too rough for offloading. The transmission coefficient for the dogleg configuration is always less than the transmission coefficient produced by existing conditions; thus, the dogleg design will allow the harbor to be used during more energetic wave events.

One might question the validity of averaging the results over different simulated wave heights. Transmission coefficients for waves with a wave period of $8 \mathrm{sec}$ and from a principal wave direction of $251 \mathrm{deg}$ are shown in Figure 53 for deepwater wave heights of $2.5(8.2 \mathrm{ft}), 3.5(11.5 \mathrm{ft})$ and $4.5 \mathrm{~m}(14.8 \mathrm{ft})$. Although the results 


\begin{tabular}{|c|c|c|c|c|c|}
\hline \multicolumn{6}{|c|}{$\begin{array}{l}\text { Table } 28 \\
\text { Average Transmission Coefficient and Maximum Deepwater Wave } \\
\text { Height That Provide for a 1.5-m Average Wave Height Along the } \\
\text { Pier }\end{array}$} \\
\hline \multirow{2}{*}{$\begin{array}{c}\text { Direction } \\
\text { (deg) }\end{array}$} & \multirow{2}{*}{$\begin{array}{c}\text { Period } \\
\text { (sec) }\end{array}$} & \multicolumn{2}{|c|}{ Transmission Coefficient $\left(\mathrm{H} / \mathrm{H}_{0}\right)$} & \multicolumn{2}{|c|}{ Maximum Wave Height, $m$ (ft) } \\
\hline & & Existing & Dogleg & Existing & Dogleg \\
\hline \multirow[t]{6}{*}{221} & 8 & 0.50 & 0.32 & $3.0(10.2)$ & $4.7(15.4)$ \\
\hline & 10 & 0.66 & 0.45 & $2.3(7.5)$ & $3.4(11.2)$ \\
\hline & 12 & 0.79 & 0.56 & $1.9(6.2)$ & $2.7(8.9)$ \\
\hline & 14 & 0.87 & 0.67 & $1.7(5.6)$ & $2.3(7.5)$ \\
\hline & 16 & 0.92 & 0.65 & $1.7(5.6)$ & $2.4(7.9)$ \\
\hline & 20 & 0.87 & 0.84 & $1.8(5.9)$ & $1.8(5.9)$ \\
\hline \multirow[t]{6}{*}{251} & 8 & 0.45 & 0.25 & $3.4(11.2)$ & $6.1(20.0)$ \\
\hline & 10 & 0.58 & 0.33 & $2.6(8.5)$ & $4.6(15.1)$ \\
\hline & 12 & 0.75 & 0.42 & $2.0(6.6)$ & $3.6(11.8)$ \\
\hline & 14 & 0.86 & 0.53 & $1.8(5.9)$ & $2.9(9.5)$ \\
\hline & 16 & 0.90 & 0.55 & $1.7(5.6)$ & $2.8(9.2)$ \\
\hline & 20 & 1.01 & 0.64 & $1.5(4.9)$ & $2.4(7.9)$ \\
\hline \multirow[t]{4}{*}{291} & 8 & 0.33 & 0.21 & $4.6(15.1)$ & $7.2(23.6)$ \\
\hline & 10 & 0.48 & 0.23 & $3.1(10.2)$ & $6.6(11.8)$ \\
\hline & 12 & 0.51 & 0.29 & $3.0(9.8)$ & $5.2(17.1)$ \\
\hline & 14 & 0.54 & 0.39 & $2.8(9.2)$ & $3.9(12.8)$ \\
\hline
\end{tabular}

Table 29

Example of Average Transmission Coefficient Calculation for 8-sec Wave from $221 \mathrm{deg}$

\begin{tabular}{|c|c|c|c|c|c||}
\hline \hline \multirow{2}{*}{$\begin{array}{c}\text { Target } \\
\boldsymbol{H}_{\mathrm{m} 0}(\mathrm{~m})\end{array}$} & \multicolumn{5}{|c||}{ Transmission Coefficient $\left(\mathrm{H}_{/} / \mathrm{H}_{\mathrm{O}}\right)$ for Gauge Number } \\
\cline { 2 - 6 } & $\mathbf{1}$ & 2 & 3 & 4 & Average \\
\hline \hline 2.5 & 0.39 & 0.19 & 0.35 & 0.38 & 0.32 \\
\hline 3.5 & 0.38 & 0.17 & 0.33 & 0.40 & 0.32 \\
\hline 4.5 & 0.38 & 0.17 & 0.32 & 0.41 & 0.32 \\
\hline Average & 0.38 & 0.17 & 0.33 & 0.40 & 0.32 \\
\hline
\end{tabular}

are different for the different wave heights, the results are close in magnitude and show that averaging the results from different incident wave heights is a valid scheme to summarize the data. 


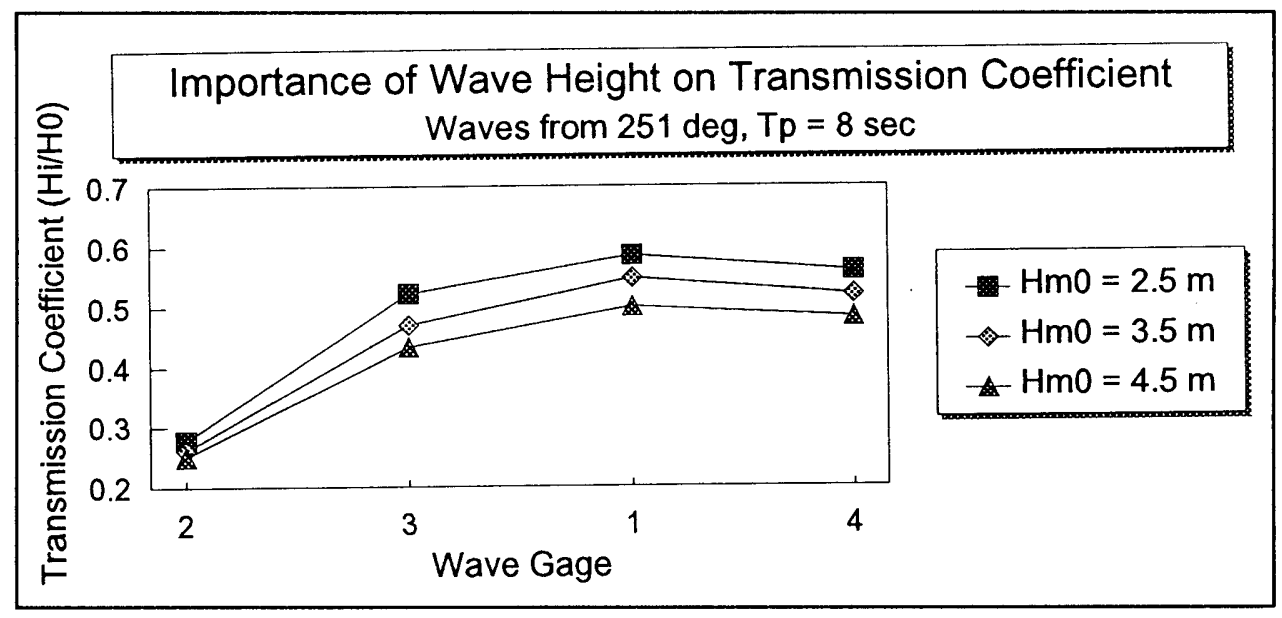

Figure 53. Importance of wave height on wave transmission coefficient for a single wave period and direction for $H_{m o}$ wave heights of $2.5,3.5$, and $4.5 \mathrm{~m}$

Another method was used to further compare results between the dogleg breakwater and existing conditions. This technique was chosen because it eliminates small differences between incident deepwater wave conditions when waves are generated for different plans or from different directions. Ideally the deepwater wave conditions would always be identical; however, this was not the case. The difference between transmission coefficients of the dogleg breakwater and existing conditions then is normalized by the transmission coefficients for existing conditions. The formula for the normalized transmission coefficients is given as follows:

$$
N_{a}=1+\frac{\left(\left(\frac{H_{i}}{H_{o}}\right)_{\text {dogleg }}-\left(\frac{H_{i}}{H_{o}}\right)_{\text {existing }}\right)}{\left(\frac{H_{i}}{H_{o}}\right)_{\text {existing }}}
$$

in which $H_{i}$ represents the wave height of the $i^{\text {th }}$ wave gauge and $H_{0}$ is the wave height at $-29 \mathrm{~m}(-95 \mathrm{ft})$. Results from this expression show the increased or decreased effectiveness of the dogleg breakwater over existing conditions. The dogleg breakwater is more effective in reducing the wave height at the pier than existing conditions if the result is less than unity. If the results are unity, there is no change in wave height, and if the result is greater than unity, the dogleg breakwater is less effective than existing conditions. The decimal percent that $\mathrm{N}_{\mathrm{a}}$ is above or below unity is how much less or more, respectively, the dogleg reduces the wave at the pier than the existing breakwater. For example, given the same deepwater wave height for the existing condition and the dogleg breakwater if $N_{a}=0.75$, then the wave height at the pier with the dogleg in place is only 75 percent as high as it would be for existing conditions. 
The dogleg breakwater does provide significant improvements over existing conditions. The dogleg breakwater and existing conditions for waves from 221 , 251 , and 291 deg referenced to north are in Figure 54. This gives an indication of the decrease in wave height at the pier with the dogleg breakwater. As was the case with the transmission coefficient results, the normalized transmission coefficients represent averaged wave heights for all wave cases from a particular direction. The dogleg breakwater has little effect on wave energy reaching gauge 2 for waves from $291 \mathrm{deg}$. Gauge 2 is sheltered from waves from this direction and increasing the breakwater would have little effect.

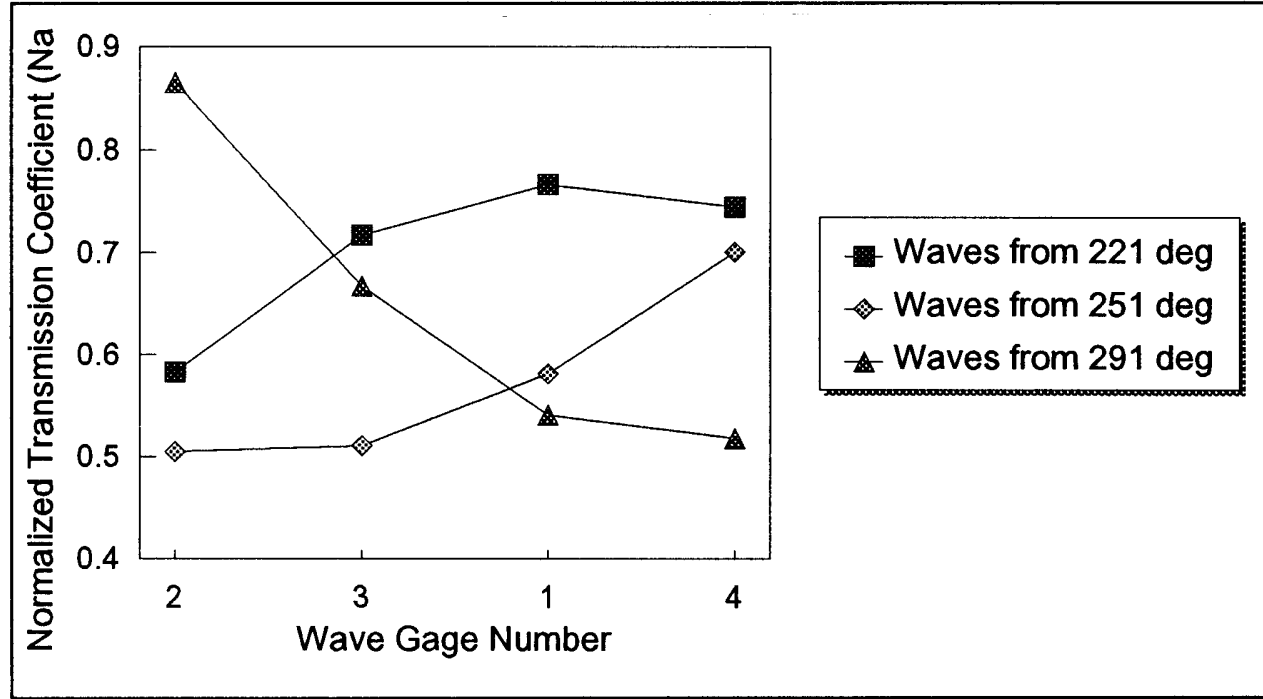

Figure 54. Normalized transmission coefficient for the dogleg breakwater

The straight and dogleg breakwaters were compared using the normalized transmission coefficient given in equation 16, and the results for gauges 1-4 are shown in Table 30 . In general, the dogleg breakwater provides a normalized transmission coefficient of 0.65 while the straight breakwater provides a normalized transmission coefficient of 0.69 . Thus, the dogleg breakwater provides slightly more sheltering than the straight breakwater.

\section{Increased Harbor Usability with the Dogleg Extension}

Before considering the increased harbor usability when the dogleg breakwater is present, some limitation of the WIS data set must be addressed. Kaumalapau Harbor is directly exposed to waves propagating from $180 \mathrm{deg}$ (due south) clockwise to approximately $330 \mathrm{deg}$ ( $30 \mathrm{deg}$ west of north). Therefore, the harbor is exposed to waves from the south and west of Lanai. The WIS Pacific Phase I grid is 


\begin{tabular}{|c|c|c|c|c|c|}
\hline \multicolumn{6}{|c|}{$\begin{array}{l}\text { Table } 30 \\
\text { Comparison Between the Straight and Dogleg Breakwater } \\
\text { Configurations Using the Normalized Transmission Coefficients } \\
\left(\mathrm{N}_{\mathrm{a}}\right)\end{array}$} \\
\hline \multirow[b]{2}{*}{ Direction } & \multirow[b]{2}{*}{ Configuration } & \multicolumn{4}{|c|}{ Gauge Number } \\
\hline & & 2 & 3 & 1 & 4 \\
\hline \multirow[t]{2}{*}{221} & Straight & 0.64 & 0.76 & 0.81 & 0.77 \\
\hline & Dogleg & 0.62 & 0.74 & 0.80 & 0.76 \\
\hline \multirow[t]{2}{*}{251} & Straight & 0.55 & 0.57 & 0.65 & 0.74 \\
\hline & Dogleg & 0.50 & 0.51 & 0.58 & 0.70 \\
\hline \multicolumn{2}{|c|}{ Average Straight } & 0.59 & 0.67 & 0.73 & 0.76 \\
\hline \multicolumn{2}{|c|}{ Average dogleg } & 0.56 & 0.63 & 0.69 & 0.73 \\
\hline \multicolumn{6}{|c|}{ Average Straight for all gauges $=0.69$. } \\
\hline
\end{tabular}

also limited in size to the west and south of Lanai, as shown in Figure 3. The WIS model does not include waves that are generated in the southern hemisphere, which are waves that affect Kaumalapau Harbor during the summer months. The grid size also is large, and low, locally generated waves are not included in the wave field calculated. Limitations of the WIS Pacific Phase I data set also do not include effects of wave sheltering from the Hawaiian Islands. Additionally, the two WIS stations are located some distance from Kaumalapau Harbor and diffraction of waves around Lanai is not known.

Given the limitations of the WIS data, a frequency of occurrence table was developed (Table 31). The table shows frequency of occurrence of waves over a 20-year record from January 1, 1956 through January 1, 1976 from wave directions that affect Kaumalapau Harbor. Percent of occurrence values were averaged over the two WIS stations. The last four columns in the table were calculated using transmission coefficient values from Table 28 and the calculated deepwater wave height, period, and direction from the 20-year WIS record. For example, waves from 206-235 occurred only 0.05 percent of the time. If existing conditions are present, the waves along the wharf are reduced to less than $1.5 \mathrm{~m}(4.9 \mathrm{ft}) 0.03$ percent of the 20 years. Since the dogleg breakwater provides better protection, the waves along the wharf are reduced to less than $1.5 \mathrm{~m} \mathrm{(4.9} \mathrm{ft}) 0.04$ percent for the 20 years. The last two columns indicate the percentage of time wave heights along the wharf are less than $1.5 \mathrm{~m}(4.9 \mathrm{ft})$ for waves from a particular direction for the existing conditions and the dogleg extension. Waves from 291 deg occur 4.8 percent of the time over the 20 -year WIS record. For 2.09 percent of the time, the waves will be from $291 \mathrm{deg}$ and less than $1.5 \mathrm{~m}(4.9 \mathrm{ft})$ along the wharf for the existing conditions while for the dogleg extension, waves meet the criteria 3.71 percent of the time. Waves meet the criteria from this direction 44 percent of the time for the existing conditions and 77 percent of the time for the dogleg extension. 


\begin{tabular}{|c|c|c|c|c|c|c|}
\hline \multicolumn{7}{|c|}{$\begin{array}{l}\text { Table } 31 \\
\text { Frequency of Occurrence for Waves Used in Physical Model }\end{array}$} \\
\hline \multirow[b]{2}{*}{$\begin{array}{l}\text { Wave } \\
\text { Direction } \\
\text { Bins }\end{array}$} & \multirow[b]{2}{*}{$\begin{array}{l}\text { Rep. } \\
\text { Wave } \\
\text { Direction }\end{array}$} & \multicolumn{3}{|c|}{$\begin{array}{c}\text { Percent of Occurrence Over 20-Year } \\
\text { Period }\end{array}$} & \multicolumn{2}{|c|}{$\begin{array}{l}\text { Percentage of Time } \\
\text { Waves from a Particular } \\
\text { Direction Generate } \\
\text { Waves at the Wharf } \\
\text { Less Than } \\
1.5 \mathrm{~m}(4.9 \mathrm{ft})\end{array}$} \\
\hline & & $\begin{array}{l}\text { WIS } \\
\text { Data }\end{array}$ & $\begin{array}{l}\text { Meets Wave } \\
\text { Criteria Along } \\
\text { the Pier with } \\
\text { Existing } \\
\text { Conditions }\end{array}$ & $\begin{array}{l}\text { Meets Wave } \\
\text { Criteria } \\
\text { Along the } \\
\text { Pier with } \\
\text { Dogleg } \\
\text { Extension }\end{array}$ & $\begin{array}{l}\text { Existing } \\
\text { Conditions }\end{array}$ & $\begin{array}{c}\text { Dogleg } \\
\text { Extension }\end{array}$ \\
\hline $206-235$ & 221 & 0.05 & 0.03 & 0.04 & 60 & 80 \\
\hline $235-264$ & 251 & 0.10 & 0.08 & 0.09 & 80 & 90 \\
\hline $265-315$ & 291 & 4.8 & 2.09 & 3.71 & 44 & 77 \\
\hline
\end{tabular}

On a wave-by-wave basis, the results are shown in Table 32. The numbers in the table represent the combined number of occurrences of a 3-hr event over the 20 years of WIS data for the two stations. The unshaded area represents maximum waves that will meet the design criteria for existing conditions. The lightly shaded area represents maximum waves that will meet the criteria for the dogleg extension, whereas the darkly shaded area represents waves that do not satisfy the criteria of a $1.5-\mathrm{m}(4.9-\mathrm{ft})$ wave height or less along the pier face with the dogleg extension. 


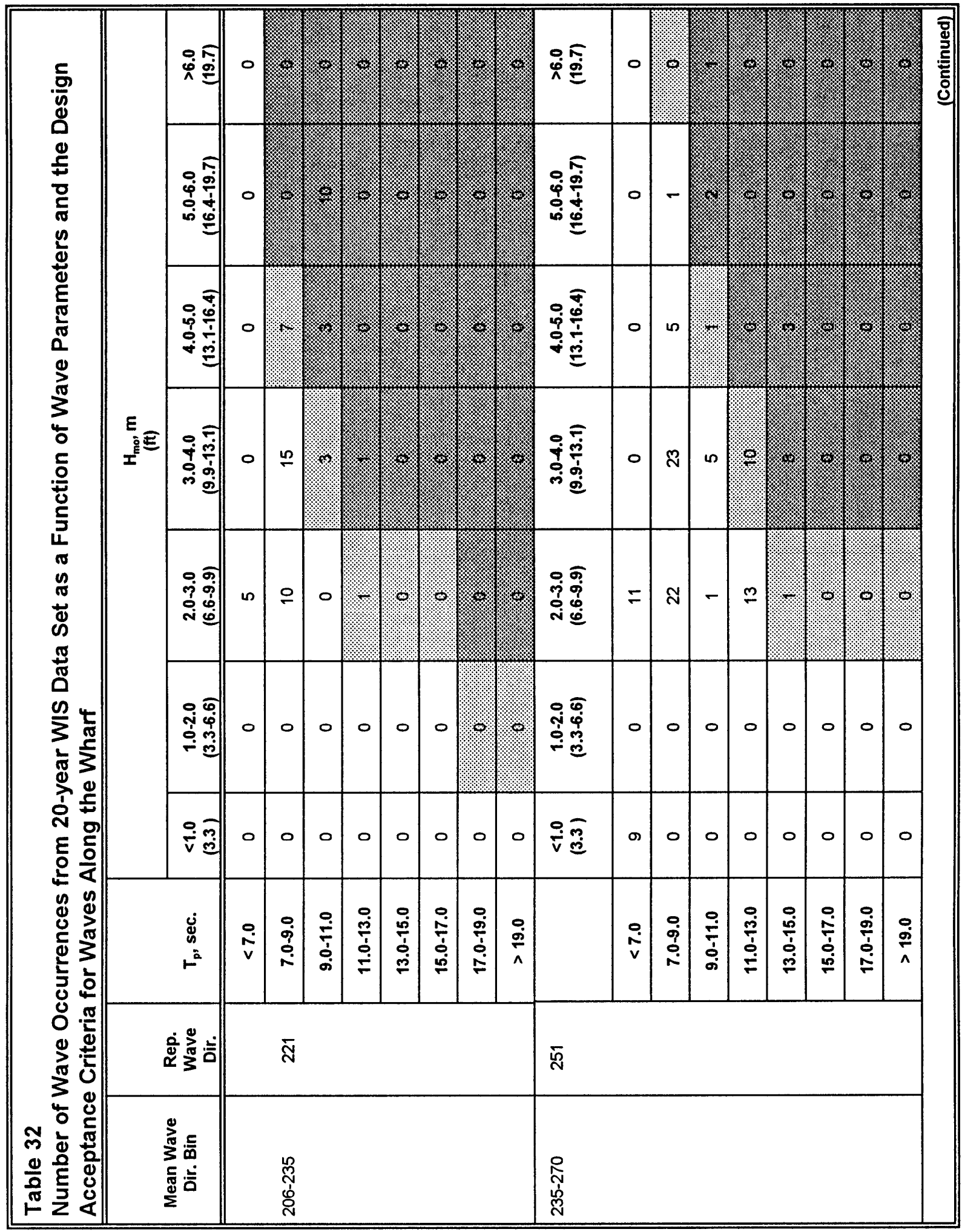




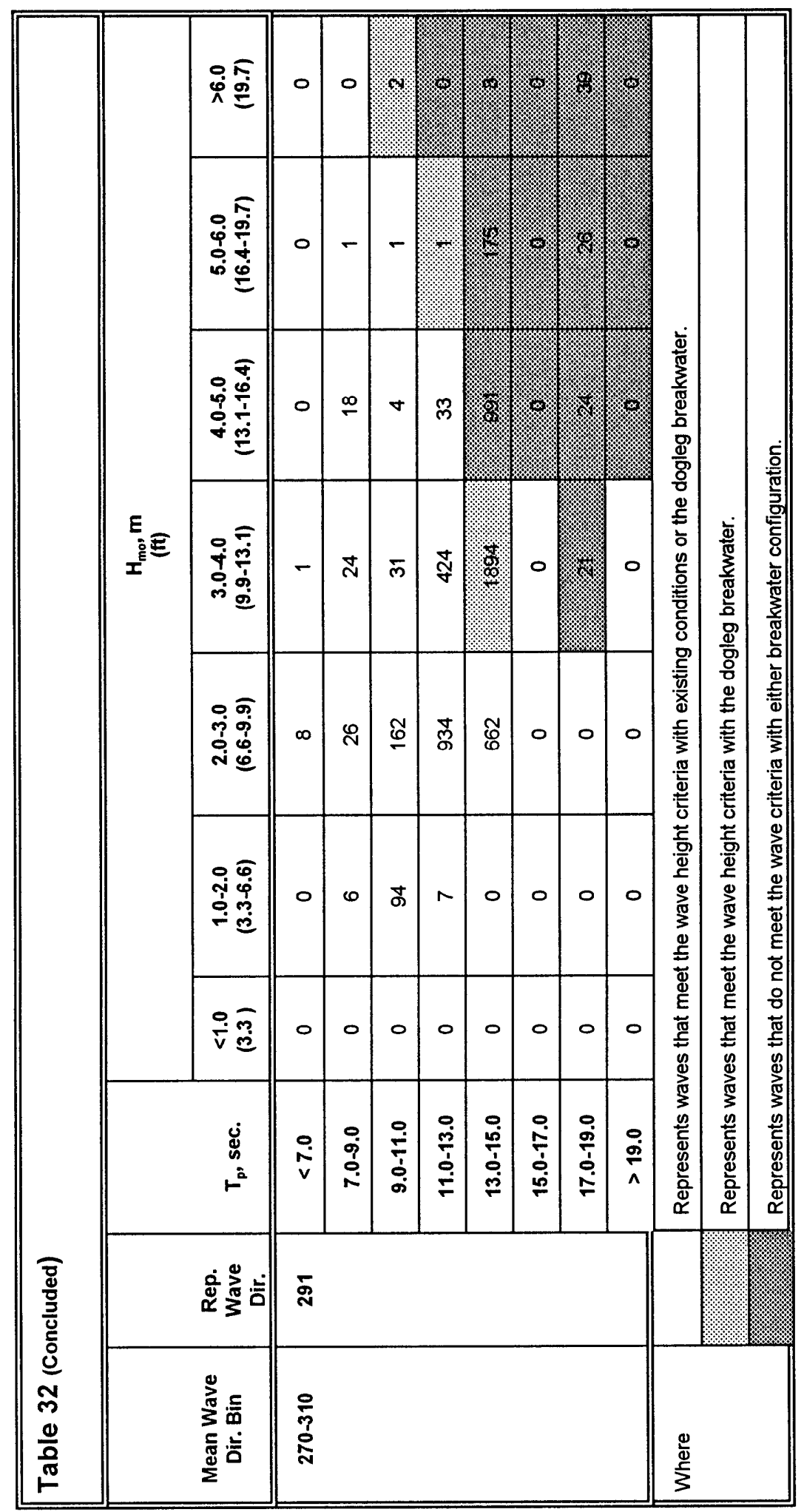




\section{Three-Dimensional Stability Study ${ }^{1}$}

Armor units placed on the ends of breakwaters often are vulnerable to waves which overtop and diffract around the structure because the units are subjected to forces from the opposing direction of a two-dimensional situation. Heavier units often are required for breakwater stability on the head of the structure. To determine stability of the entire Kaumalapau breakwater, three-dimensional experiments were conducted.

\section{The Model}

\section{Design of model}

Three-dimensional stability experiments were conducted at a geometrically undistorted linear scale of 1:49, model to prototype, on the proposed breakwater at Kaumalapau Harbor, Hawaii. Experiments were performed on the same model used for the physical harbor model experiments. Scale was based on size availability of model armor units, the capabilities of the available wave generator to produce required wave heights at the modeled water depth, and necessary size to also conduct three-dimensional harbor model experiments.

Because the specific weights of water and armor layer material differed between the model and prototype, the transference equation of Hudson (1975) was used to determine the model scale that most closely represented prototype weights for the core-locs available at WES:

$$
\frac{\left(W_{a}\right)_{m}}{\left(W_{a}\right)_{p}}=\frac{\left(\gamma_{a}\right)_{m}}{\left(\gamma_{a}\right)_{p}}\left(\frac{l_{m}}{l_{p}}\right)^{3}\left[\frac{\left(S_{a}\right)_{p}-1}{\left(S_{a}\right)_{m}-1}\right]^{3}
$$

in which the subscripts $m$ and $p$ refer to model and prototype quantities, respectively, and $l_{m} / l_{p}$ is the linear scale of the model.

${ }^{1}$ Written by Ernest R. Smith. 
A 1:49 scale, $\left(\gamma_{a}\right)_{p}=2,320 \mathrm{~kg} / \mathrm{m}^{3}\left(145 \mathrm{lb} / \mathrm{ft}^{3}\right)$, and model core-loc weights of 150 and $220 \mathrm{~g}$ used in Equation 17 yielded prototype weights of 18.1 and 31.4 tonnes (20 and 34.6 tons), respectively, and were used as primary armor layer $W_{1}$ (Figures 55 and 56). Time relations were scaled according to Froude Model Law (Stevens et. al. 1942), and model-to-prototype relations were derived in terms of $l$ and $t$ shown in Table 15.

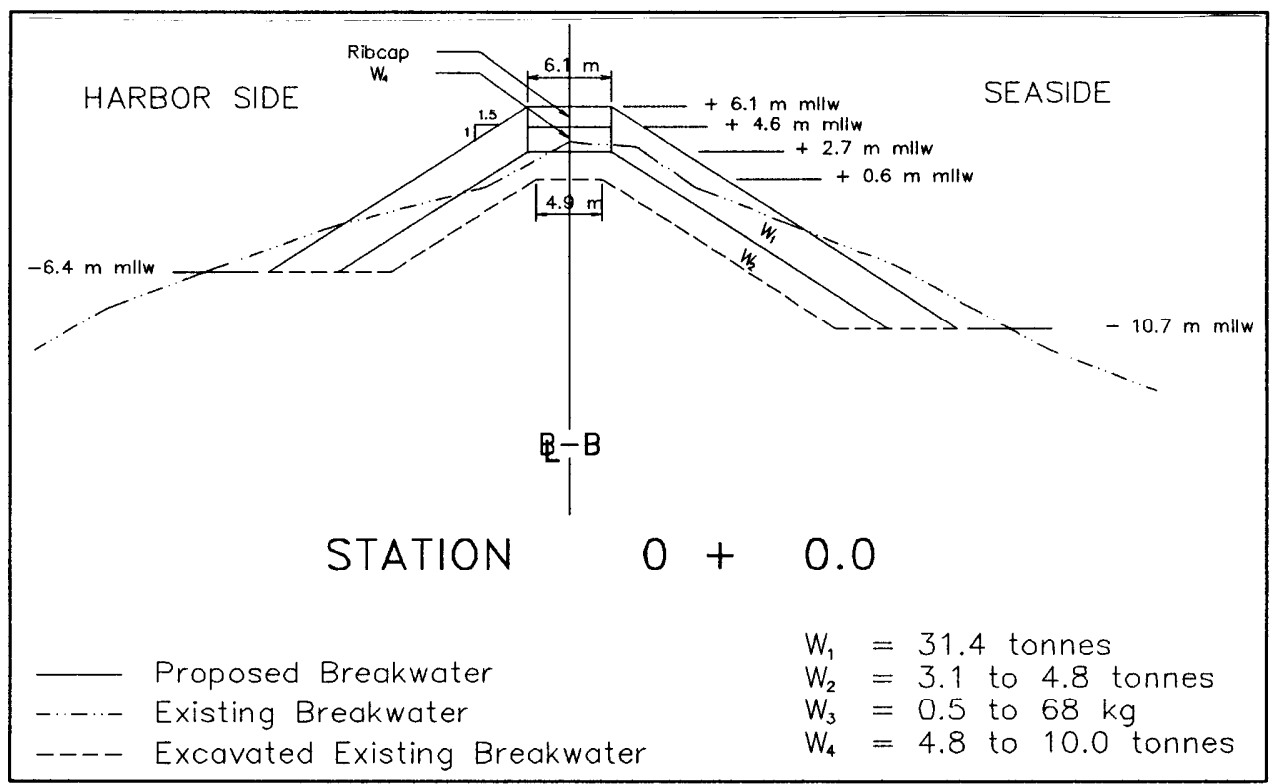

Figure 55. Cross section of Station $0+00$

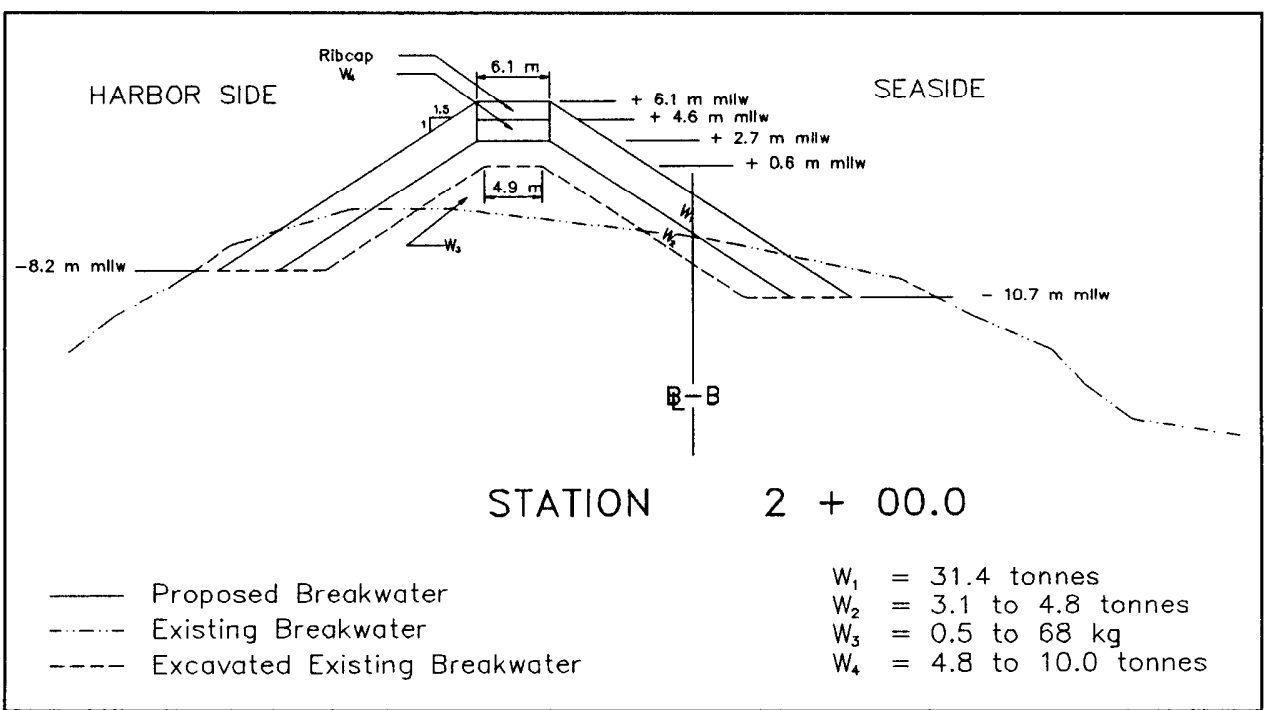

Figure 56. Cross section of Station $2+00$ 
Scale effects of viscous forces associated with flow through the underlayer and core of the proposed breakwater were addressed using the method of Keulegan (1973) to assure that flow through the model structure was turbulent. Stone weights of 18.6 to $29.0 \mathrm{~g}, 0.68$ to $2.3 \mathrm{~g}$, and 29.0 to $60.0 \mathrm{~g}$ with a specific gravity of approximately 2.68 represented prototype sizes of 3.1 to 4.8 tonnes (3.4 to 5.3 tons), 0.5 to $68 \mathrm{~kg}$ ( 1 to $150 \mathrm{lb}$ ), and 4.8 to 10.0 tonnes (5.3 to 11.0 tons) for underlayer stone $W_{2}$, core material $W_{3}$, and armor cap stone, $W_{4}$, respectively. Model underlayer, core material, and armor cap stone remained the same for all three-dimensional stability plans, and are listed in Figures 55 and 56 with corresponding prototype sizes.

\section{Model construction}

The proposed breakwater was constructed on the existing structure at a crest elevation of $+6.1 \mathrm{~m}(+20 \mathrm{ft})$ mllw and a crown width of $6.1 \mathrm{~m}(20 \mathrm{ft})$. The new breakwater consisted of an armor layer, an underlayer, and, where necessary, a core. Typical cross sections of the breakwater are shown in Figures 55 and 56 at Stations $0+00$ and $2+00$, respectively. It was necessary in certain locations to excavate material from the existing breakwater to place the armor layer and underlayer. This excavated material was used as a base near the end of the proposed structure. Core material was added only in locations where it was required to raise the elevation of the existing breakwater to the bottom elevation of the underlayer.

Construction of the model breakwater simulated prototype construction as closely as possible. The core and underlayer material were dumped by shovel, smoothed to grade, and compacted with hand trowels to simulate consolidation that would have occurred due to wave action.

The armor layer was comprised of either 18.1-tonne or 31.4-tonne (20- or 34.6-ton) core-locs placed on a $1 \mathrm{~V}$ to $1.5 \mathrm{H}$ slope. Core-locs extended to $-10.7 \mathrm{~m}$ $(-35 \mathrm{ft}) \mathrm{mllw}$ on the sea side of the structure, and extended into the existing breakwater profile on the harbor side one armor unit height. Core-loc armor units were placed in a single armor layer using a selective random placement described by Melby and Turk (1995). The first row of core-locs were aligned with vertical flukes abutting the adjacent units (Figure 57). The second-row units were placed in a manner that the flukes overlapped the waist portion of the first-row units (Figure 57). Units above these were placed in a random fashion with the exception that no unit was placed on the slope with vertical flukes directly above a unit also placed with vertical flukes (Figure 58). Basic two-dimensional research experiments with core-locs have shown that two units placed atop each other (both with flukes oriented vertically) do not interlock well and can create a weakness in the armor layer.

The number of core-loc units placed on the breakwater, or density of units, was based on the equation:

$$
\frac{N}{A}=\phi V^{-\frac{2}{3}}
$$




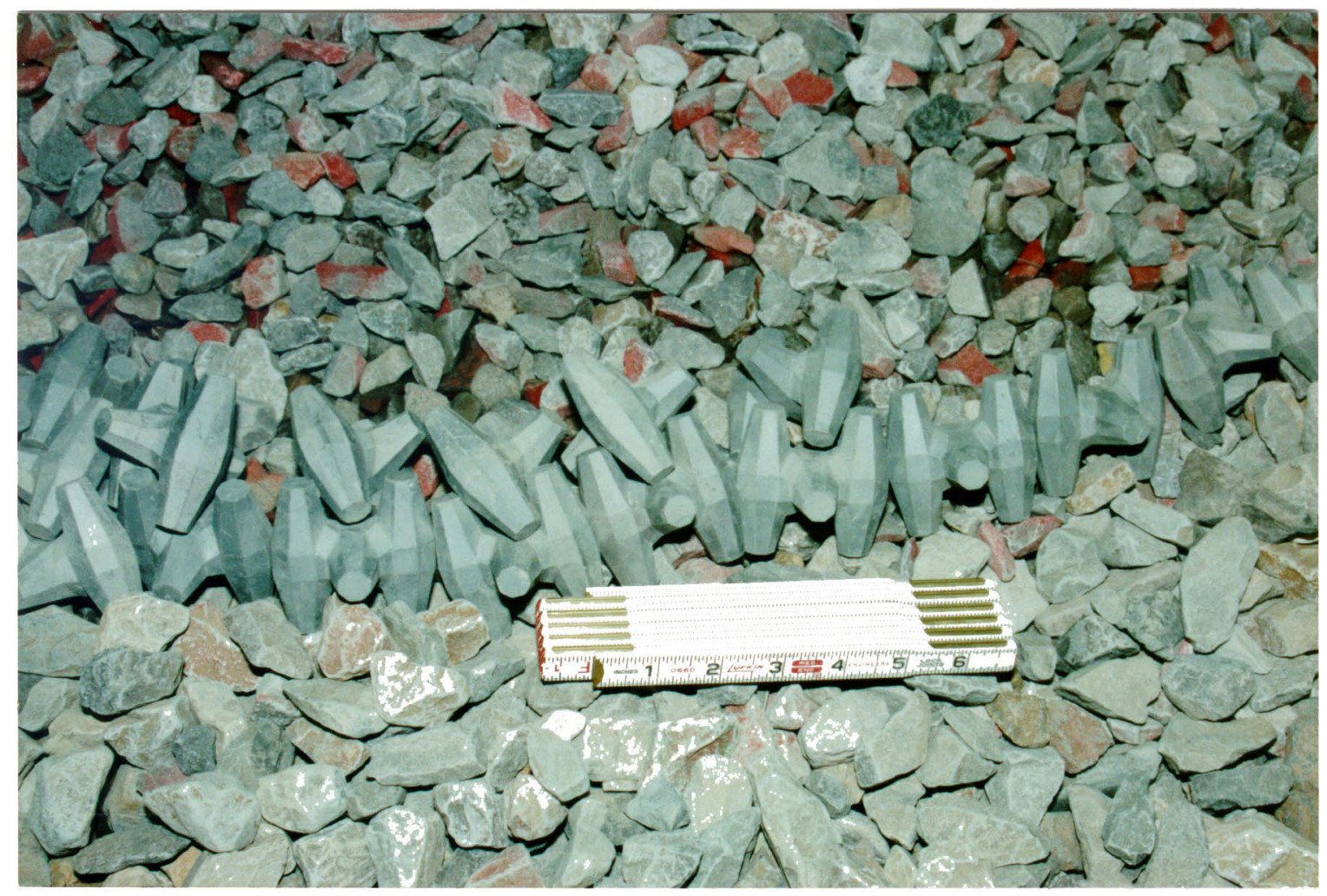

Figure 57. Placement of toe core-locs

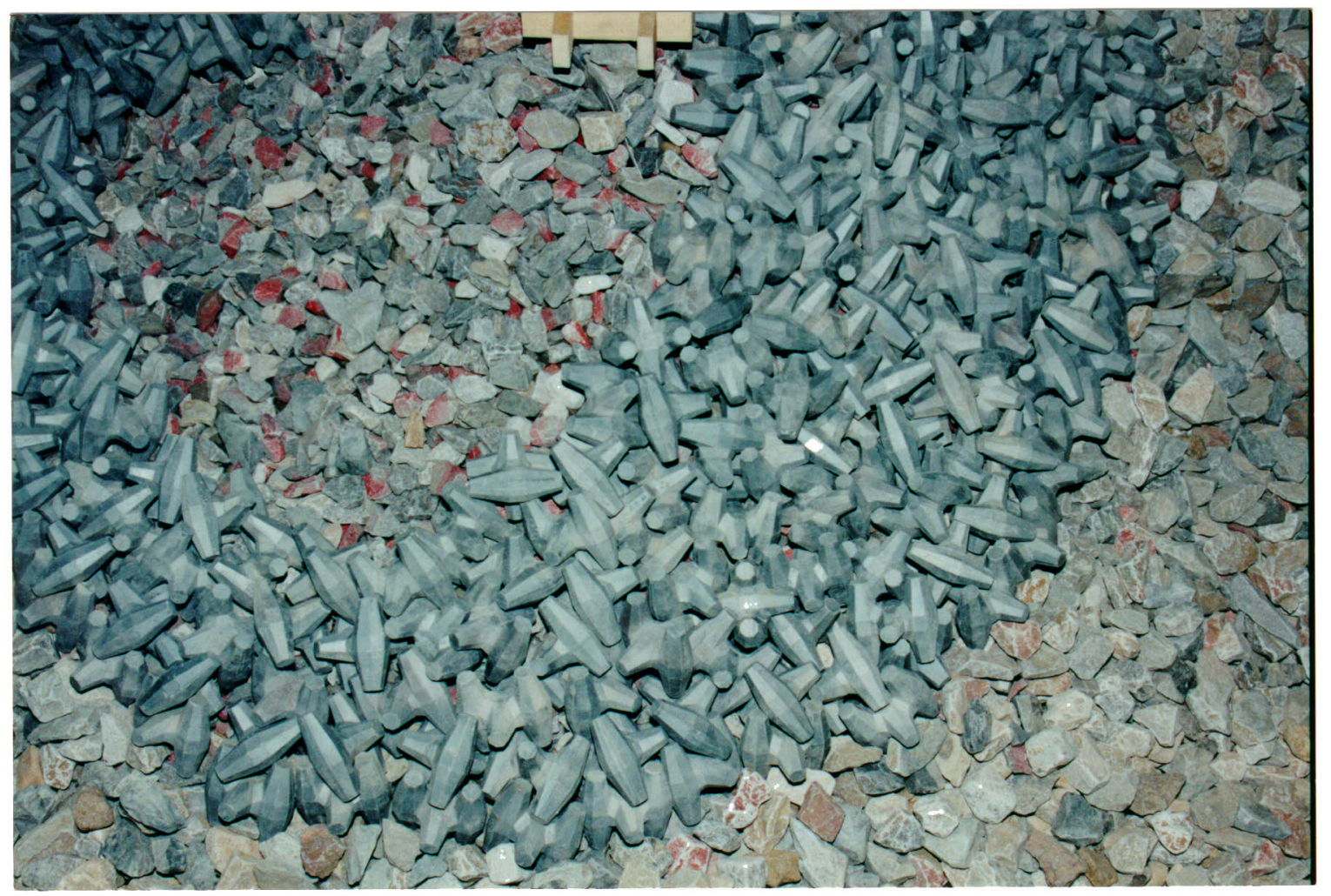

Figure 58. Placement of core-locs 
where $N$ is the number of units in a given area $A, V$ is the armor unit volume, and $\phi$ is the packing density coefficient, which is dependent upon armor layer thickness and armor layer porosity. Armor layer thickness is equal to about 0.92 of the respective core-loc leg length and the average armor layer porosity is about 60 percent.

The core-loc is a relatively new armor unit and studies are ongoing to determine placement density of the units. Results of basic research experiments indicated that the packing density coefficient for core-locs ranges from $0.58<\phi<0.63$. The lower value, $\phi=0.58$, (Plans 4-4E) was used for initial buildings of the model Kaumalapau breakwater.

A rib cap was placed at the crown of the structure to an elevation of $+6.1 \mathrm{~m}$ $(+20 \mathrm{ft})$ mllw. It was assumed that the rib cap would be stable in the prototype; therefore, it was not necessary that the cap be dynamically similar to the prototype. The model rib cap, constructed of wood, was geometrically similar to the prototype and was anchored in the model, thus ensuring proper transmission, reflection, and dissipation of wave energy and the assumed stability of the structure. Individual ribs were $0.9-\mathrm{m}(3-\mathrm{ft})$ wide, $1.5-\mathrm{m}(5-\mathrm{ft})$ high, $6.1-\mathrm{m}(20-\mathrm{ft})$ long, and spaced $1.8 \mathrm{~m}$ $(6 \mathrm{ft})$ on centers. The ribs were oriented at a $90-\mathrm{deg}$ angle to the longitudinal axis of the breakwater. The rib cap included $0.6-\mathrm{m}-(2-\mathrm{ft}-)$ wide runners placed $1.5 \mathrm{~m} \mathrm{(5 \textrm {ft } )}$ on center from the rib ends (Figure 59). POD desired to use a rounded rib cap end at the breakwater head; however, previous experiments with rib caps indicated that a rounded head in the model did not allow for interlocking between the cap and armor units (Bottin, Markle, and Mize 1987). Bottin, Markle, and Mize found that interlocking between units in the model could be achieved using a square-end rib cap. Therefore, a square-end rib cap was used in the present study, but a rounded rib cap can be constructed in the prototype with no effect on stability anticipated.

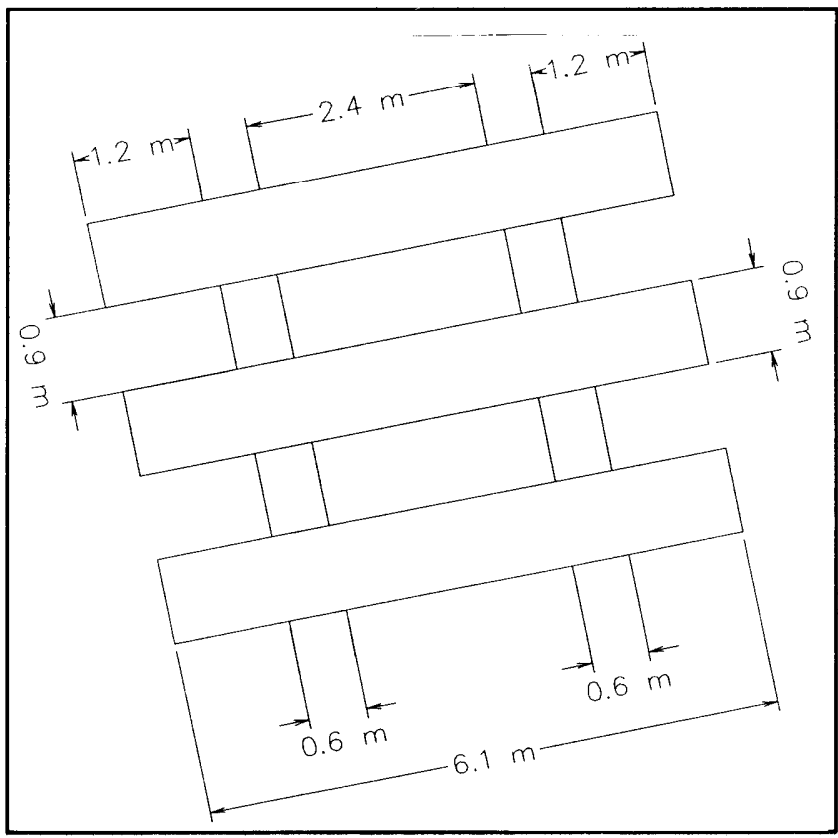

Figure 59. Dimensions of rib cap 


\section{Study facilities and equipment}

The basin used for physical model harbor response experiments also was used to conduct the stability study. Stability experiments were performed from two wave directions; 221 and 251 deg referenced to north which were selected based on the direction of the highest waves approaching the harbor. The head of the proposed breakwater is exposed to waves approaching from the 221-deg wave direction, and would be most vulnerable to wave attack from this direction. Therefore, experiments to optimize the breakwater were initiated from the 221-deg direction. After a stable plan was developed, the wave generators were moved to the 251-deg wave direction and stability was verified for the optimal plan.

Wave conditions studied from the 221- and 251-deg directions are given in Table 33, which lists the wave periods used during the stability study, zero-moment deepwater wave height $H_{o}$, zero-moment wave height at the wave generator depth of $29 \mathrm{~m}(95 \mathrm{ft}) \mathrm{mllw} H^{\prime}$, average zero-moment wave height at the structure $H_{d}$, and duration of each wave series in model seconds. The design wave was specified in a reconnaissance report as a $9.8-\mathrm{sec}, 8.5-\mathrm{m}(28-\mathrm{ft})$ deepwater wave (USAED, Honolulu 1993). To determine a factor of safety for the structure, waves exceeding the design height were generated for 9.8- and 12-sec periods. Wave heights associated with 16-sec periods from the 221- and 251-deg directions are low in

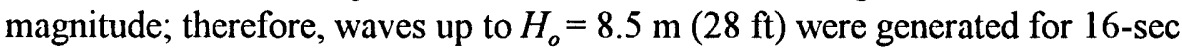
waves. The total duration of the conditions shown in Table 33 represents a prototype storm of approximately $24 \mathrm{hr}$. All wave conditions were conducted at a storm surge water level of $+1.5 \mathrm{~m}(+5.0 \mathrm{ft})$ mllw. Because the breakwater location is in relatively deep water, a breaking wave condition was not reached during calibration without the structure in place. However, because of the interaction of reflected and incident waves, breaking waves were observed during stability experiments with the structure in place.

\section{Study procedures}

Photographs were taken of the harbor side, head, and sea side before the experiment was initiated without water in the basin. Following before-experiment photographs, the basin was flooded to $+1.5 \mathrm{~m}$ mllw and the structure was exposed to $9.8-\mathrm{sec}, 3.0-\mathrm{m}(10-\mathrm{ft})$ waves. The low-level series allowed settling and nesting of the newly constructed section which would occur under typical daily wave conditions prior to being exposed to a design level storm. The remainder of the storm conditions for the particular direction were generated upon completion of the low-level waves. Response of the structure was recorded during and after each wave condition. A detailed inspection of the structure was performed between wave series, and effects of the waves on individual units, toe stability, and the general condition of the breakwater were recorded. The basin was drained upon completion of the entire storm series or after the structure had been severely damaged, and after test photographs were taken of the harbor side, head, and sea side. The same procedure was followed if the plan was subjected to additional storm conditions. Before and after photographs are located in Appendix B. 


\begin{tabular}{|c|c|c|c|c|c|}
\hline \multicolumn{6}{|c|}{$\begin{array}{l}\text { Table } 33 \\
\text { Kaumalapau Stability Study Conditions }\end{array}$} \\
\hline $\begin{array}{c}T_{p} \\
\text { sec }\end{array}$ & $\begin{array}{c}H_{0} \\
\text { m (ft) }\end{array}$ & $\begin{array}{c}\mathbf{H}^{\prime} \\
\mathbf{m}(\mathbf{f})\end{array}$ & $\begin{array}{c}H_{d}(221 \text { deg) } \\
m \text { (ft) }\end{array}$ & $\begin{array}{c}H_{d}(251 \text { deg) } \\
m \text { (ft) }\end{array}$ & $\begin{array}{c}\text { Duration } \\
\text { sec } \\
\text { (model) }\end{array}$ \\
\hline 9.8 & $3.6(11.8)$ & $3.0(10.0)$ & $3.2(10.5)$ & $3.0(10.0)$ & 880 \\
\hline 9.8 & $5.5(18.0)$ & $4.615 .0)$ & $4.8(15.7)$ & $4.4(14.4)$ & 880 \\
\hline 9.8 & $7.3(24.0)$ & $6.1(20.0)$ & $6.4(21.0)$ & $5.9(19.4)$ & 880 \\
\hline 9.8 & $8.5^{\dagger}(28.0)$ & $7.2(23.6)$ & $7.5^{\circ}(24.7)$ & $6.9^{\circ}(22.6)$ & 880 \\
\hline 9.8 & $9.1(30.0)$ & $7.6(25.0)$ & $8.3(27.3)$ & $7.3(24.0)$ & 880 \\
\hline 9.8 & $9.9(32.5)$ & $8.3(27.2)$ & $8.7(28.5)$ & $8.0(26.2)$ & 880 \\
\hline 12.0 & $5.5(18.0)$ & $4.6(15.0)$ & $4.3(14.1)$ & $4.3(14.1)$ & 880 \\
\hline 12.0 & $7.3(24.0)$ & $6.1(20.0)$ & $5.8(19.0)$ & $5.7(18.7)$ & 880 \\
\hline 12.0 & $8.5(28.0)$ & $7.2(23.6)$ & $6.8(22.3)$ & $6.7(22.0)$ & 880 \\
\hline 12.0 & $9.1(30.0)$ & $7.6(25.0)$ & $7.3(24.7)$ & $7.2(23.6)$ & 880 \\
\hline 12.0 & $10.8(35.4)$ & $9.1(30.0)$ & $8.6(28.2)$ & $8.5(28.0)$ & 880 \\
\hline 16.0 & $4.9(16.0)$ & $4.6(15.0)$ & $3.9(12.8)$ & $4.5(14.8)$ & 880 \\
\hline 16.0 & $6.6(21.7)$ & $6.1(20.0)$ & $5.2(17.1)$ & $6.0(19.7)$ & 880 \\
\hline 16.0 & $8.5(28.0)$ & $7.9(26.0)$ & $6.7(22.0)$ & $7.7(25.3)$ & 880 \\
\hline \multicolumn{6}{|c|}{$\begin{array}{l}\text { Note: } \\
H_{0} \text { - deepwater zero-moment wave height } \\
H^{\prime} \text { - zero-moment wave height at wave generator depth (95 ft prototype) } \\
H_{d} \text { - average zero-moment wave height at structure }\end{array}$} \\
\hline
\end{tabular}

Visual inspections were made during and after wave action on the structure. Qualitative results were taken for overtopping, and the wave height and category of overtopping (minor, moderate, or major) were noted for each wave condition.

\section{Results}

Results from the harbor model experiments indicated that the dogleg breakwater configuration, Plan 4, was the more desirable plan; therefore, all stability experiments were conducted with the dogleg configuration.

Nine different stability plans were studied which differed by armor unit weight, armor placement density, and toe protection schemes. The following paragraphs summarize each plan studied. Unless otherwise specified, wave heights are referred to as wave height at the structure $H_{d}$. 


\section{Plan 4}

Plan 4 armor consisted of all 18.1-tonne (20-ton) core-locs (Photos B1 through B3). Experiments were initiated with a low-level $(9.8-\mathrm{sec}, 3.2-\mathrm{m}(10.5-\mathrm{ft}))$ wave spectra from the 221-deg direction for a model duration of $880 \mathrm{sec}$ to allow settling and consolidation of the armor and underlayer materials. Following the low-level waves, heights $\left(H_{d}\right)$ of $4.8,6.4,7.5$, and $8.3 \mathrm{~m}(15.8,21.0,24.7$, and $27.3 \mathrm{ft}$, respectively) were generated at $9.8 \mathrm{sec}$. The breakwater was stable for $4.8-\mathrm{m}$ (15.8-ft) waves, but six units were displaced off the sea side of the structure at the shore interface during $6.4-\mathrm{m}(21.0-\mathrm{ft})$ waves. The structure continued to unravel in this area for the design height of $7.5 \mathrm{~m}(24.7 \mathrm{ft})$ (20 additional units displaced), and for the subsequent series of 8.3-m (27.2-ft) waves (28 total units displaced, Photo B4). However, the remainder of the breakwater was stable with no units displaced for the conditions studied (Photos B5 and B6). The damaged area is located in shallow water on a reef. The alignment of the breakwater with the underwater bathymetry of the reef causes wave energy to converge at the base of the structure, and incident waves from deeper water break in this region.

\section{Plan 4A}

The damaged area was repaired and additional 18.1-tonne (20-ton) core-locs were placed on the sea side at the shoreward end of the structure. The 18.1-tonne (20-ton) core-locs were placed farther shoreward to the seawall in an attempt to provide additional support. Experiments with Plan 4A were initiated with 9.8-sec, $4.8-\mathrm{m}(15.8-\mathrm{ft})$ waves. Six units were displaced on the sea side at the shoreward end, and subsequent waves of $6.4 \mathrm{~m}(21 \mathrm{ft})$ displaced 20 additional units (Photo B7). The remainder of the structure was stable during Plan 4A experiments.

\section{Plan 4B}

To provide additional armor in the problem area, 18.1-tonne (20-ton) core-locs were placed farther offshore for Plan $4 \mathrm{~B}$ to provide a wider armor area and gentler slope (Photo B8). Experiments of Plan 4B were initiated with 9.8-sec, 4.8-m $(15.8-\mathrm{ft})$ waves, which displaced six units. The wider toe area was not sufficient to stabilize the shoreward end, and was damaged after $9.8-\mathrm{sec}, 6.4-\mathrm{m}(21.0-\mathrm{ft})$ waves (Photo B9). It appeared from Plan 4B experiments that the toe was in a region of high energy, and units above the toe were not displaced directly by wave energy, but by toe failure.

\section{Plan 4C}

To avoid placing the toe units in the region of high energy, a narrower armor section of 18.1-tonne (20-ton) core-locs was constructed at the shoreward end of the sea side for Plan 4C (Photo B10). However, the plan also failed at the toe after 9.8-sec, 6.4-m (21.0-ft) waves were generated (Photo B11). 


\section{Plan 4D}

To protect the toe units on the sea side at the shoreward end, a $15.2-\mathrm{m}-\mathrm{long}$ (50-ft-long) spur of 18.1-tonne (20-ton) core-locs was constructed perpendicular to the breakwater, Plan 4D (Photo B12). The spur was destroyed, and the toe of Plan 4D failed after 9.8-sec, 6.4-m (21.0-ft) waves (Photo B13). Experiments with Plans 1 through ID showed that the area of toe instability on the sea side at the shoreward end was subjected to high wave forces and velocities. The area is located in shallow water, and the breakwater height is low relative to the depth. Toe units of the breakwater in this area do not have sufficient weight to support unraveling of the structure toe.

\section{Plan 4E}

To stabilize the toe in the problem area, a strip of sheet metal was placed in front of the toe units on the reef, Plan $4 \mathrm{E}$, to simulate a toe trench in prototype (Photo B14). The sheet metal toe strip originated at the shoreward end of the structure and extended down the reef for an overall length of $41.1 \mathrm{~m}(135 \mathrm{ft})$, prototype. Plan 4E was subjected to the series of 9.8 -sec waves listed in Table 33. The 18.1-tonne (20-ton) core-locs in the vicinity of the toe trench were stable; however, three units were displaced off the breakwater head during 7.5-m (24.7-ft) waves. The breakwater was subjected to $12-\mathrm{sec}, 4.3-$ and $5.8-\mathrm{m}$ (14.2- and 19.0-ft) waves and 16-sec, 3.9- and 5.2-m (12.8- and 17.0-ft) waves. No additional corelocs were displaced off the structure for 12-sec waves or the 16-sec, 3.9-m (12.8-ft) condition; however, units were observed to move on the head during wave action. The sea side of the structure was damaged during $16-\mathrm{sec}, 5.2-\mathrm{m}(17.0-\mathrm{ft})$ waves.

Plan 4E was rebuilt with 18.1-tonne (20-ton) core-locs (Photos B15 through $\mathrm{B} 17)$, and experiments were conducted for 9.8 -sec waves up to $7.5 \mathrm{~m}(24.7 \mathrm{ft})$. The overall condition of the breakwater was good, but the head was damaged; four corelocs were displaced off the head near the crown and the underlayer and stone beneath the rib cap was exposed (Photos B18 through B20). Experiments of Plan $4 \mathrm{E}$ continued with $12-\mathrm{sec}$ waves up to $6.8 \mathrm{~m}(22.3 \mathrm{ft})$. The head deteriorated further, but no additional displacement of units occurred and the breakwater condition was good (Photos B21 through B23). The plan was subjected to 16-sec waves for all heights shown in Table 10-1. Four additional units were displaced on the sea side of the structure during 5.2-m (17.1-ft) waves, and five additional units were displaced on the sea side during 6.7- $\mathrm{m}(22.0-\mathrm{ft})$ waves (Photos B24 through B26). Plan 4E was then subjected to $9.8-\mathrm{sec}, 8.7-\mathrm{m}(28.7-\mathrm{ft})$ waves, and the head was severely damaged (Photos B27 through B29).

\section{Plan 4F}

The breakwater head was rebuilt using 18.1-tonne (20-ton) core-locs and a denser placement, $\phi=0.63$, and experiments were conducted for all 9.8 -sec waves. Units on the head began to settle during the design wave, but no core-locs were displaced off the structure. One core-loc was displaced during 8.7-m (28.5-ft) waves. The entire structure was rebuilt using the denser placement of units 
(Photos B30 through B32). Stability experiments of Plan 4F were conducted for all periods up to $H_{o}=8.5 \mathrm{~m}(28.0 \mathrm{ft})$. Two units were displaced for 9.8-sec waves at the design wave height, $H_{d}=7.5 \mathrm{~m}(24.7 \mathrm{ft})$ (Photos B33 through B35). No further displacement occurred during 12-sec waves, but units were observed to move on the head (Photos B36 through B38). One additional core-loc was displaced during 16-sec, 3.9-m (12.8-ft) waves, but no displacement occurred for 5.2-m (17.1-ft) waves. Eleven additional core-locs were removed by $16-\mathrm{sec}, 6.7-\mathrm{m}(22.0-\mathrm{ft})$ waves on the sea side of the breakwater near the shoreward end (Photos B39 through B41). Rundown of waves displaced units at the toe, which were not protected by the trench, and caused instability on the slope. Waves were generated for 9.8- and 12.0-sec periods for heights greater than the design height. No additional units were displaced for $9.8-\mathrm{sec}, 8.3-\mathrm{m}$ (27.3-ft) waves, but four units were displaced off the head for $12-\mathrm{sec}, 7.3-\mathrm{m}(23.8-\mathrm{ft})$ waves. The $9.8-\mathrm{sec}, 8.7-\mathrm{m}(28.5-\mathrm{ft})$ wave condition removed six additional units off the head, and the $12-\mathrm{sec}, 8.6-\mathrm{m}(28.3-\mathrm{ft})$ wave severely damaged the harbor side of the structure (Photos B42 through B44).

\section{Plan 4G}

Stability experiments of the breakwater continued from the 221-deg wave direction with Plan $4 \mathrm{G}$ which consisted of 18.1-tonne (20-ton) core-locs placed $(\phi=0.62)$ on the seaside and harbor-side trunks and 31.4-tonne (34.6-ton) units placed $(\phi=0.62)$ on the head of the structure (Figure 60, Photos B45 through B47). Plan $4 \mathrm{G}$ was subjected to the conditions listed in Table 33 for 9.8- and 12.0-sec waves up to $H_{o}=8.5 \mathrm{~m}(28.0 \mathrm{ft})$, and $16.0-\mathrm{sec}$ waves up to $H_{o}=6.6 \mathrm{~m}(21.6 \mathrm{ft})$. Wave hindcast data indicated that waves associated with the 16.0-sec period from the 221-deg direction did not approach deepwater heights of the magnitude of $8.5 \mathrm{~m}(28.0 \mathrm{ft})$; therefore, this condition was excluded from further stability experiments from the 221-deg direction. The structure was not damaged for the conditions described above (Photos B48 through B50). Waves were generated for heights greater than $H_{o}=8.5 \mathrm{~m}$ $(28 \mathrm{ft}$ ). Two 31.4-tonne (34.6-ton) core-locs

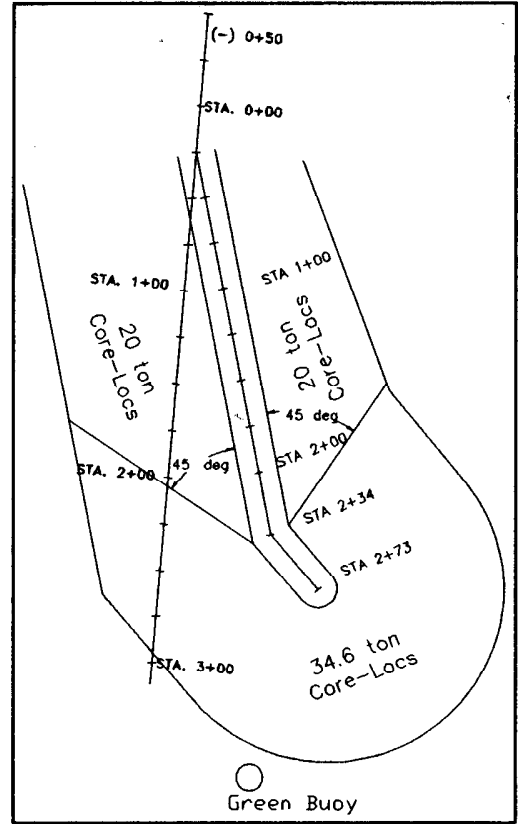

Figure 60. Plan 4G were displaced off the head for $9.8-\mathrm{sec}, 8.7-\mathrm{m}$ (28.5- $\mathrm{ft}$ ) waves (Photos B51 and B52). The harbor side of the breakwater was severely damaged for 12-sec, 8.6-m (28.2-ft) waves (Photos B51 and B52), but the sea side of the structure remained stable for all waves (Photo B53).

\section{Plan 4H}

To determine if the harbor side could be stabilized, 31.4-tonne (34.6-ton) corelocs were placed $(\phi=0.62)$ on both the head and the trunk of the harbor side (Figure 61, Photos B54 and B55). Due to the lack of an adequate number of 
31.4-tonne (34.6-ton) model core-locs, the breakwater sea side was constructed $(\phi=$ $0.62)$ using 18.1-tonne (20-ton) core-locs (Photo B56). The structure was subjected to all 221-deg wave conditions listed in Table 33 with the exception of 16.0 -sec, 6.7-m (22.0-ft) waves. Three 31.4-tonne (34.6-ton) core-locs were displaced off the harbor side during 12-sec, 8.6-m (28.2-ft) waves, but the breakwater was in stable condition (Photos B57 through B59).

The wave generator was moved to the 251-deg wave direction. Plan $4 \mathrm{H}$ was rebuilt using $\phi=0.62$ (Photos B60 through B62) and subjected to 9.8 - and 12.0-sec waves up to the design wave height listed in Table 33 , $H_{d}=6.9$ and $6.7 \mathrm{~m}(22.6$ and $22.0 \mathrm{ft})$ respectively, and 16.0 -sec waves up to $H_{d}=$ $6.0 \mathrm{~m}(19.7 \mathrm{ft})$. One 18.1-tonne (20-ton) core-loc was displaced on the sea side near the toe trench during 9.8-sec, $6.9-\mathrm{m}(22.6-\mathrm{ft})$

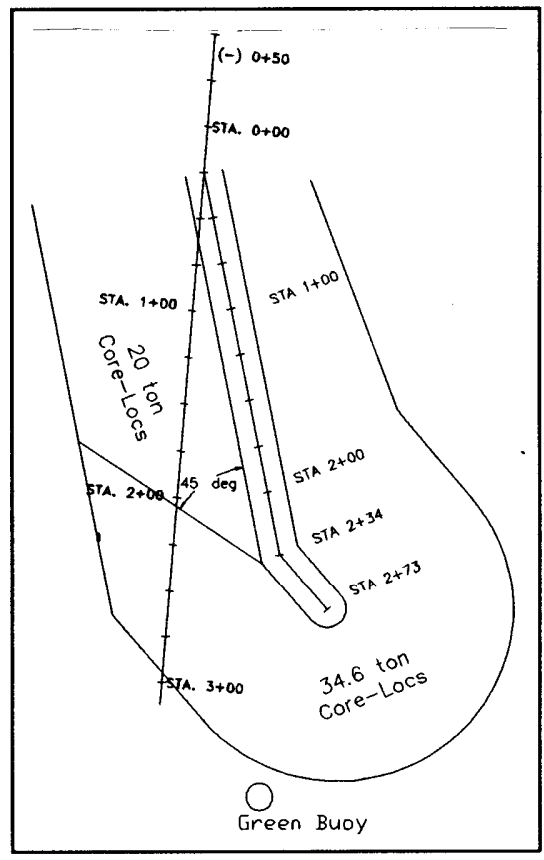

Figure 61. Plan 4H waves, but the breakwater was stable (Photos B63 through B65). Experiments continued with 9.8 -sec waves up to $8.0 \mathrm{~m}(26.2 \mathrm{ft})$ and 12 -sec waves up to $8.5 \mathrm{~m}$ $(28.0 \mathrm{ft}$ ) (Table 33). The structure was stable for the conditions studied; however, five 18.1-tonne (20-ton) units were displaced on the sea side and one 31.4-tonne (34.6-ton) core-loc was displaced on the harbor side (Photos B66 through B68). The breakwater was subjected to the $16.0-\mathrm{sec}, 7.7-\mathrm{m}(25.3-\mathrm{ft})$ wave (Table 33) without rebuilding, and no further damage occurred (Photos B69 through B71).

Plan $4 \mathrm{H}$ was rebuilt $(\phi=0.62)$ and stability experiments were conducted for 9.8and $12.0-\mathrm{sec}$ waves up to $H_{o}=8.5 \mathrm{~m}(28.0 \mathrm{ft})$, and $16.0-\mathrm{sec}$ waves up to $H_{o}=6.6 \mathrm{~m}$ $(21.7 \mathrm{ft}$ ), and no damage was observed (Photos B72 through B74). The structure remained stable when subjected to waves exceeding the design height for 9.8-sec and 12.0-sec waves (Table 33), and the 16.0-sec wave at the design height (Photos B75 through B77).

\section{Summary}

Nine stability plans were studied for the proposed dogleg breakwater. It was determined that:

a. A toe trench at the shoreward end on the sea side of the breakwater was necessary to obtain stability. The trench had an overall length of approximately $41.1 \mathrm{~m}(135 \mathrm{ft})$, prototype. 
$b$. Densely placed ( $\phi=0.63)$ 18.1-tonne (20-ton) core-locs were stable for the design wave conditions, but failed for wave heights exceeding the design conditions.

c. A heavier core-loc, 31.4 tonnes (34.6-tons), placed on the head and harbor side at $\phi=0.62$ was found to be stable for wave heights exceeding the design condition from the 221- and 251-deg wave directions.

Although experiments were not conducted with 31.4-tonne (34.6-ton) units on the sea side of the breakwater because of the limited number of model units, 31.4-tonne (34.6-ton) core-locs placed on the sea side are expected to be stable for the conditions studied. It may be desirable to place one size unit on the entire structure to reduce costs of constructing an additional armor unit mold. Also, less 31.4-tonne (34.6-ton) units would be required to cover an area than 18.1-tonne (20-ton) units. 


\section{Conclusions and Recommendations ${ }^{1}$}

\section{Harbor Response to Wind Waves, Swell, and Long Waves}

Field data were collected to validate physical and numerical models and assess hindcast data. A numerical model study was used to assist in optimizing the placement of field wave gauges, maximize efficiency of physical model experiments by identifying the most promising modification plans and most damaging incident wave directions, and to evaluate harbor oscillation characteristics of the proposed plan. An undistorted, three-dimensional physical model of Kaumalapau Harbor was used to evaluate harbor response to short period waves for existing conditions and two alternative harbor layout configurations, straight and dogleg breakwater plans, respectively, for three incident wave directions as well as optimize the stability of the proposed breakwater design.

\section{Conclusions}

a. For existing conditions, the area just west of the west end of the wharf is significantly sheltered. Wave heights in this area can be expected to be less than half the incident height for most incident conditions.

b. The western end of the wharf is also relatively sheltered if compared to the middle and eastern part of the wharf for most wave periods for existing conditions.

c. The longest wave (swell) periods, especially those from the northwesterly incident directions, are amplified at the middle and western part of the wharf but not at the eastern part for existing conditions. This result is interesting in light of local reports that high northerly swell can cause problems in Kaumalapau Harbor.

\footnotetext{
${ }^{1}$ Written by Edward F. Thompson, Lori L. Hadley, Gordon S. Harkins, and Ernest R. Smith.
} 
d. For existing conditions, harbor response varies considerably with incident wave direction.

e. A 45.7-m (150-ft) straight extension to the existing breakwater will reduce short-period wind wave heights at the wharf to about 60 to 80 percent of those in the existing harbor.

$f$. The 45.7-m (150-ft) dogleg breakwater extension is slightly more effective than the straight breakwater for reducing short-period wave action at the pier and for this reason is the recommended plan.

g. Neither the straight nor the dogleg extension met short-period wave reduction criteria established by POD. Further wave reduction could be accomplished but the breakwater would not meet the navigational criteria and economic constraints.

$h$. Although the dogleg plan is prone to stronger oscillations than the existing harbor, the differences will have little operational significance. Wind waves and swell can be expected to continue as a primary operational concern which will probably outweigh any practical problems due to increased long-period oscillations.

$i$. Wave absorbers along the northeast or south shores of the embayment have minimal impact on wave heights at the pier.

Nine stability plans were studied using the dogleg breakwater configuration. Based on model experiments, it was determined that:

a. A toe trench at the shoreward end on the sea side of the breakwater was necessary to obtain armor stability. The trench had an overall length of approximately $41.1 \mathrm{~m}(135 \mathrm{ft})$, prototype.

$b$. Densely placed ( $\phi=0.63)$ 18.1-tonne (20-ton) core-locs were stable for design wave conditions, but failed for wave heights exceeding the design conditions.

c. A heavier core-loc, 31.4 tonnes ( 34.6 tons), placed on the head and harbor side $(\phi=0.62)$, was found to be stable for wave heights exceeding the design condition from the 221- and 251-deg wave directions.

d. It may be desirable to place one size unit on the entire structure to reduce costs of constructing an additional armor unit form. Additionally, less armor units would be required for placement if the breakwater rehabilitation was constructed entirely of the larger unit. Therefore it is recommended that, if the breakwater is constructed using one unit, 31.4-tonne (34.6-ton) core-locs be placed using $\phi=0.62$. 


\section{References}

Berkhoff, J. C. W. (1972). "Computation of combined refraction-diffraction." Proceedings of the 13th International Conference on Coastal Engineering. American Society of Civil Engineers, Vol 1, 471-490.

Bottin, R. R., Jr., Markle, D. G., and Mize, M. G. (1987). "Design for navigation improvements, and breakwater stability for proposed boat-launching facility; Laupahoehoe Point, Hawaii; Coastal Model Investigation," Technical Report CERC-87-3, U.S. Army Engineer Waterways Experiment Station, Vicksburg, MS.

Bottin, R. R., Jr., Sargent, F. E., and Mize, M. G. (1985). "Fisherman's Wharf Area, San Francisco Bay, California, design for wave protection: Physical and numerical model investigation," Technical Report CERC-86-7, U.S. Army Engineer Waterways Experiment Station, Vicksburg, MS.

Briggs, M. J., Lillycrop, L. S., and McGehee, D. D. (1992). "Comparison of model and field results for Barbers Point Harbor." Proceedings, Coastal Engineering Practice. American Society of Civil Engineers, 387-99.

Briggs, M. J., Lillycrop, L. S., Harkins, G. R., Thompson, E. F., and Green, D. R. (1994). "Physical and numerical model studies of Barbers Point Harbor, Oahu, Hawaii," Technical Report CERC-94-14, U.S. Army Engineer Waterways Experiment Station, Vicksburg, MS.

Chen, H. S. (1986). "Effects of bottom friction and boundary absorption on water wave scattering," Applied Ocean Research, 8 (2), 99-104.

Chen, H. S., and Houston, J. R. (1987). "Calculation of water oscillation in coastal harbors: HARBS and HARBD user's manual," Instruction Report CERC-87-2, U.S. Army Engineer Waterways Experiment Station, Vicksburg, MS.

Chen, H. S., and Mei, C. C. (1974). "Oscillations and wave forces in an offshore harbor," Report No. 190, Department of Civil Engineering, Massachusetts Institute of Technology, Cambridge, MA. 
Clausner, J. E., and Abel, C. E. (1986). "Contained aquatic disposal: Site location and cap material investigations for outer Indiana Harbor, IN and southern Lake Michigan," Appendix J., Vol 11, of "Disposal alternatives for PCB-contaminated sediments from Indiana Harbor," Miscellaneous Paper EL-87-9, U.S. Army Engineer Waterways Experiment Station, Vicksburg, MS.

Corson, W. D., Abel, C. E., Brooks, R. M., and Farrar, P. D. (1986). "Pacific Coast hindcast deepwater wave information," WIS Report 14, U.S. Army Engineer Waterways Experiment Station, Vicksburg, MS.

Crawford, P. L., and Chen, H. S. (1988). "Comparison of numerical and physical models of wave response in a harbor," Miscellaneous Paper CERC-88-11, U.S. Army Engineer Waterways Experiment Station, Vicksburg, MS.

Ebersole, B. A., Cialone, M. A., and Prater, M. D. (1986). "Regional coastal processes numerical modeling system: Report 1: RCPWAVE--A linear wave propagation model for engineering use," Technical Report CERC-86-4, U.S. Army Engineer Waterways Experiment Station, Vicksburg, MS.

Farrar, P. D., and Chen, H. S. (1987). "Wave response of the proposed harbor at Agat, Guam: Numerical Model Investigation," Technical Report CERC-87-4, U.S. Army Engineer Waterways Experiment Station, Vicksburg, MS.

Farrar, P. D., and Houston, J. R. (1982). "Tsunami response of Barbers Point Harbor, Hawaii," Miscellaneous Paper HL-82-1, U.S. Army Engineer Waterways Experiment Station, Vicksburg, MS.

Goda, Y. (1985). Random seas and design of maritime structures. University of Tokyo Press, Tokyo, Japan.

Hasselmann, K., Barnett, T. P., Bouws, E., Carlson, H., Cartwright, D. E., Enke, K., Ewing, J. A., Gienapp, H., Hasselmann, D. E., Kruseman, D., Meerburg, A., Muller, D., Olberg, D. J., Richter, K., Sell, W., and Walden, H. (1973).

"Measurements of wind wave growth and swell decay during the Joint North Sea Wave Project (JONSWAP)," Deutsches Hydrographisches Institut, Hamburg, Germany.

Houston, J. R. (1976). "Long Beach Harbor numerical analysis of harbor oscillation; Report 1, Existing conditions and proposed improvements," Miscellaneous Paper H-76-20, U.S. Army Engineer Waterways Experiment Station, Vicksburg, MS.

(1978) "Interaction of tsunamis with the Hawaiian Islands calculated by a finite-element numerical model," Journal of Physical Oceanography $8(1), 93-101$. 
Houston, J. R. (1981). "Combined refraction and diffraction of short waves using the finite element method," Applied Ocean Research 3 (4), 163-170.

Houston, J. R., and Garcia, A. W. (1978). "Type 16 flood insurance study: Tsunami predictions for the west coast of the continental United States," Technical Report H-78-26, U.S. Army Engineer Waterways Experiment Station, Vicksburg, MS.

Hudson, R. Y. (1975). "Reliability of rubble-mound breakwater stability models," Miscellaneous Paper H-75-5, U.S. Army Engineer Waterways Experiment Station, Vicksburg, MS.

Kaihatu, J. M., Lillycrop, L. S., and Thompson, E. F. (1989). "Effects of entrance channel dredging at Morro Bay, California," Miscellaneous Paper CERC-89-3, U.S. Army Engineer Waterways Experiment Station, Vicksburg, MS.

Keulegan, G. H. (1973). "Wave transmission through rock structures; Hydraulic model investigation," Research Report H-73-1, U.S. Army Engineer Waterways Experiment Station, Vicksburg, MS.

Leenknecht, D. A., Szuwalski, A., and Sherlock, A. R. (1992). "Automated coastal engineering system," U.S. Army Engineer Waterways Experiment Station, Vicksburg, MS.

Lillycrop, L. S., and Boc, S. J. (1992). "Numerical modeling of proposed Kawaihae Harbor, HI." Proceedings, Coastal Engineering Practice. American Society of Civil Engineers, 412-24.

Lillycrop, L. S., and Thompson, E. F. (1995). "Harbor wave oscillation model (HARBD) theory and program documentation," Chapter 9 in Instruction Report CERC-91-1, "Coastal Modeling System (CMS) User's Manual," by Cialone, M. A., U.S. Army Engineer Waterways Experiment Station, Vicksburg, MS.

Lillycrop, L. S., Bratos, S. M., and Thompson, E. F. (1990). "Wave response of proposed improvements to the shallow-draft harbor at Kawaihae, Hawaii," Miscellaneous Paper CERC-90-8, U.S. Army Engineer Waterways Experiment Station, Vicksburg, MS.

Lillycrop, L. S., Bratos, S. M., Thompson, E. F., and Rivers, P. (1993). "Wave response of proposed improvements to the small boat harbor at Maalaea, Maui, Hawaii," Miscellaneous Paper CERC-93-4, U.S. Army Engineer Waterways Experiment Station, Vicksburg, MS.

Melby, J. A., and Turk, G. F. (1995). "CORE-LOC: Optimized concrete armor units," Bulletin No. 87, Permanent International Association of Navigational Congresses, 5-21. 
Mesa, C. (1992). "A dual approach to low frequency energy definition in a small craft harbor." Proceedings, Coastal Engineering Practice. American Society of Civil Engineers, 400-11.

Sargent, F. E. (1989). "Los Angeles -Long Beach Harbor Complex 2020 Plan harbor resonance analysis: Numerical model investigation," Technical Report CERC-89-16, U.S. Army Engineer Waterways Experiment Station, Vicksburg, MS.

Shore protection manual. (1984). 4th ed., 2 Vol., U.S. Army Engineer Waterways Experiment Station, U.S. Government Printing Office, Washington, D.C.

Stevens, J. C., Bardsley, C. E., Lane, E. W., and Straub, L. G. (1942). "Hydraulic models." Manuals on Engineering Practice No. 25. American Society of Civil Engineers, New York.

Thompson, E. F., and Hadley, L. L. (1994a). "Wave response of Port Allen Harbor, Kauai, Hawaii" Miscellaneous Paper CERC-94-9, U.S. Army Engineer Waterways Experiment Station, Vicksburg, MS.

(1994b). "Wave response of proposed improvement plan 6 to the small boat harbor at Maalaea, Maui, Hawaii" Miscellaneous Paper CERC-9417, U.S. Army Engineer Waterways Experiment Station, Vicksburg, MS.

. (1995). "Numerical modeling of harbor response to waves," J. Coastal Research 11(3), 744-753.

(1996). "Validation of a numerical model for wind waves and swell in harbors," J. Waterway, Port, Coastal and Ocean Engineering, American Society of Civil Engineers (accepted for publication).

Thompson, E. F., Chen, H. S., and Hadley, L. L. (1993). "Numerical modeling of waves in harbors." Proceedings, WAVES 93. American Society of Civil Engineers, 590-601.

Turner, P. J., and Baptista, A. M. (1993). "ACE/gredit user's manual," Center for Coastal and Land-Margin Research, Oregon Graduate Institute of Science and Technology, Beaverton, OR.

U. S. Army Corps of Engineers. (1986). "Design of breakwaters and jetties," Engineer Manual 1110-2-2904, Washington, DC.

U.S. Army Corps of Engineers. (1989). "Water levels and wave heights for coastal engineering design," Engineer Manual 1110-2-1414, Washington, DC.

U.S. Army Engineer District, Honolulu. (1993). "Kaumalapau Harbor navigation improvements, Island of Lanai, Hawaii, Reconnaissance Report," Honolulu, HI. 
Weishar, L. L., and Aubrey, D. G. (1986). "A study of inlet hydraulics at Green Harbor, Marshfield, Mass.," Miscellaneous Report CERC 88-10, U.S. Army Engineer Waterways Experiment Station, Vicksburg, MS. 


\section{Appendix A Monthly Summaries of Proto- type Data}




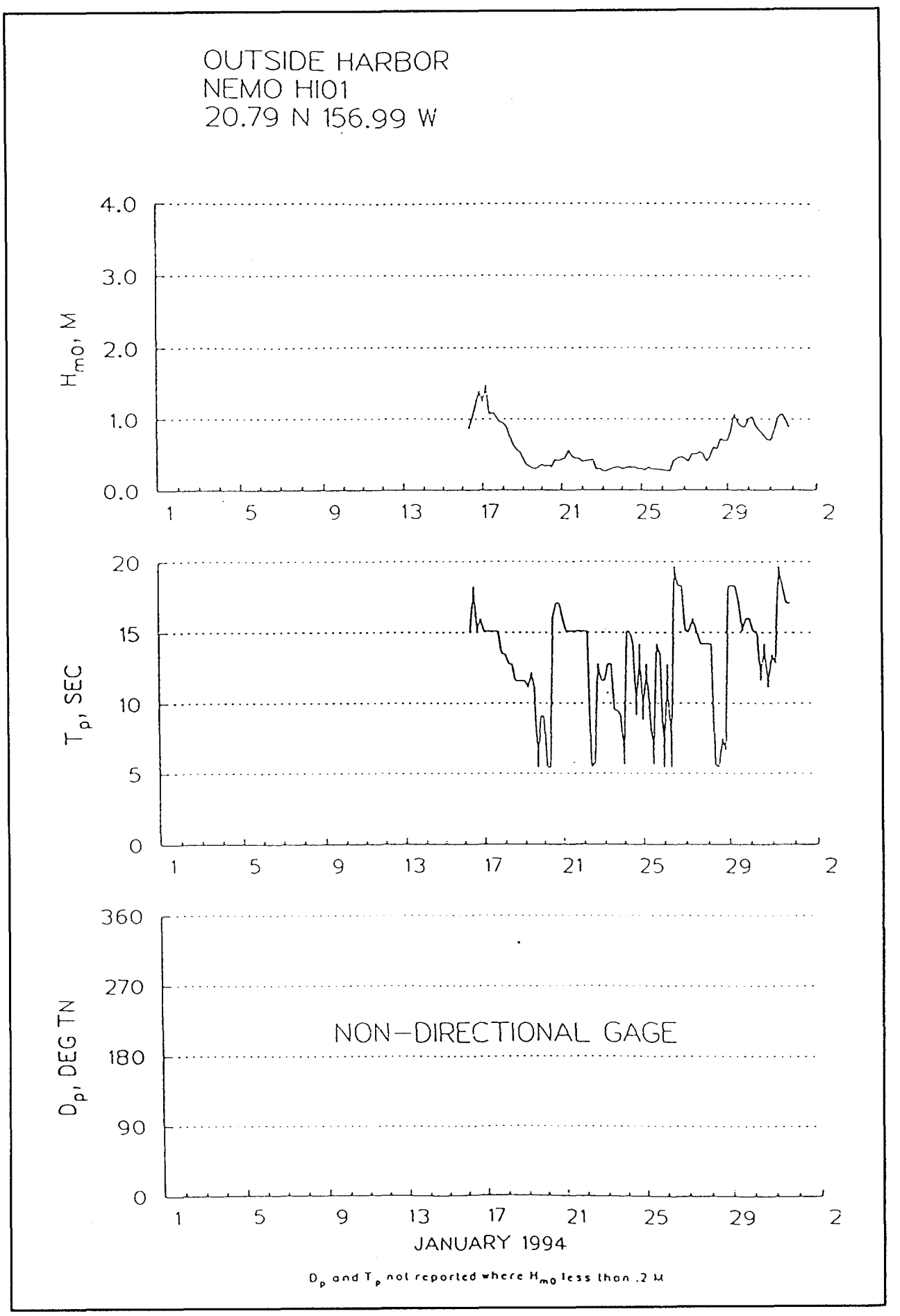

Figure A1. Prototype data summary for January, 1994, outside harbor 


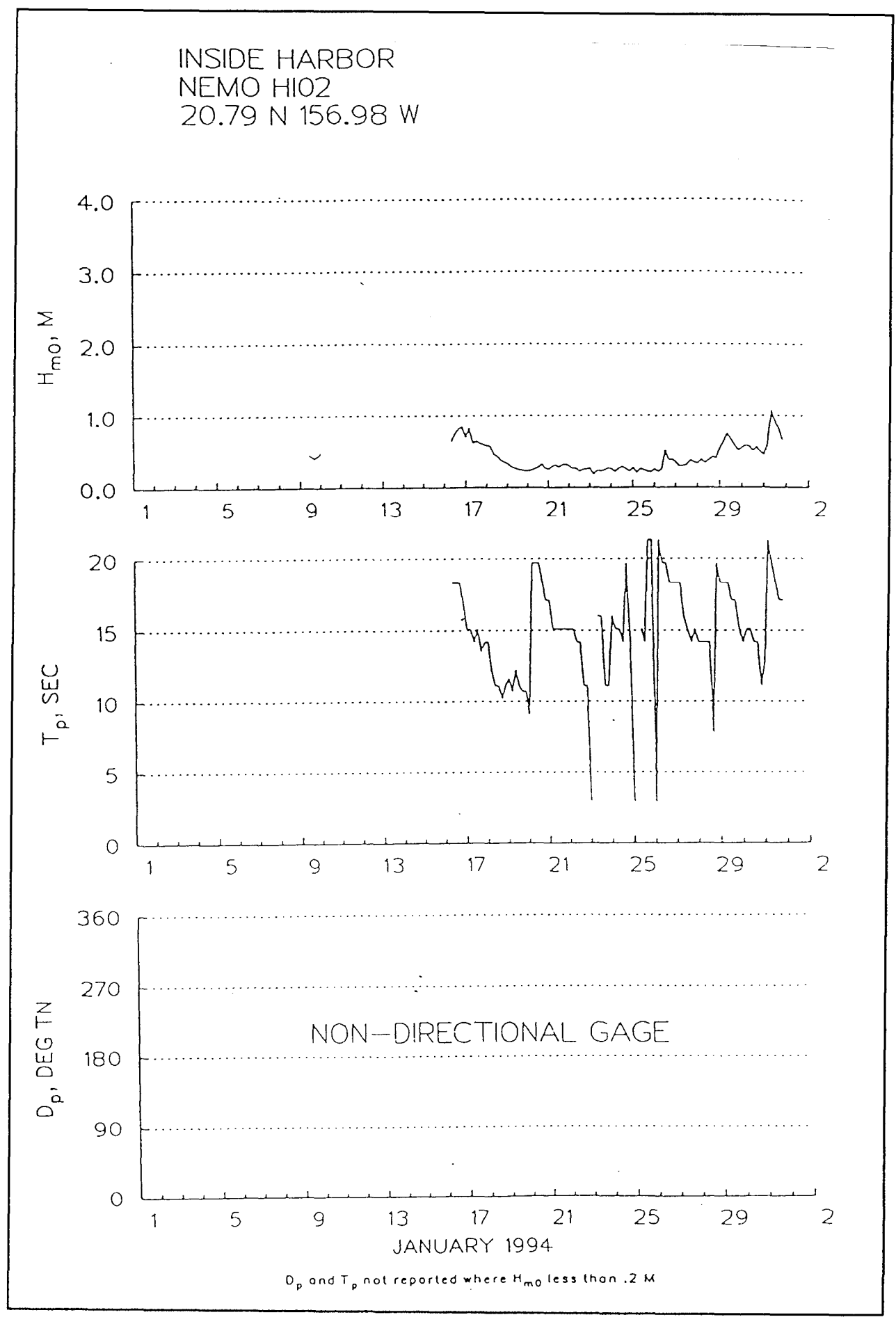

Figure A2. Prototype data summary for January, 1994, inside harbor 


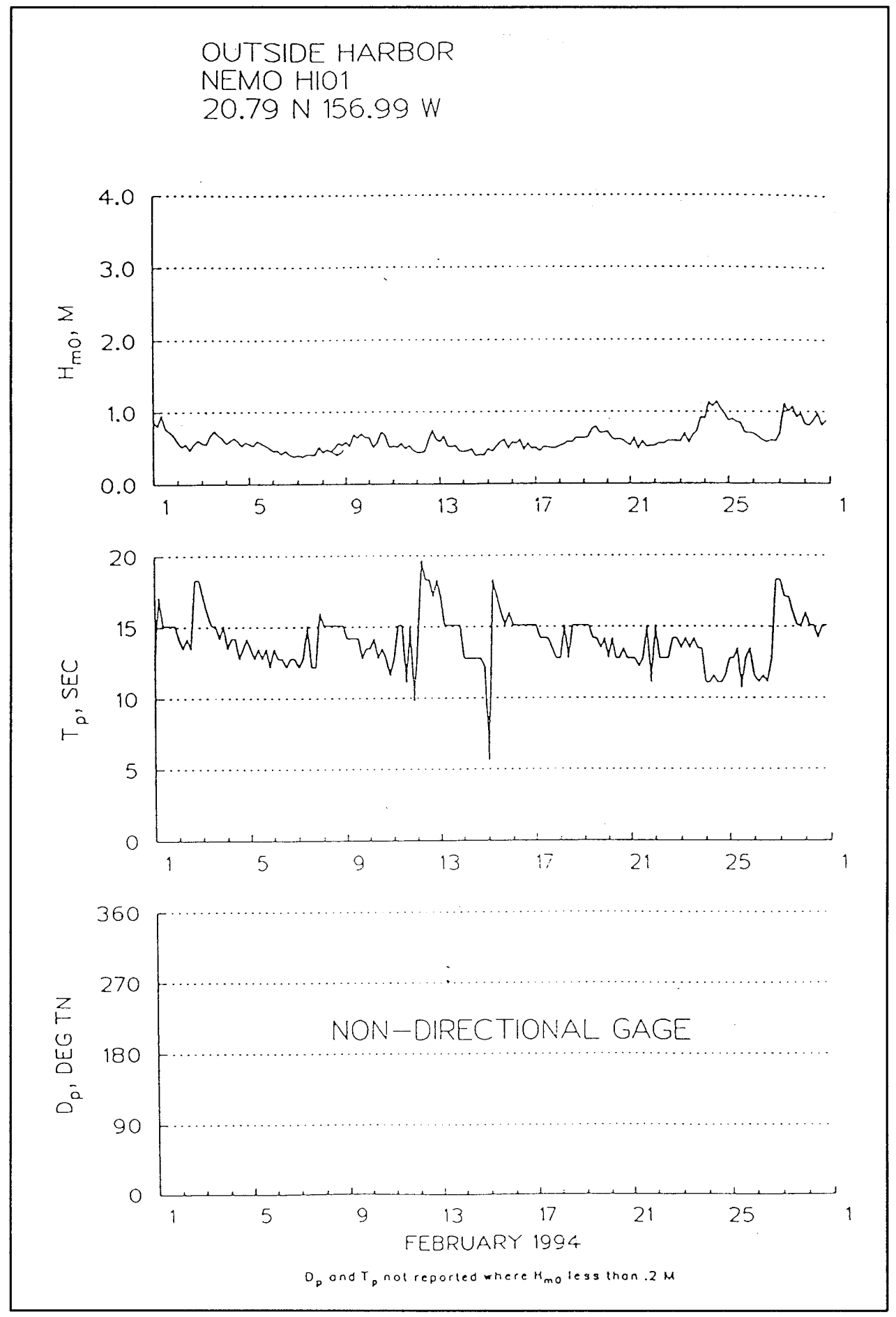

Figure A3. Prototype data summary for February, 1994, outside harbor 
INSIDE HARBOR

NEMO HIO2

$20.79 N 156.98$ W
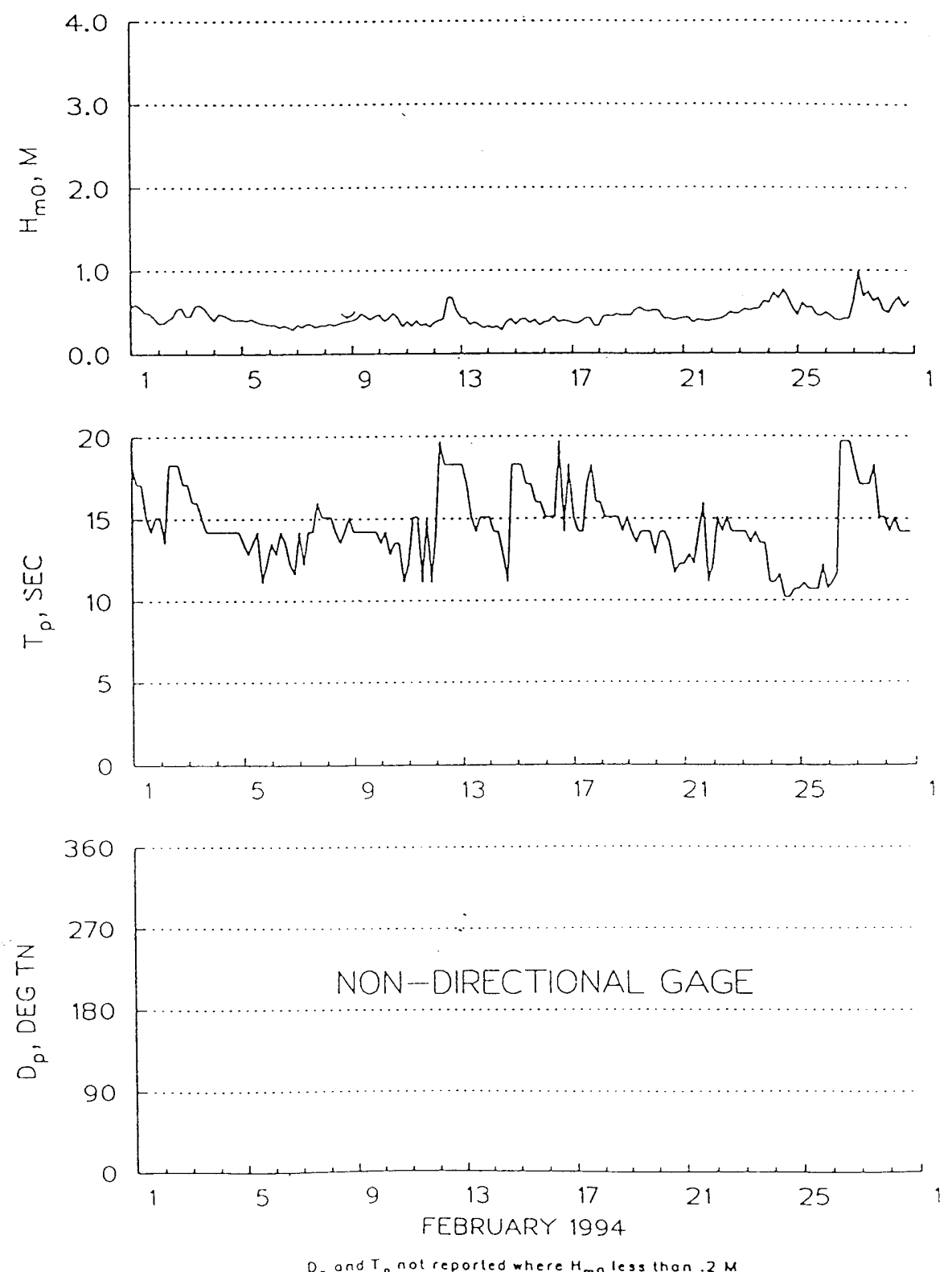

Figure A4. Prototype data summary for February, 1994, inside harbor 
OUTSIDE HARBOR

NEMO HIO1

20.79 N 156.99 W
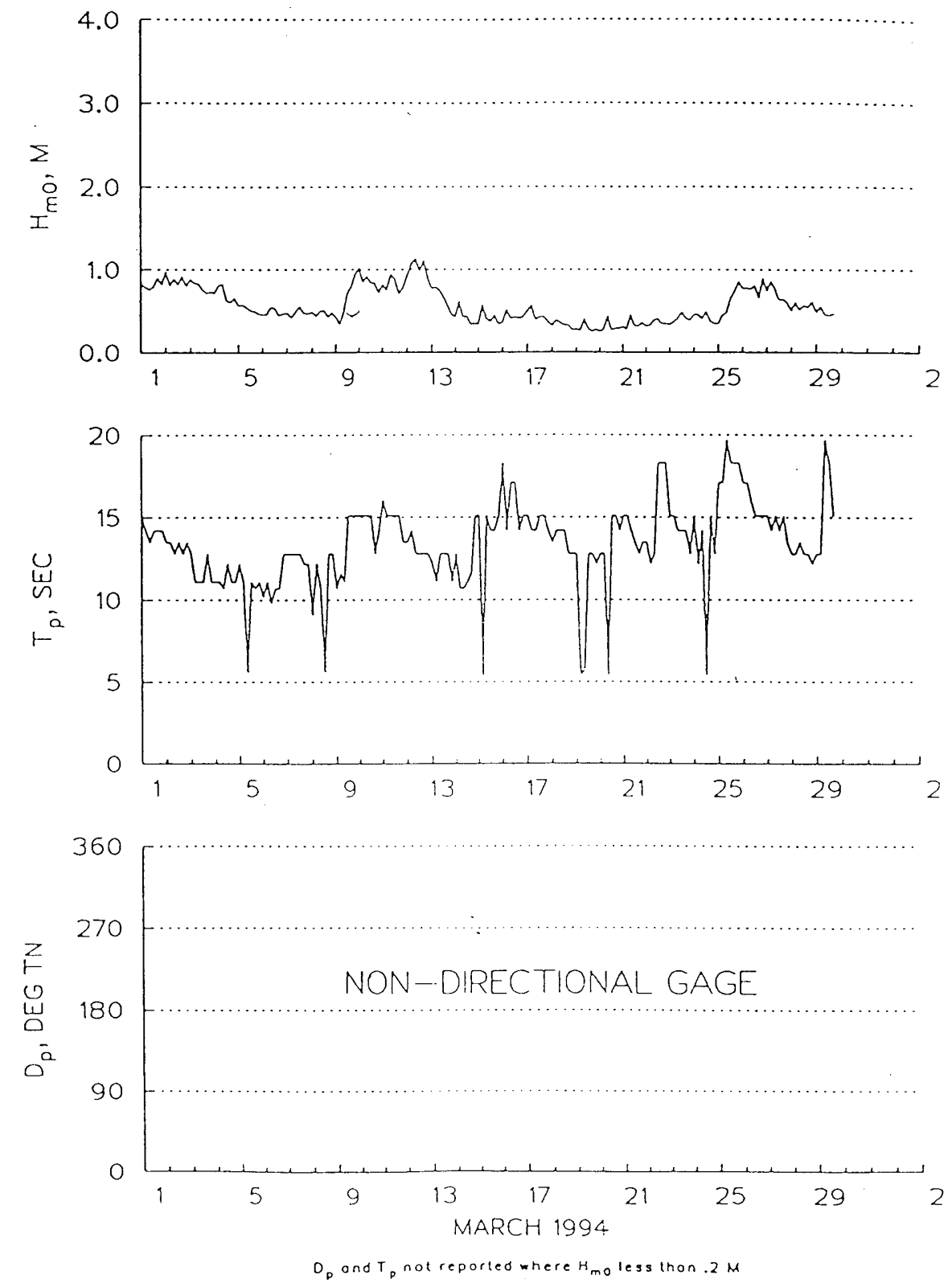

Figure A5. Prototype data summary for March, 1994, outside harbor 


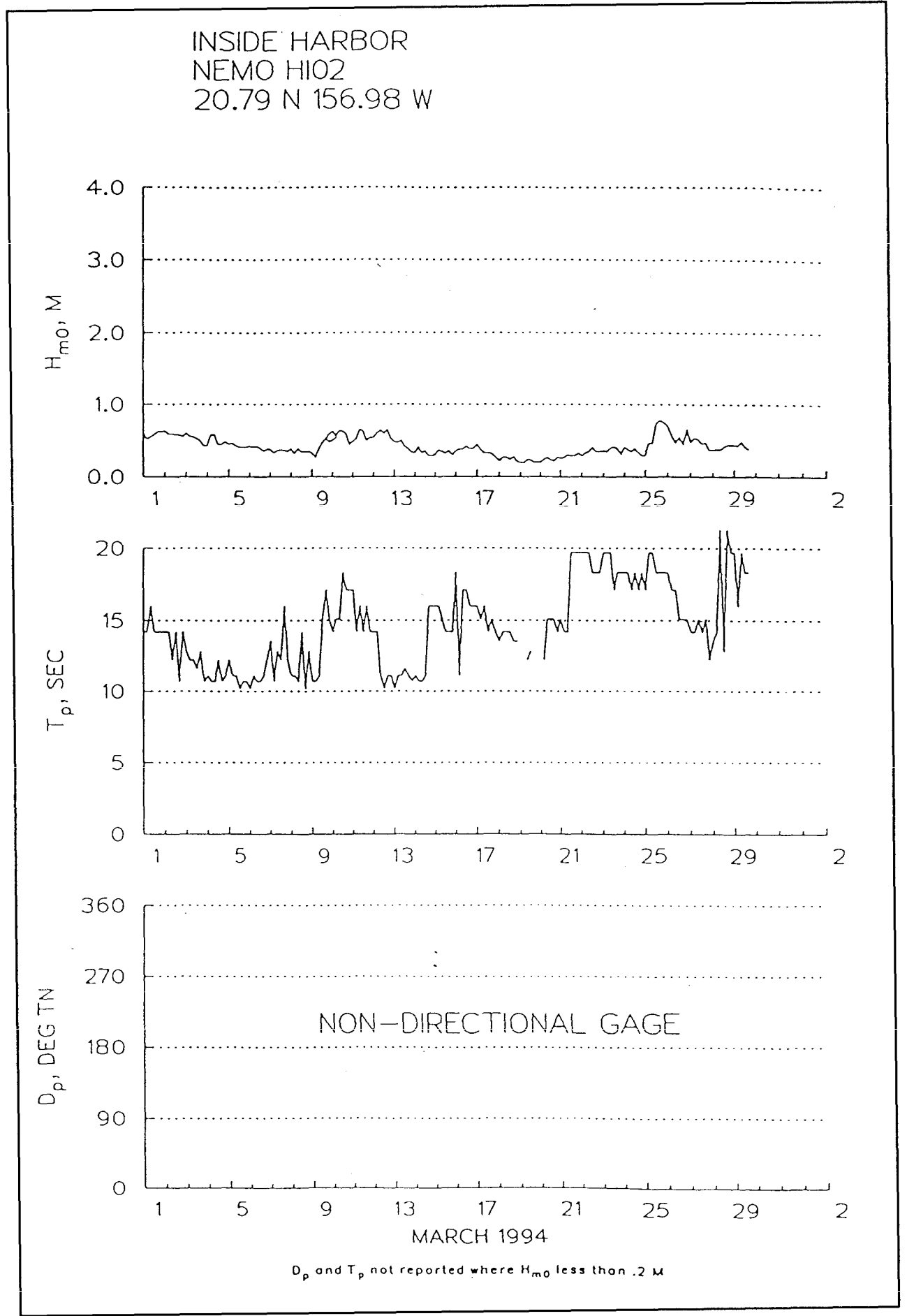

Figure A6. Prototype data summary for March, 1994, inside harbor 


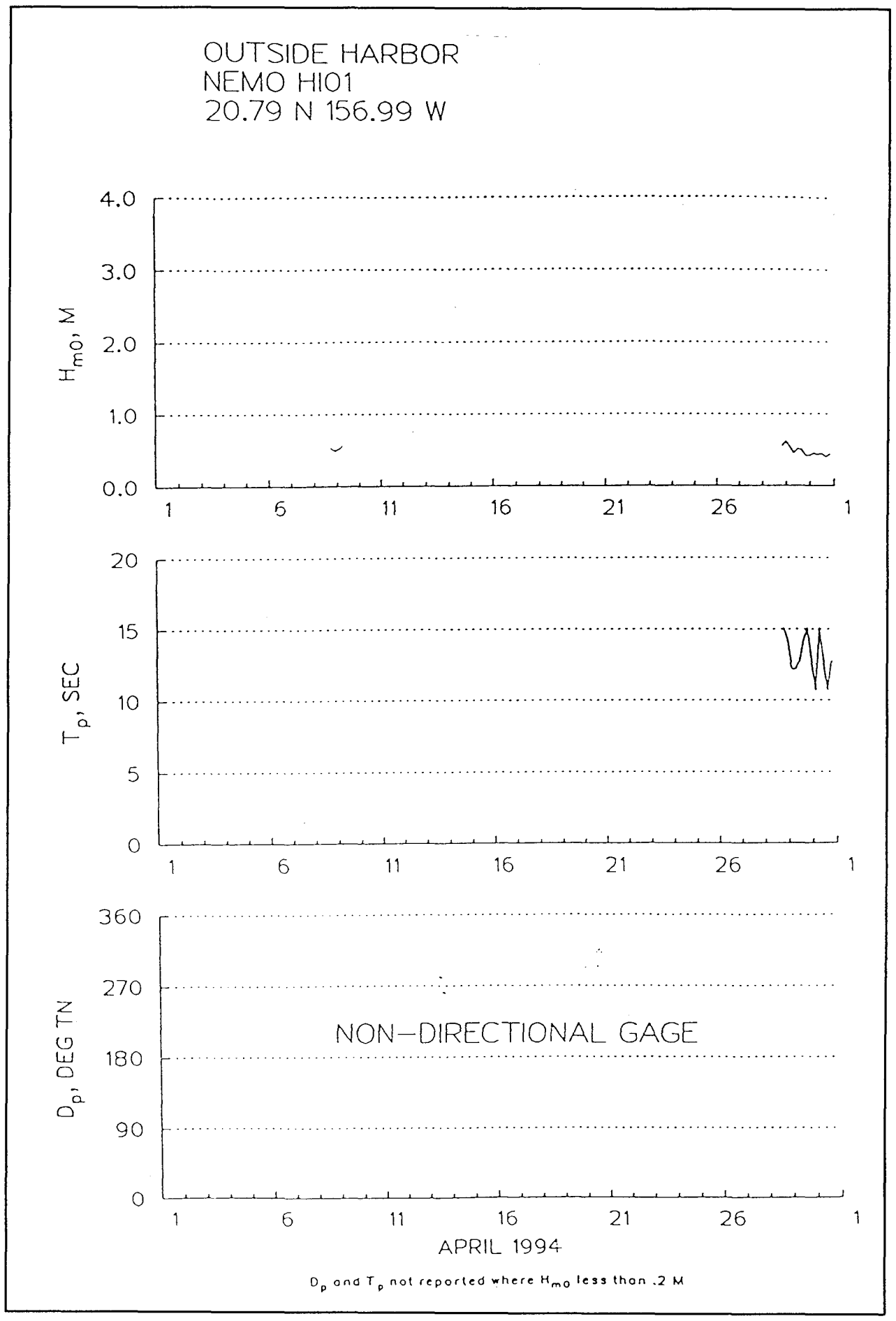

Figure A7. Prototype data summary for April, 1994, outside harbor 


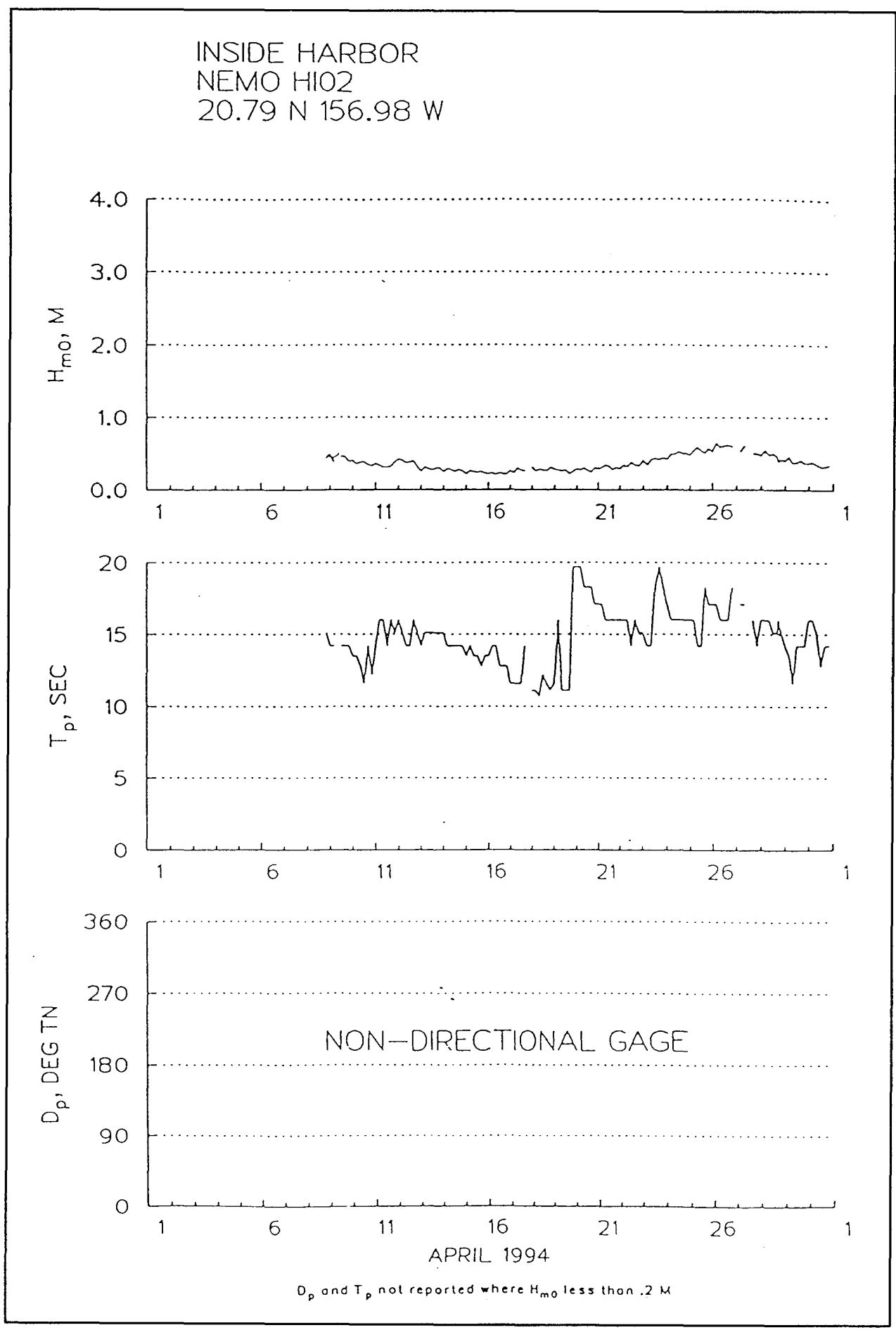

Figure A8. Prototype data summary for April, 1994, inside harbor 


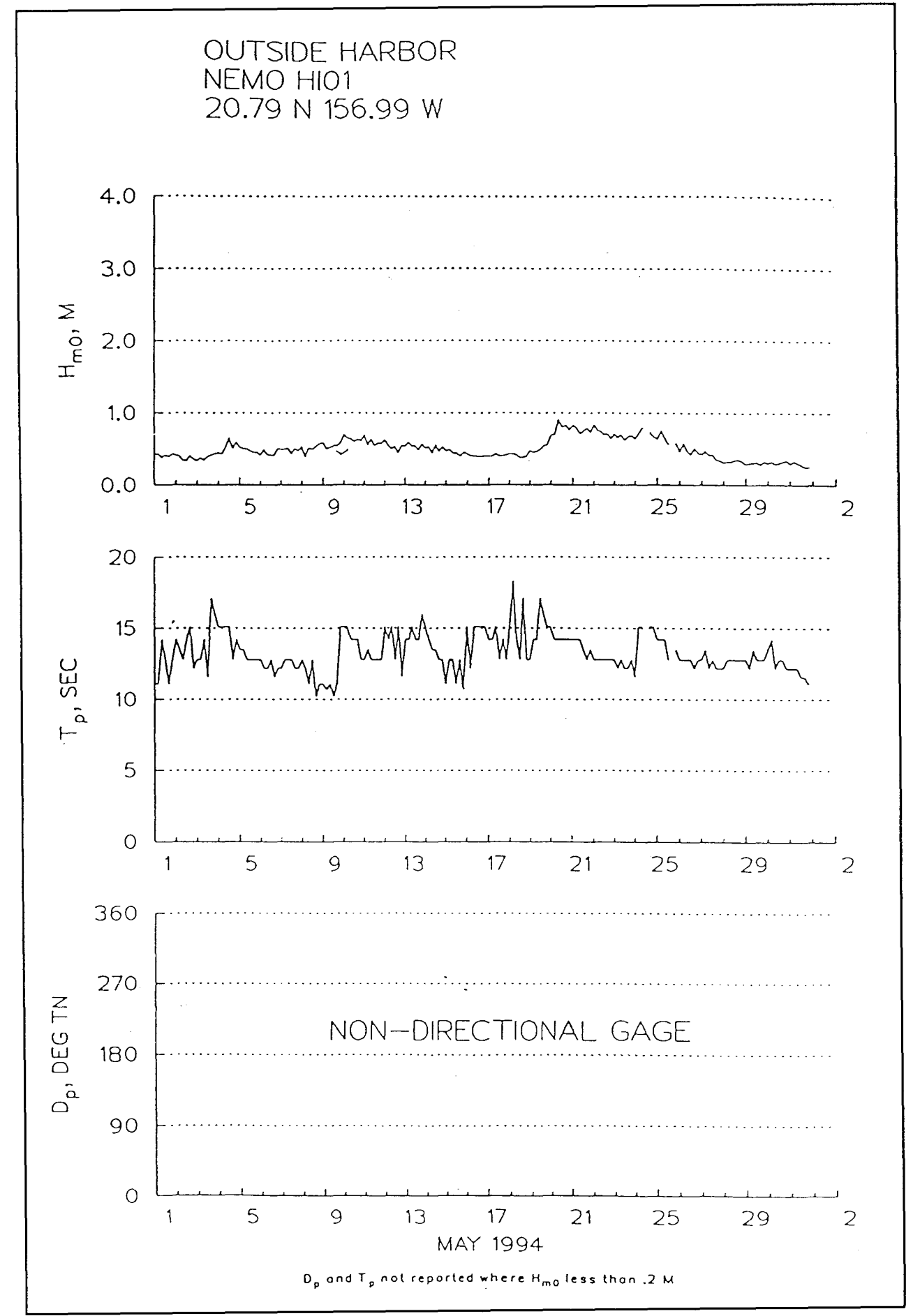

Figure A9. Prototype data summary for May, 1994, outside harbor 


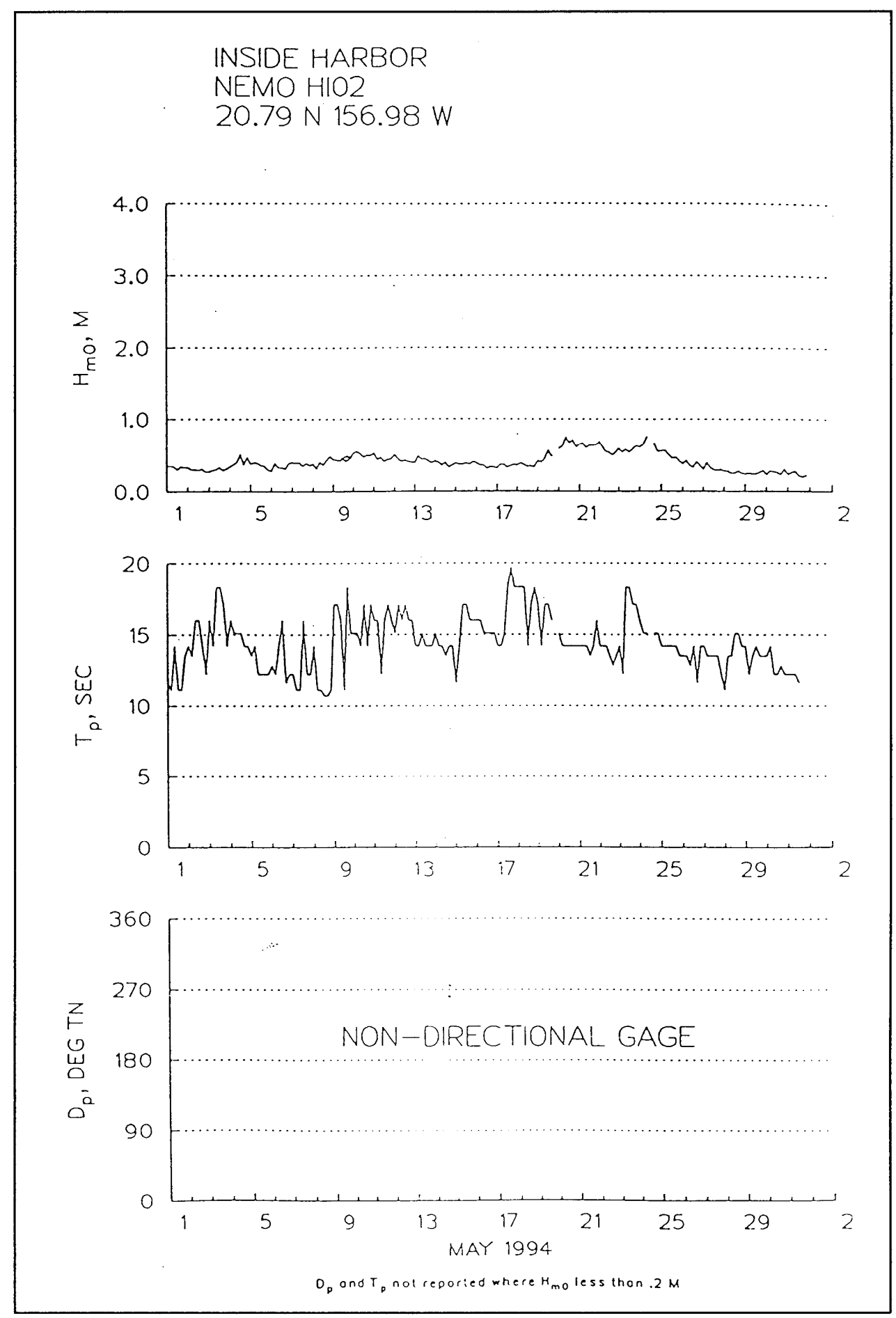

Figure A10. Prototype data summary for May, 1994, inside harbor 


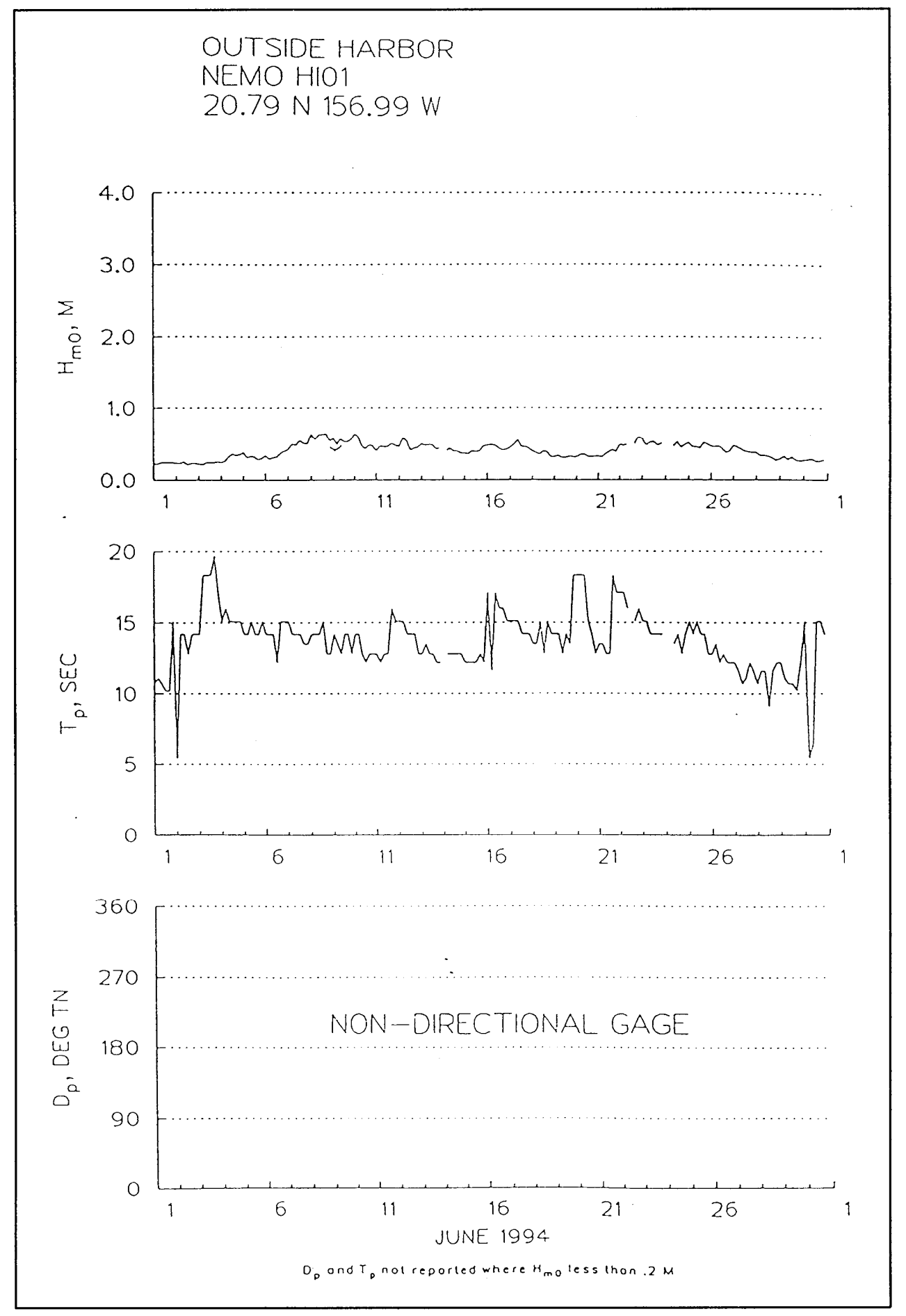

Figure A11. Prototype data summary for June, 1994, outside harbor 


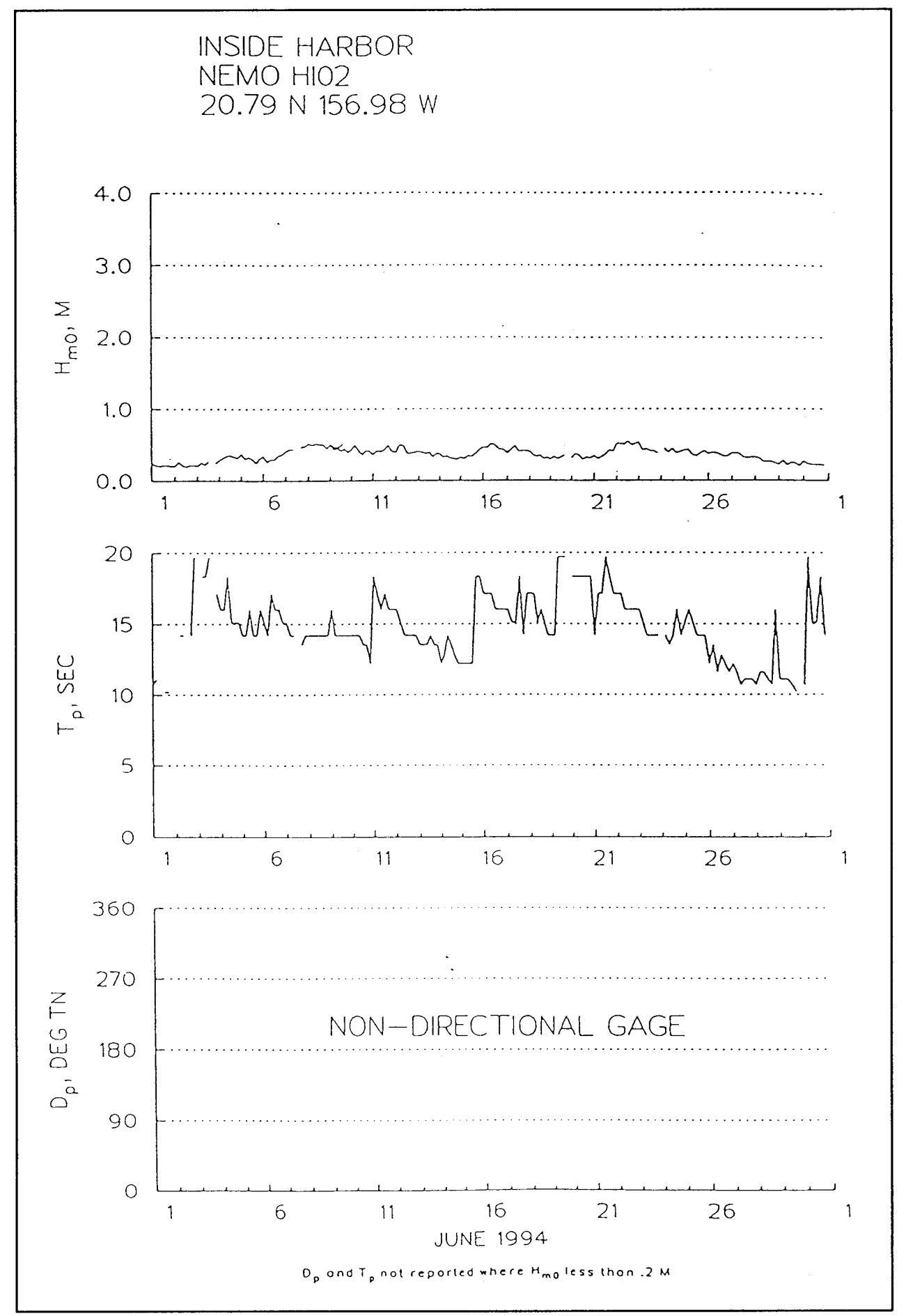

Figure A12. Prototype data summary for June, 1994, inside harbor 


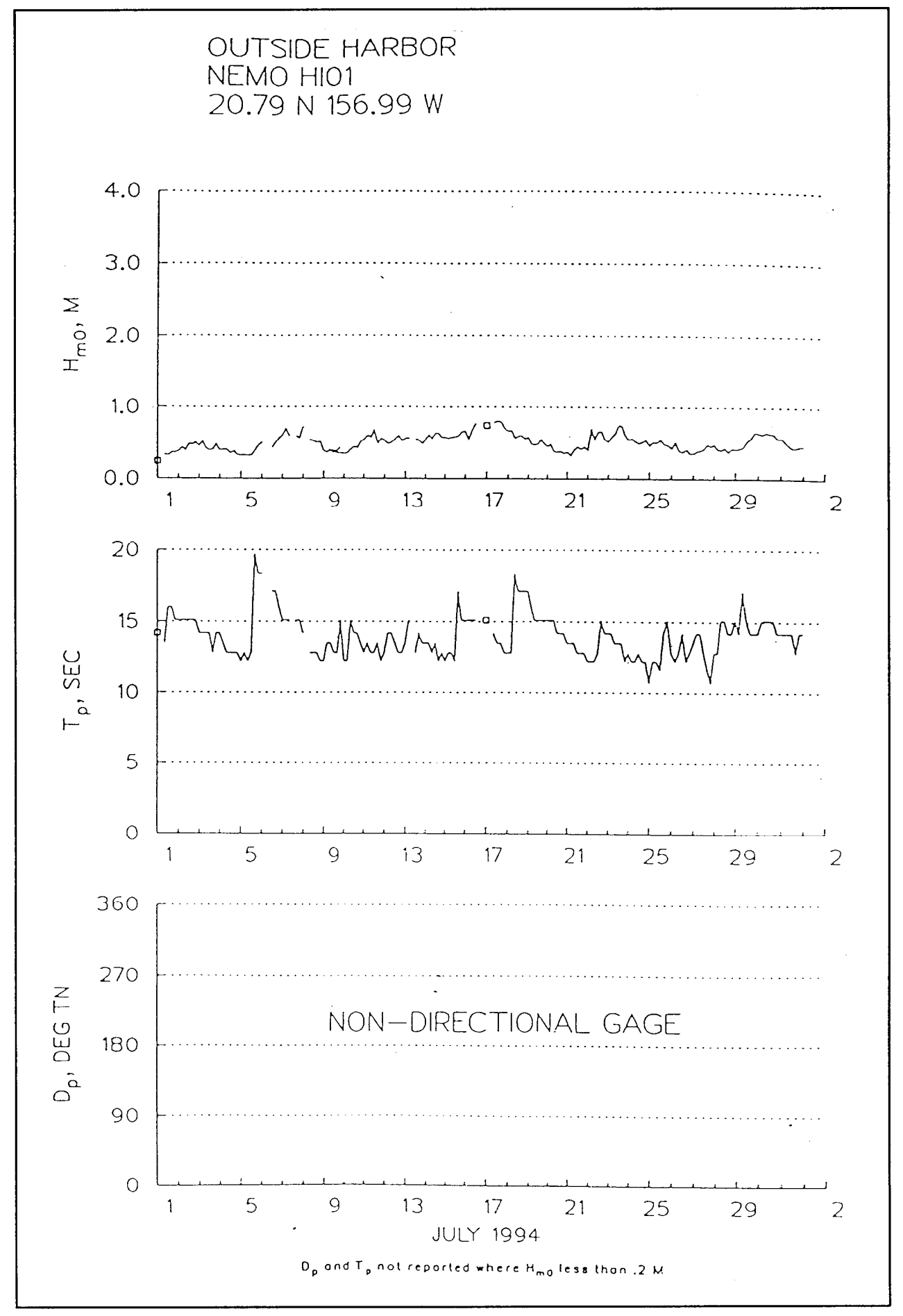

Figure A13. Prototype data summary for July, 1994, outside harbor 


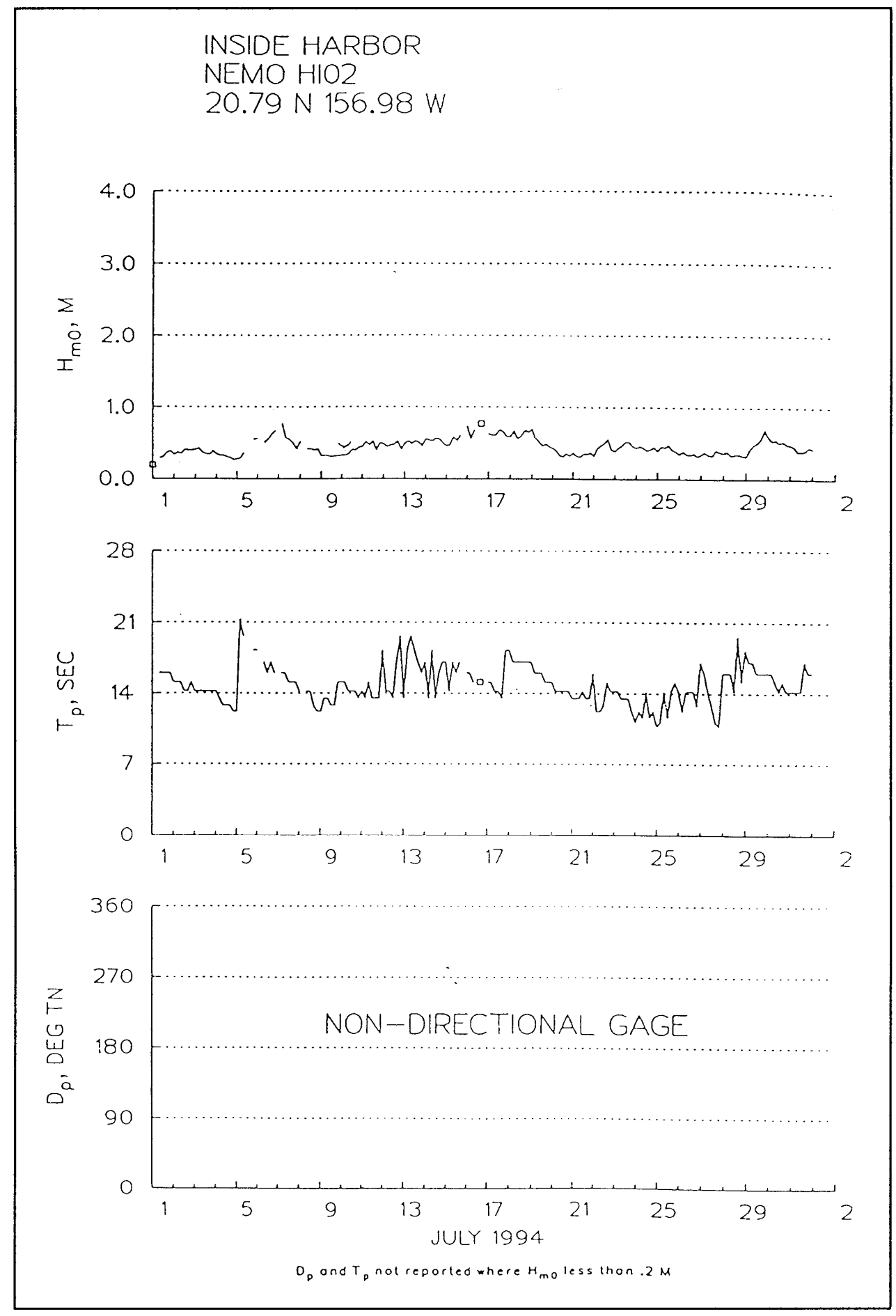

Figure A14. Prototype data summary for July, 1994, inside harbor 


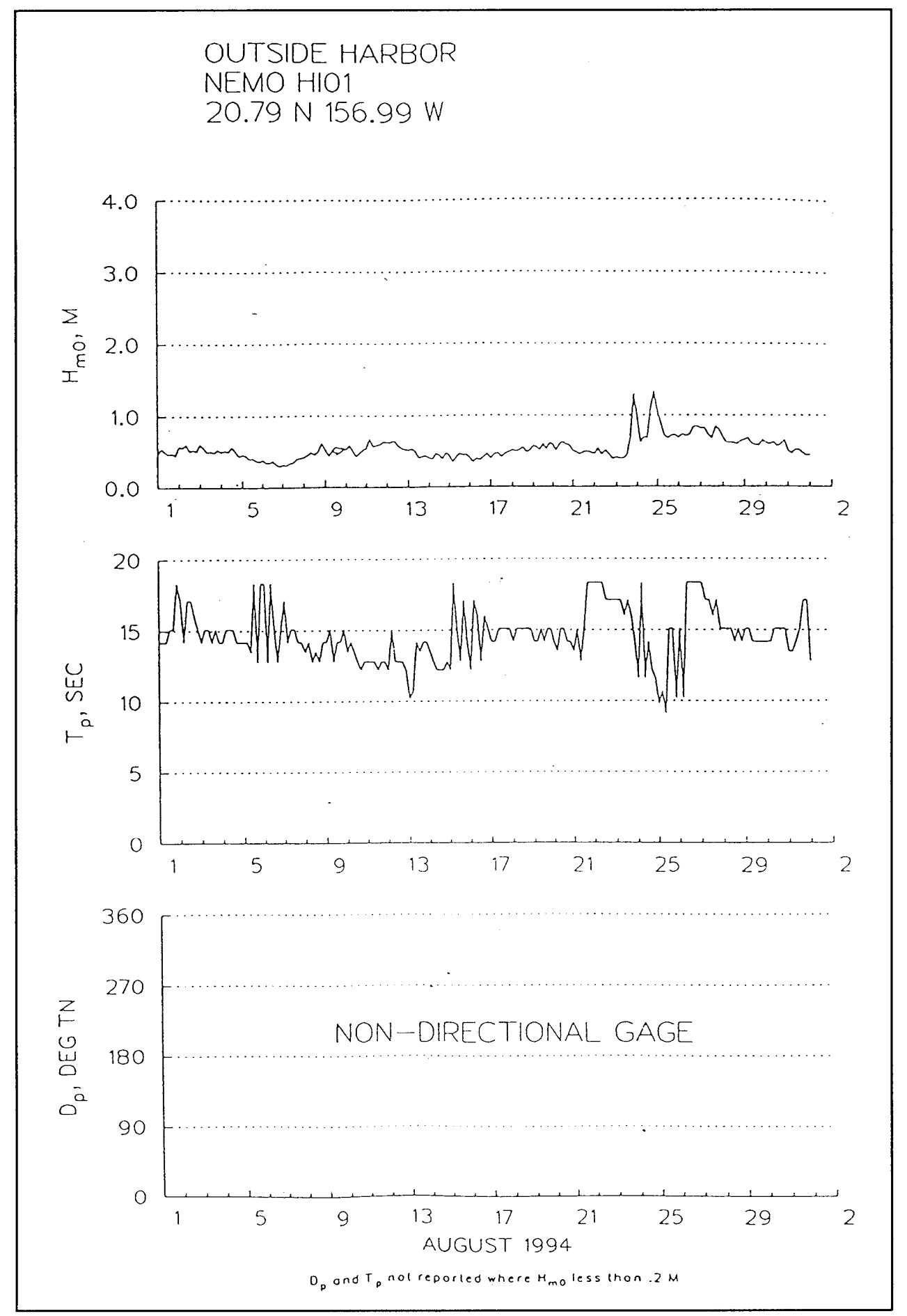

Figure A15. Prototype data summary for August, 1994, outside harbor 


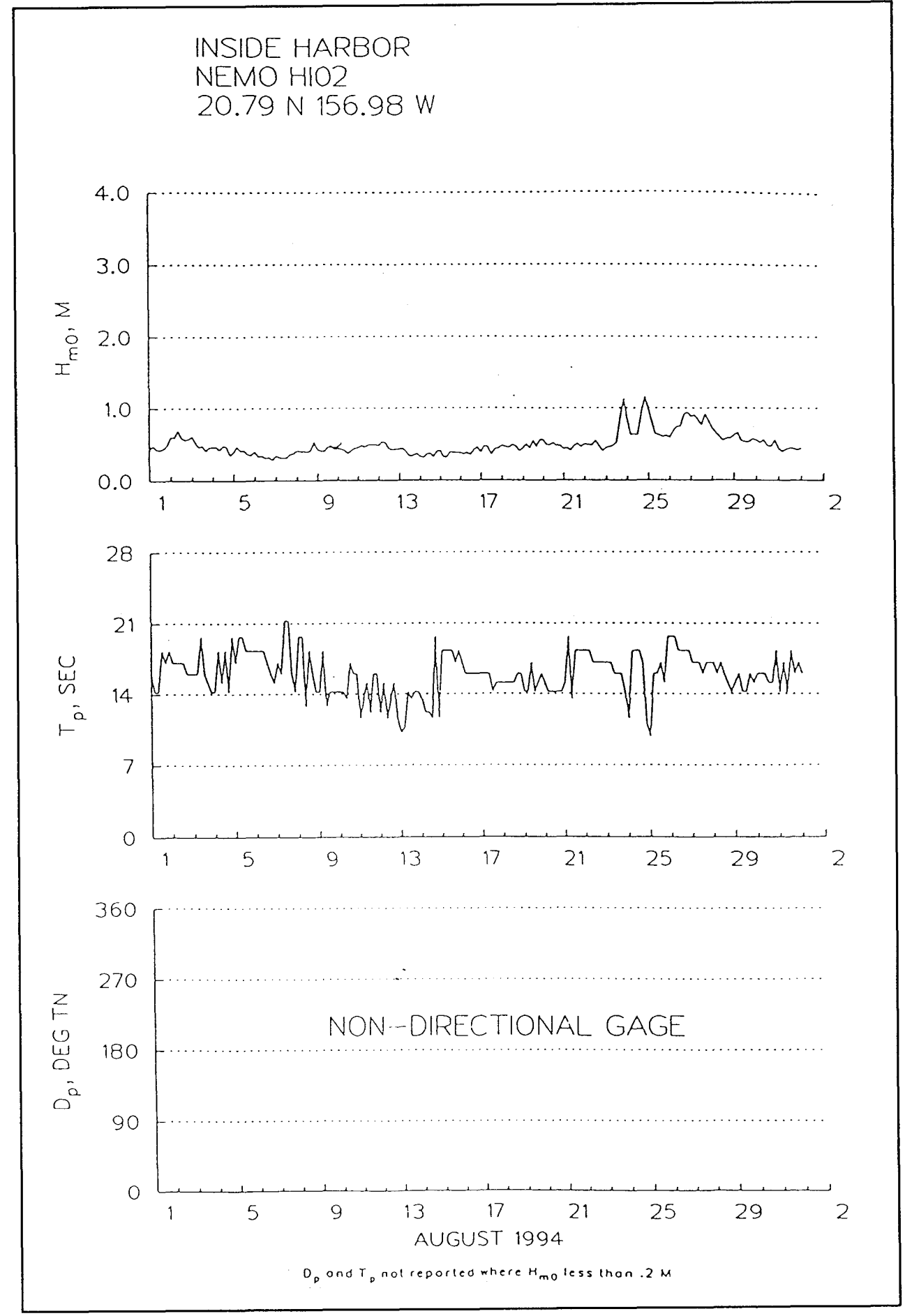

Figure A16. Prototype data summary for August, 1994, inside harbor 


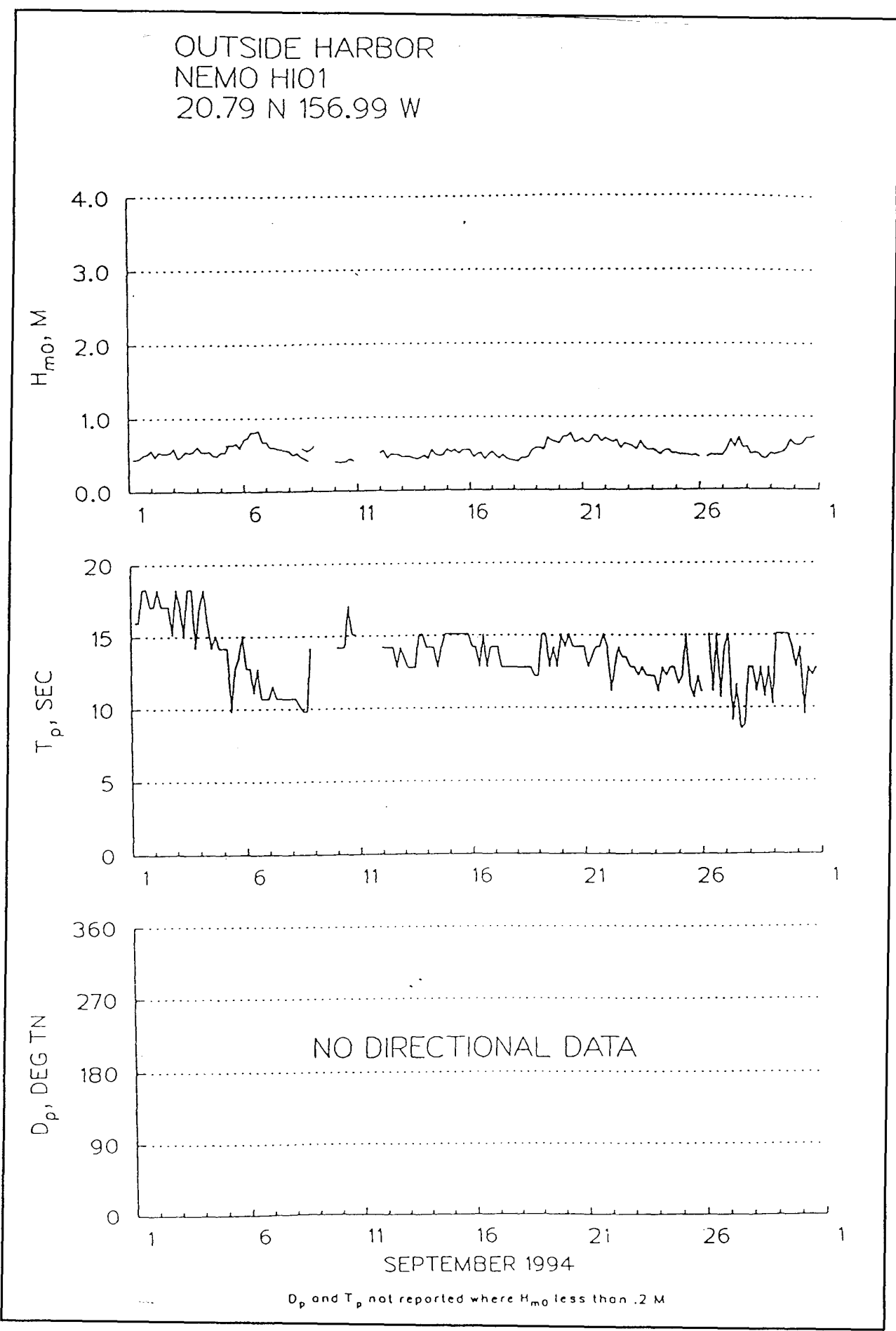

Figure A17. Prototype data summary for September, 1994, outside harbor 


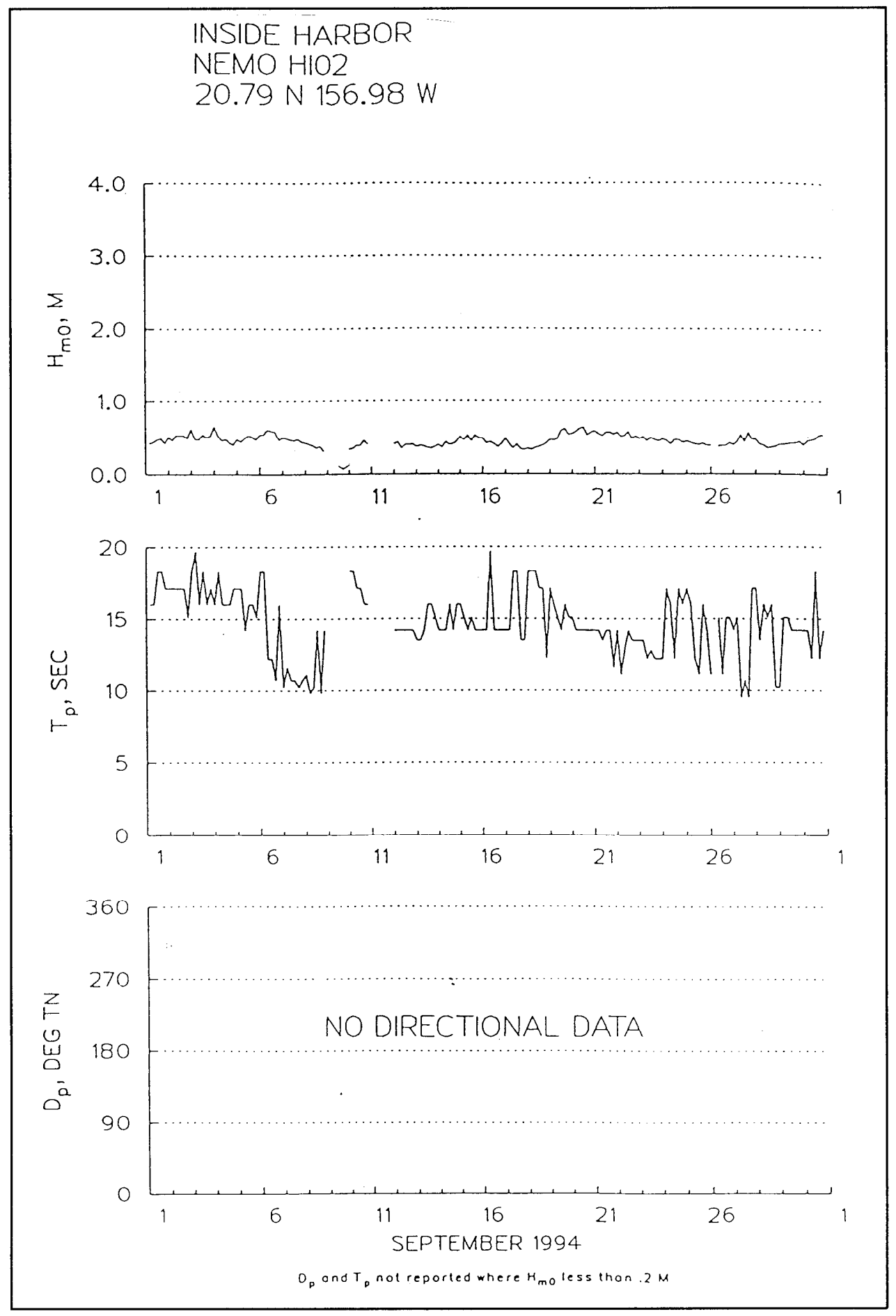

Figure A18. Prototype data summary for September, 1994, inside harbor 


\section{Appendix B Three-Dimensional Stability Photographs}




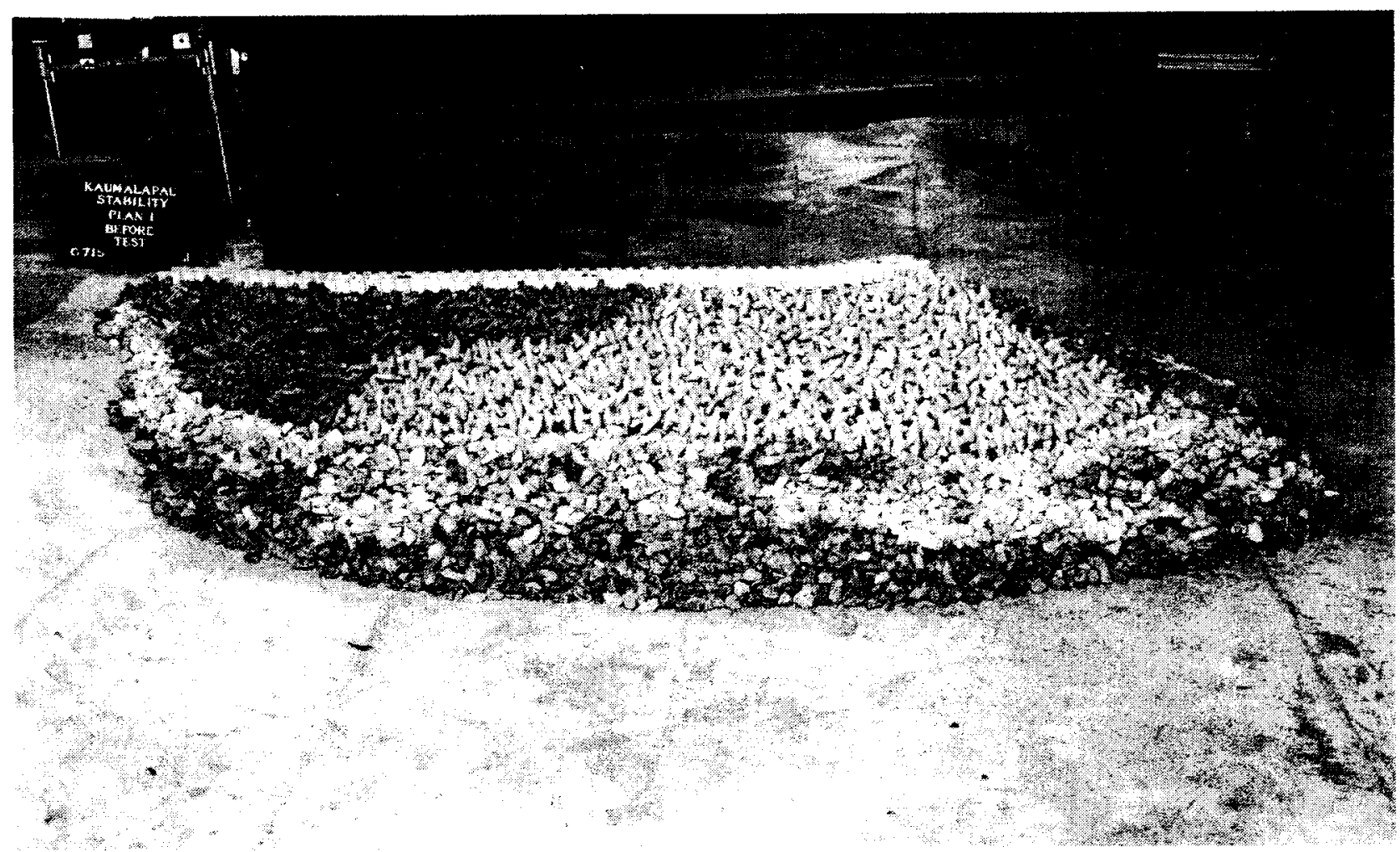

Photo B1. Sea-side view of Plan 4 before experiments

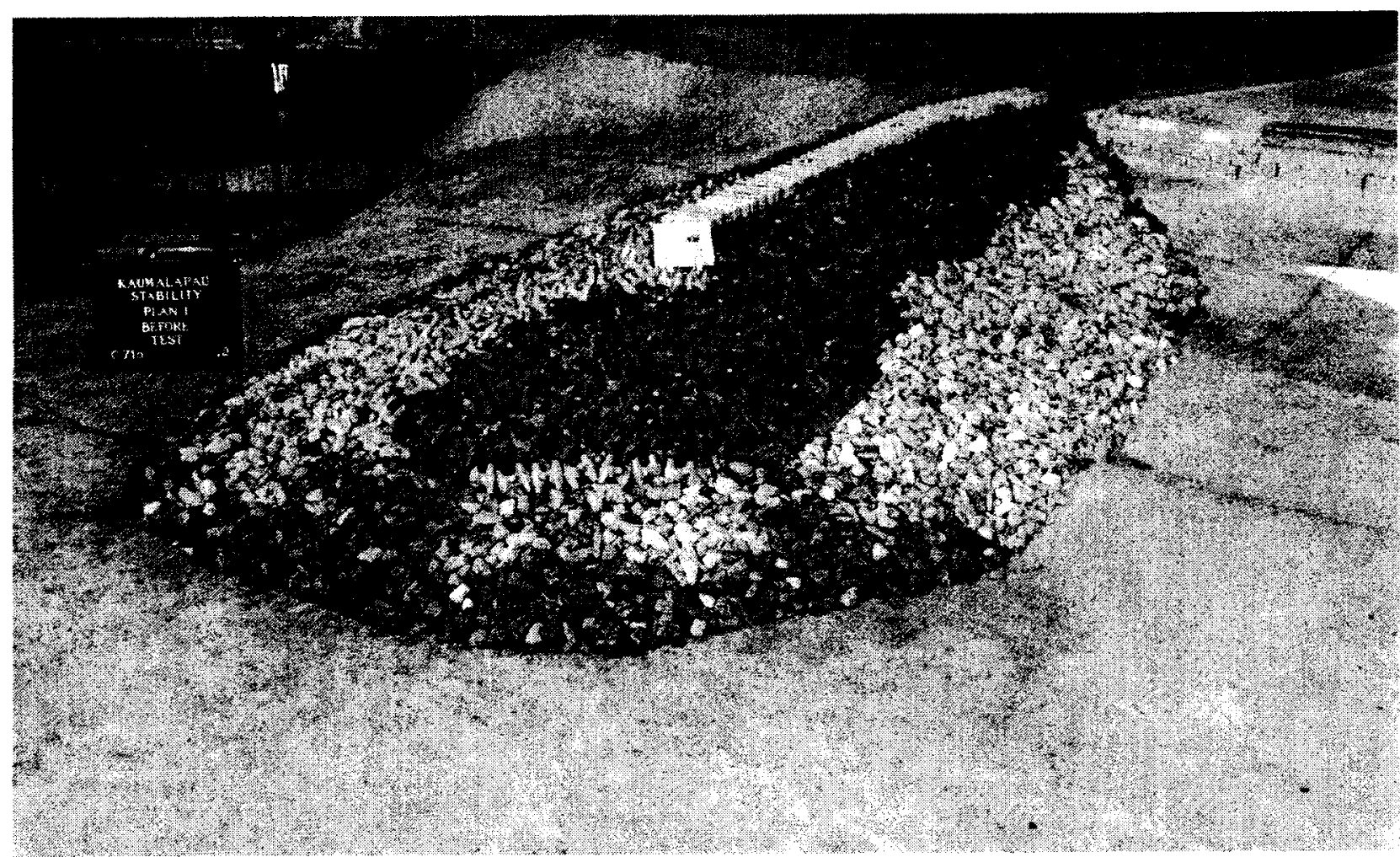

Photo B2. Plan 4, breakwater head before experiments 


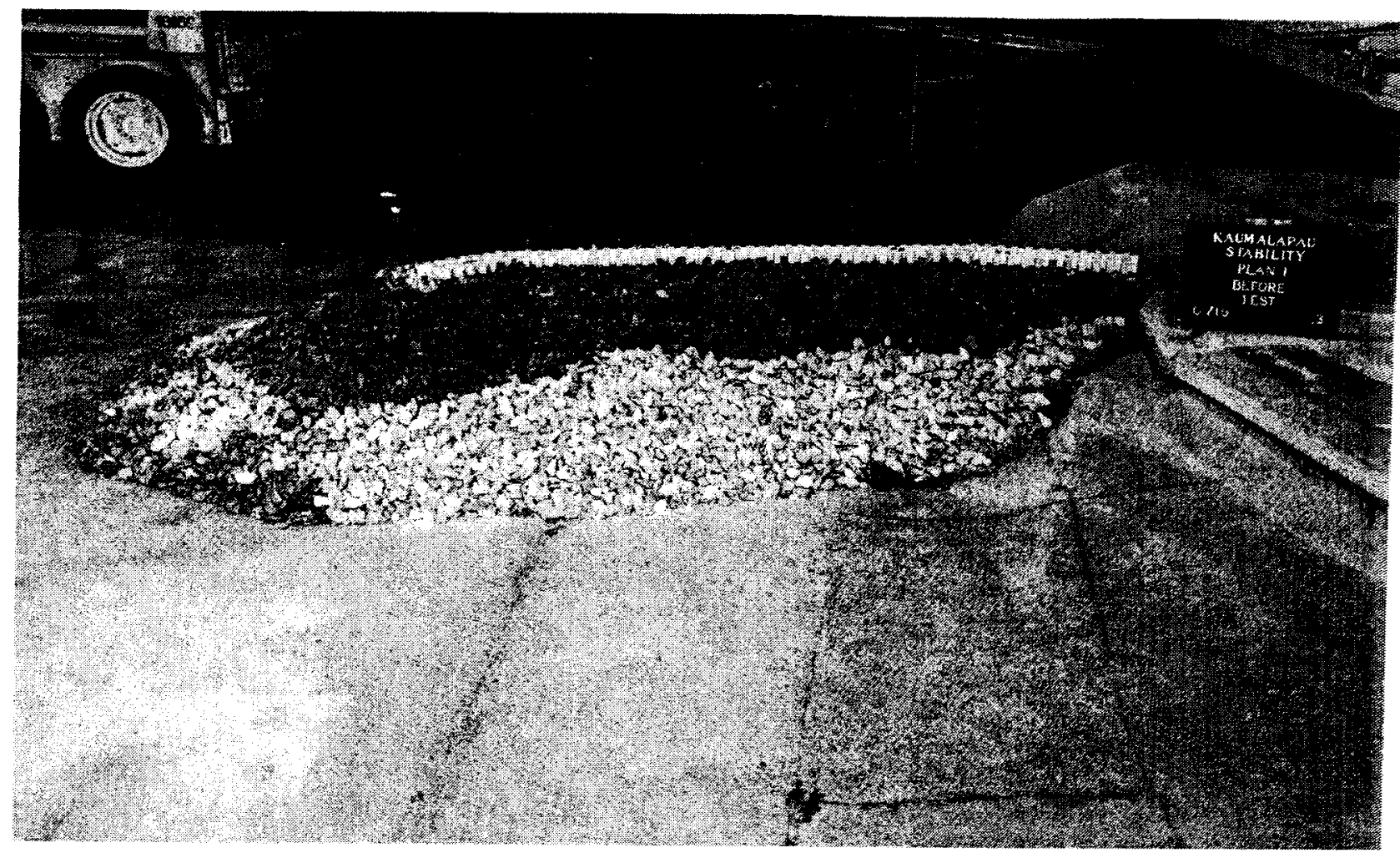

Photo B3. Leeside view of Plan 4 before experiments

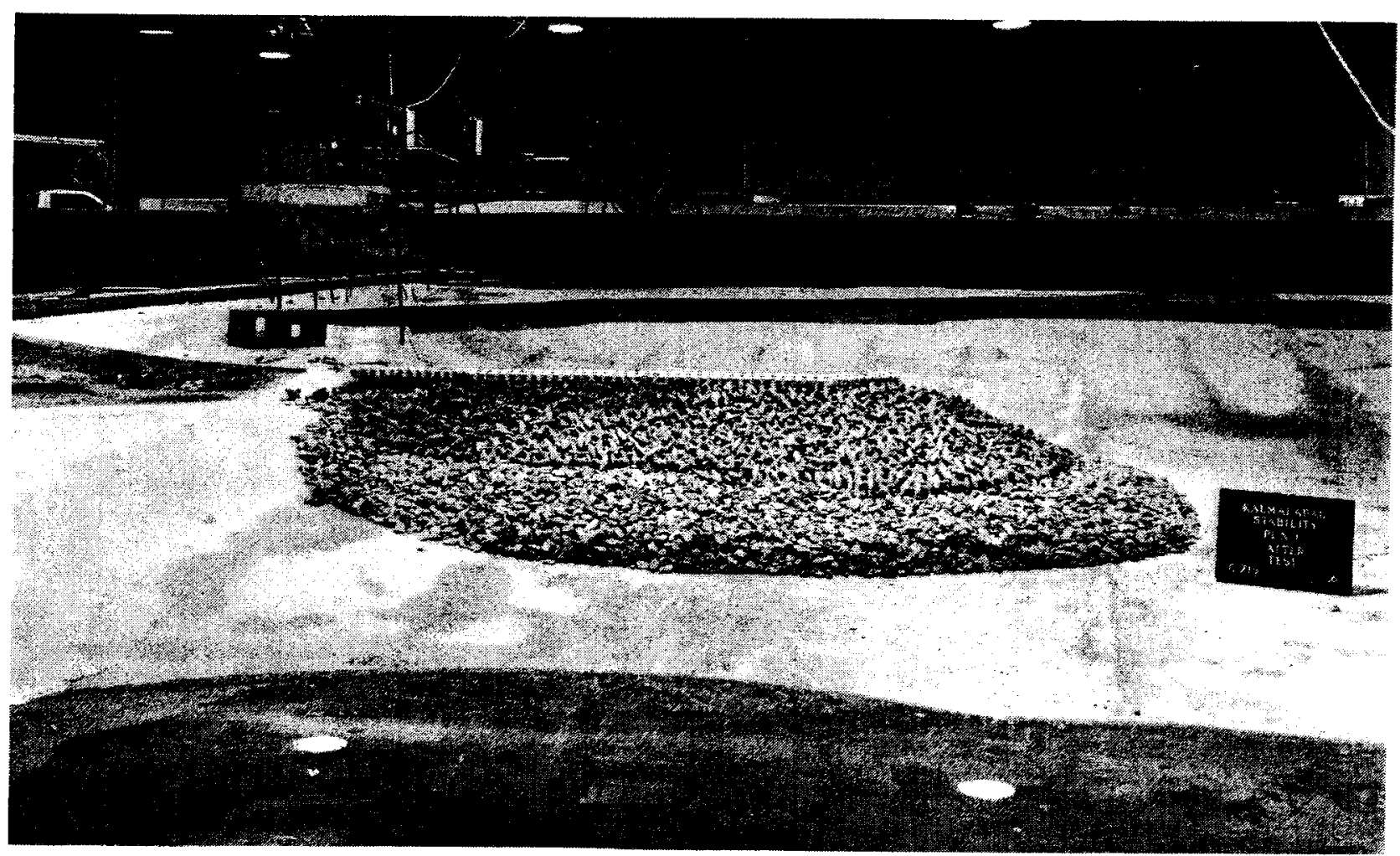

Photo B4. Sea-side view of Plan 4 after $9.8-\mathrm{sec}, 7.5-\mathrm{m}$ waves 


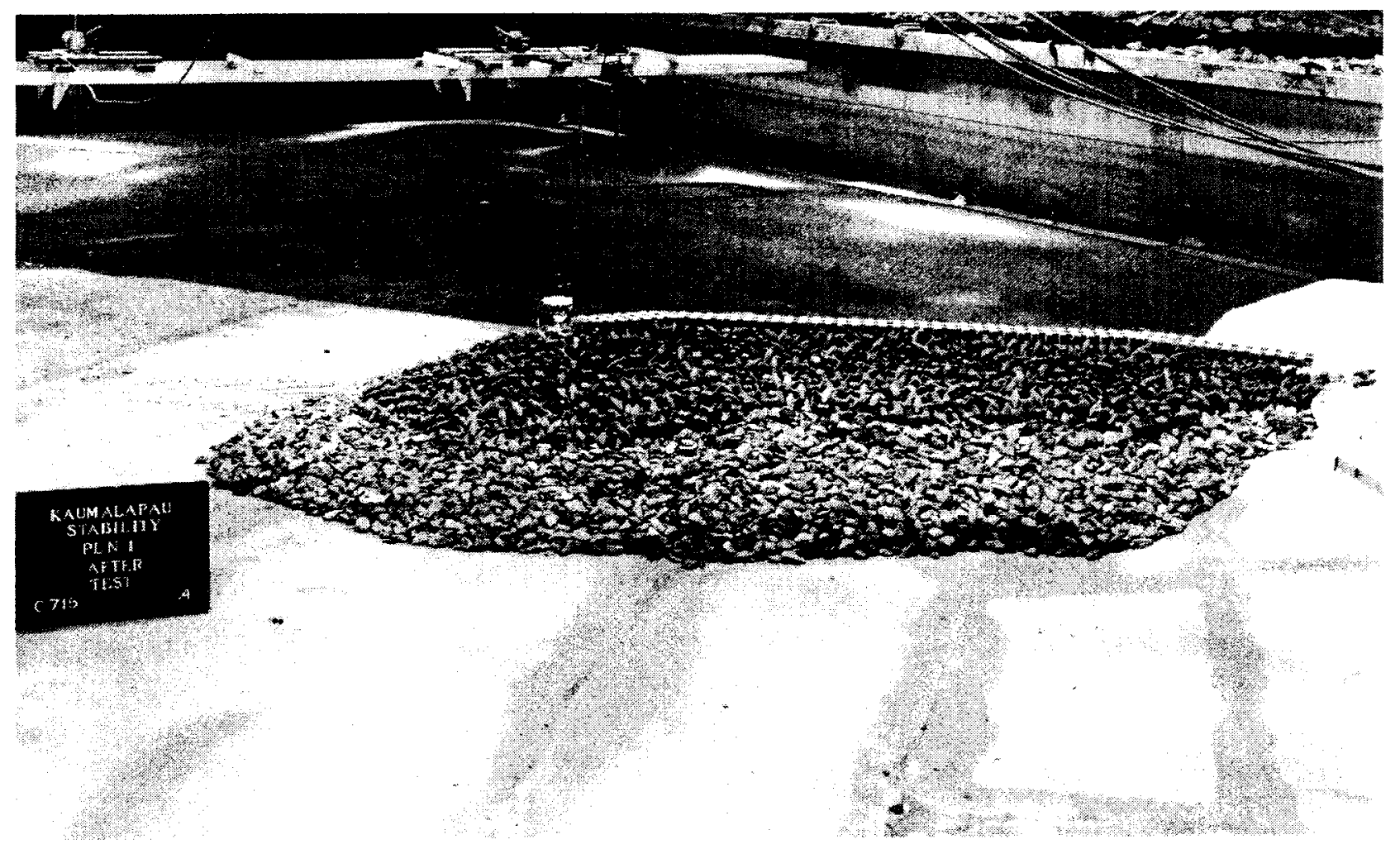

Photo B5. Plan 4, leeside view of breakwater after $9.8-\mathrm{sec}, 7.5-\mathrm{m}$ waves

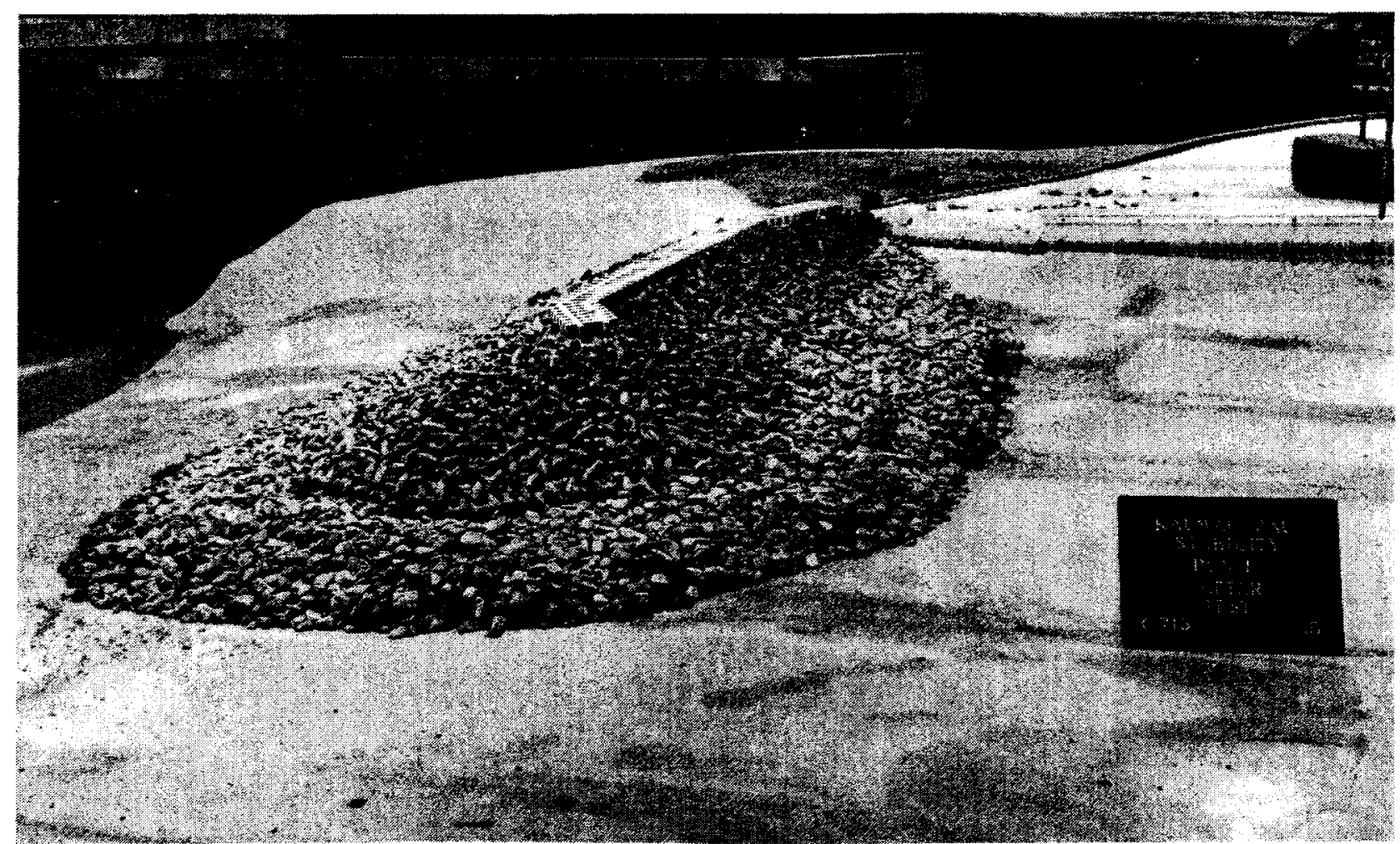

Photo B6. Head view of Plan 4 after 9.8-sec, 7.5-m waves 


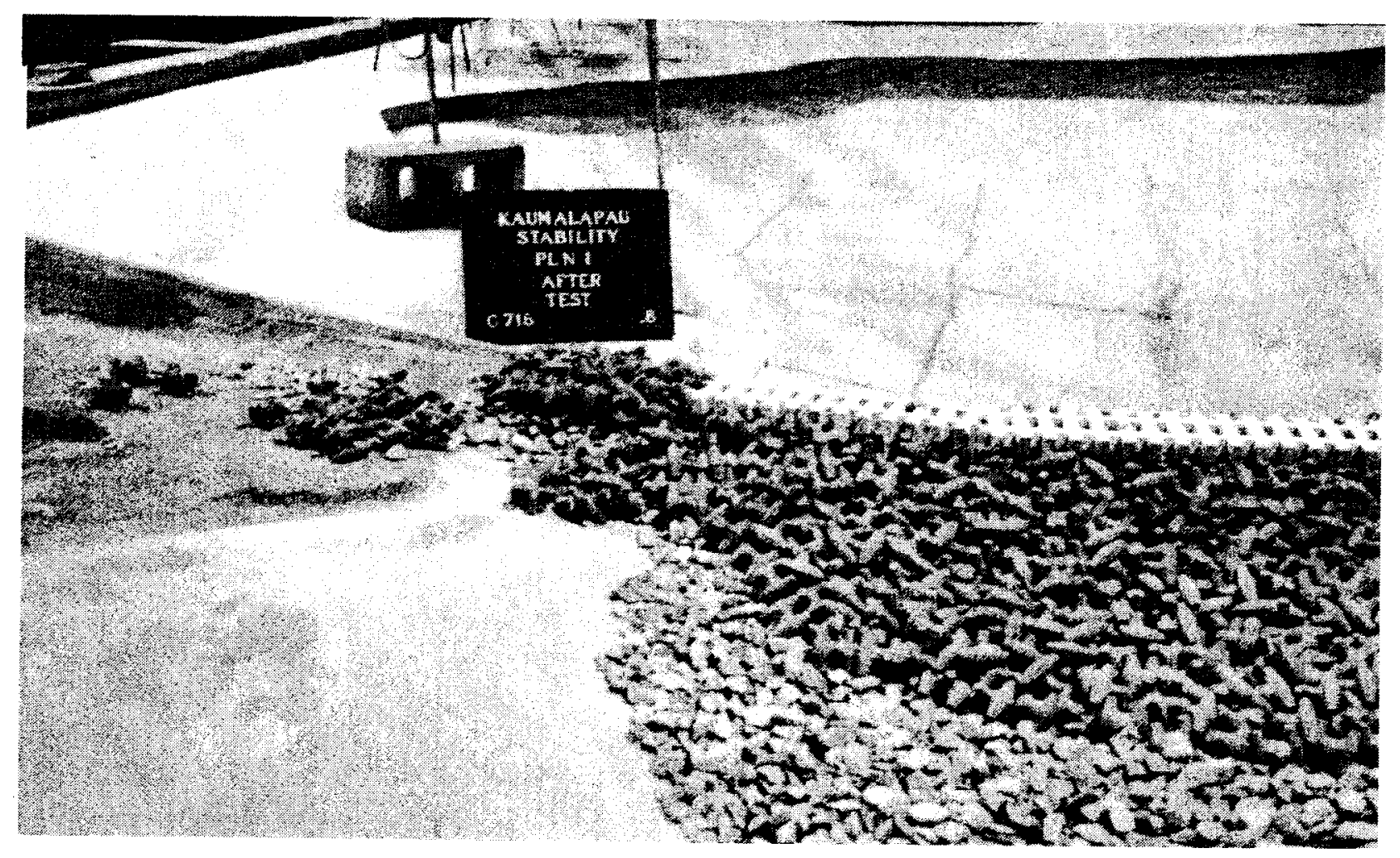

Photo B7. Sea-side shoreward end view of Plan 4A after 9.8-sec, 6.4-m waves

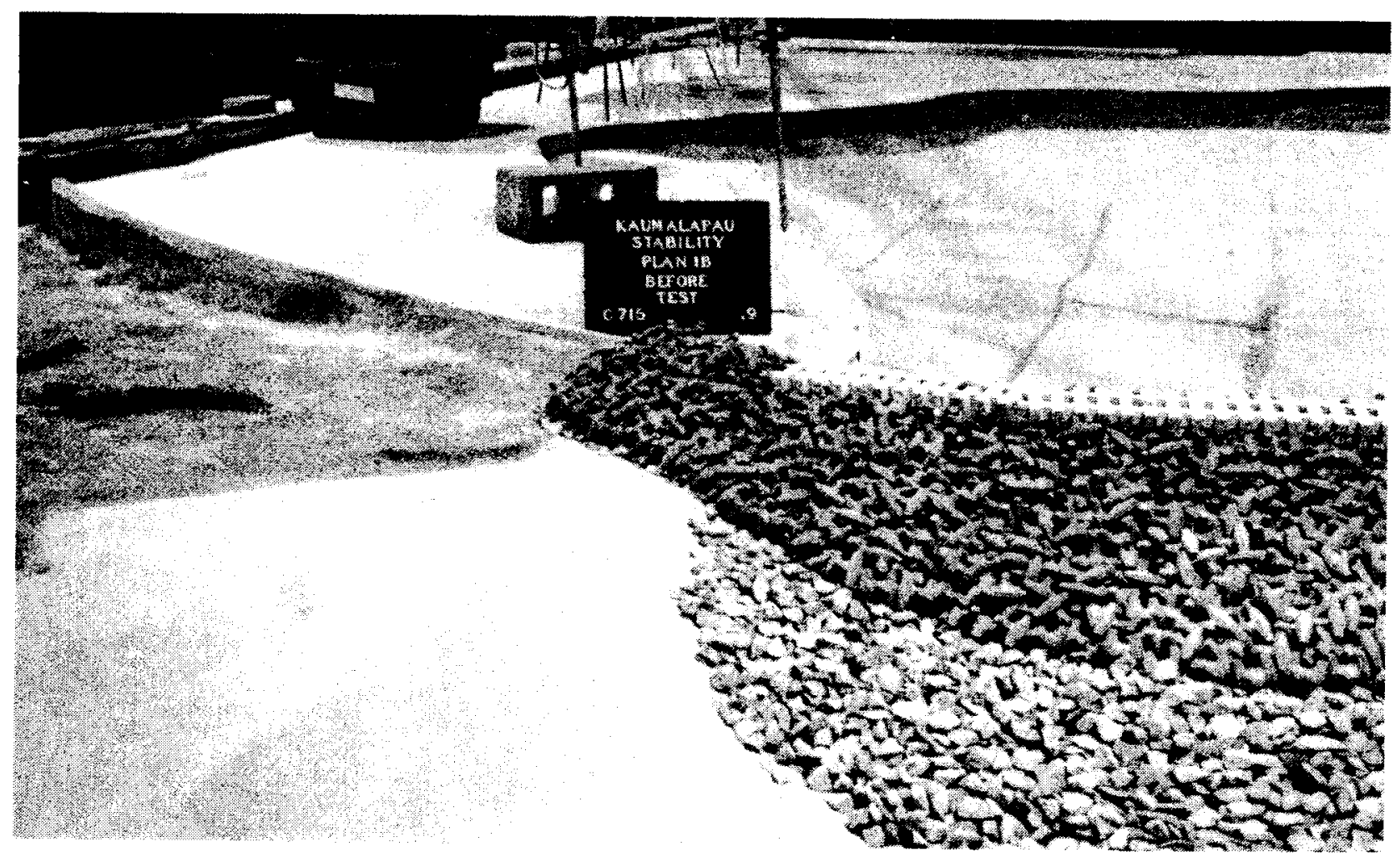

Photo B8. Sea-side shoreward end view of Plan 4B, before experiments 


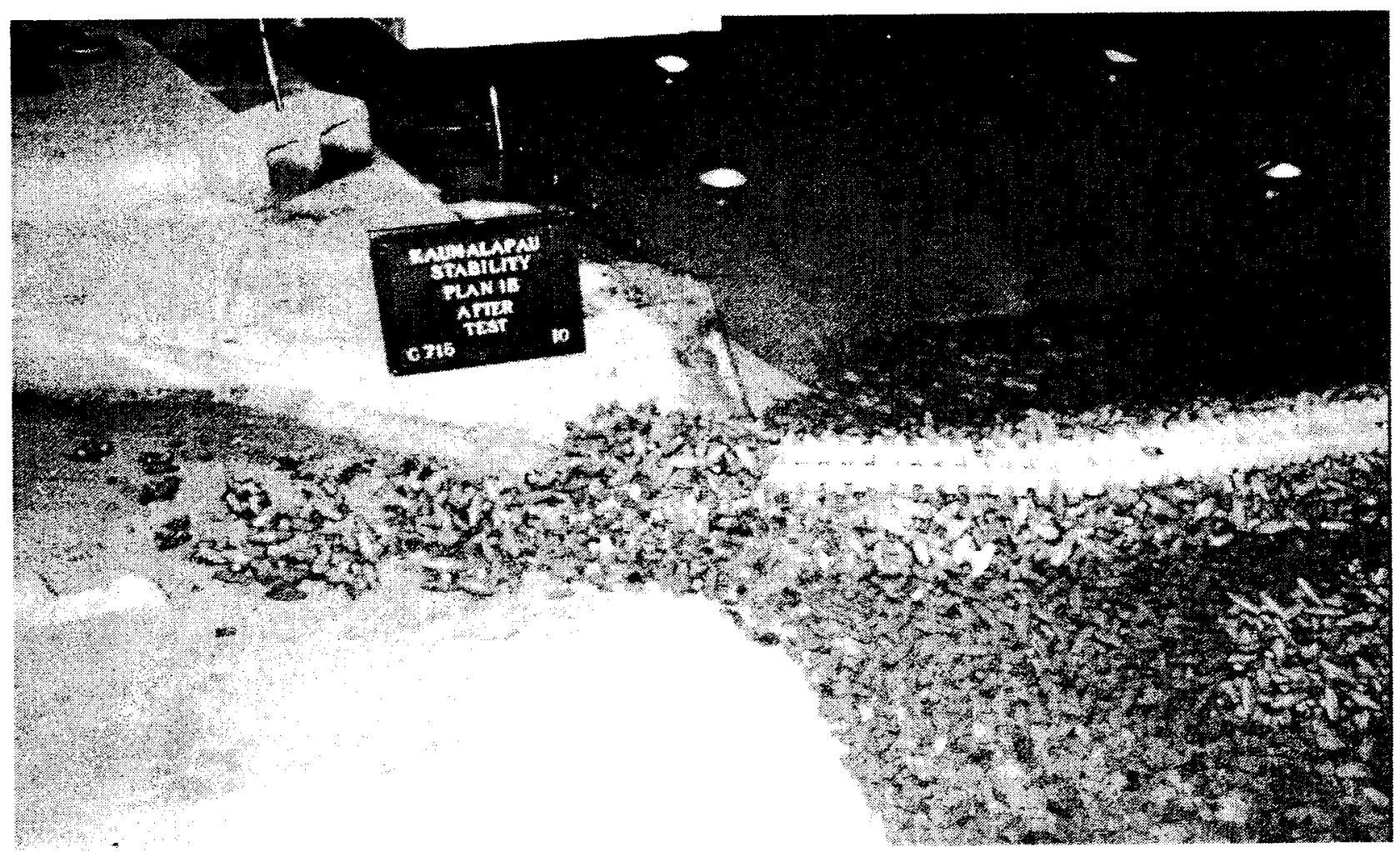

Photo B9. Sea-side shoreward end view of Plan 4B, after 9.8-sec, 6.4-m waves

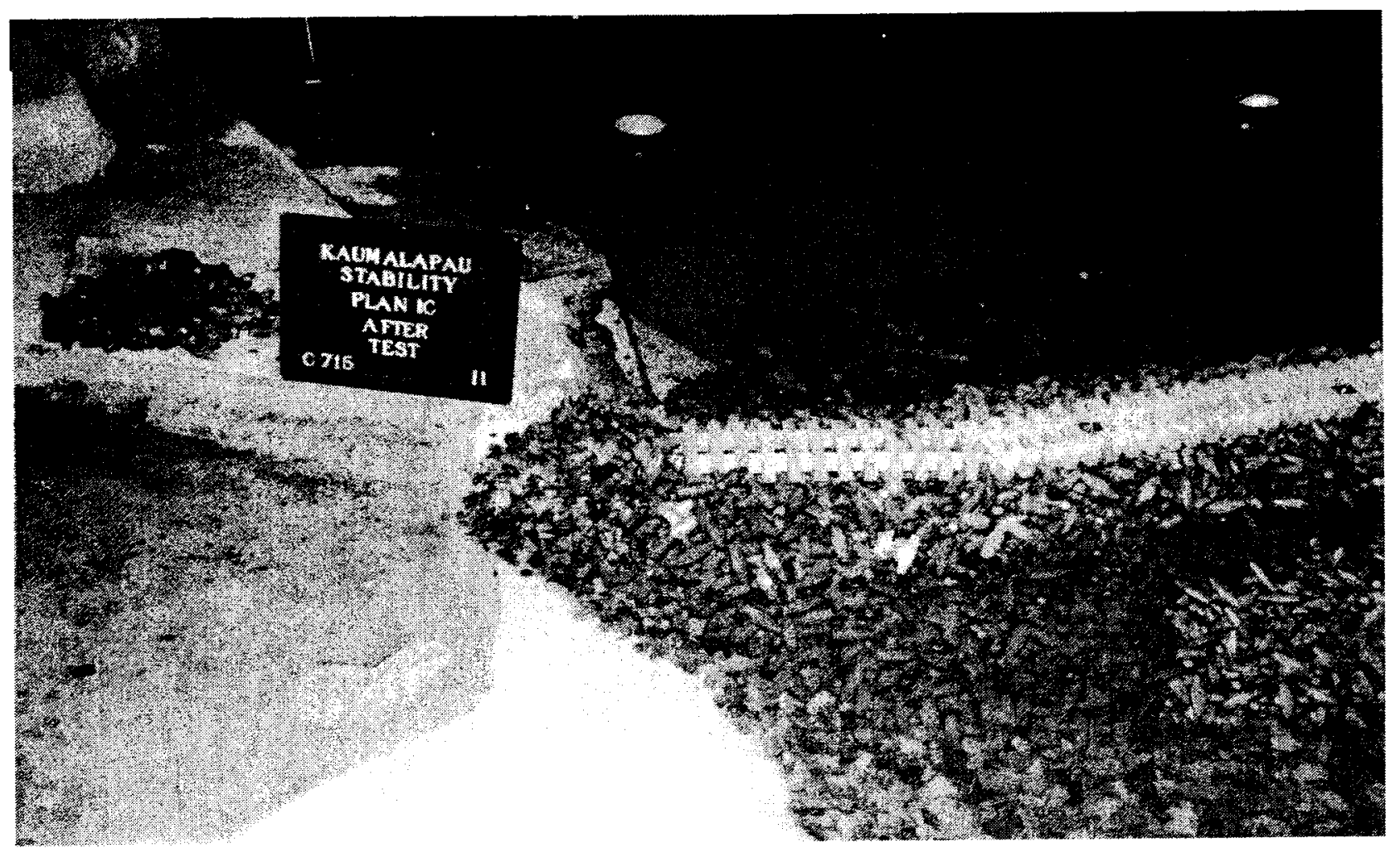

Photo B10. Sea-side shoreward end view of Plan $4 \mathrm{C}$ before experiments 


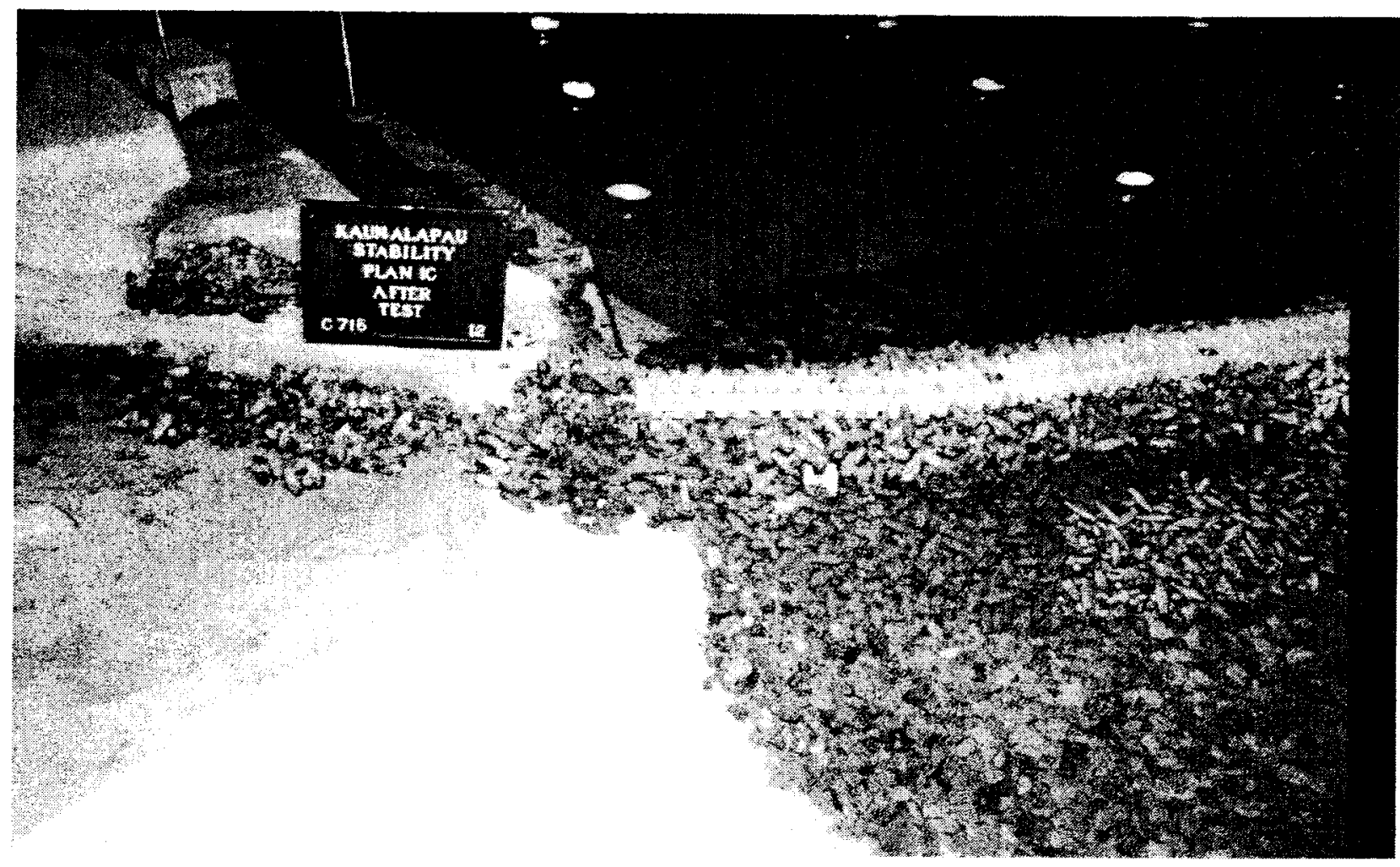

Photo B11. Sea-side shoreward end view of Plan $4 \mathrm{C}$, after $9.8-\mathrm{sec}, 6.4-\mathrm{m}$ waves

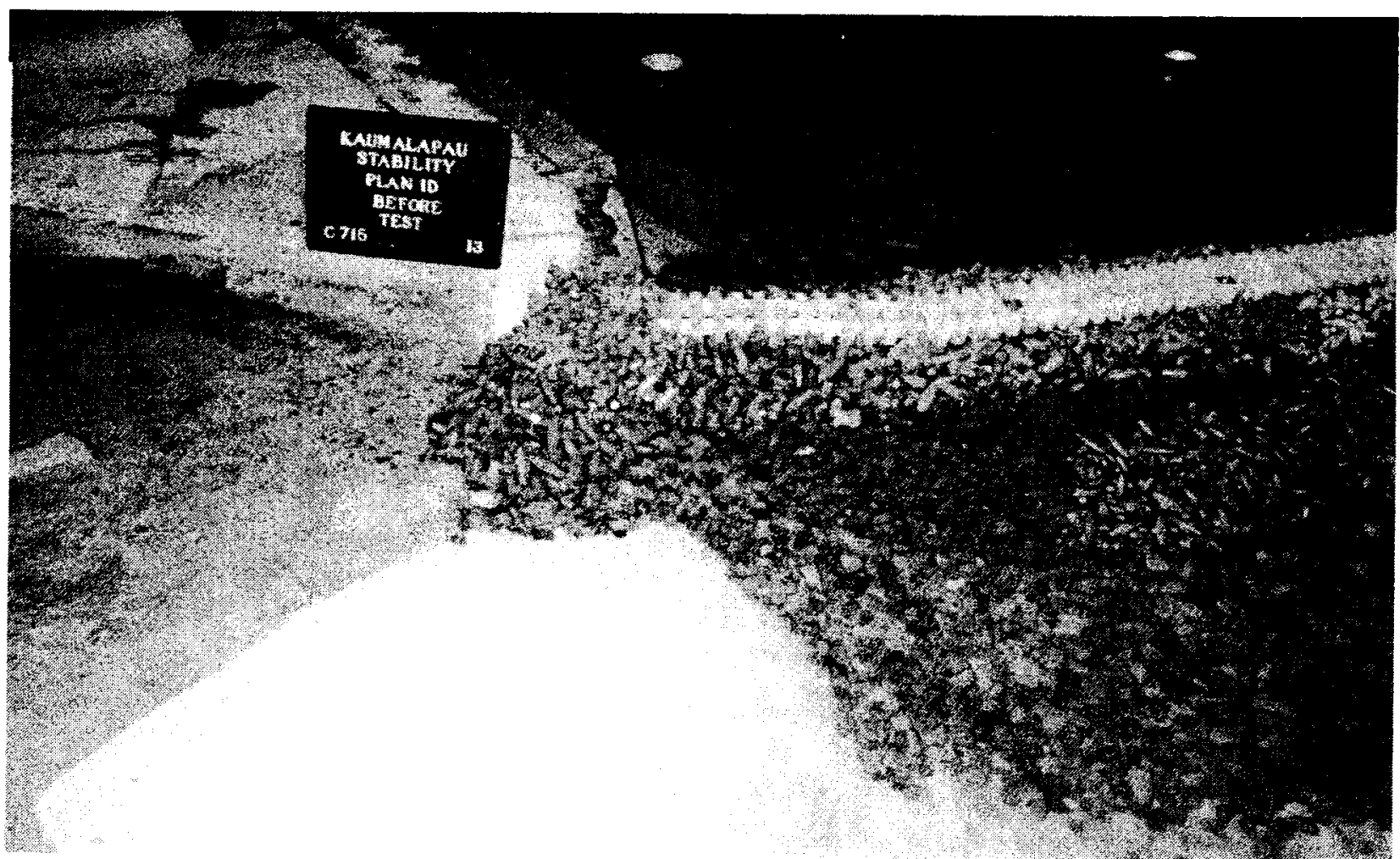

Photo B12. Sea-side shoreward end view of Plan 4D before experiments 


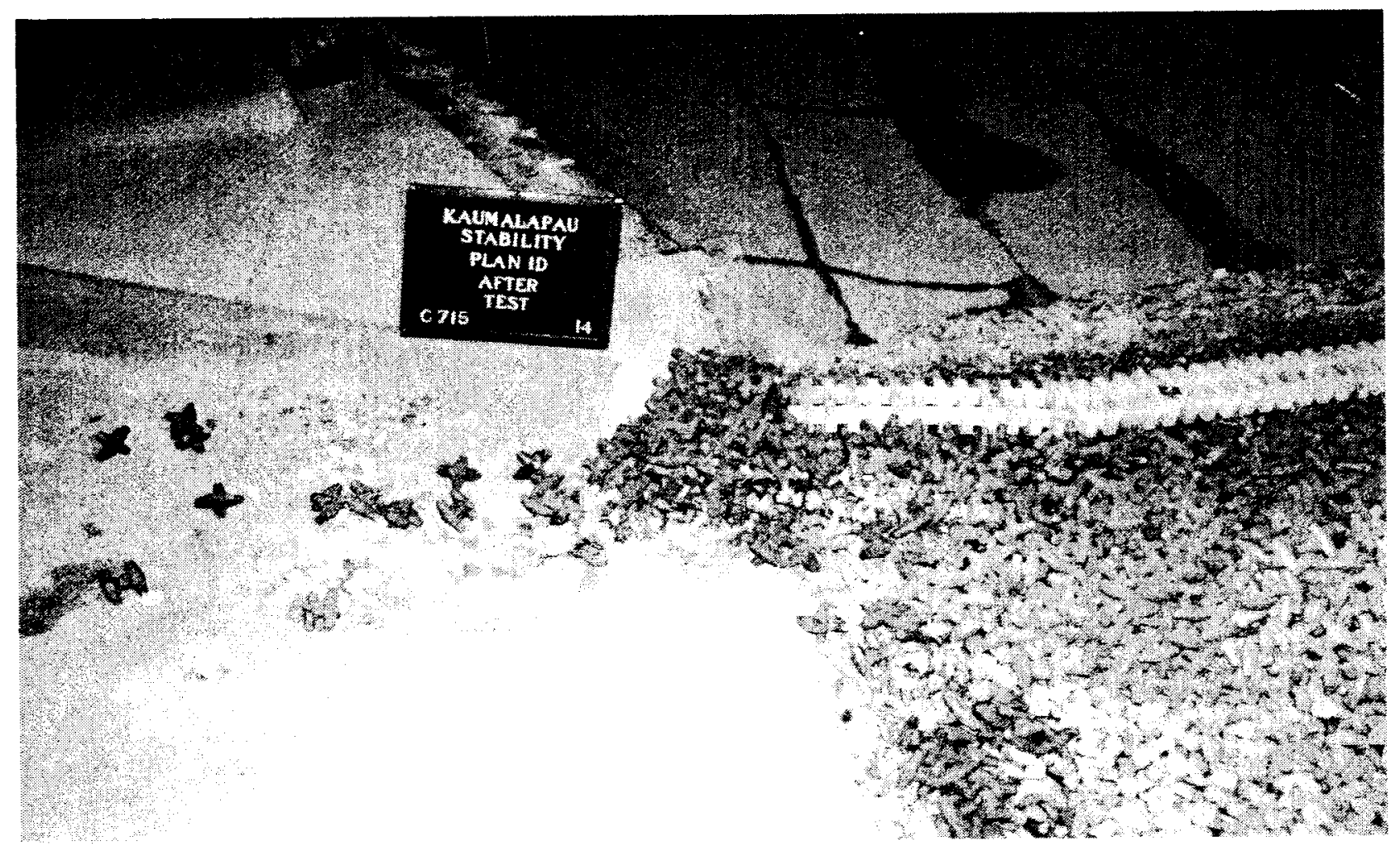

Photo B13. Sea-side shoreward end view of Plan 4D, after 9.8-sec, 6.4-m waves

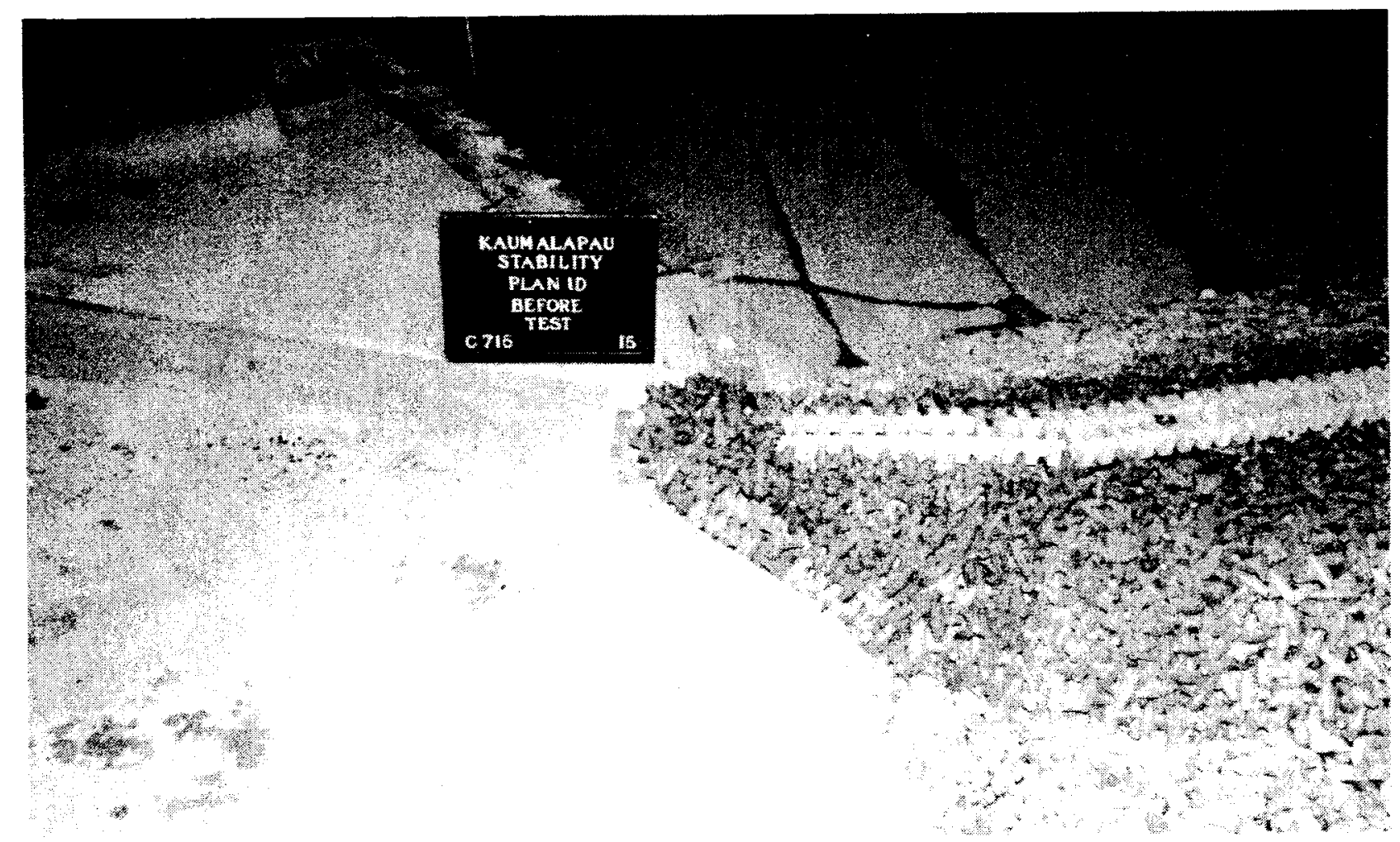

Photo B14. Sea-side shoreward end view of Plan 4E, before experiments 


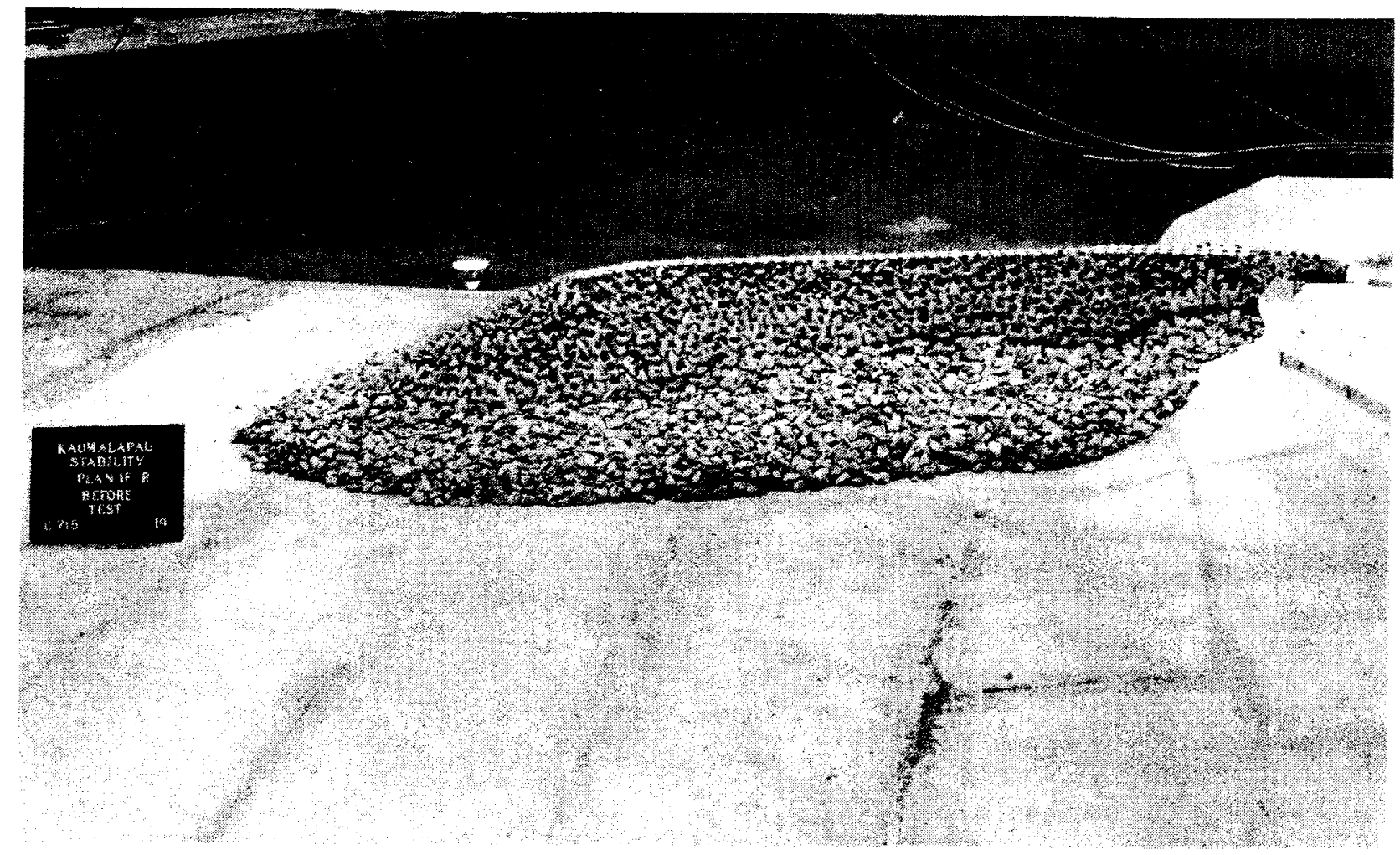

Photo B15. Leeside view of Plan $4 \mathrm{E}$ before experiments

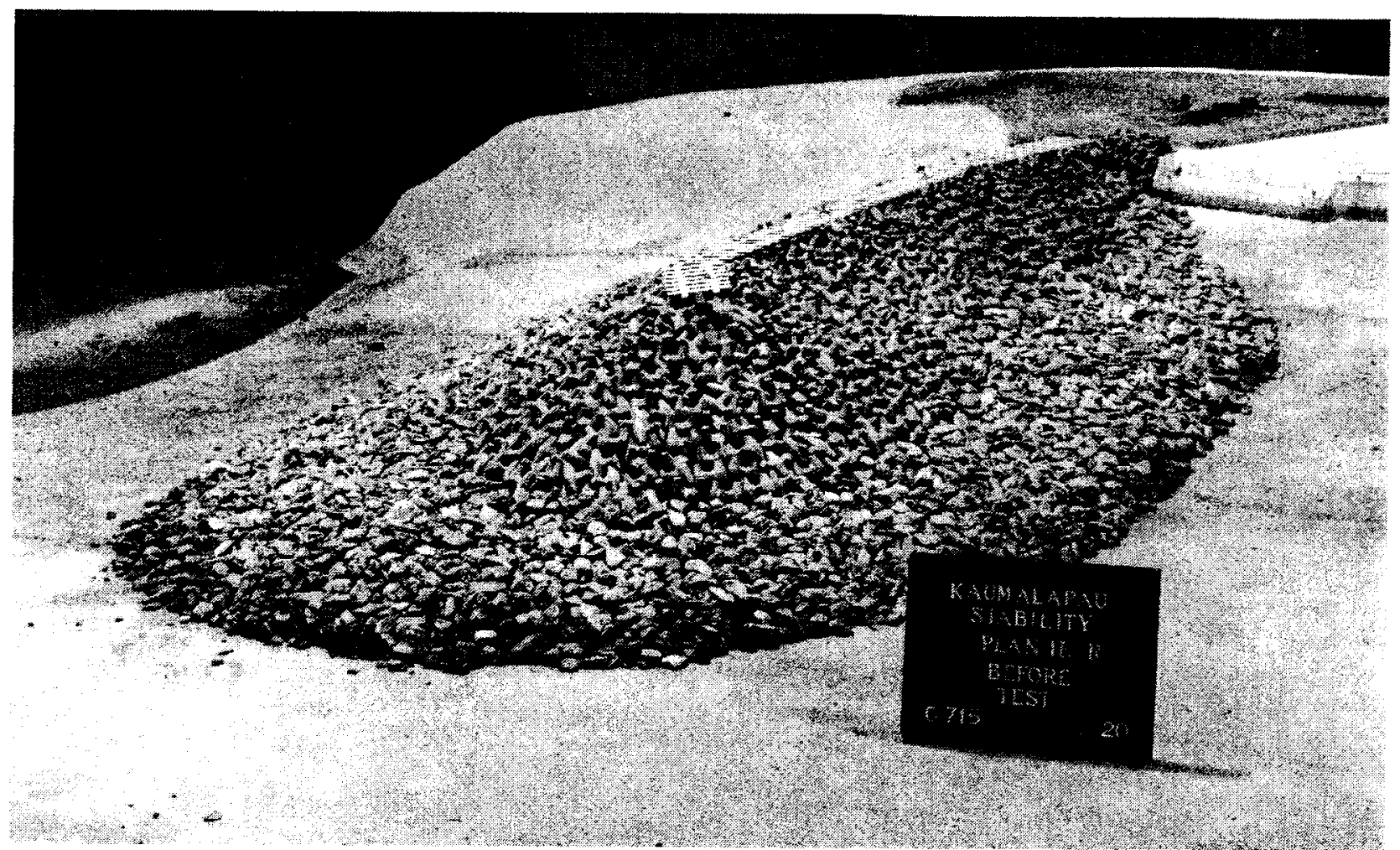

Photo B16. Plan 4E, breakwater head before experiments 


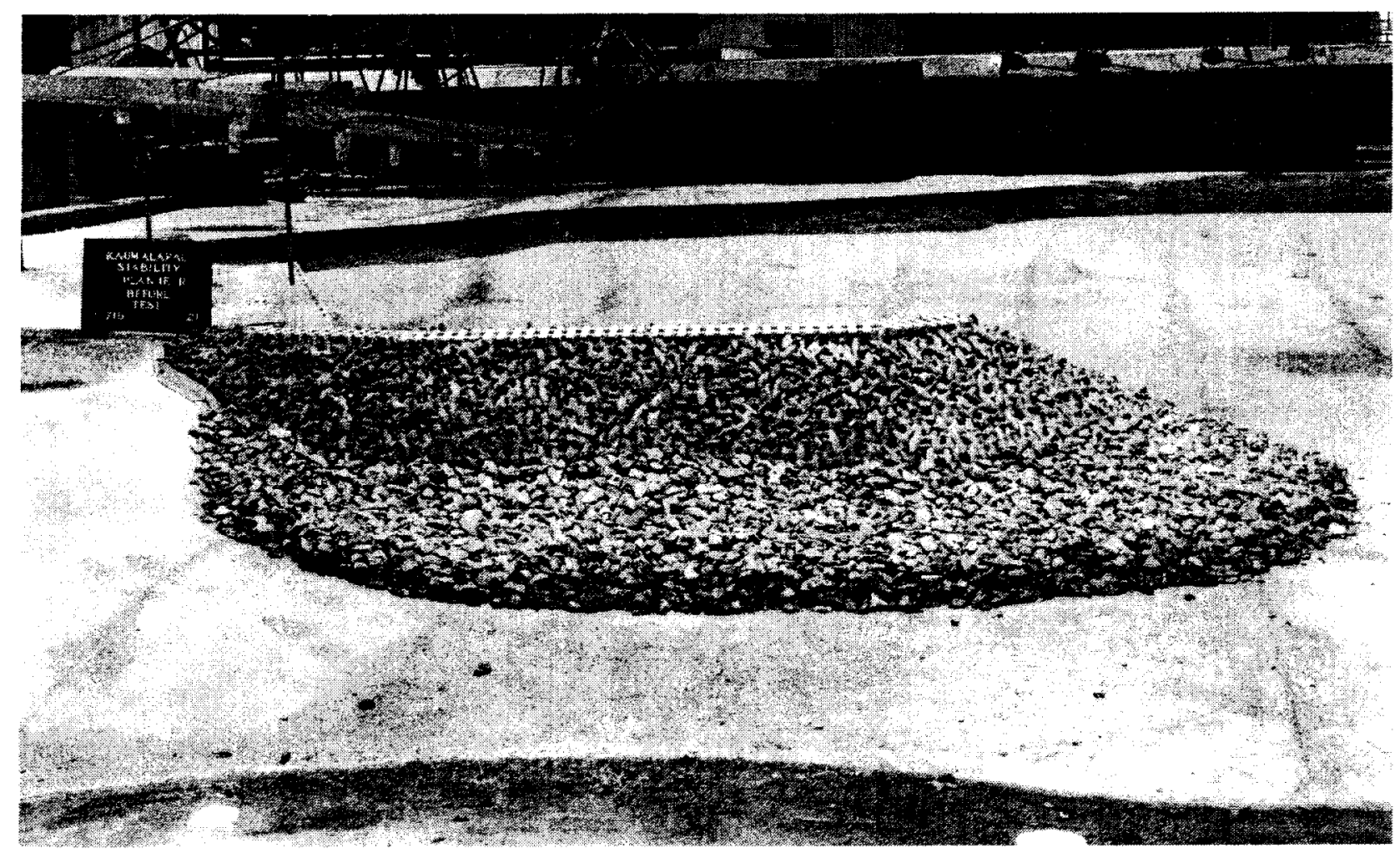

Photo B17. Sea-side view of Plan 4E, before experiments

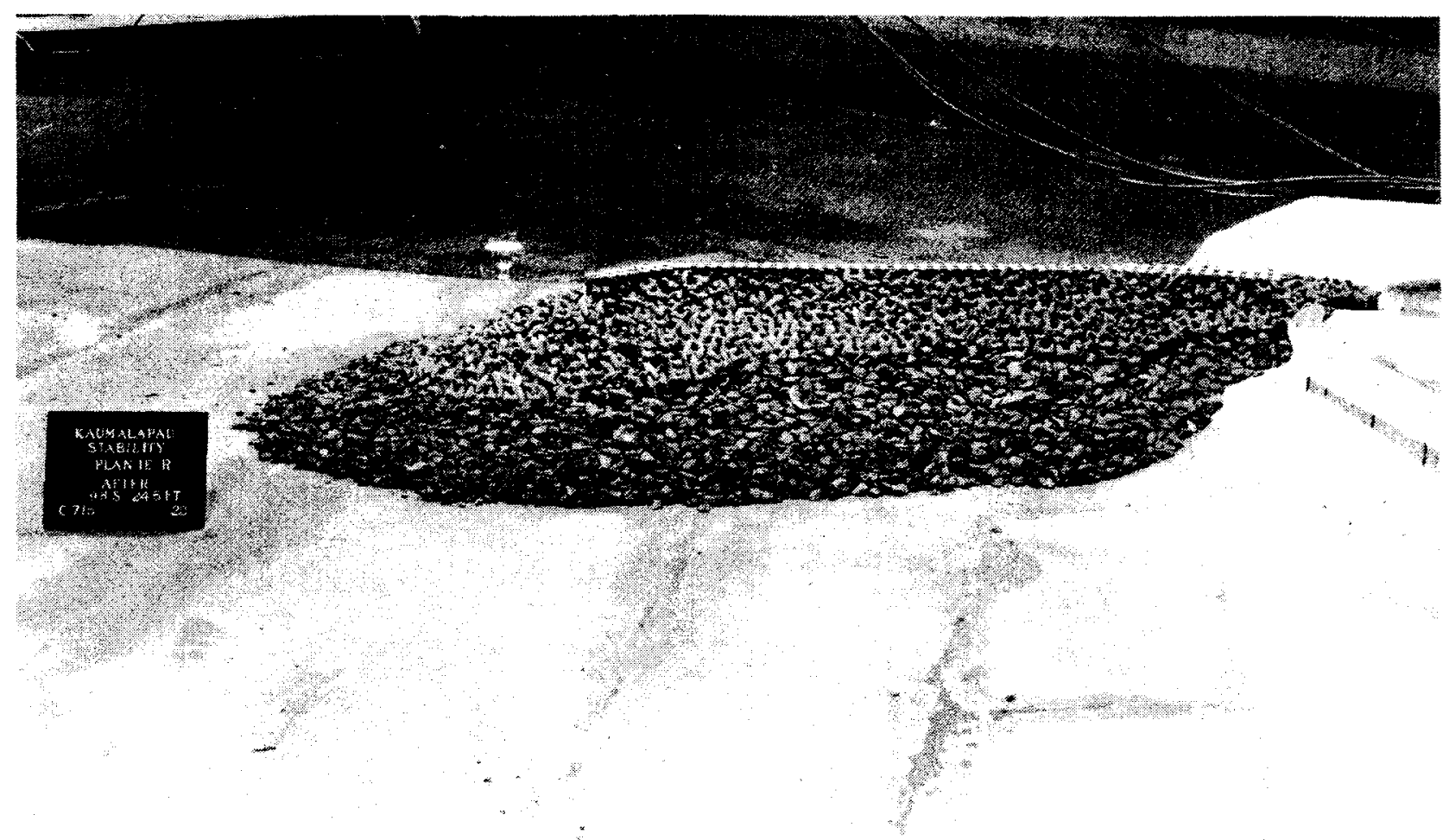

Photo B18. Leeside view of Plan 4E, after 9.8-sec, 7.5-m waves

B10 


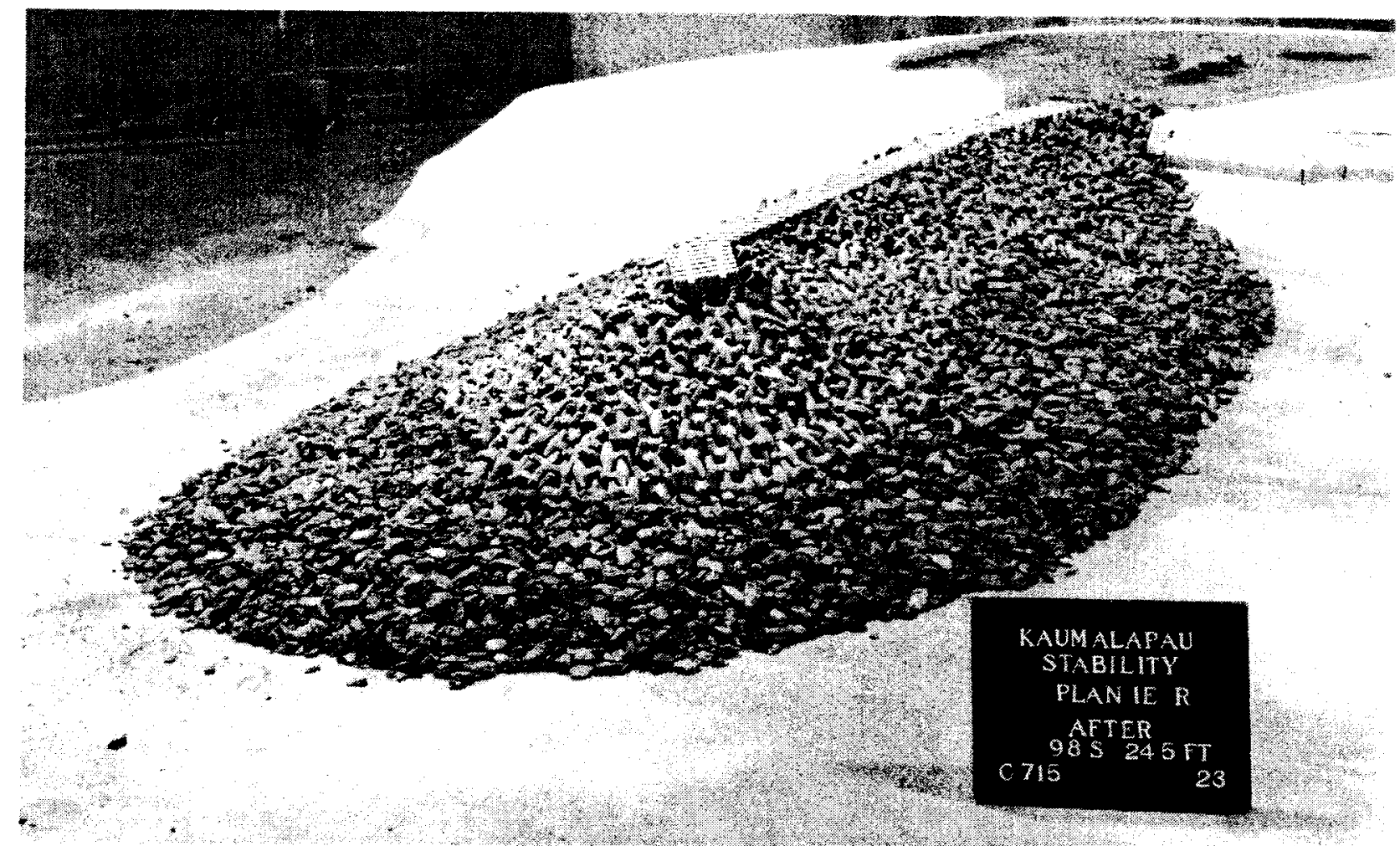

Photo B19. Plan 4E, breakwater head after 9.8-sec, 7.5-m waves

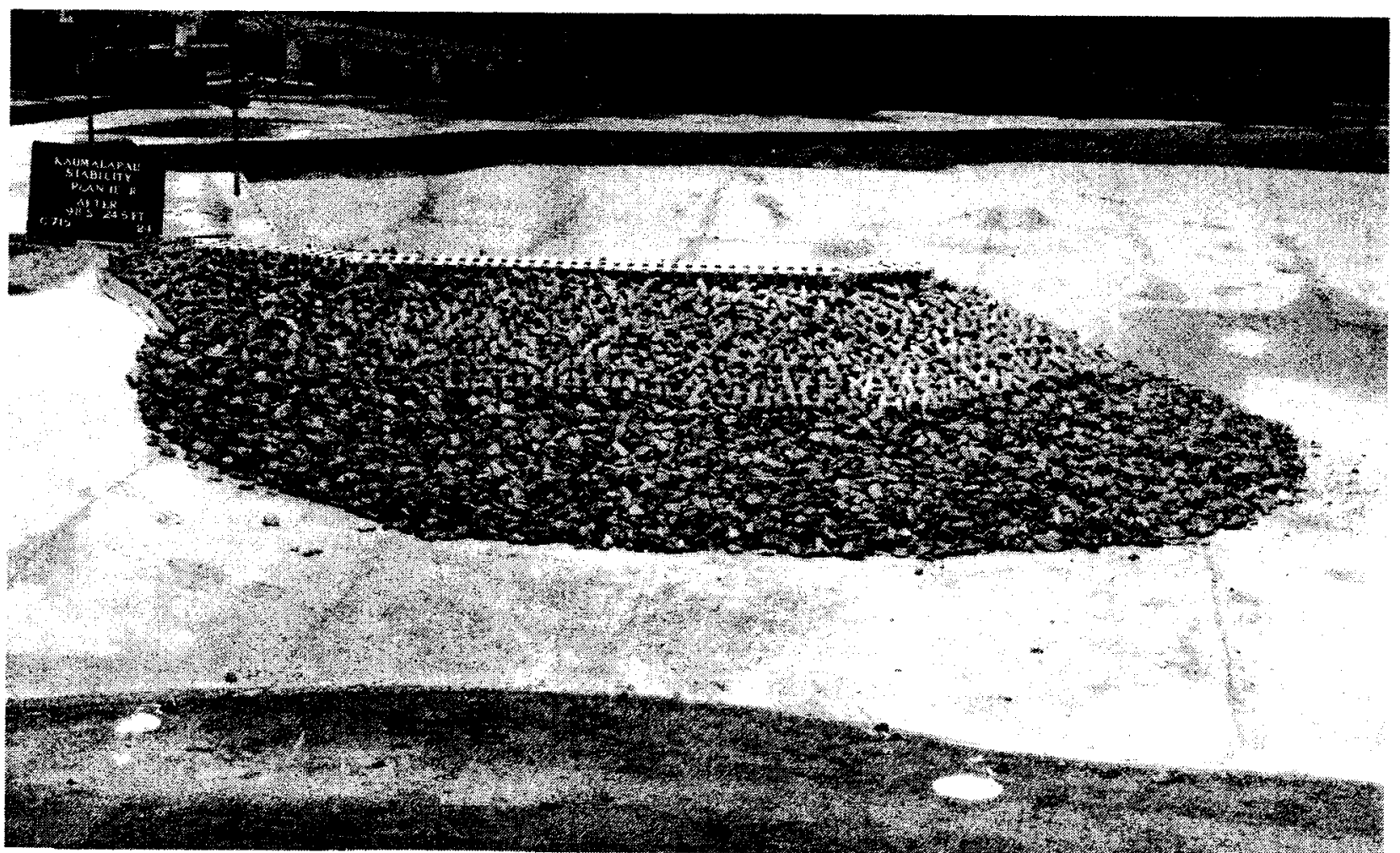

Photo B20. Sea-side view of Plan 4E after 9.8-sec, 7.5-m waves 


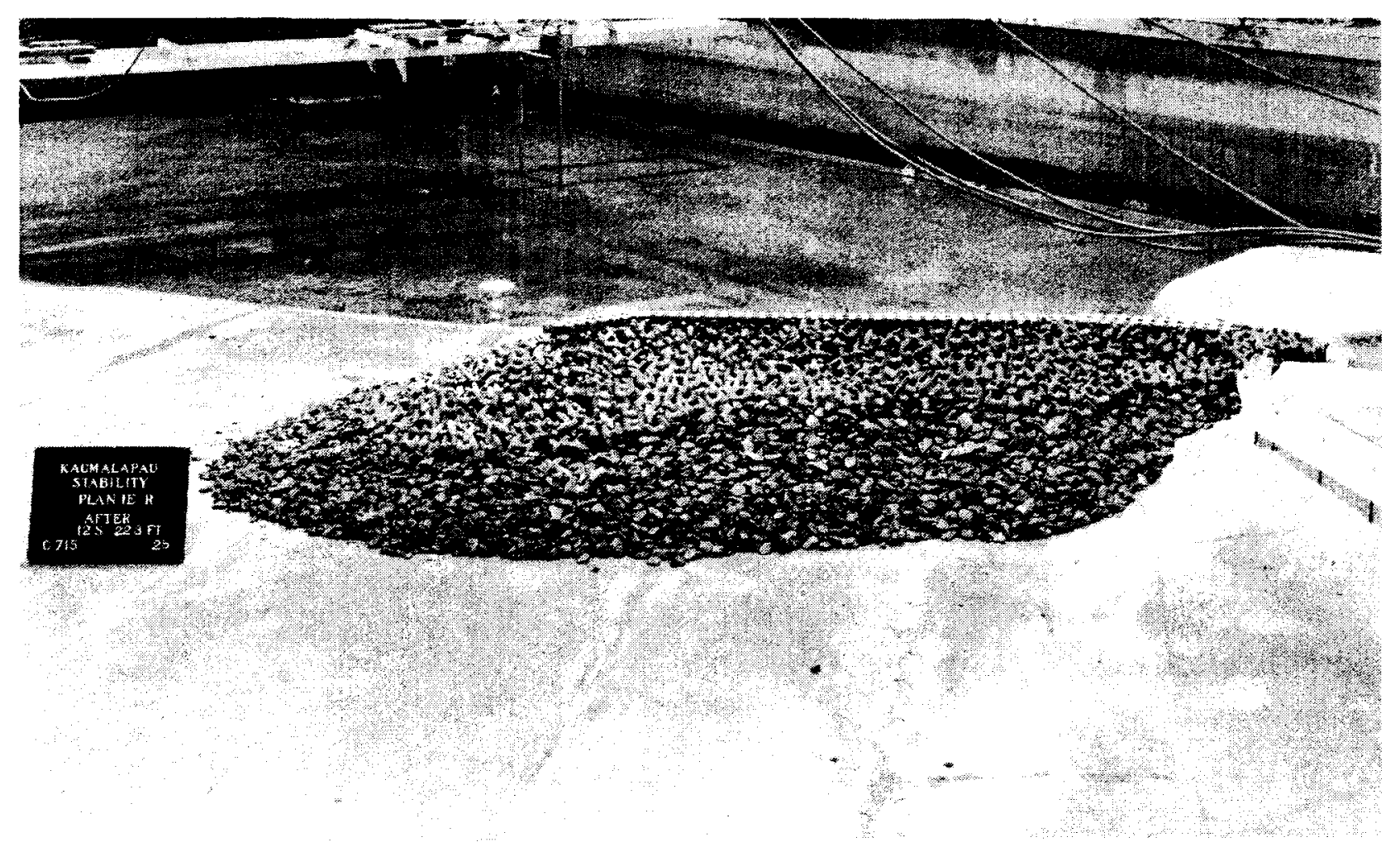

Photo B21. Leeside view of Plan 4E after 12-sec, 6.8-m waves

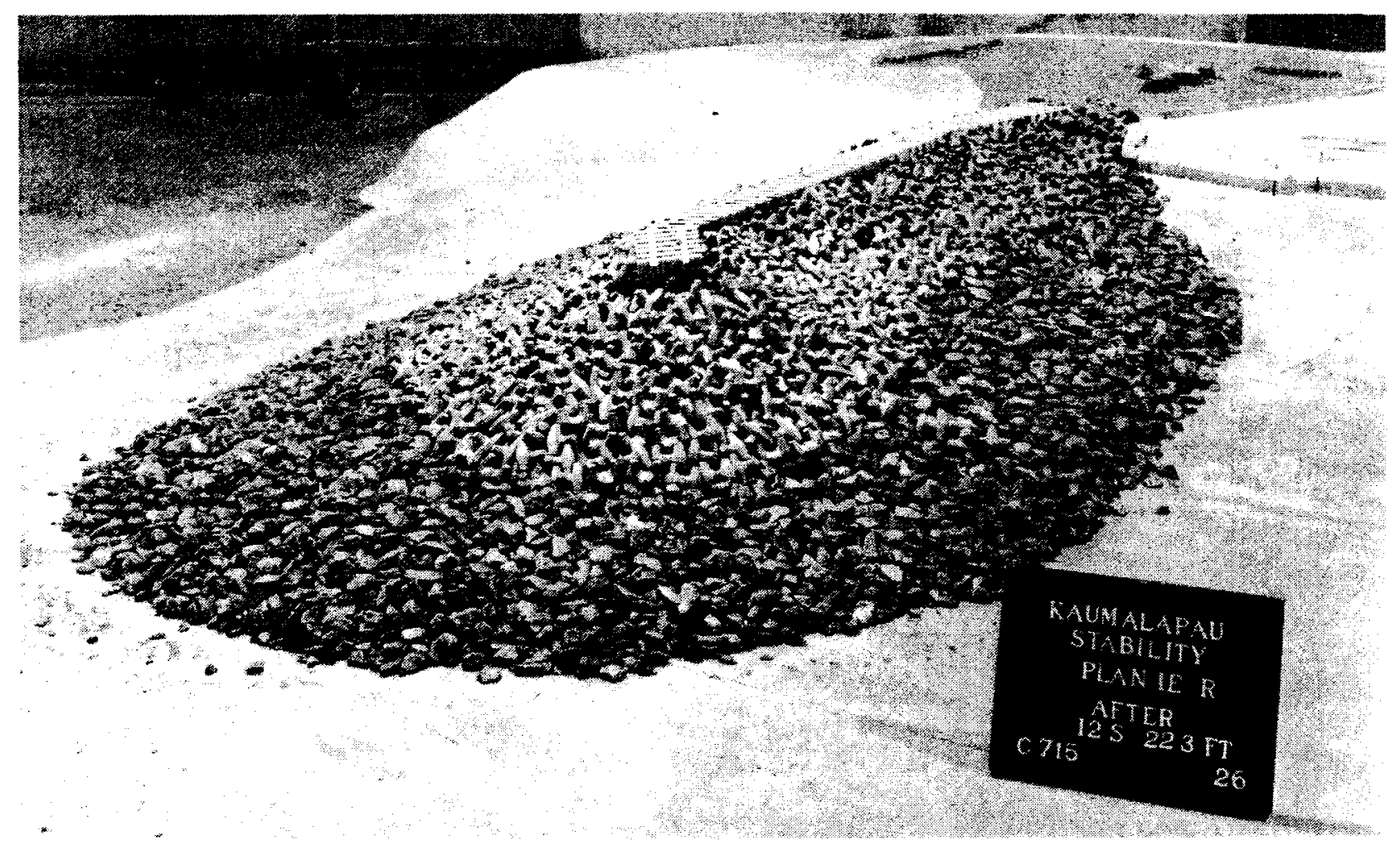

Photo B22. Plan 4E, breakwater head after 12-sec, 6.8-m waves

B12 


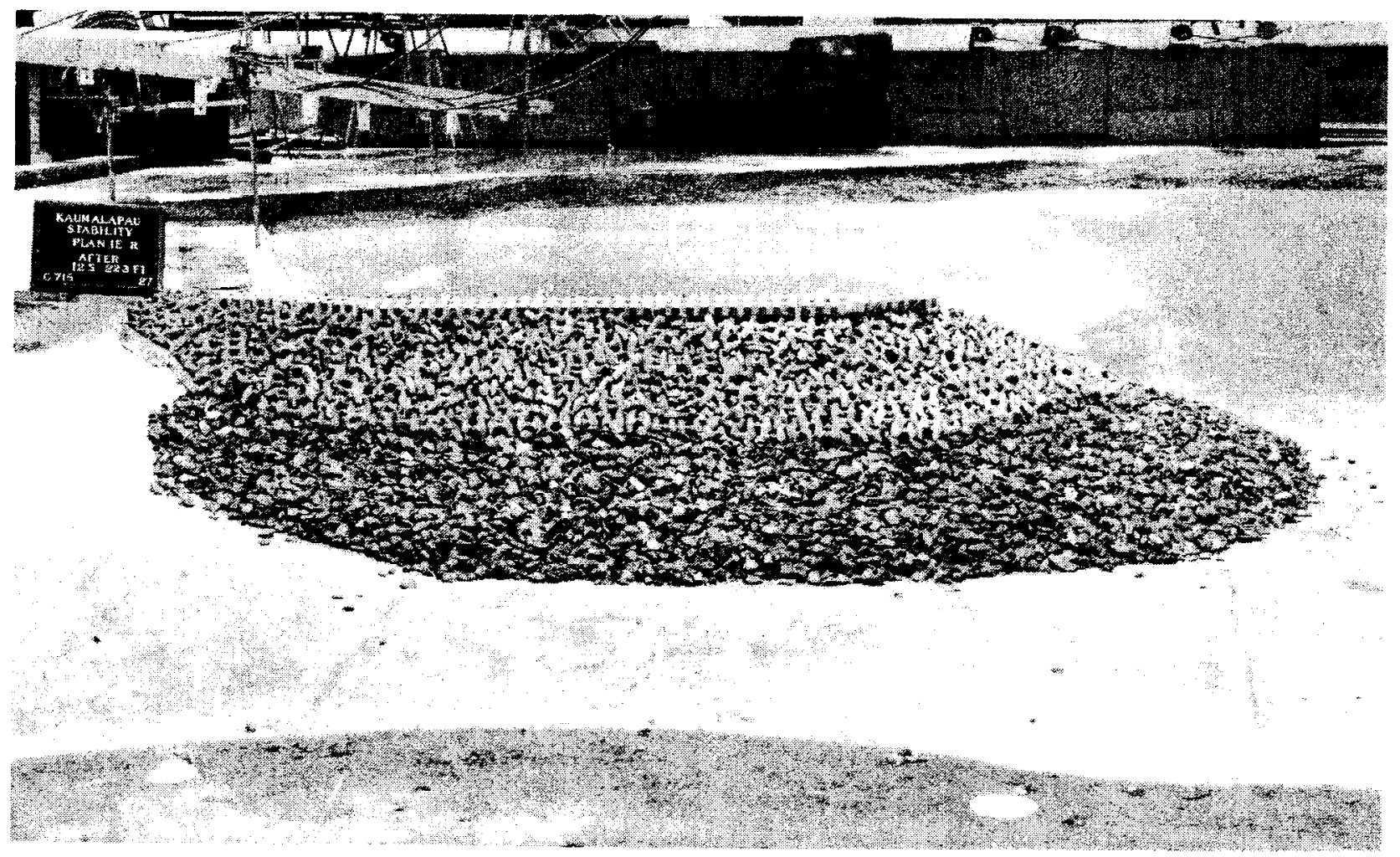

Photo B23. Sea-side view of Plan 4E after 12-sec, 6.8-m waves

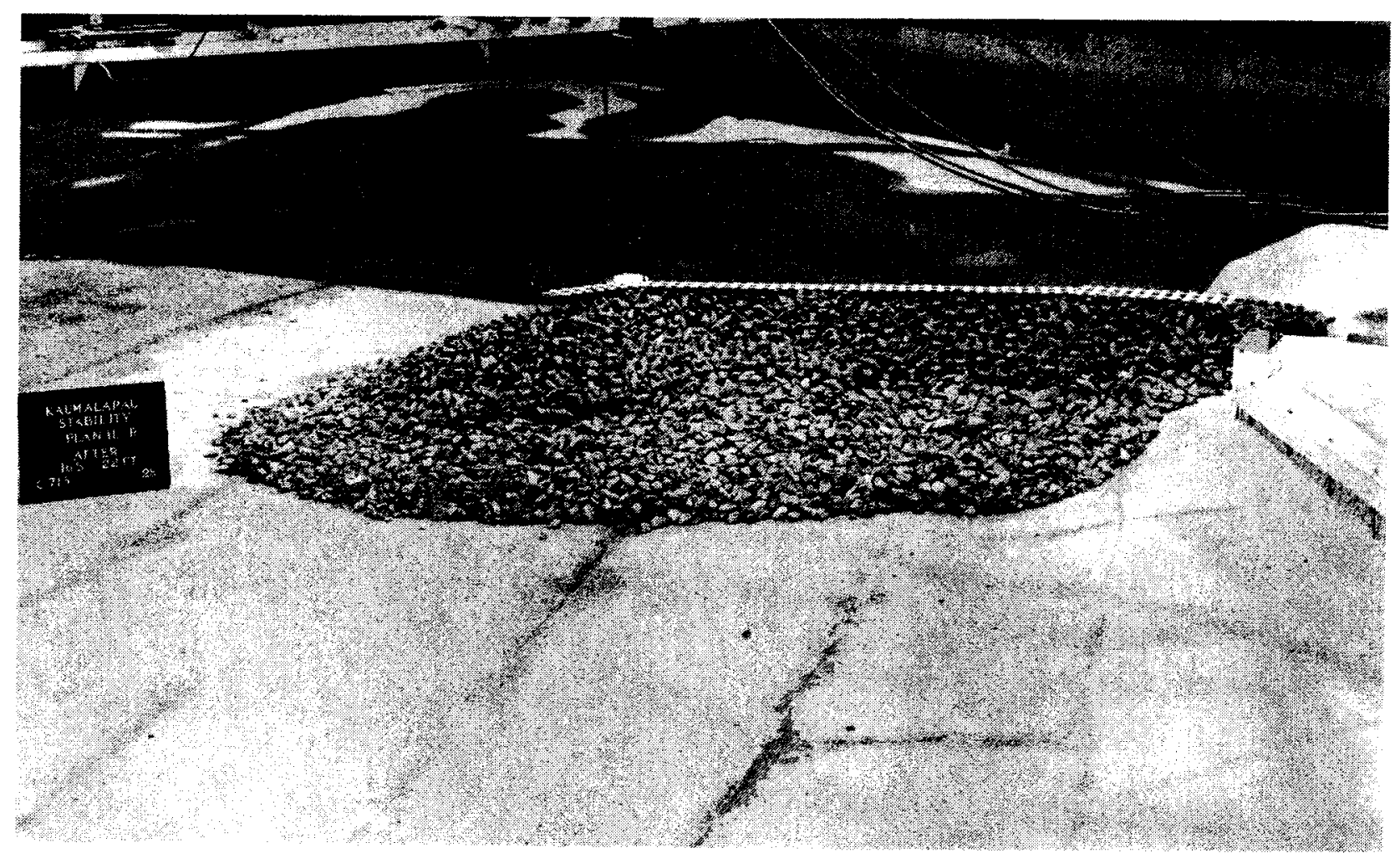

Photo B24. Leeside view of Plan 4E after 16-sec, 6.7-m waves 


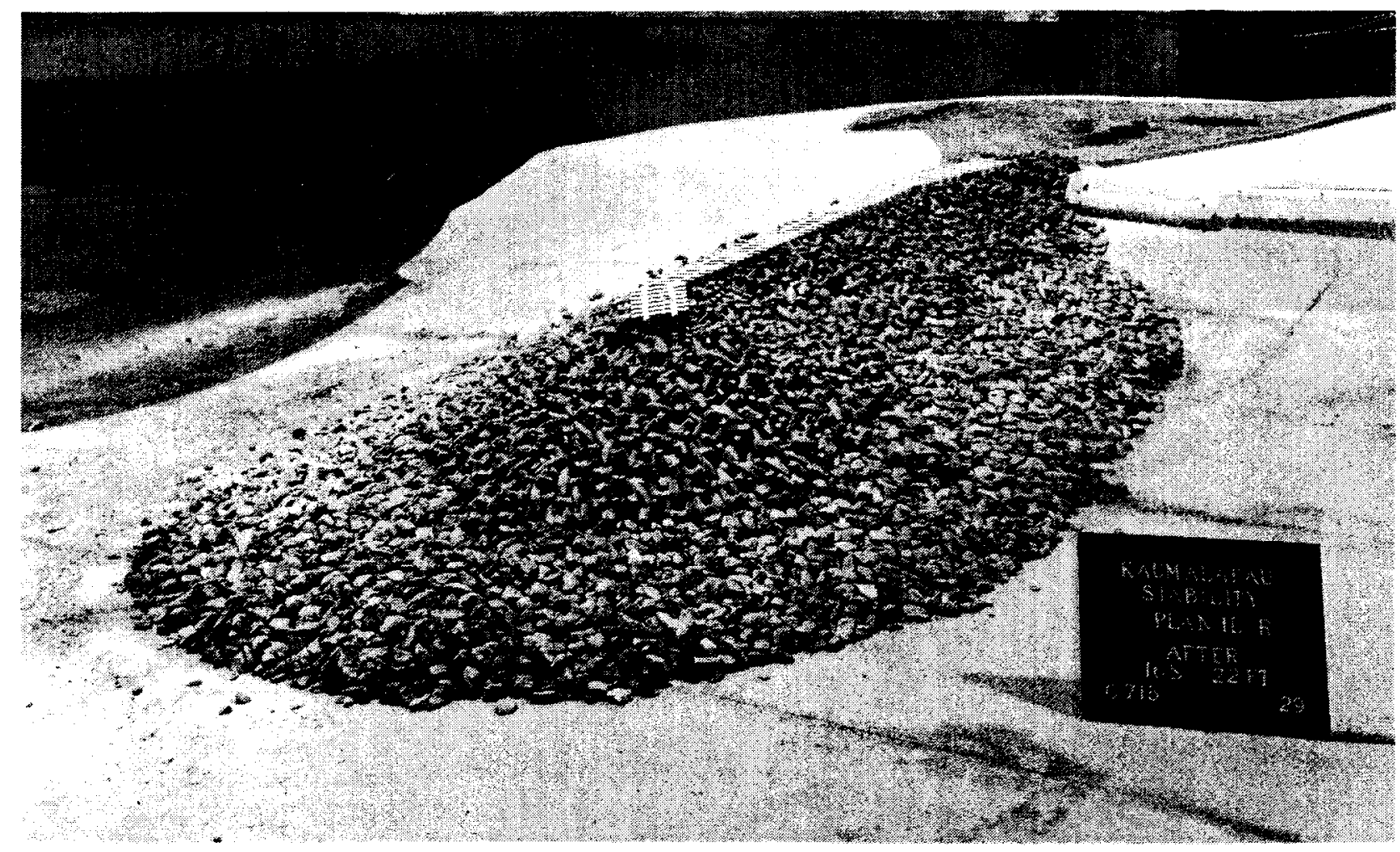

Photo B25. Plan 4E, breakwater head after 16-sec, 6.7-m waves

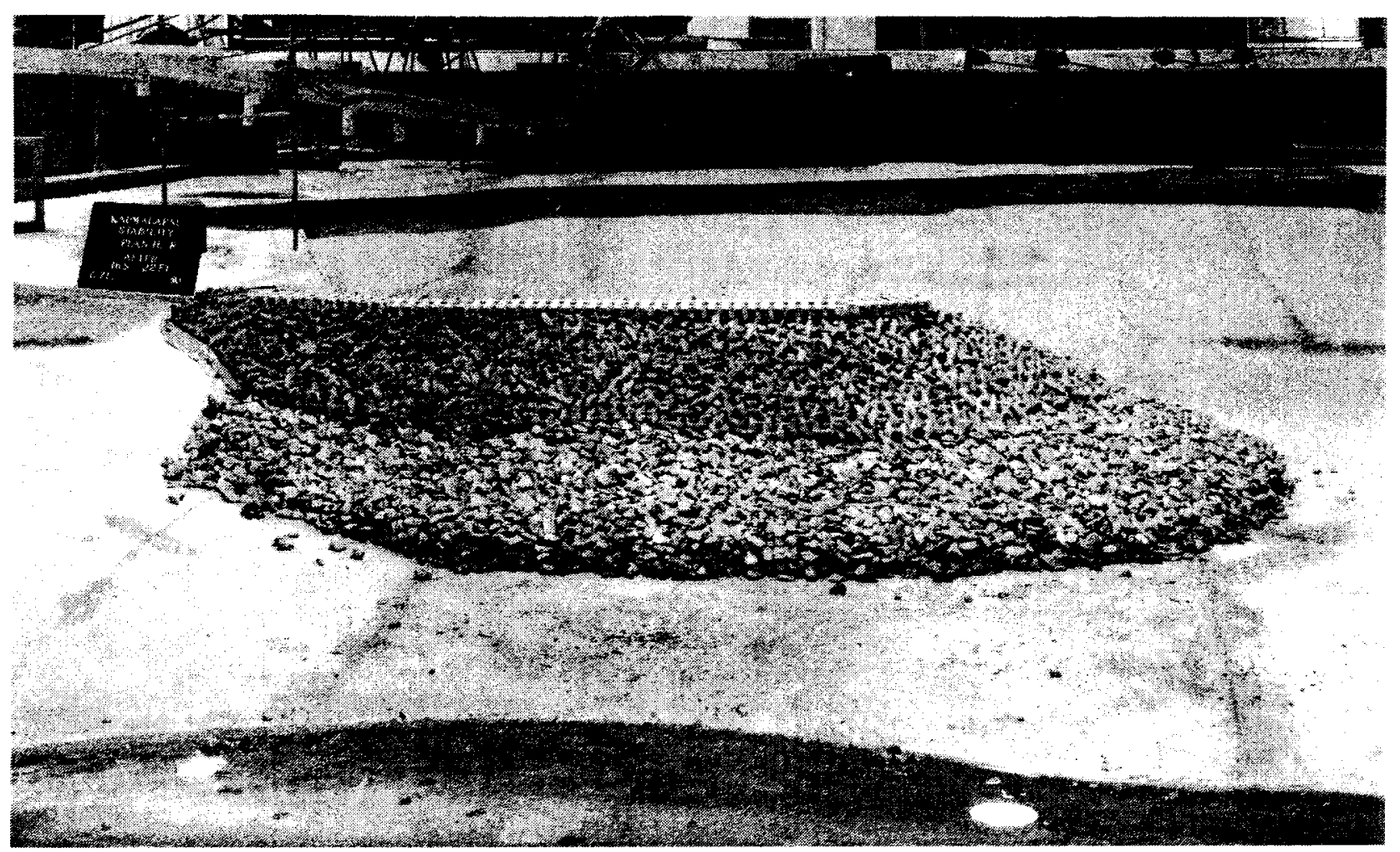

Photo B26. Sea-side view of Plan 4E after 16-sec, 6.7-m waves 


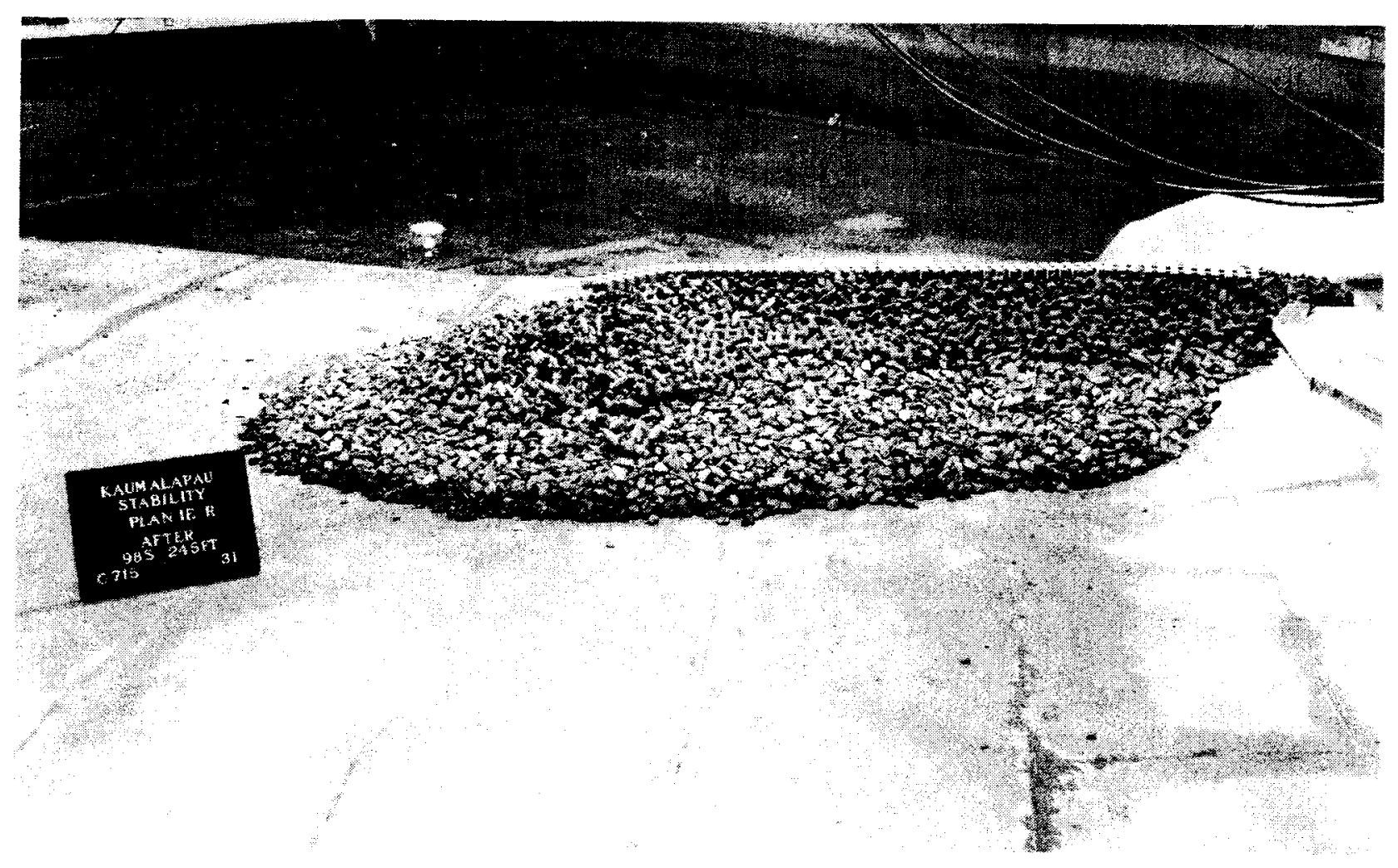

Photo B27. Leeside view of Plan 4E, after 9.8-sec, 8.7-m waves

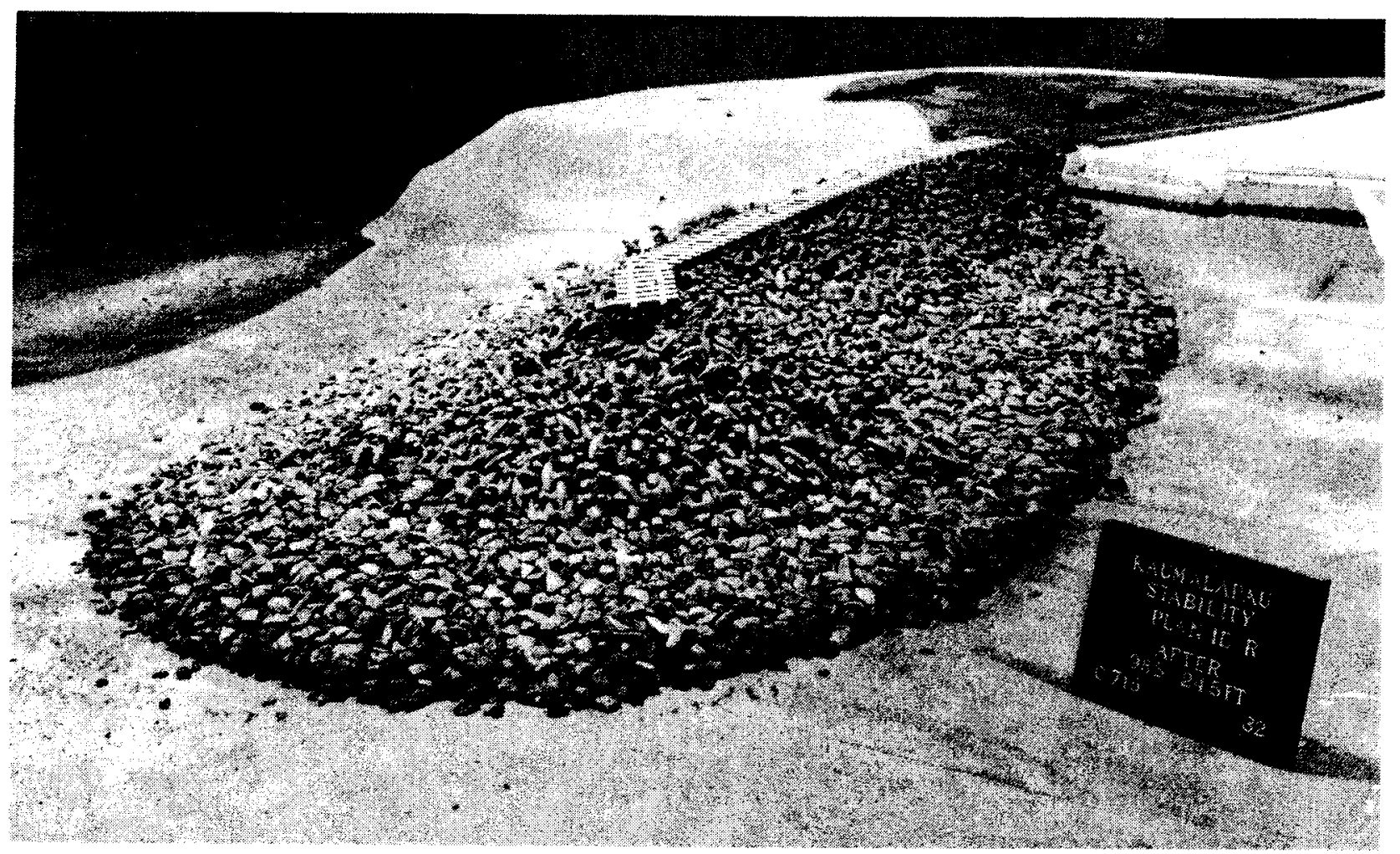

Photo B28. Plan 4E, breakwater head after 9.8-sec, 8.7-m waves 


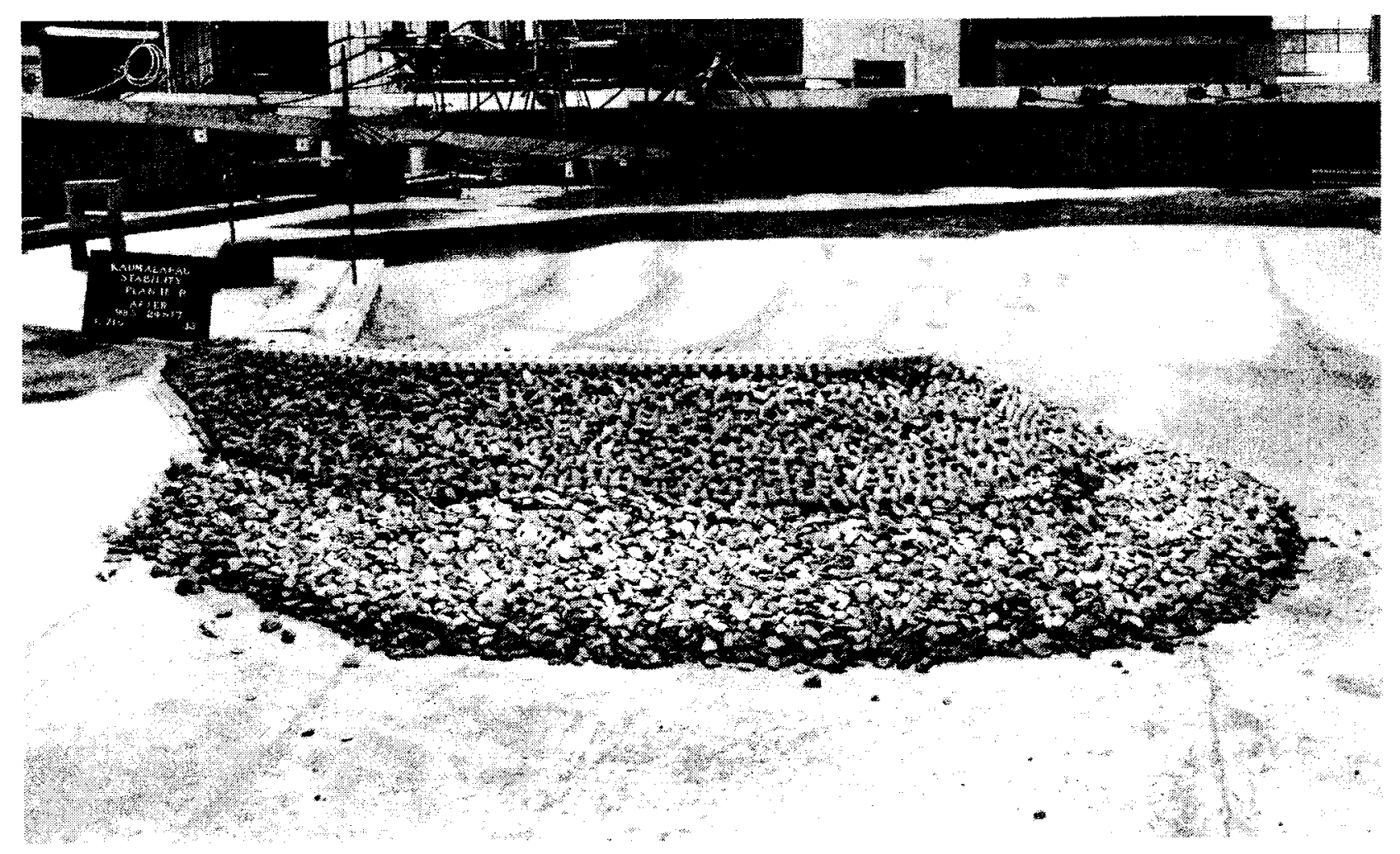

Photo B29. Sea-side view of Plan 4E after 9.8-sec, 8.7-m waves

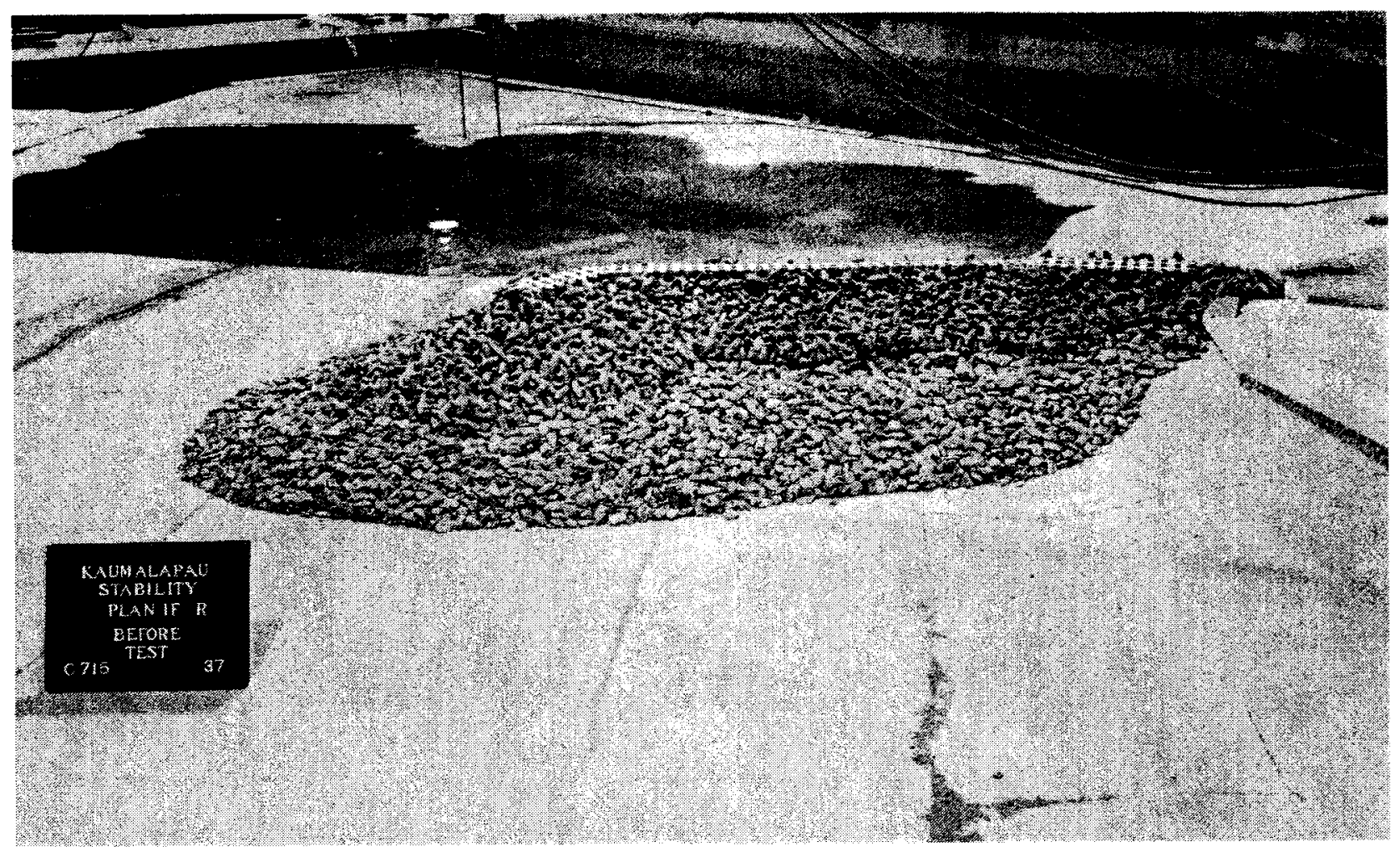

Photo B30. Leeside view of Plan 4F before experiments 


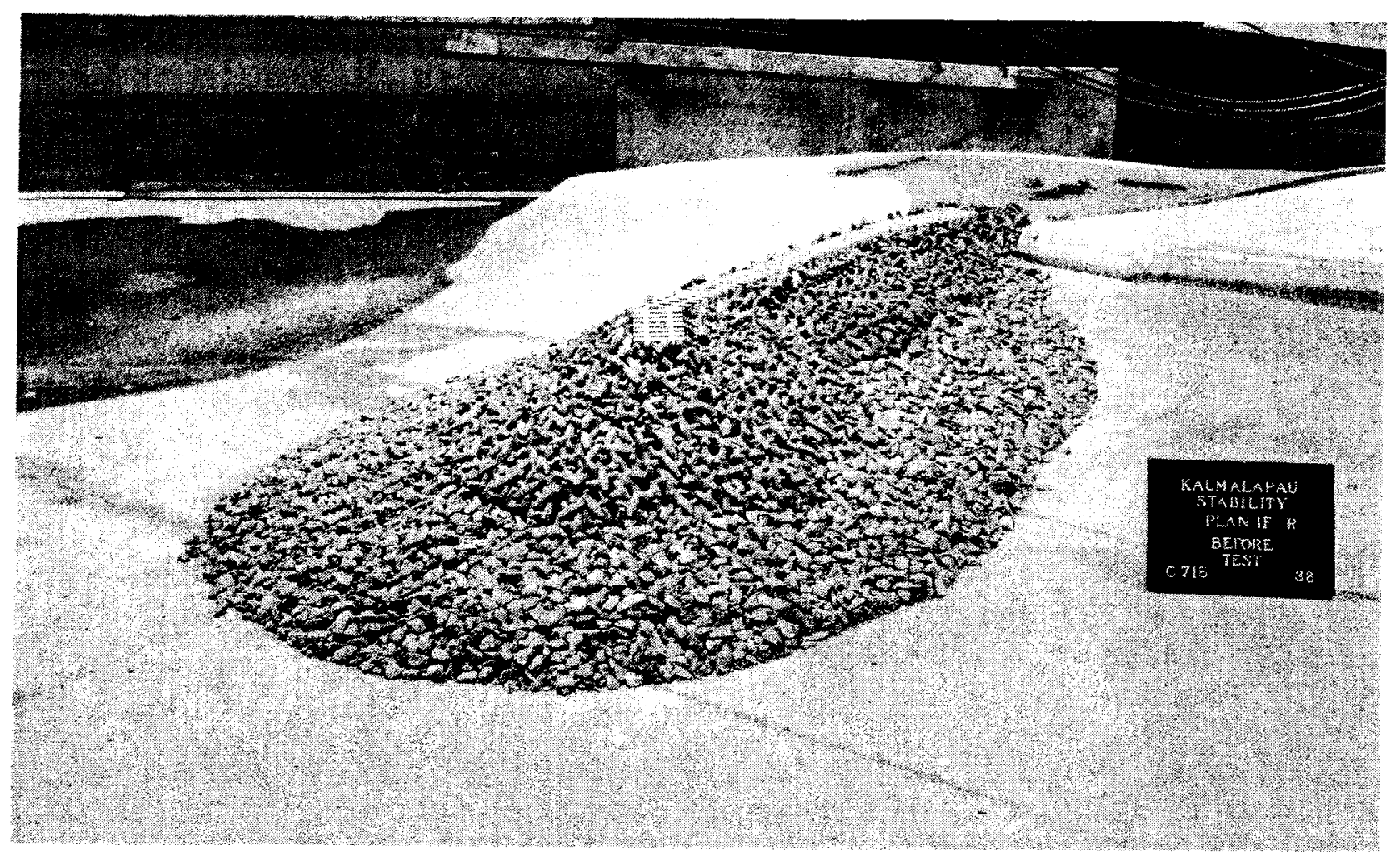

Photo B31. Plan 4F, breakwater head before experiments

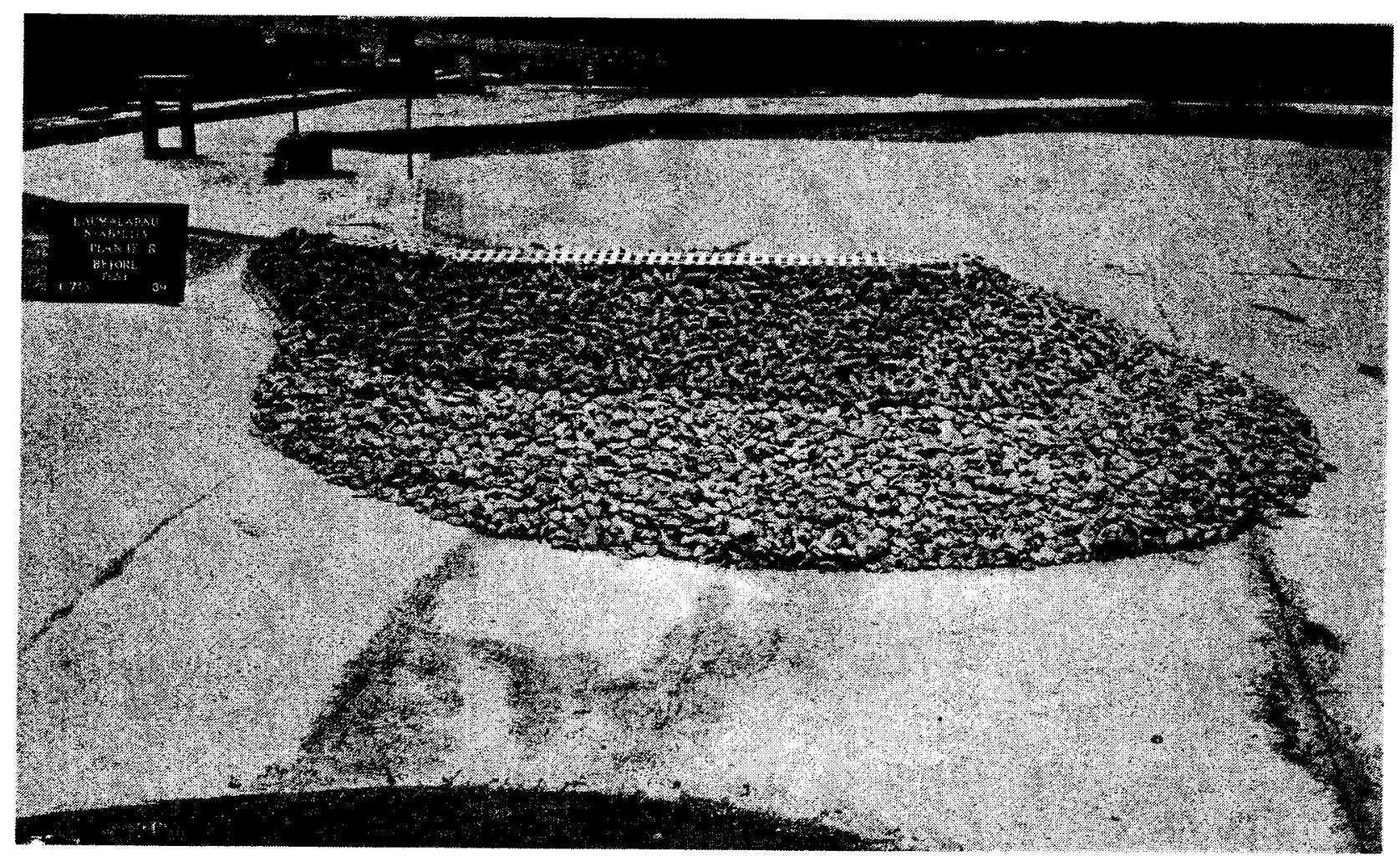

Photo B32. Sea-side view of Plan 4F before experiments 


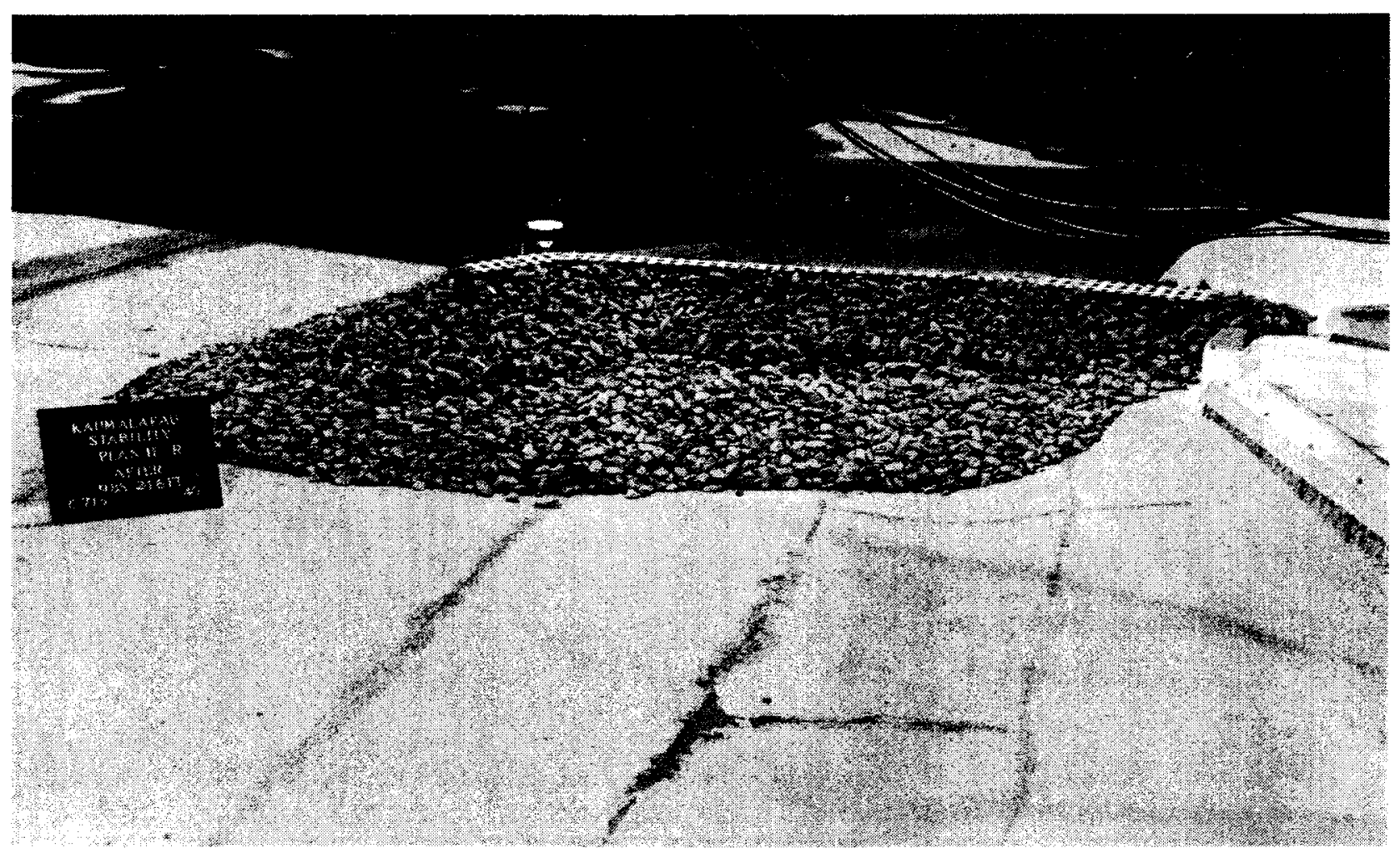

Photo B33. Leeside view of Plan 4F after 9.8-sec, 7.5-m waves

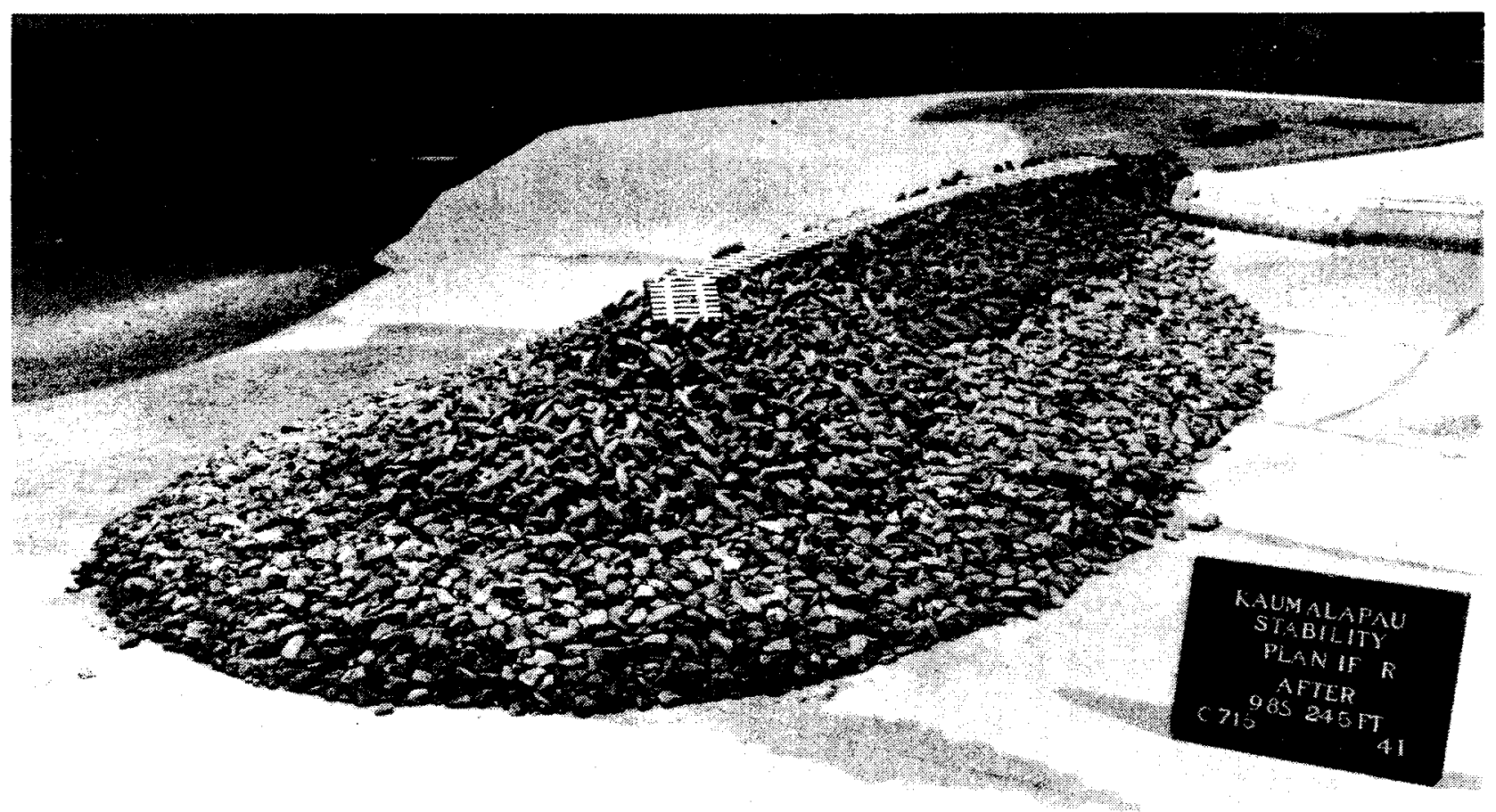

Photo B34. Plan 4F, breakwater head after 9.8-sec, 7.5-m waves 


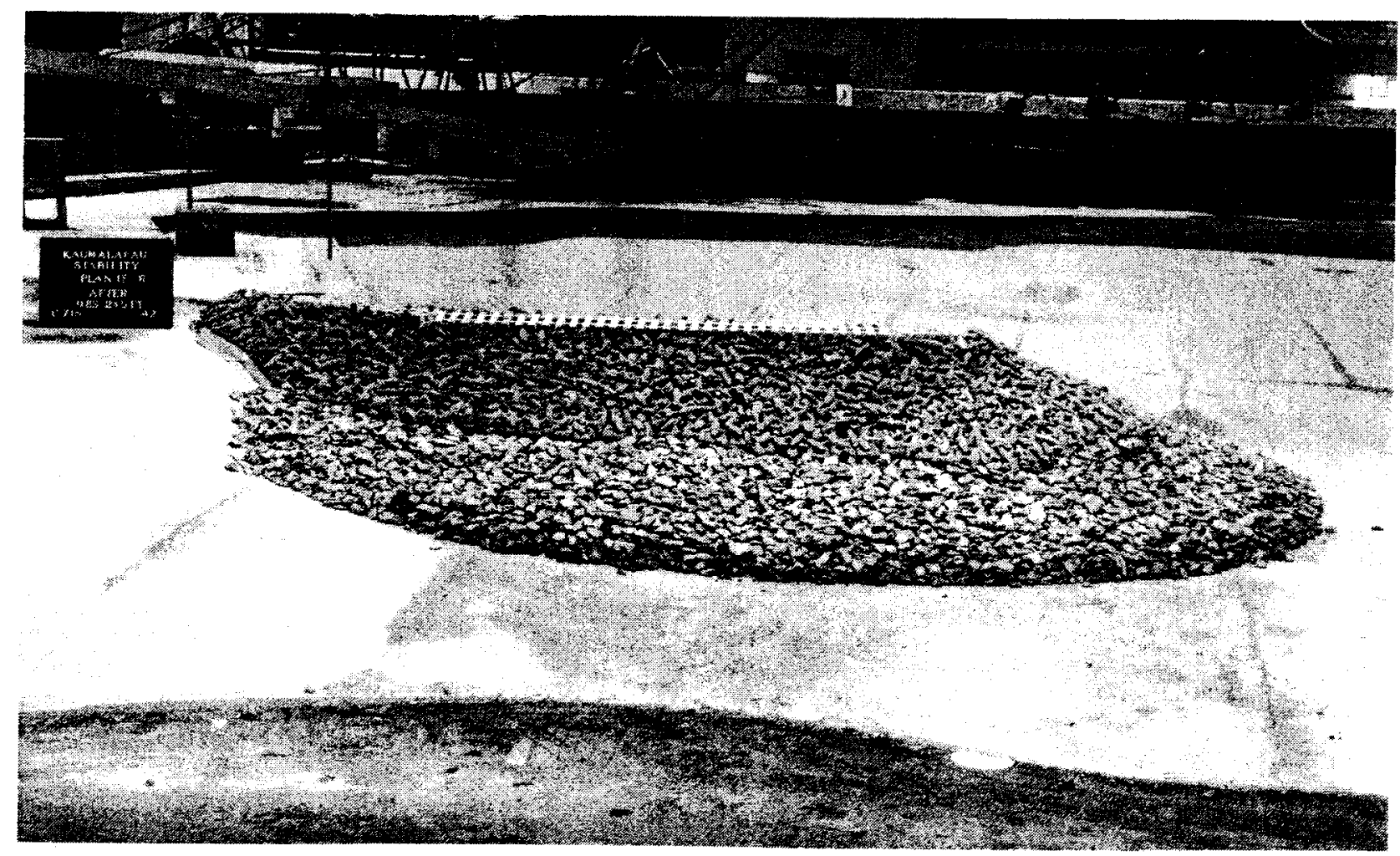

Photo B35. Sea-side view of Plan 4F, after 9.8-sec, 7.5-m waves

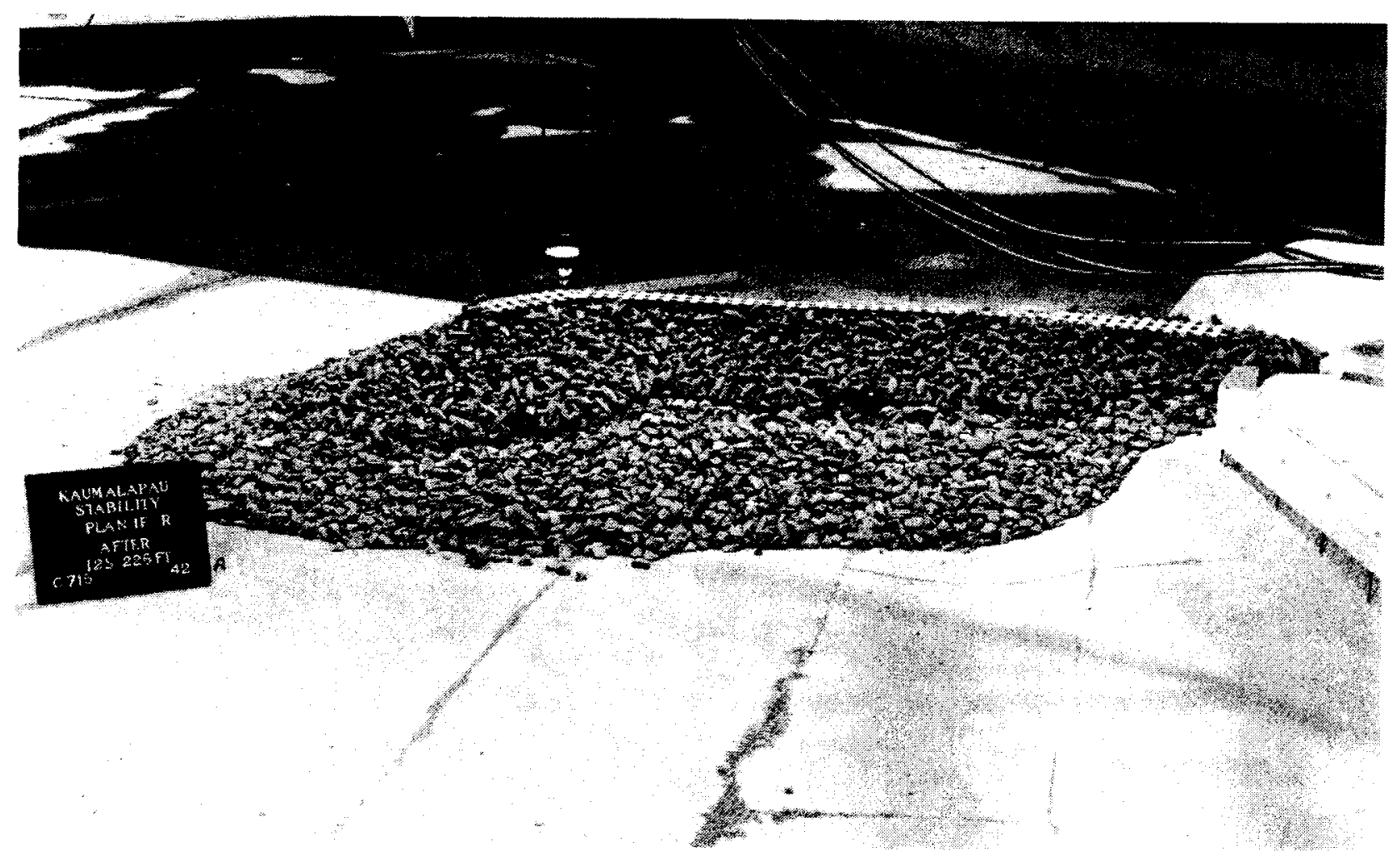

Photo B36. Leeside view of Plan 4F after 12-sec, 6.8-m waves 


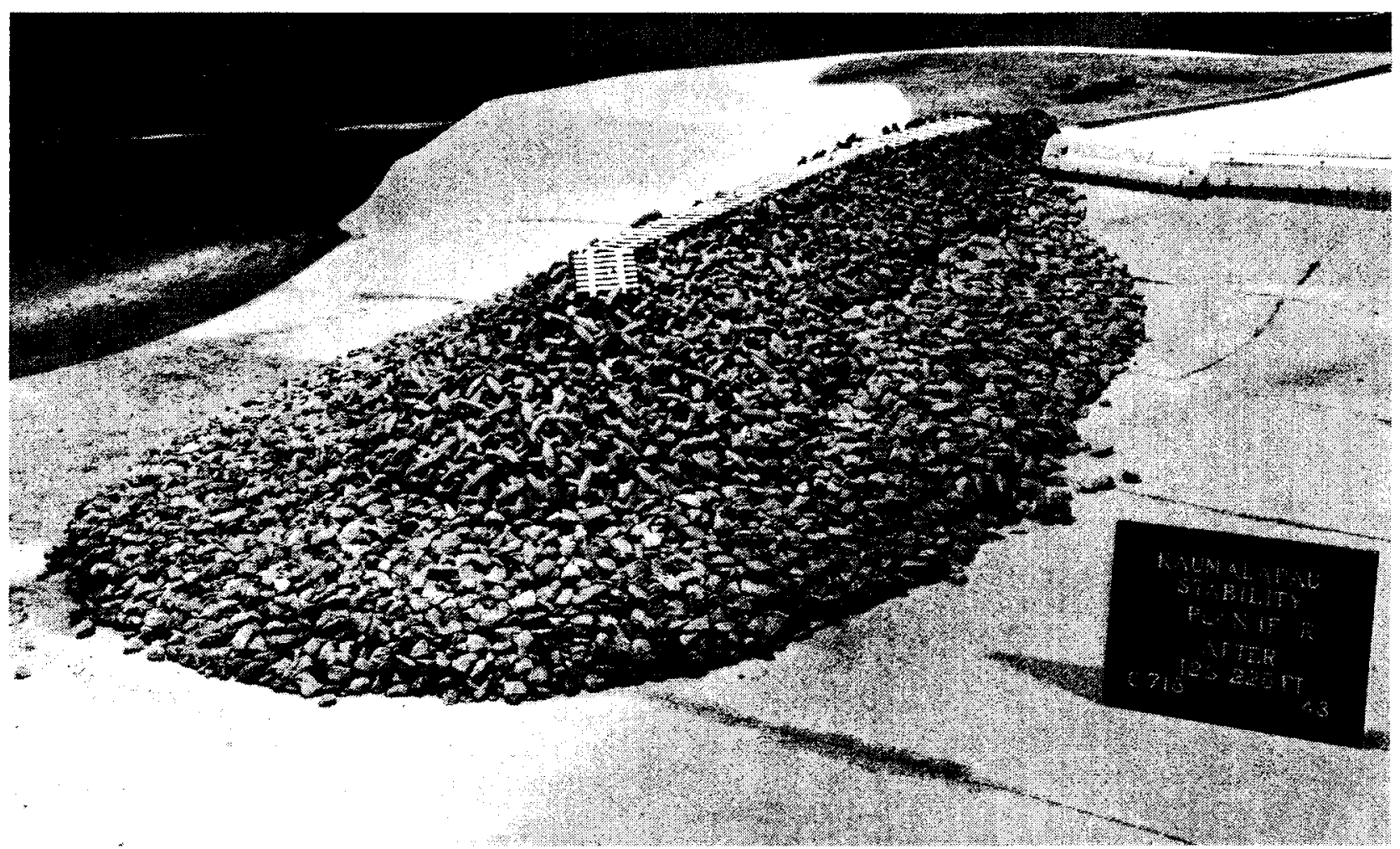

Photo B37. Plan 4F, breakwater head after 12-sec, 6.8-m waves

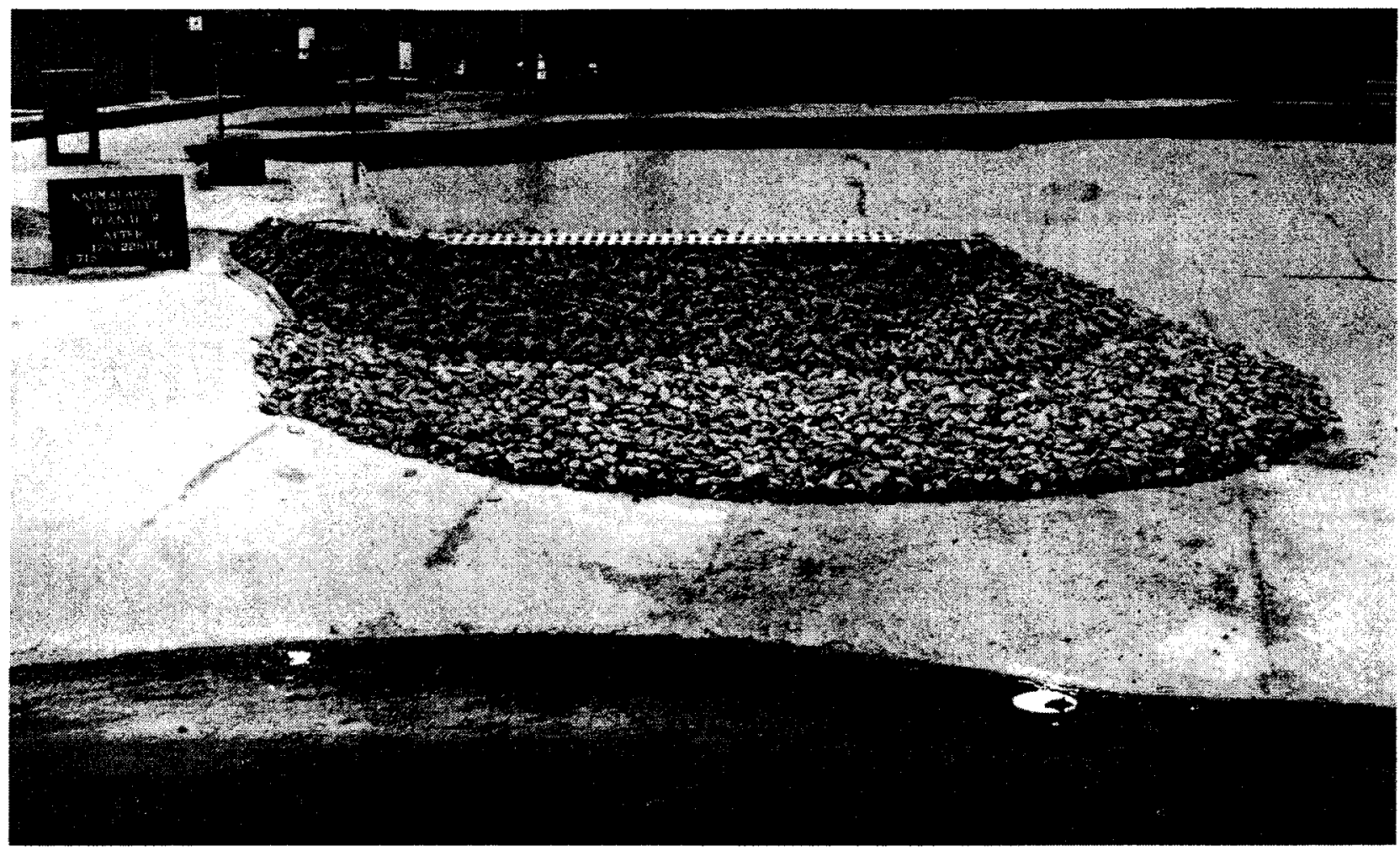

Photo B38. Sea-side view of Plan 4F, after 12-sec, 6.8-m waves 


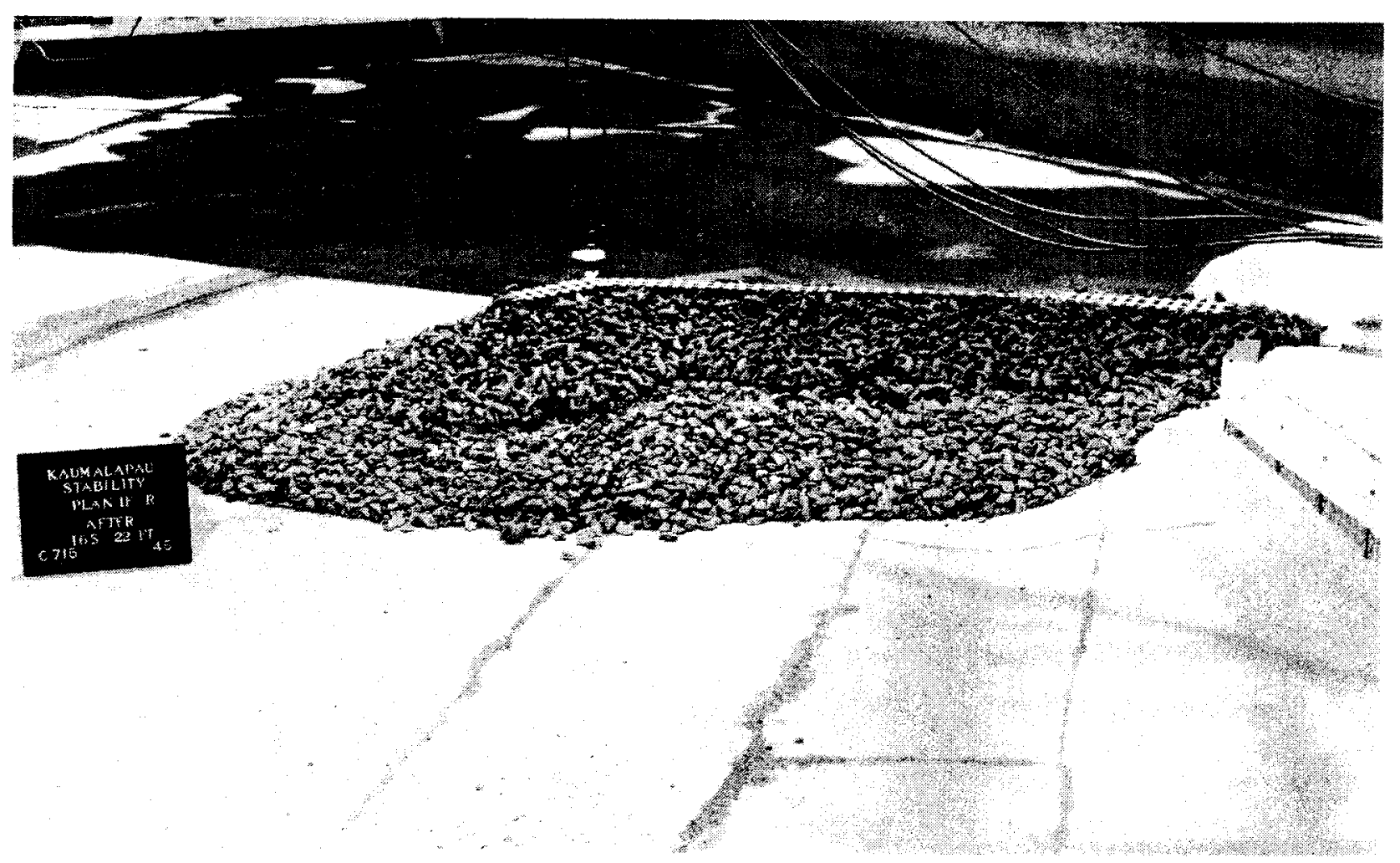

Photo B39. Leeside view of Plan 4F, after 16-sec, 6.7-m waves

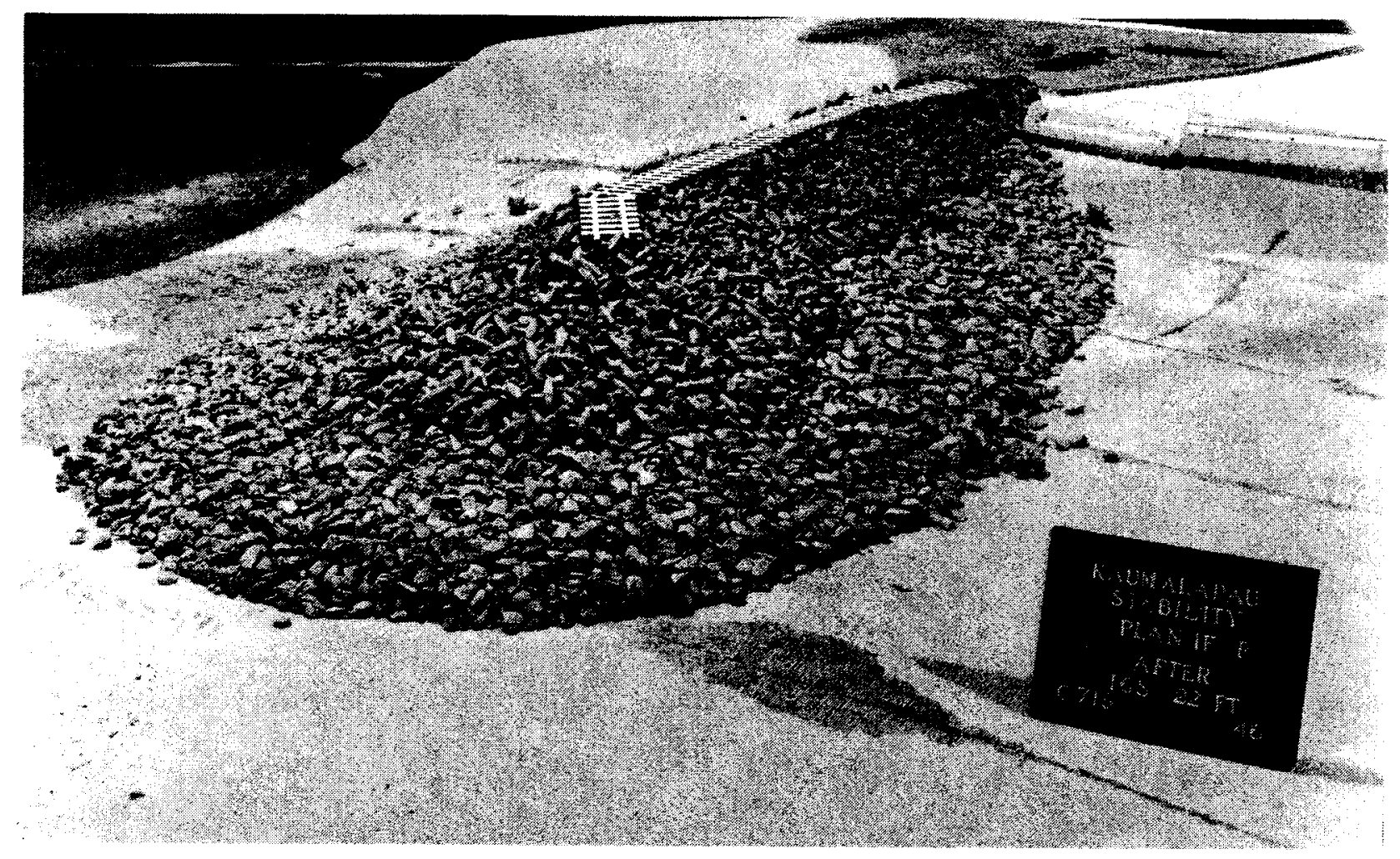

Photo B40. Plan 4, breakwater head after $16-\mathrm{sec}, 6.7-\mathrm{m}$ waves 


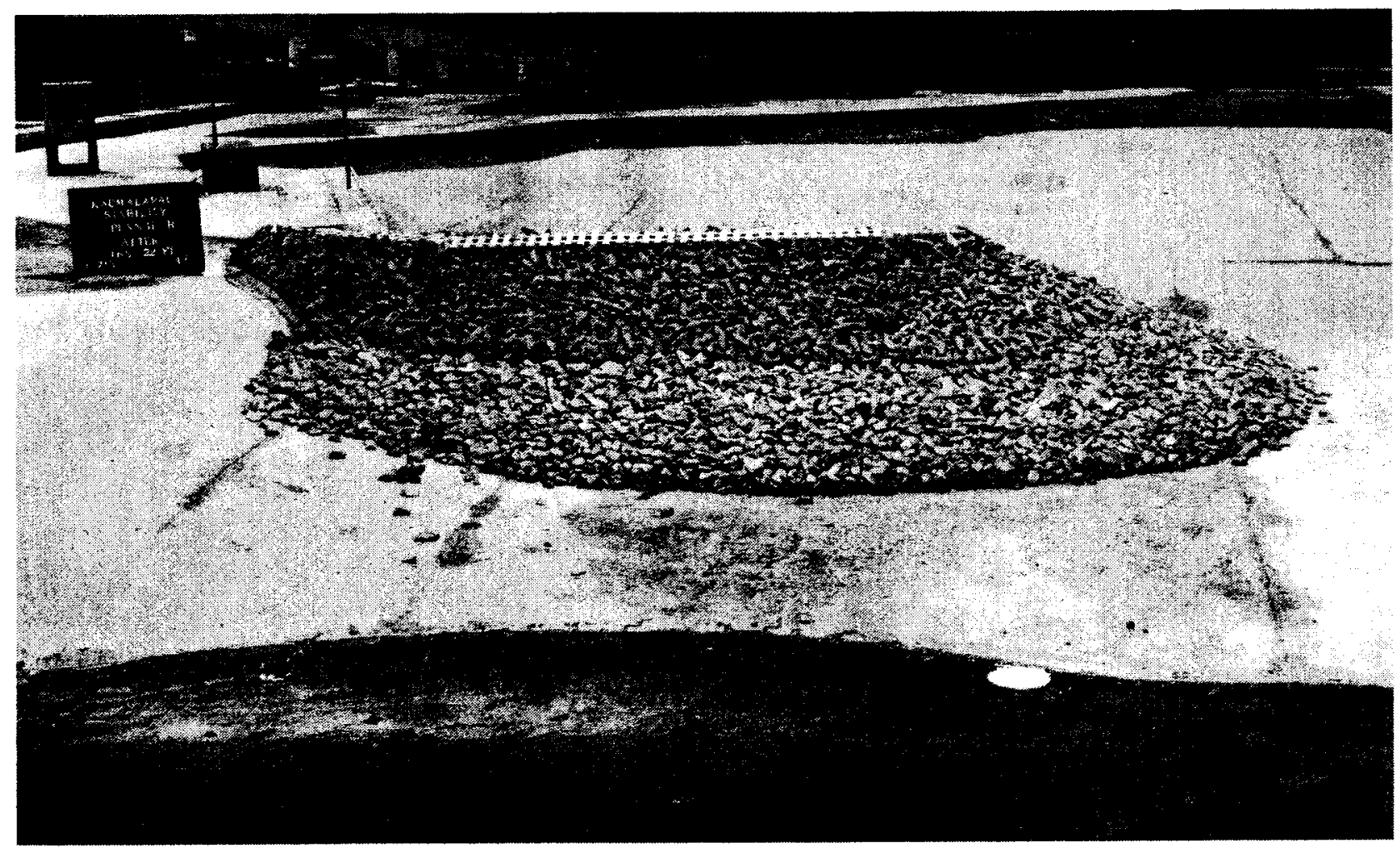

Photo B41. Sea-side view of Plan 4F, after 16-sec, 6.7-m waves

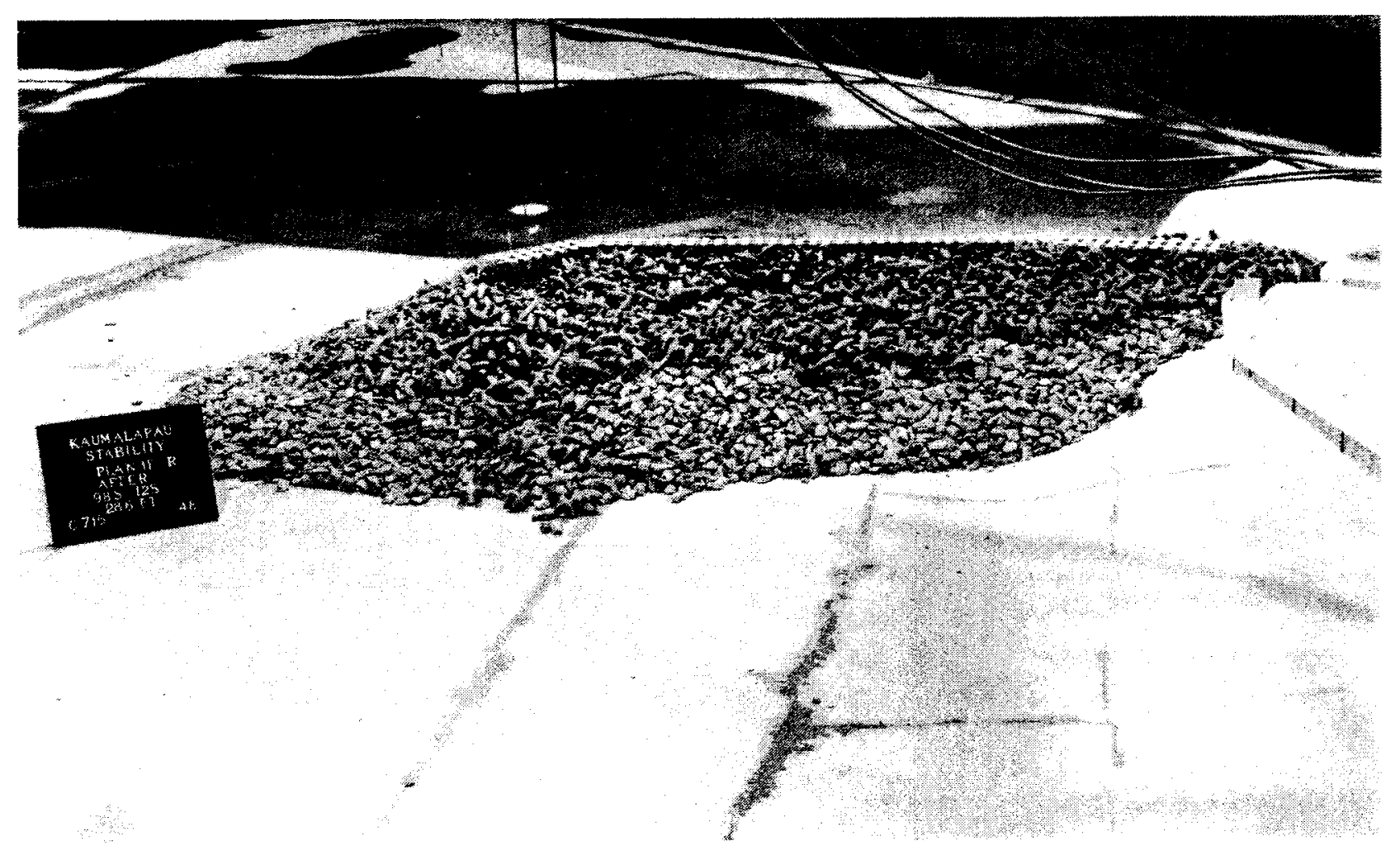

Photo B42. Leeside view of Plan 4F after maximum 9.8- and 12-sec waves 


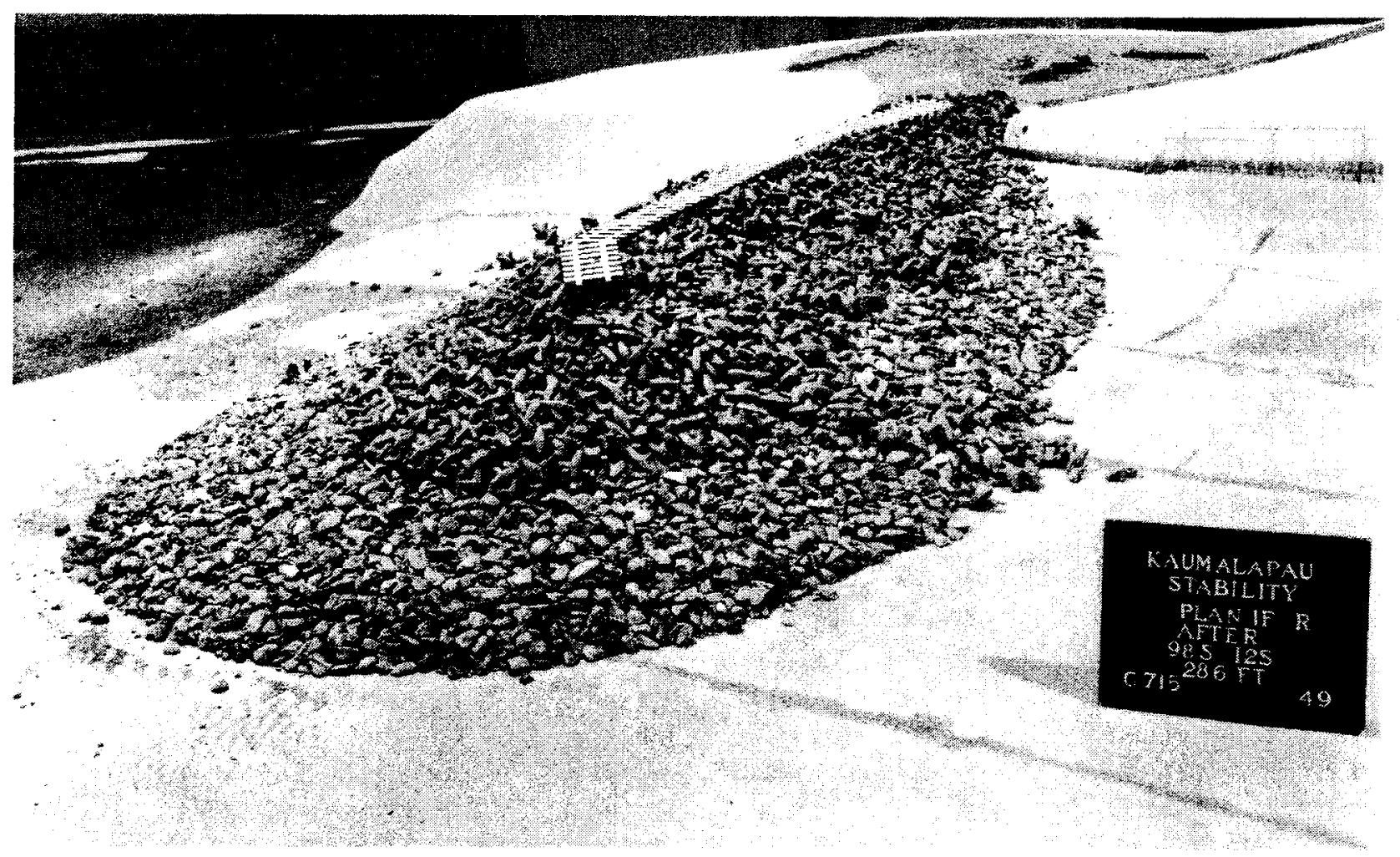

Photo B43. Plan 4F, breakwater head after maximum 9.8-and 12-sec waves

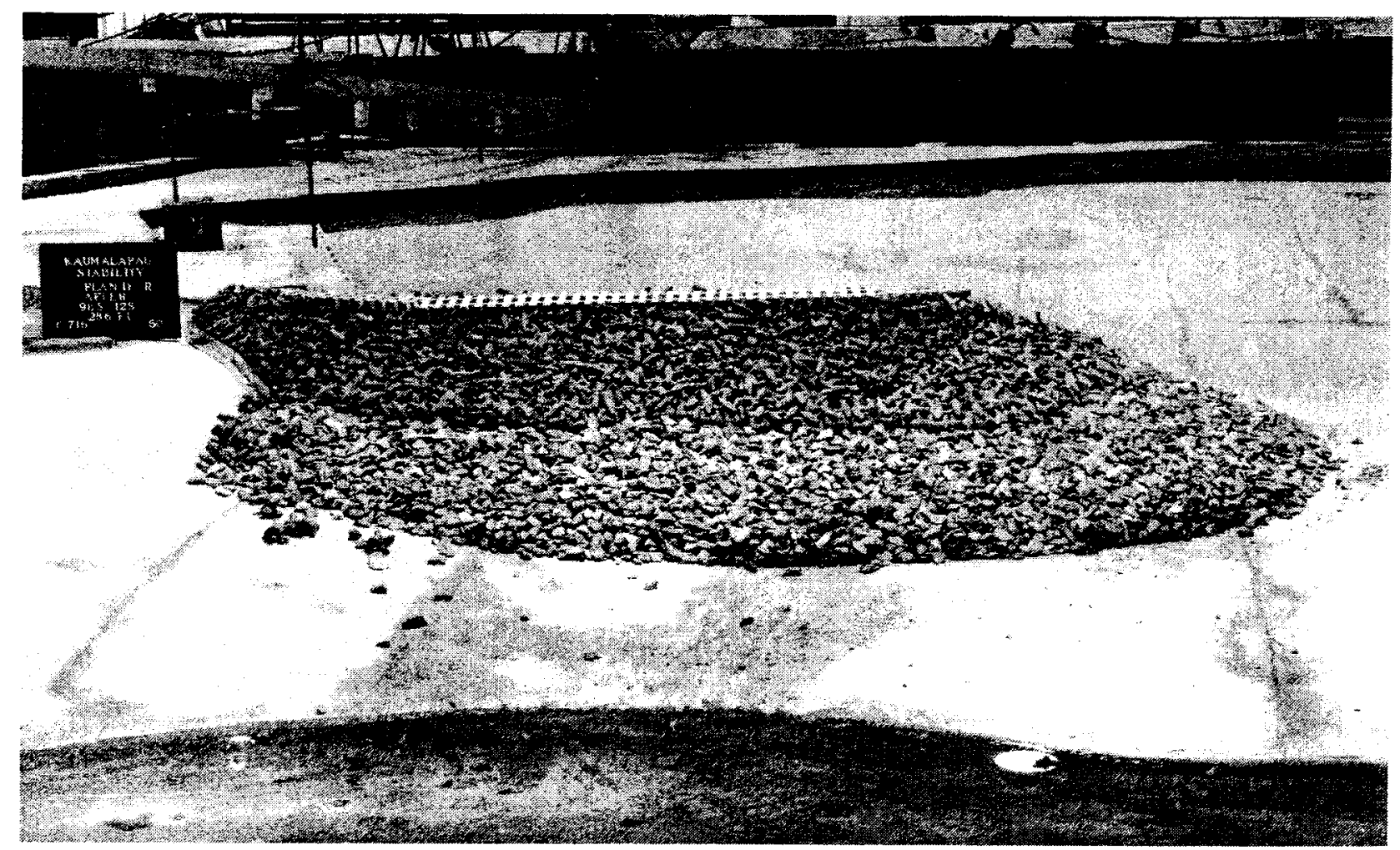

Photo B44. Sea-side view of Plan 4F after maximum 9.8- and 12-sec waves 


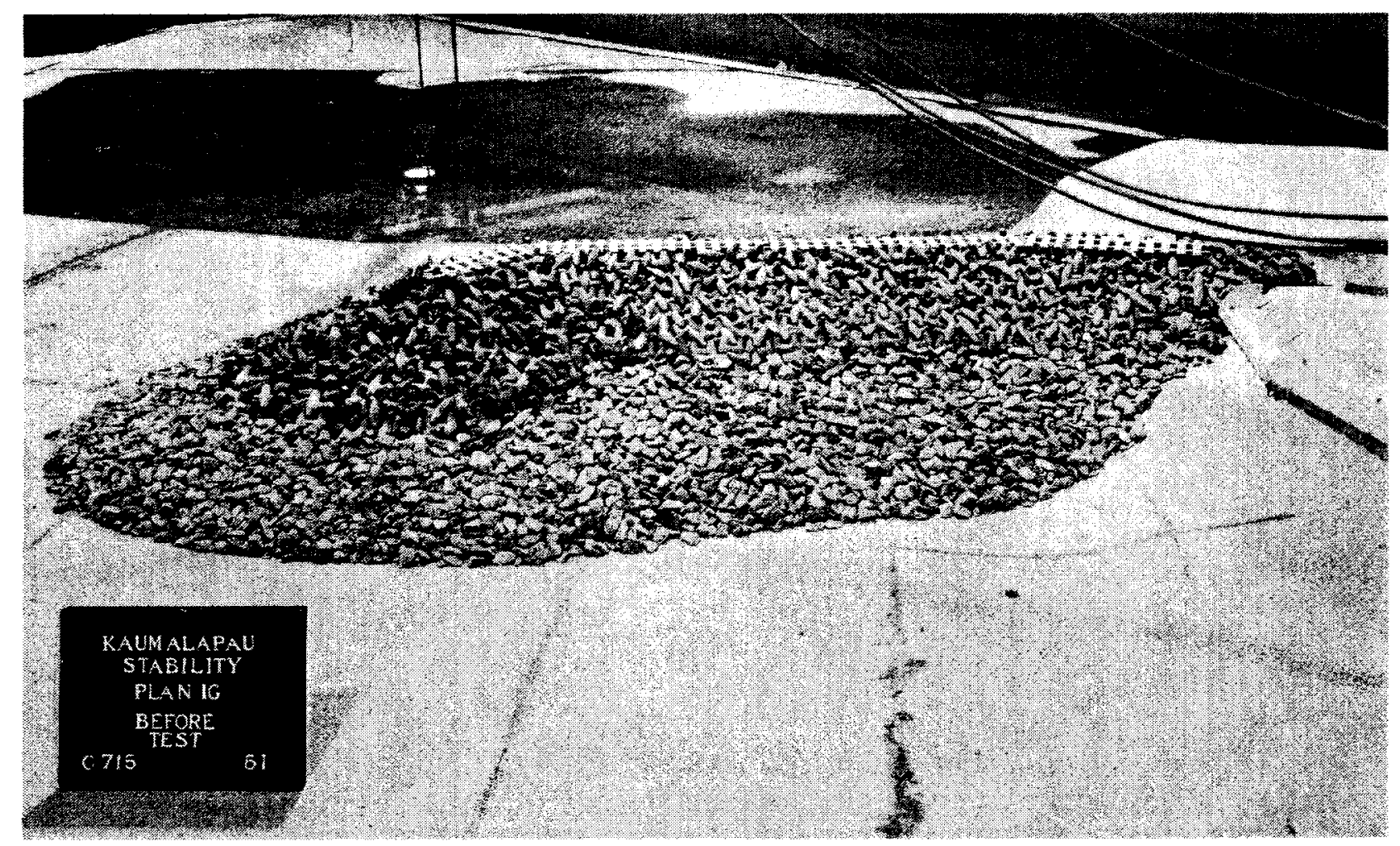

Photo B45. Leeside view of Plan 4G before experiments

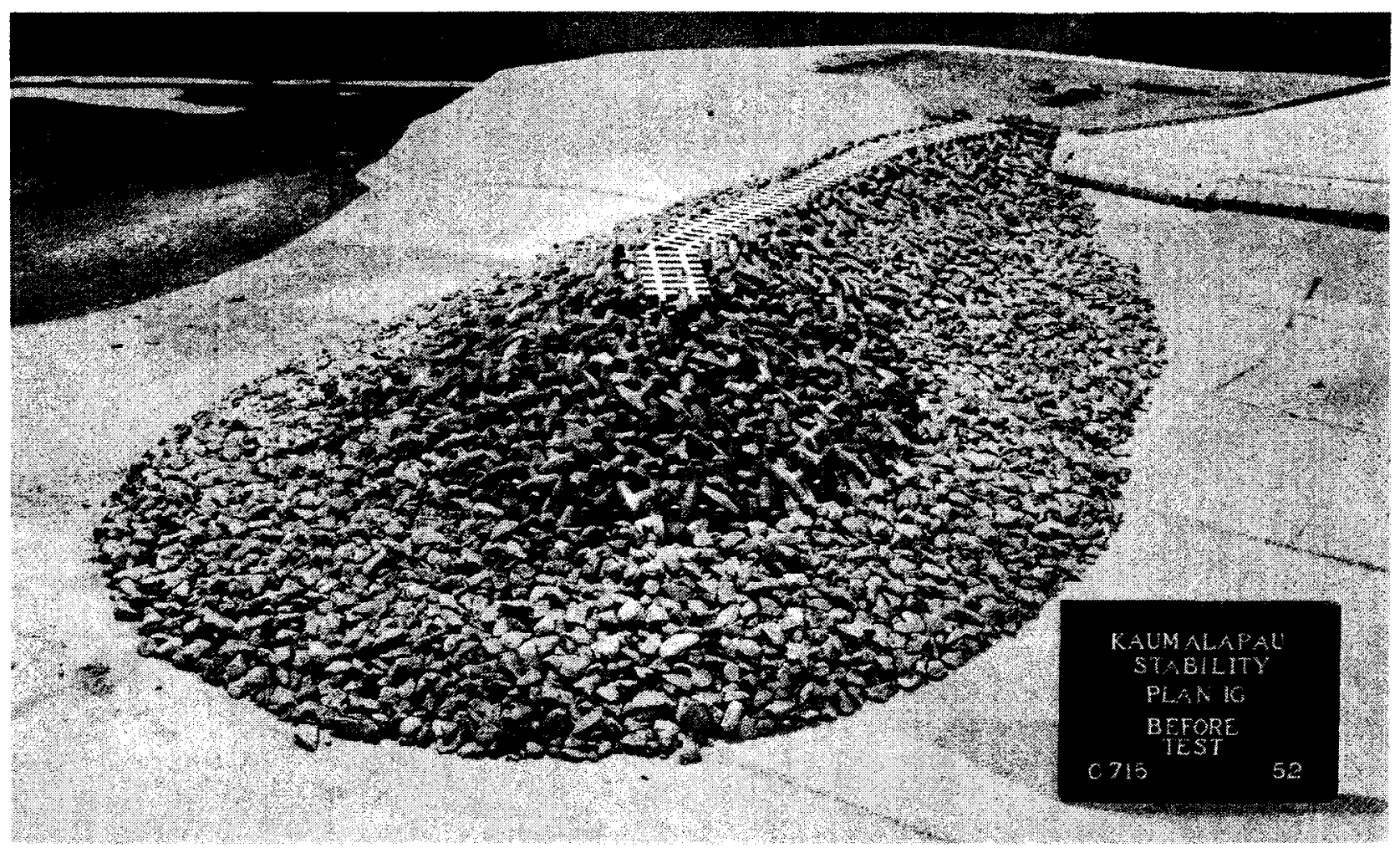

Photo B46. Plan 4G, breakwater head before experiments 


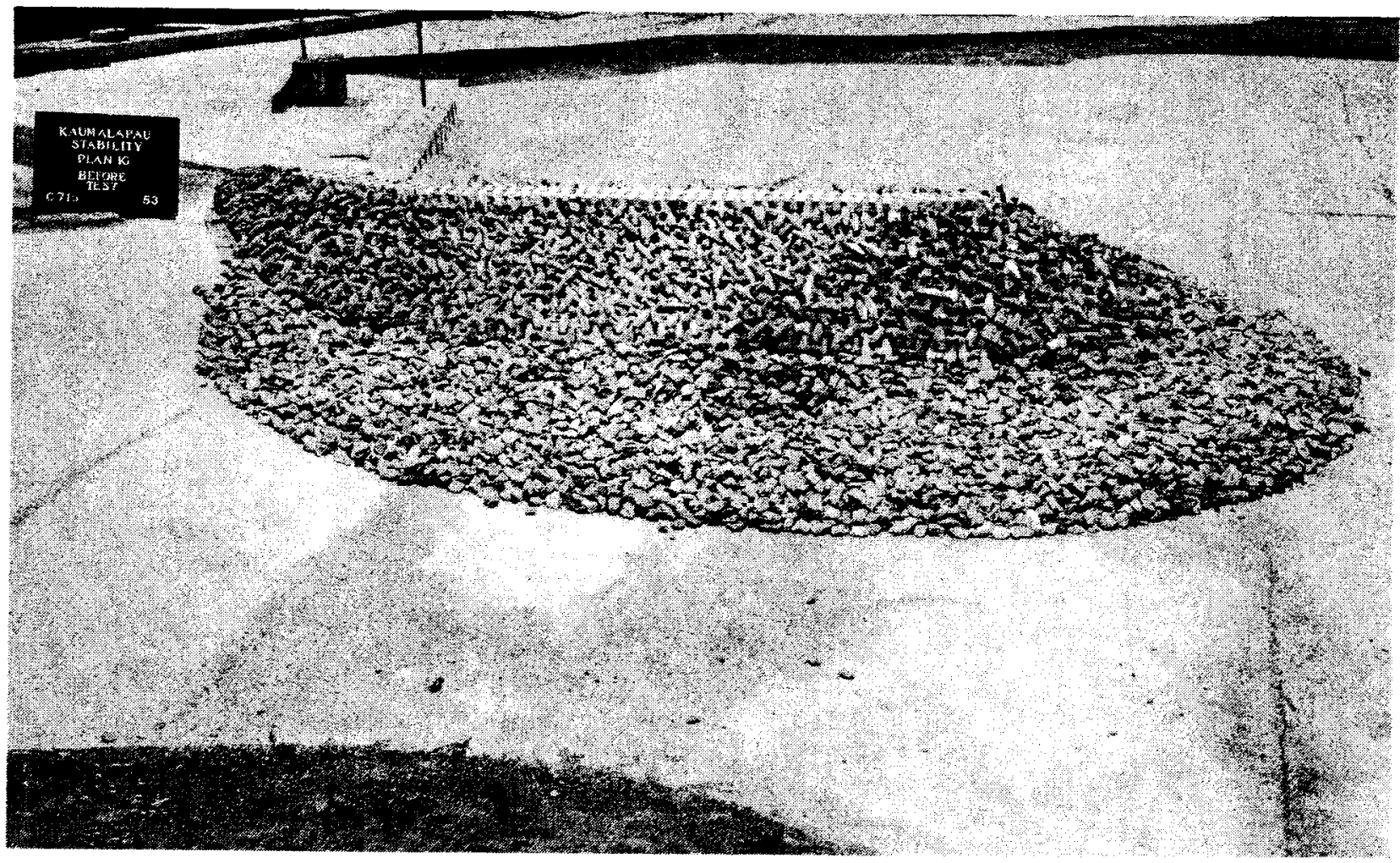

Photo B47. Sea-side view of Plan 4G, before experiments

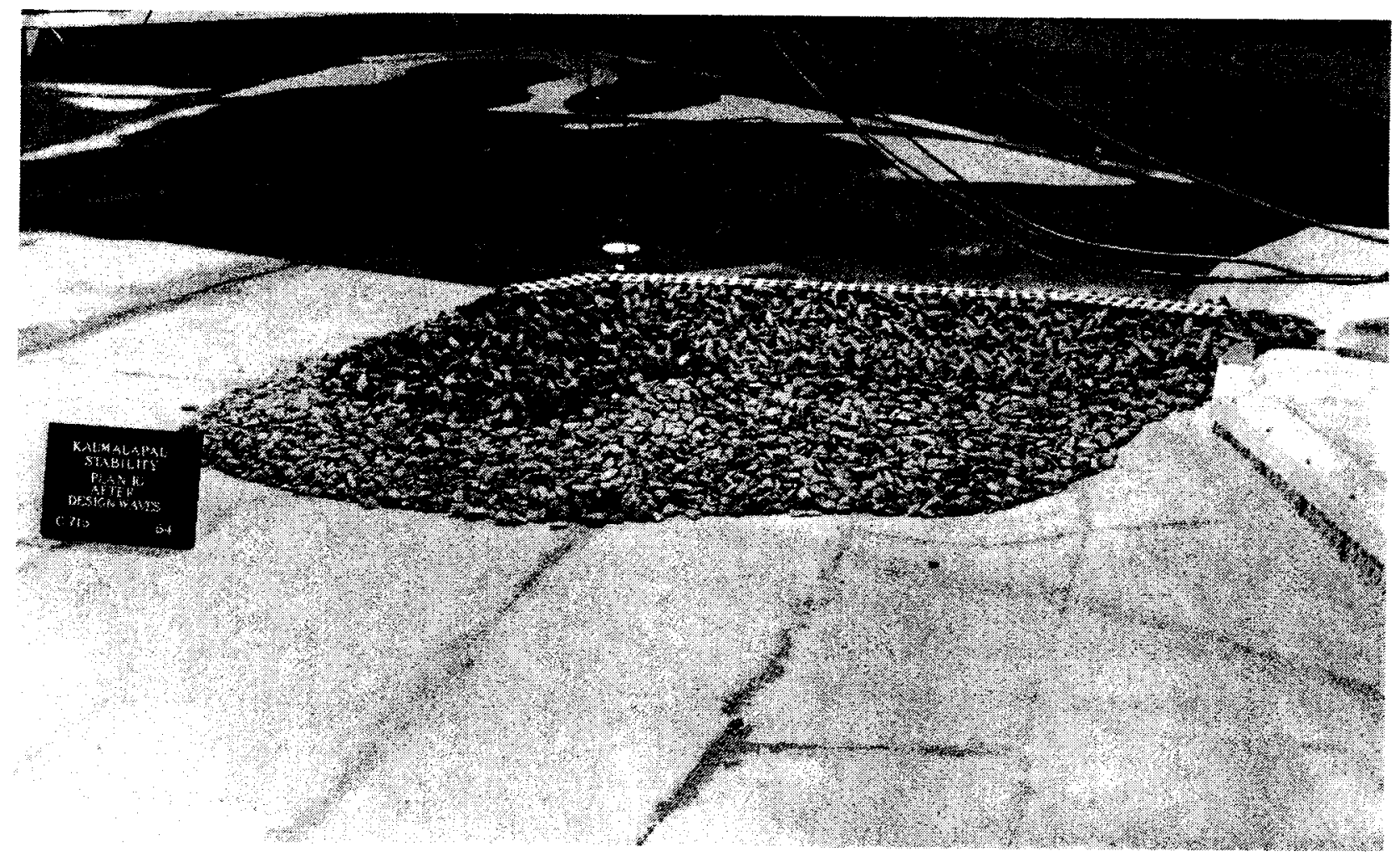

Photo B48. Leeside view of Plan 4G after 9.8- and 12-sec waves at design height and 16-sec waves up to $H_{0}=6.6 \mathrm{~m}$ 


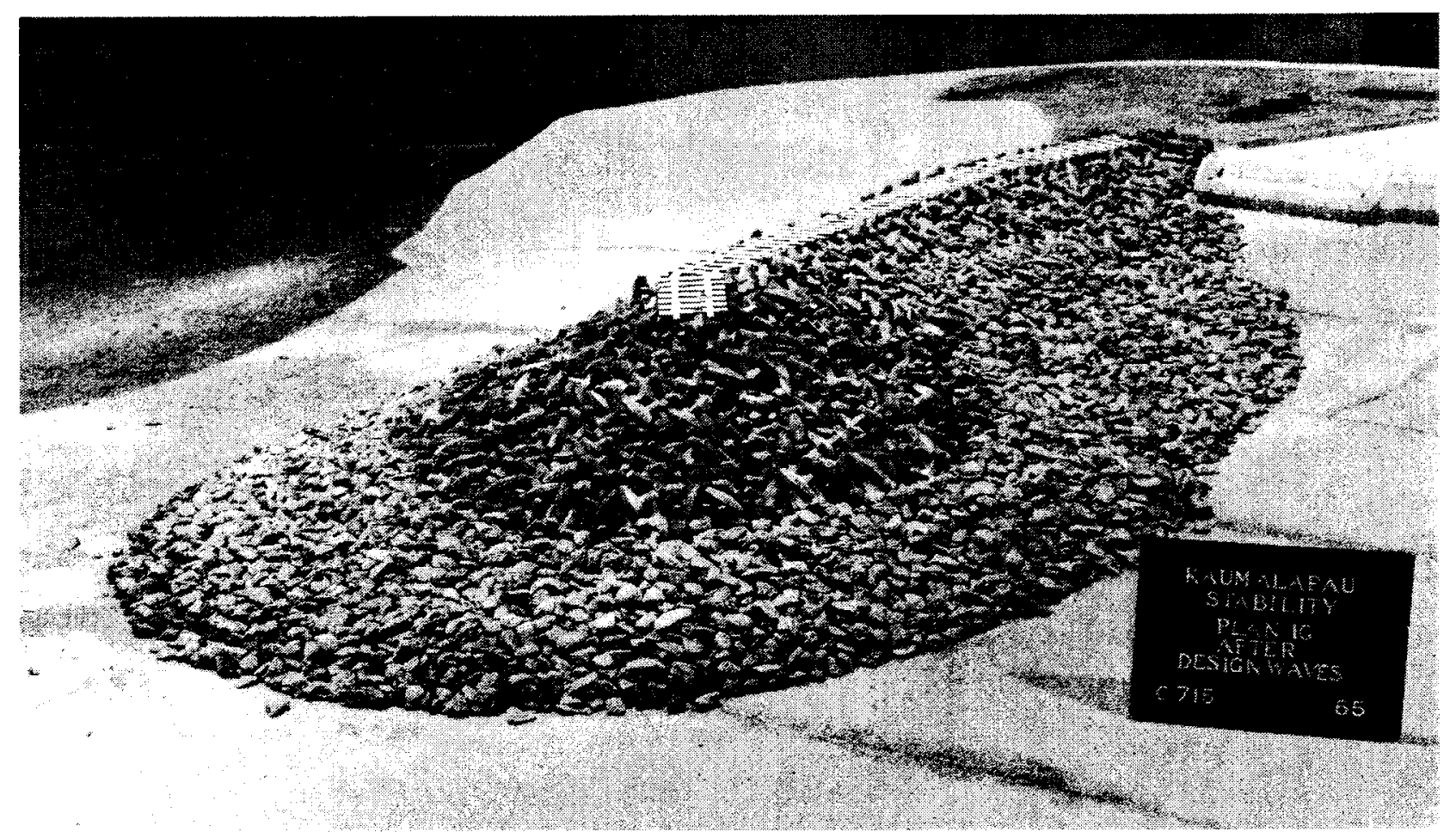

Photo B49. Plan 4G, breakwater head after 9.8- and 12-sec waves at design height and 16-sec waves up to $H_{o}=6.6 \mathrm{~m}$

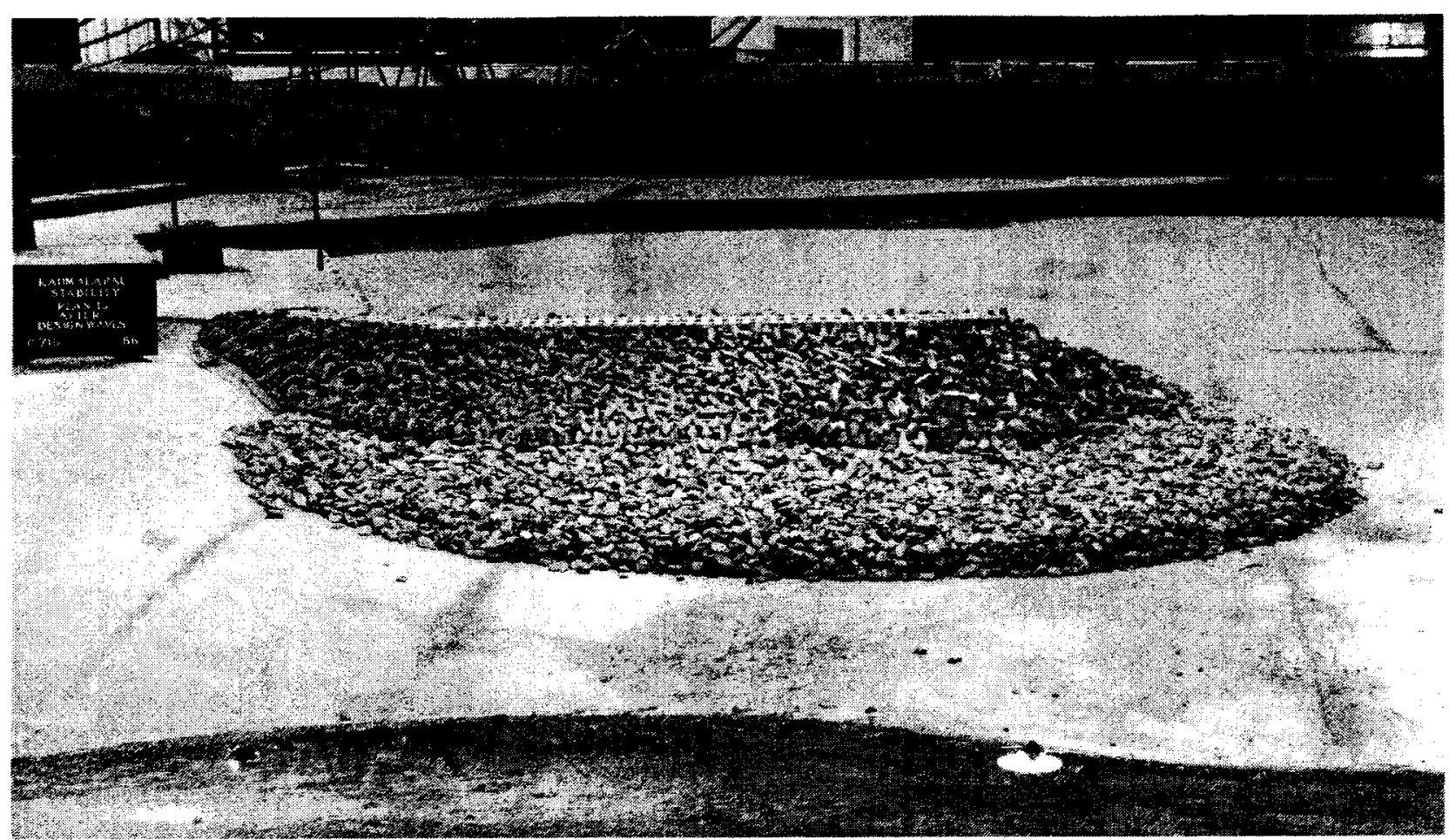

Photo B50. Sea-side view of Plan 4G after 9.8- and 12-sec waves at design height and 16-sec waves up to $H_{o}=6.6 \mathrm{~m}$ 


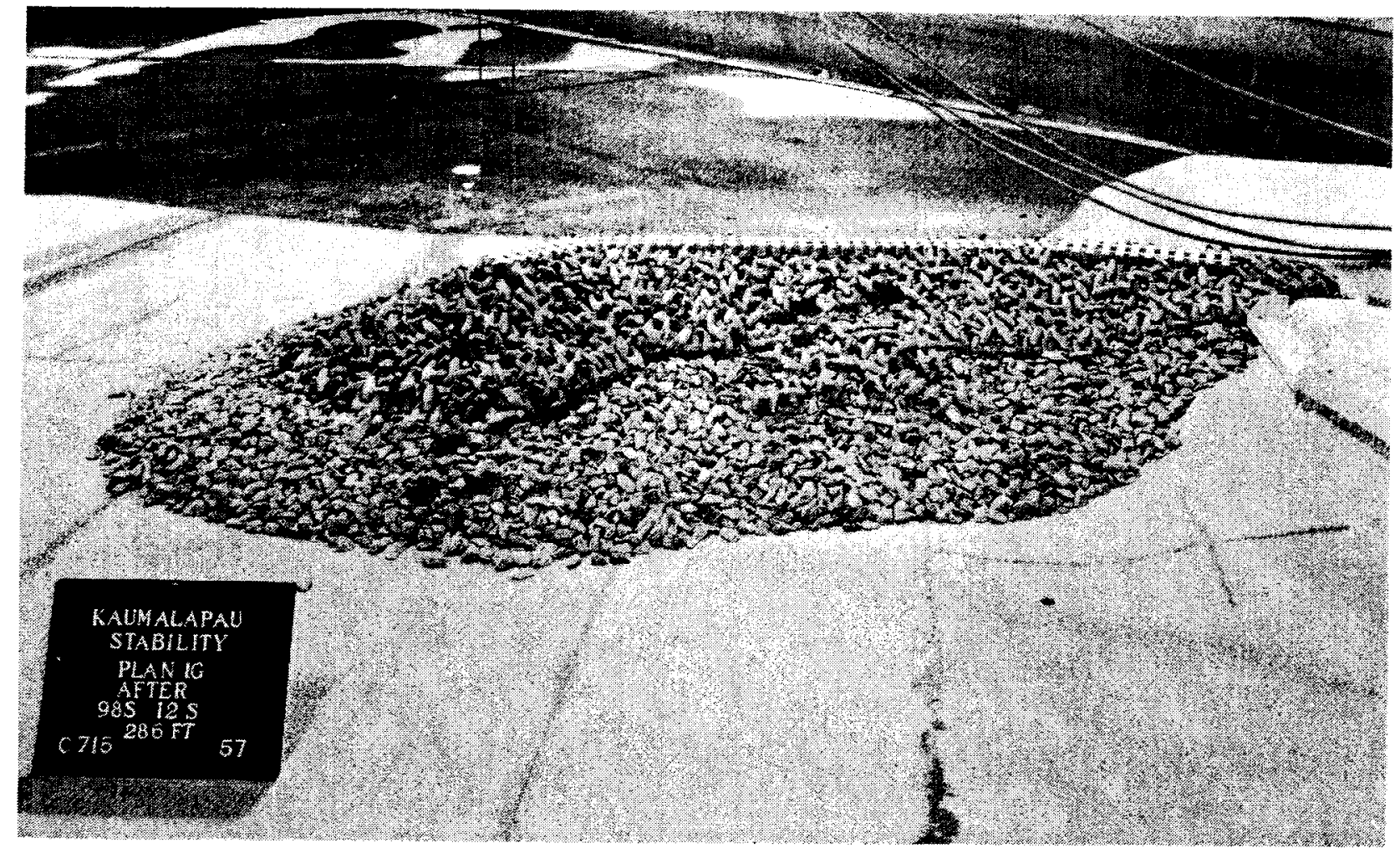

Photo B51. Leeside view of Plan 4G after maximum 9.8- and 12-sec waves

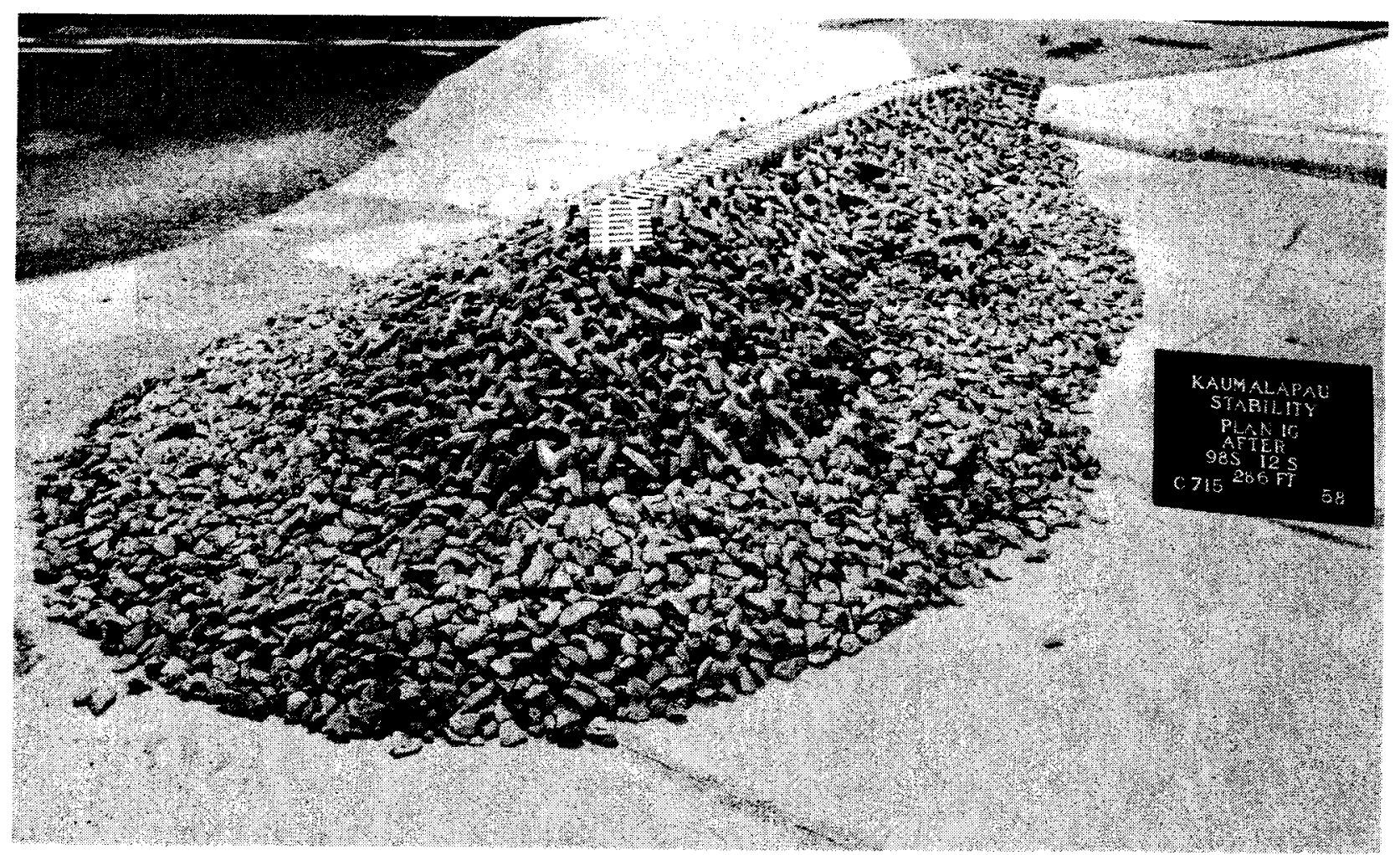

Photo B52. Plan 4G, breakwater head after maximum 9.8- and 12-sec waves 


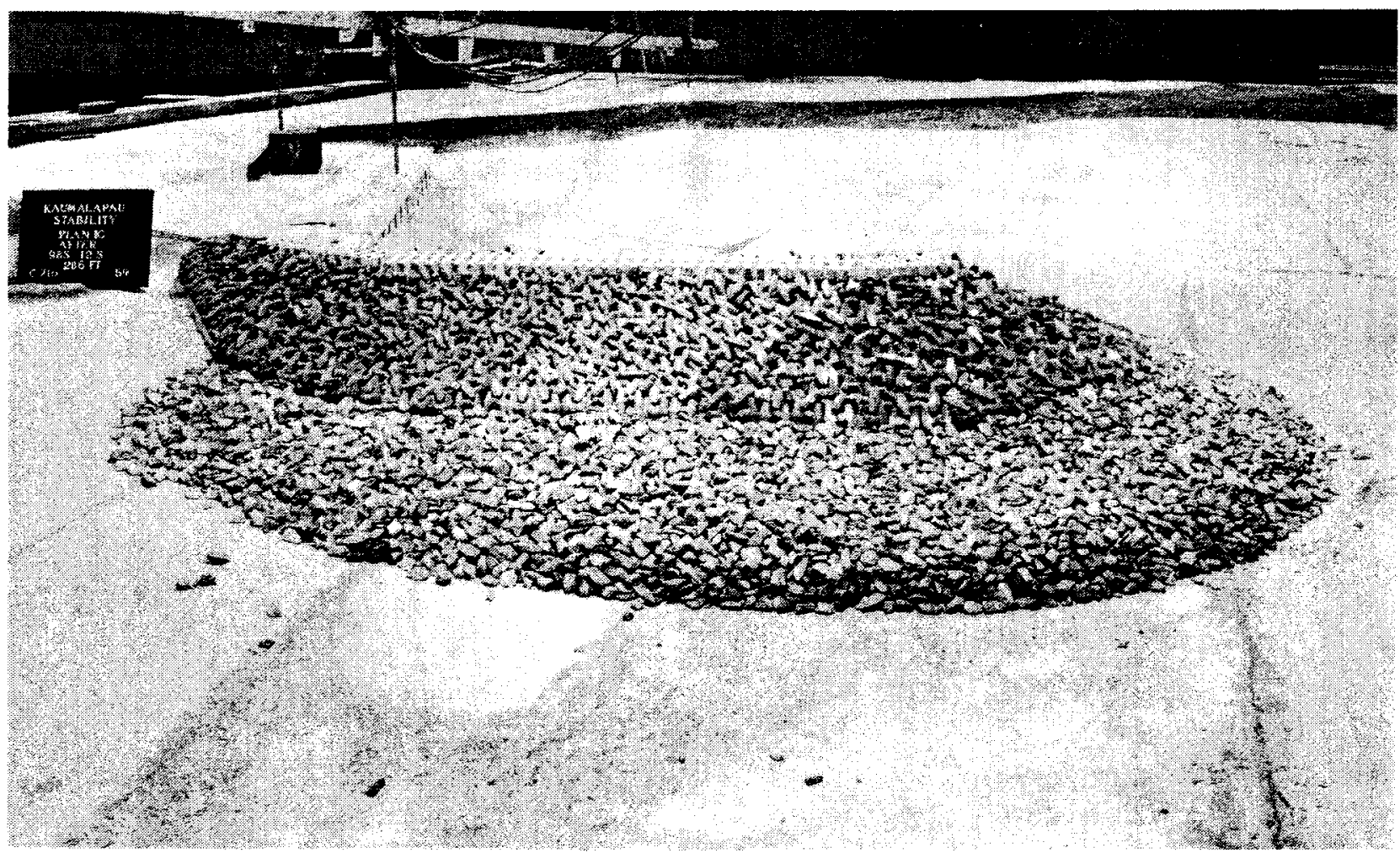

Photo B53. Sea-side view of Plan $4 G$ after maximum 9.8- and 12-sec waves

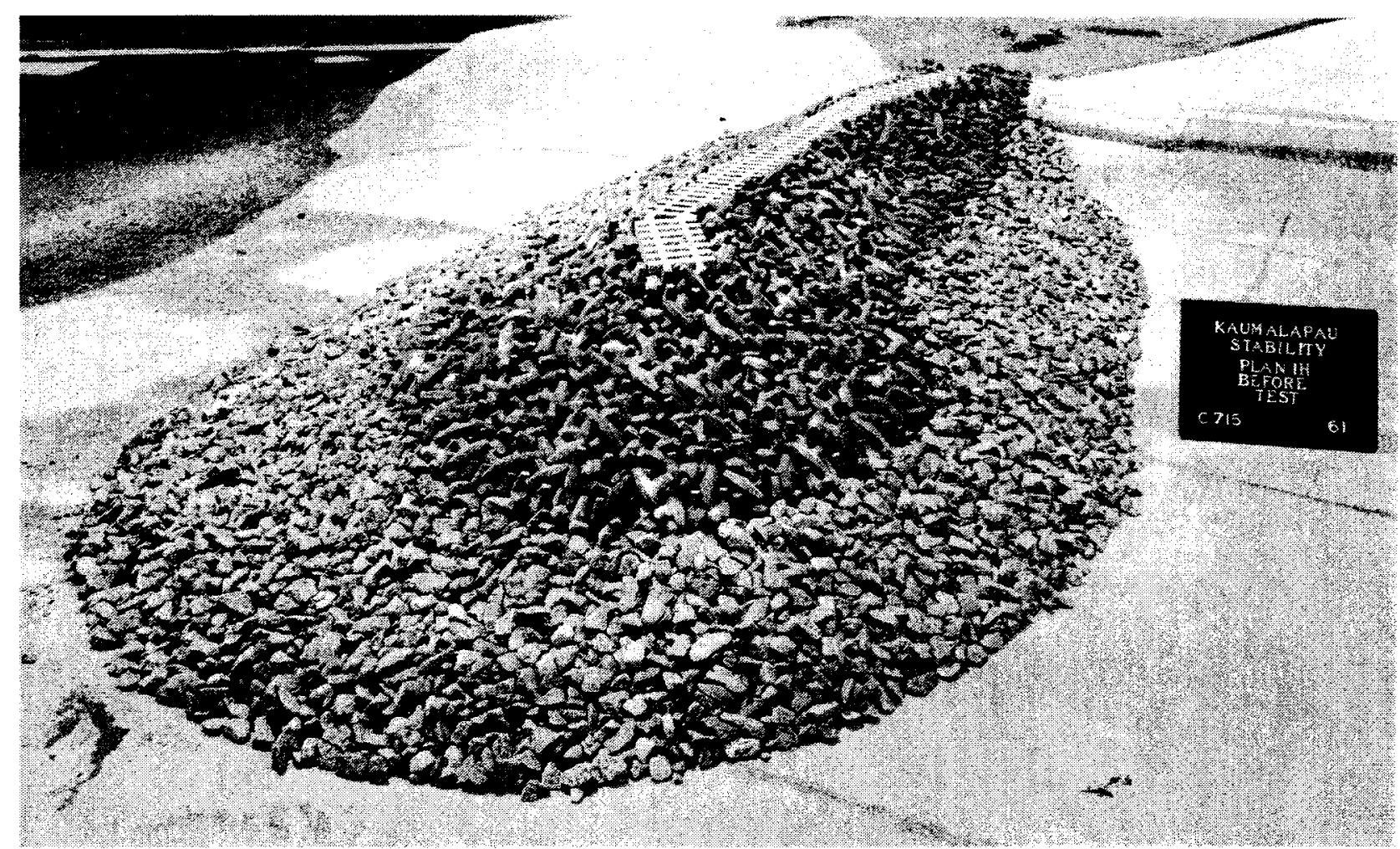

Photo B54. Head view of Plan $4 \mathrm{H}$ before experiments 


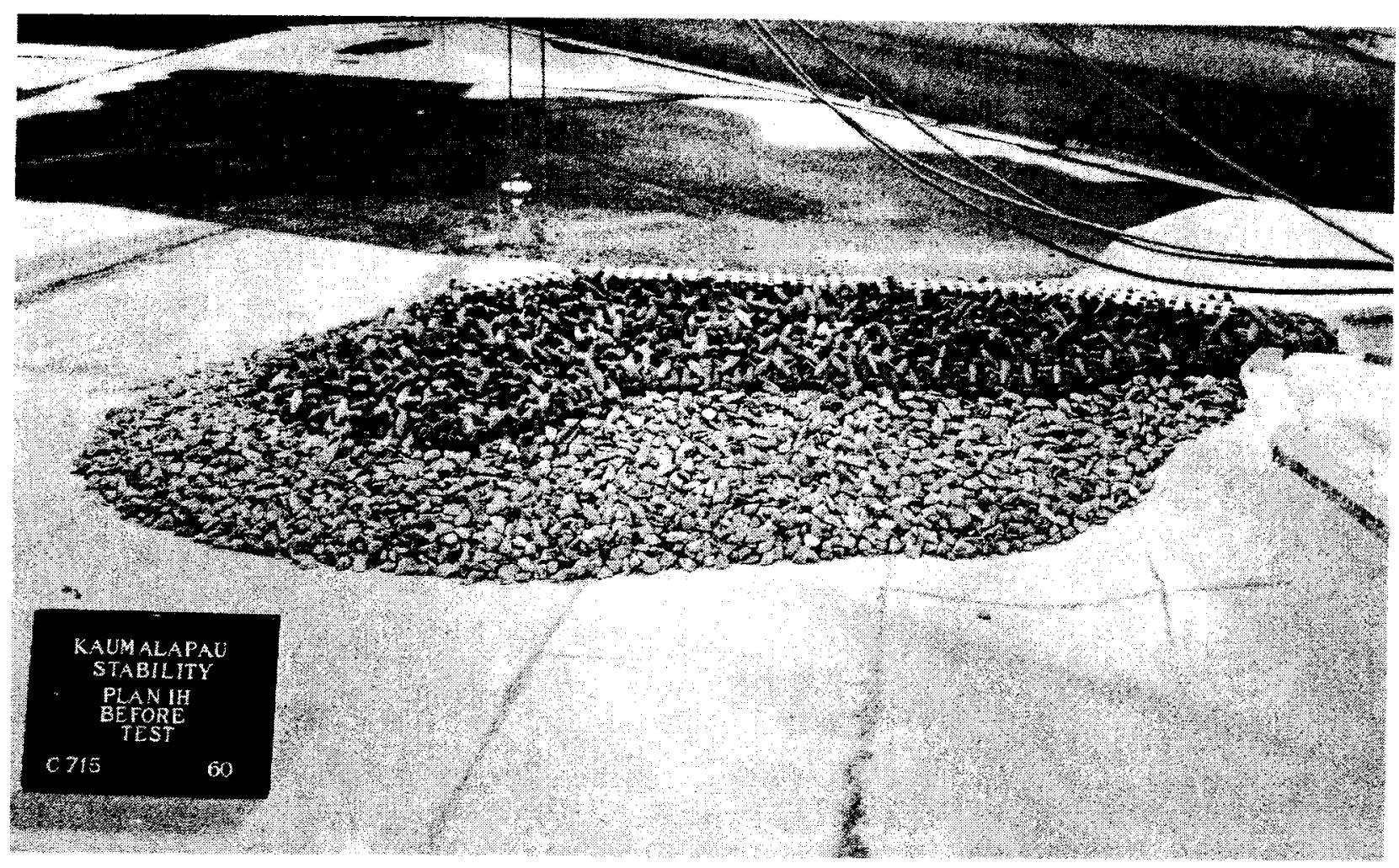

Photo B55. Plan $4 \mathrm{H}$, leeside view of breakwater head before experiments

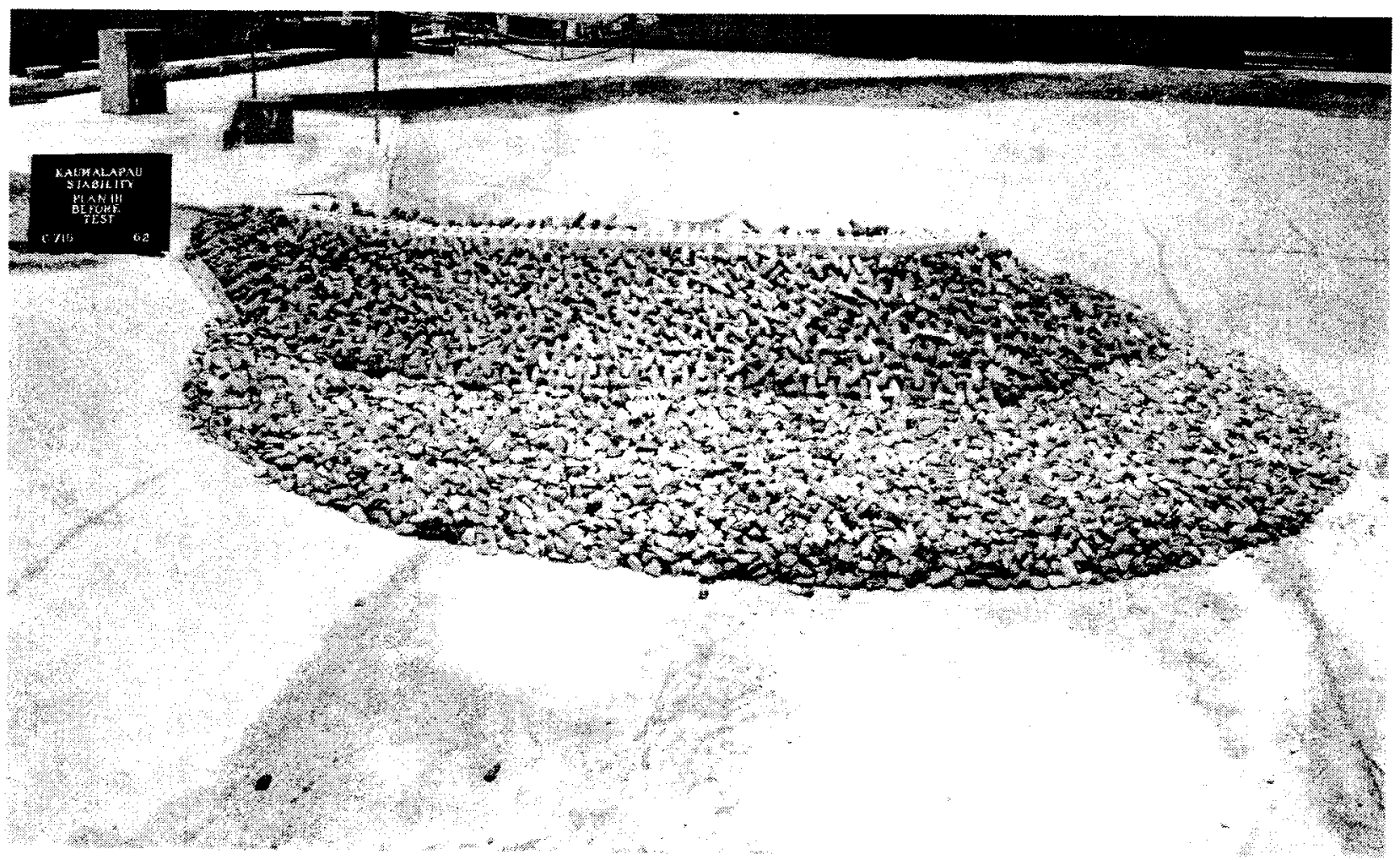

Photo B56. Sea-side view of Plan $4 \mathrm{H}$ before experiments 


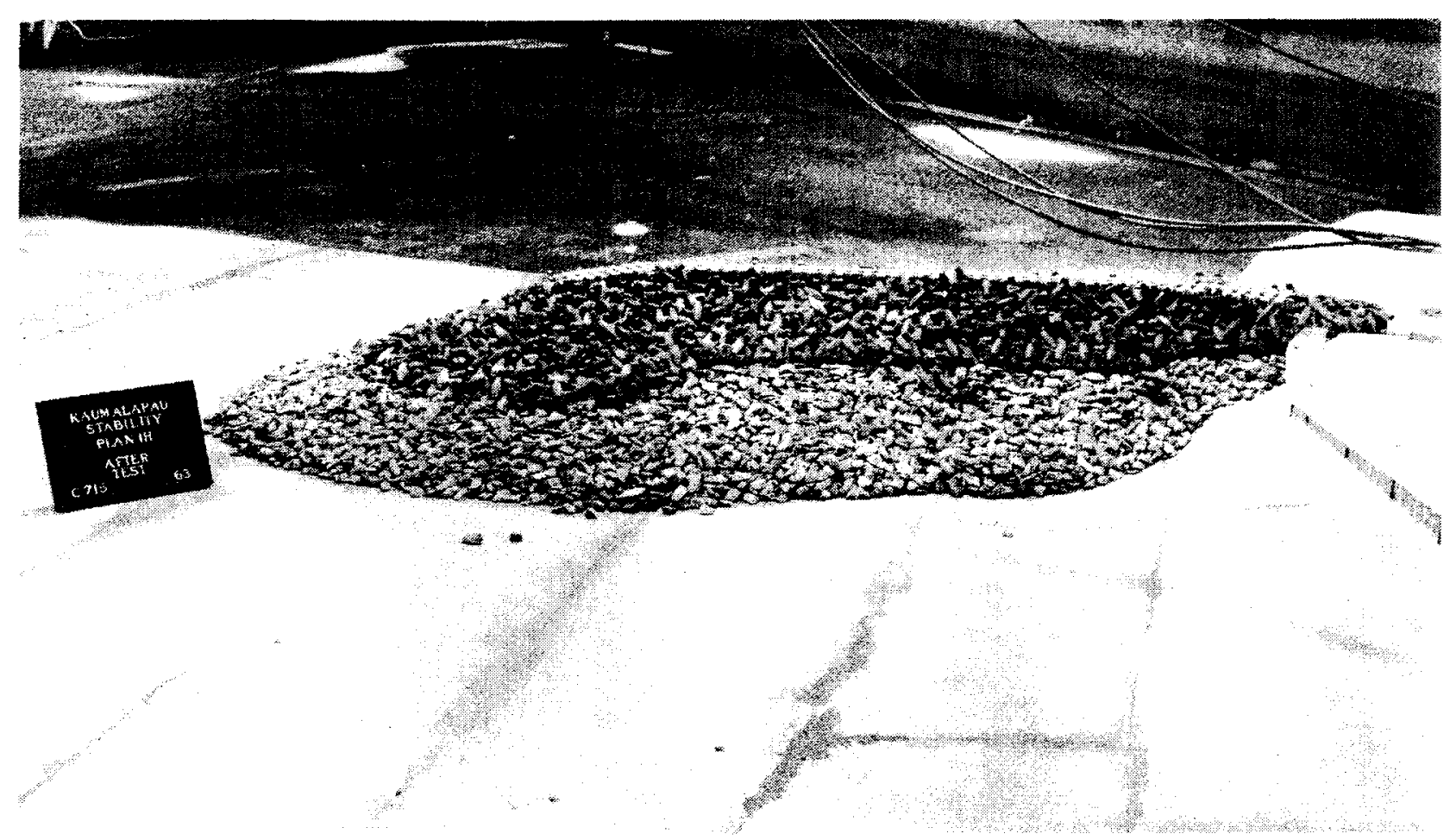

Photo B57. Leeside view of Plan $4 \mathrm{H}$ after maximum 9.8- and 12-sec waves and 16-sec waves up to $H_{0}=6.6 \mathrm{~m}$

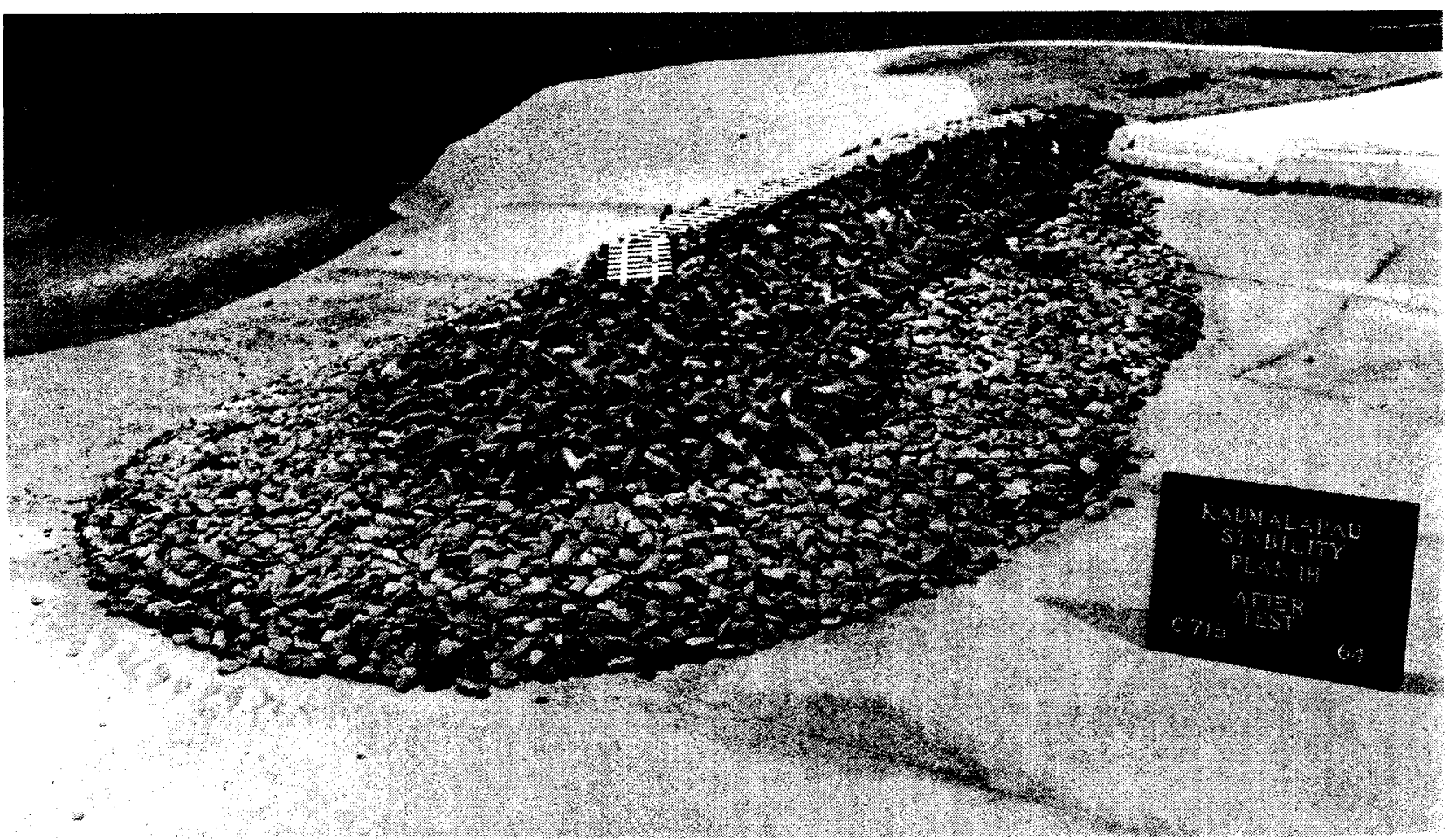

Photo B58. Plan 4H, breakwater head after maximum 9.8- and 12-sec waves and 16-sec waves up to $H_{0}=6.6 \mathrm{~m}$ 


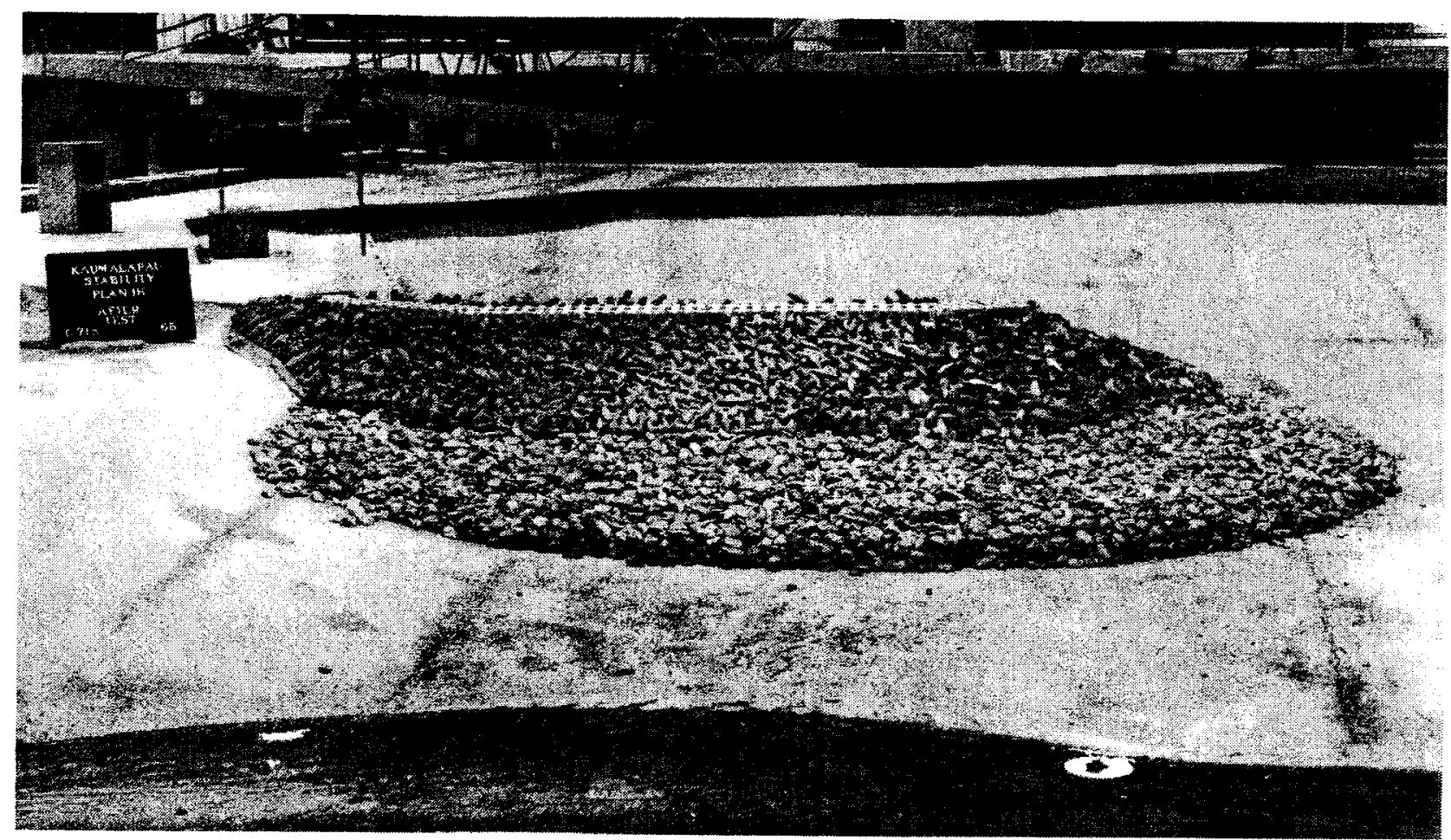

Photo B59. Sea-side view of Plan 4H after maximum 9.8- and 12-sec waves and 16-sec waves up to $H_{o}=6.6 \mathrm{~m}$

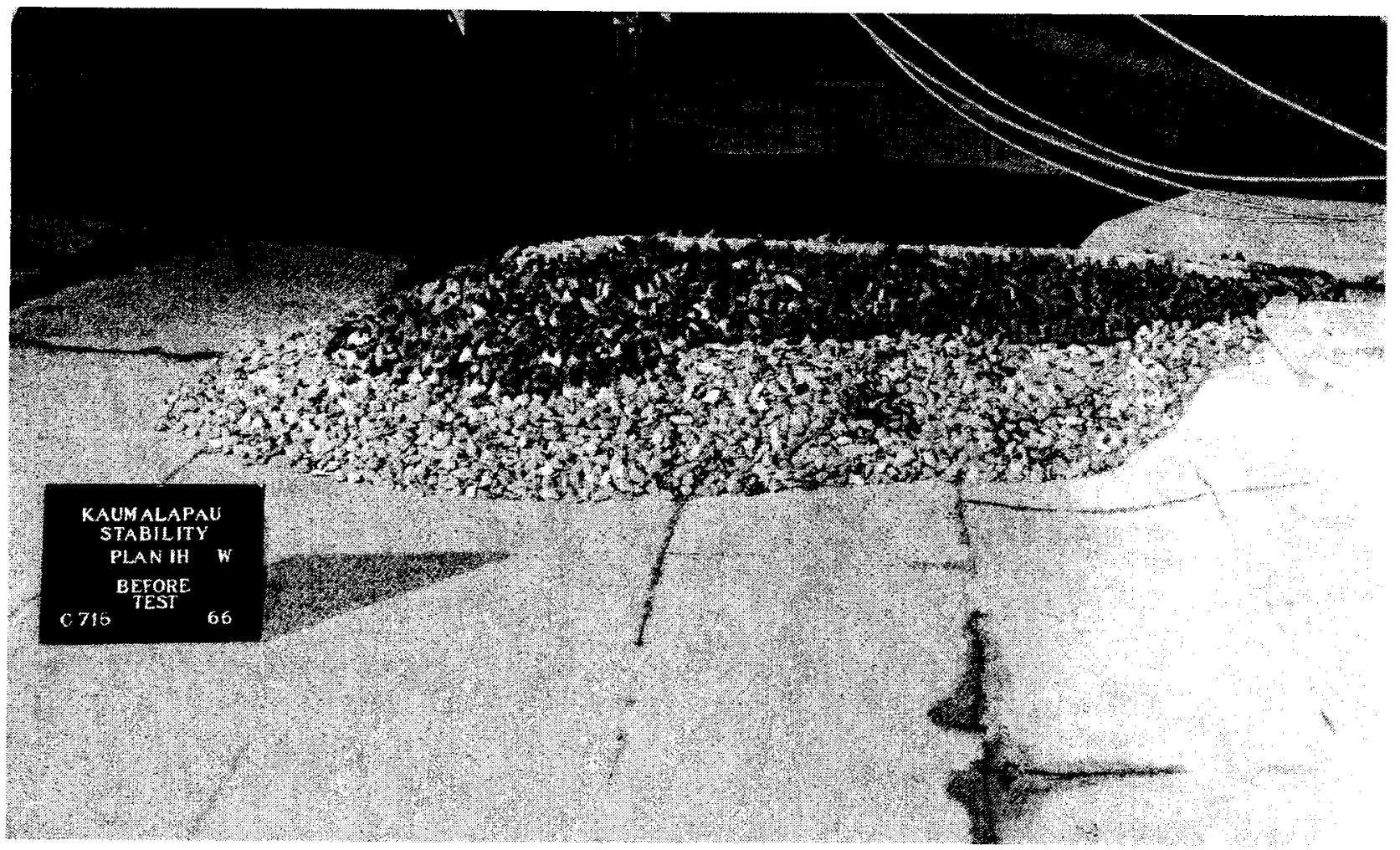

Photo B60. Leeside view of Plan 4H before experiments from 251-deg direction 


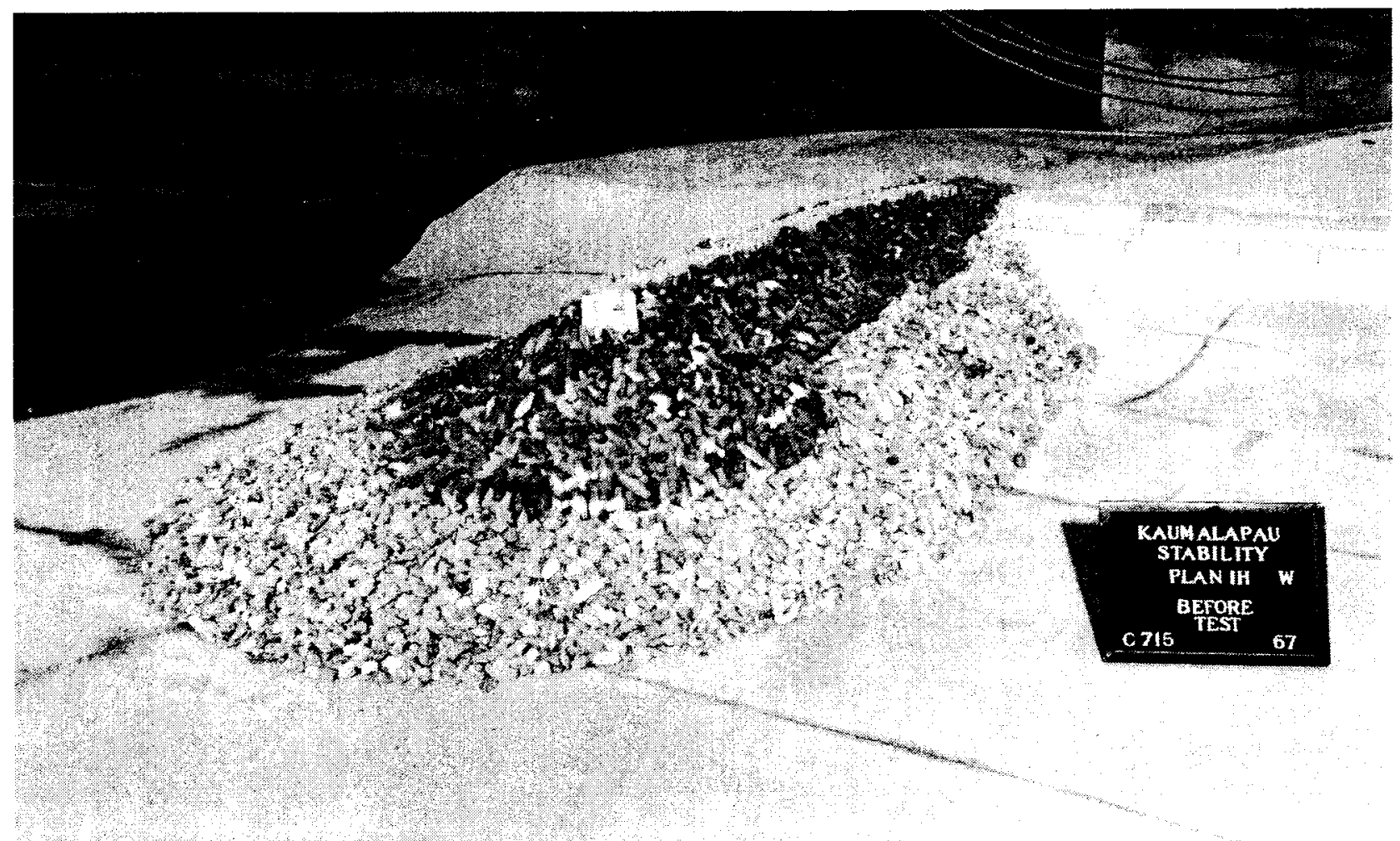

Photo B61. Plan 4H, breakwater head before experiments from 251-deg direction

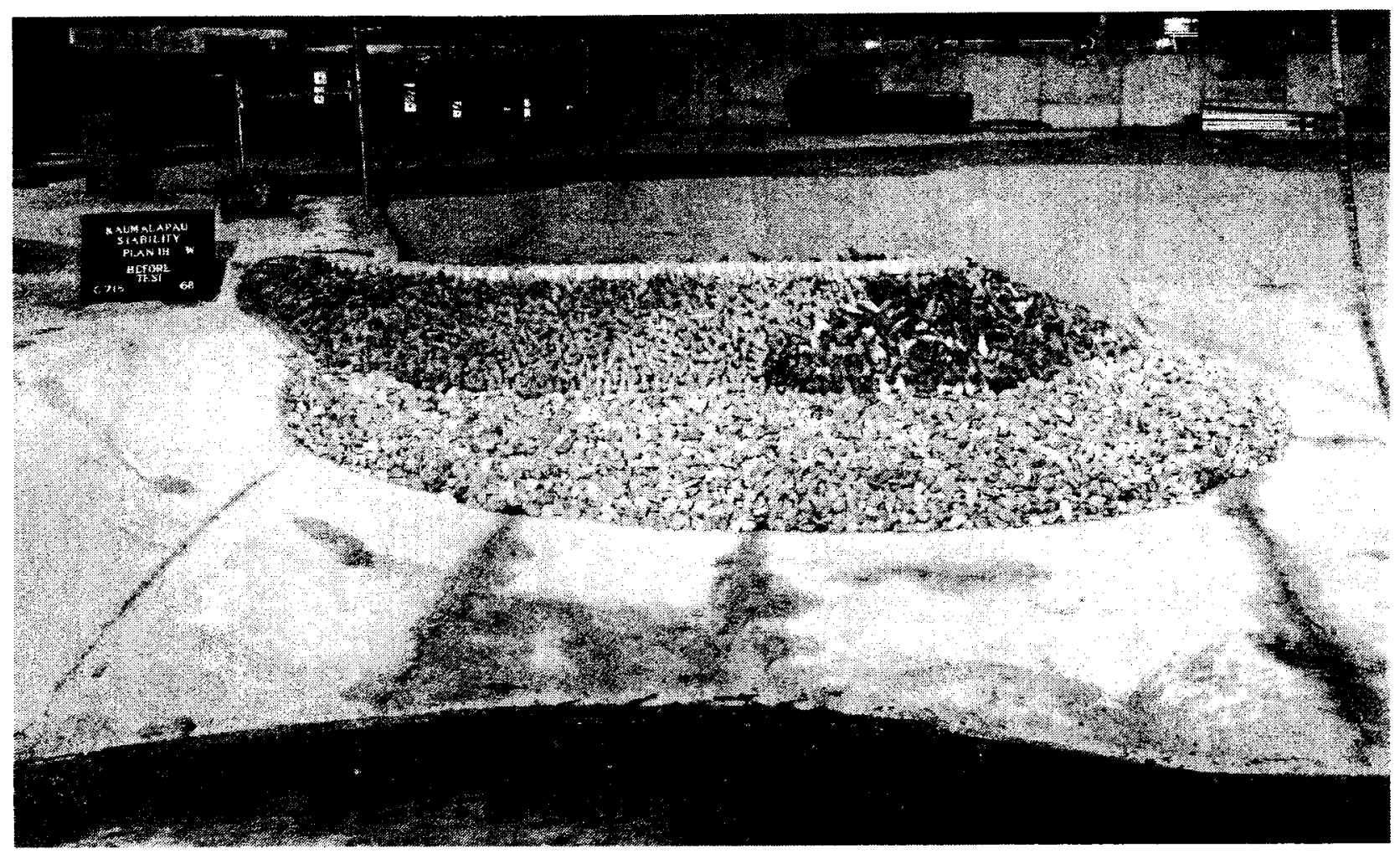

Photo B62. Sea-side view of Plan $4 \mathrm{H}$ before experiments from 251-deg direction 


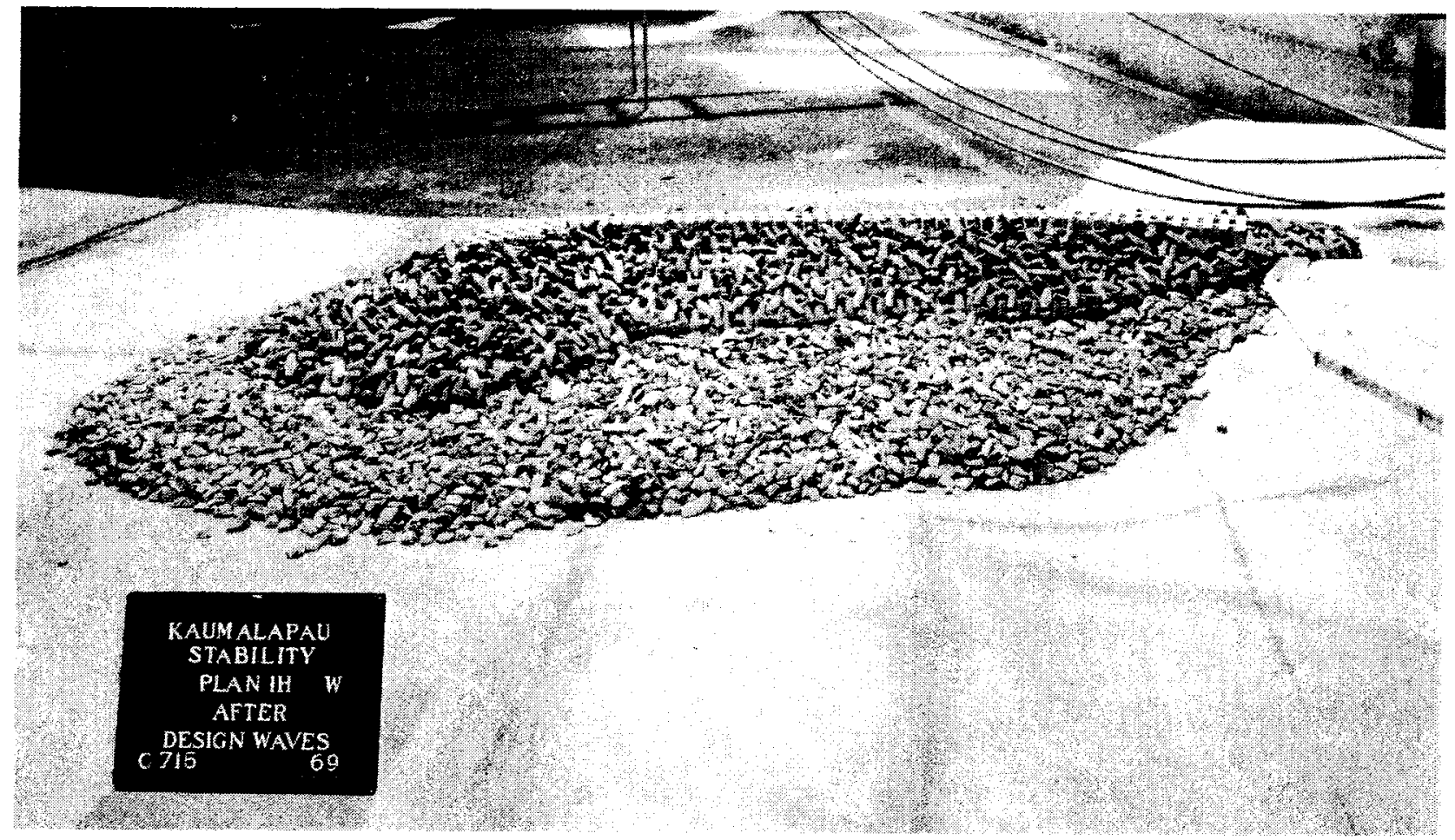

Photo B63. Leeside view of Plan $4 \mathrm{H}$ after 9.8- and 12-sec waves at design height and 16-sec waves up to $H_{o}=6.6 \mathrm{~m}$ from $251-\mathrm{deg}$ direction

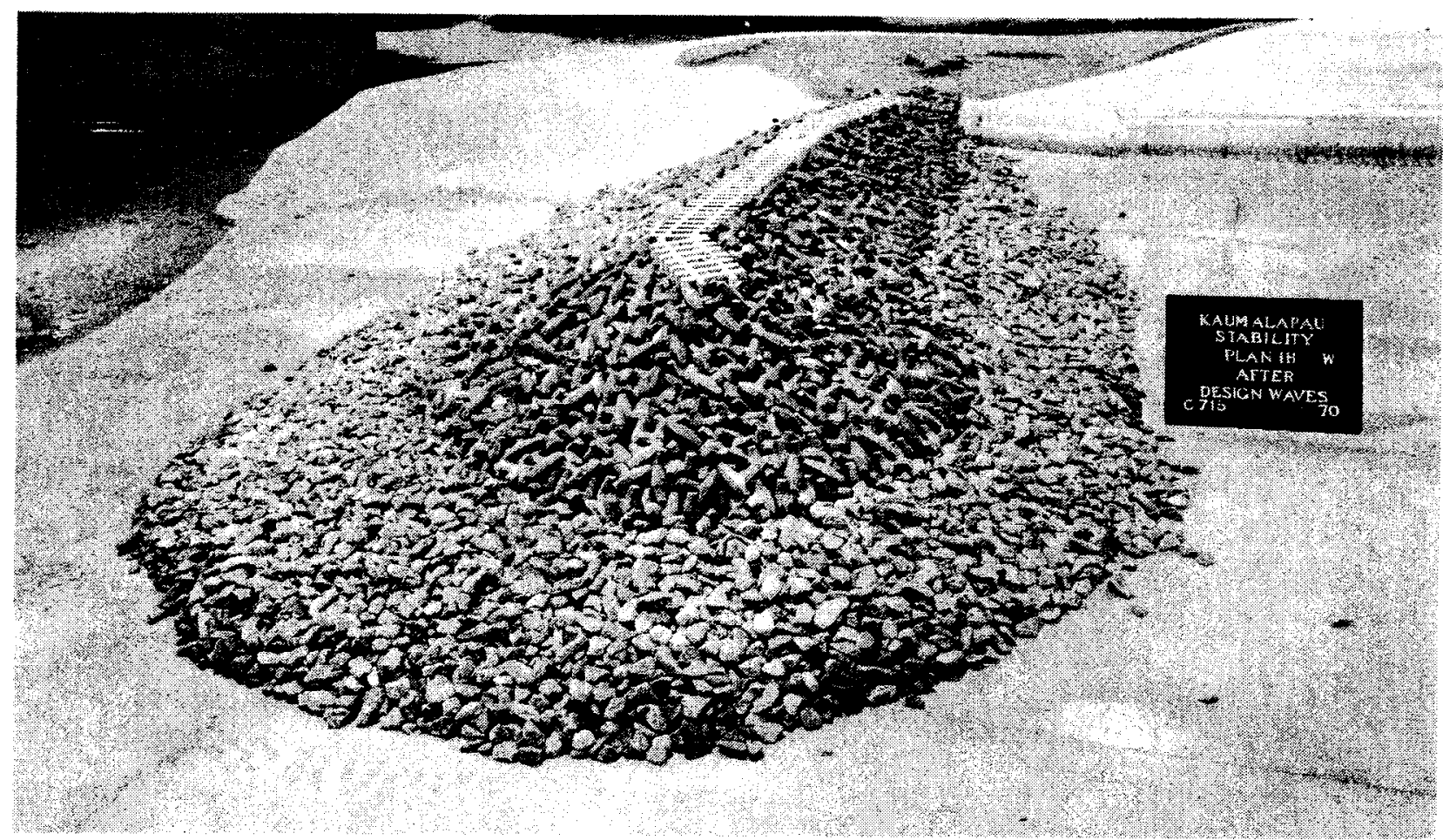

Photo B64. Plan 4H, breakwater head after 9.8- and 12-sec waves at design height and 16-sec waves up to $H_{0}=6.6 \mathrm{~m}$ from 251 -deg direction 


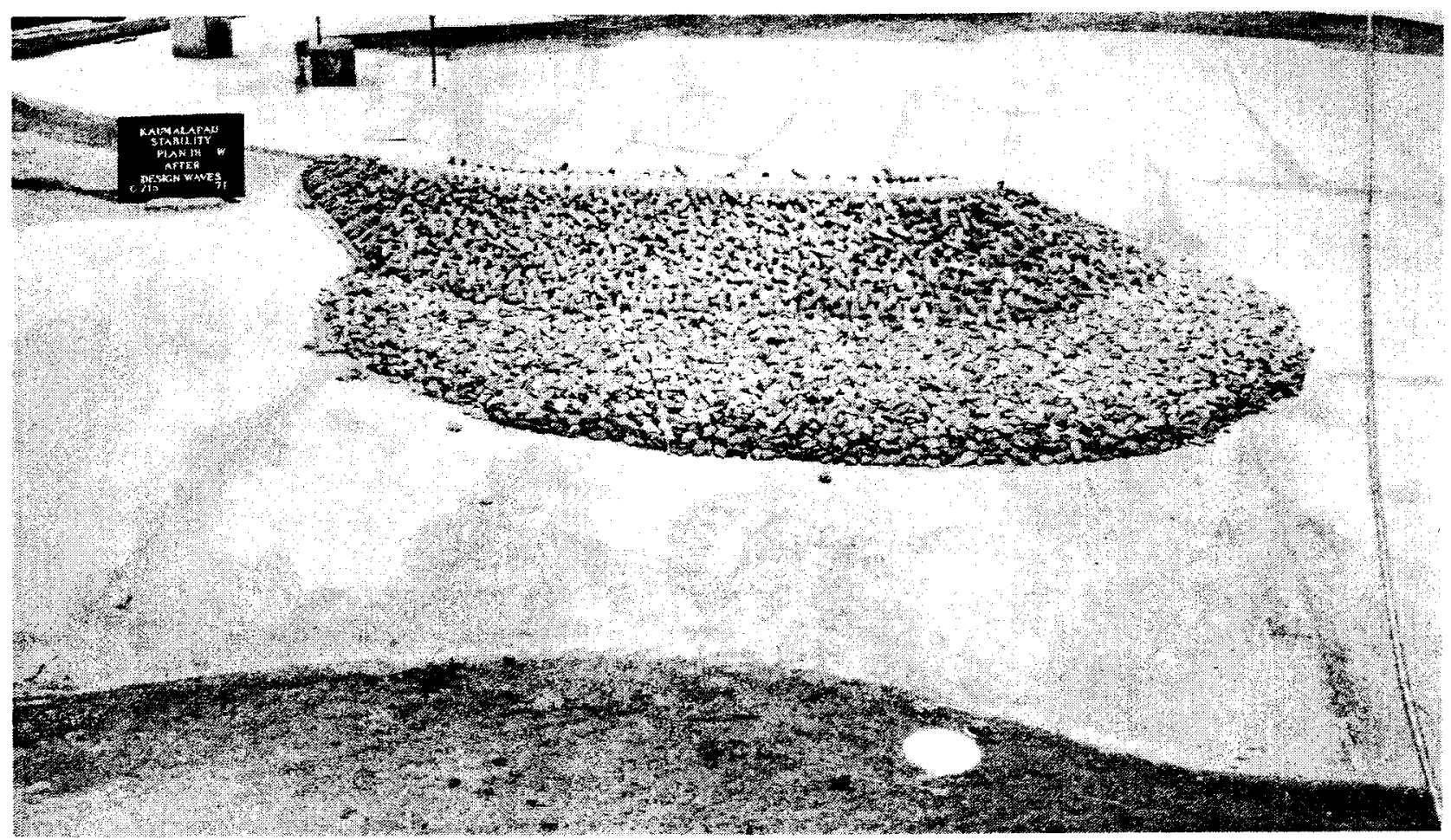

Photo B65. Sea-side view of Plan 4H after 9.8- and 12-sec waves at design height and 16-sec waves up to $H_{o}=6.6 \mathrm{~m}$ from 251-deg direction

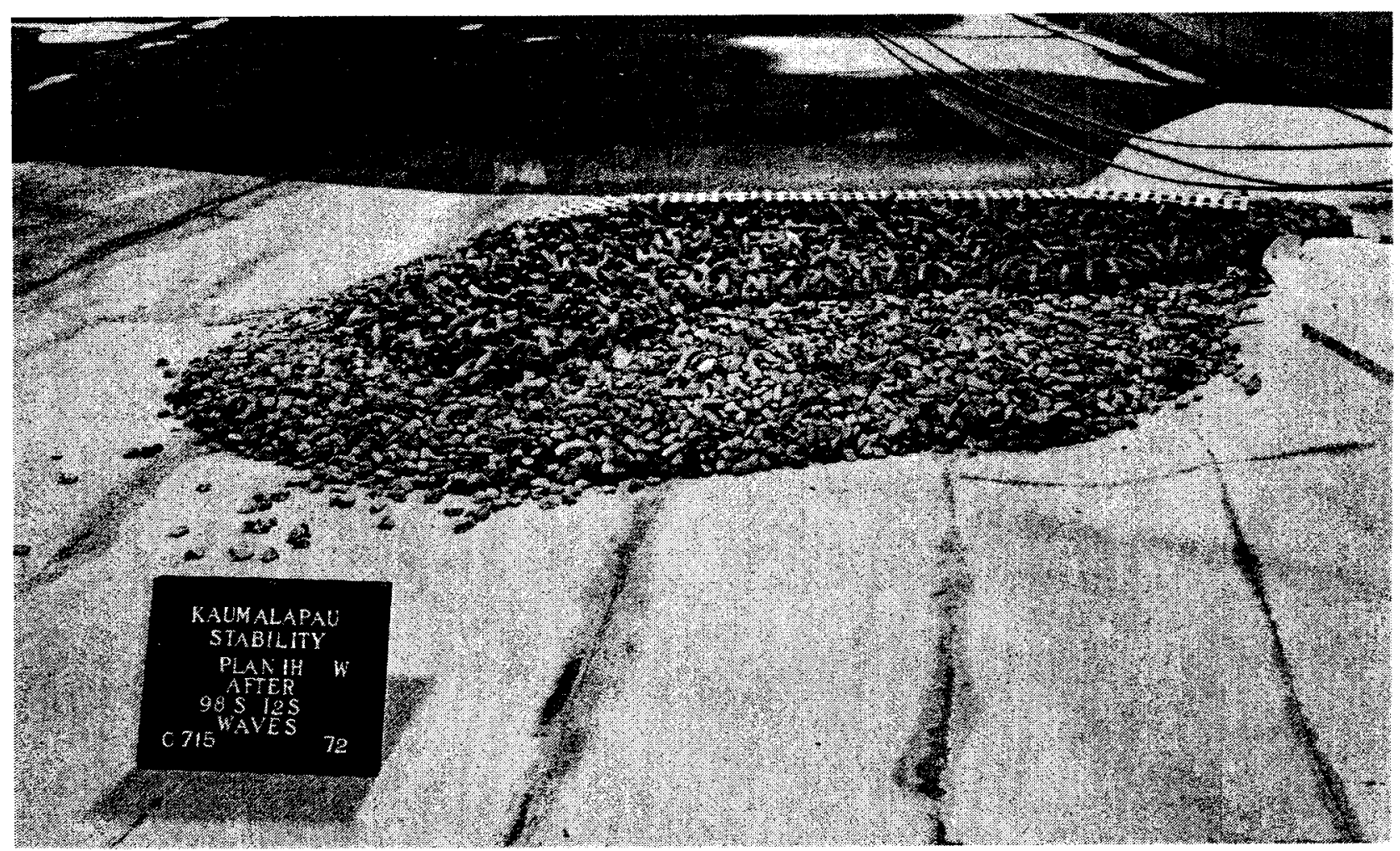

Photo B66. Leeside view of Plan 4H after maximum 9.8- and 12-sec waves from 251-deg direction 


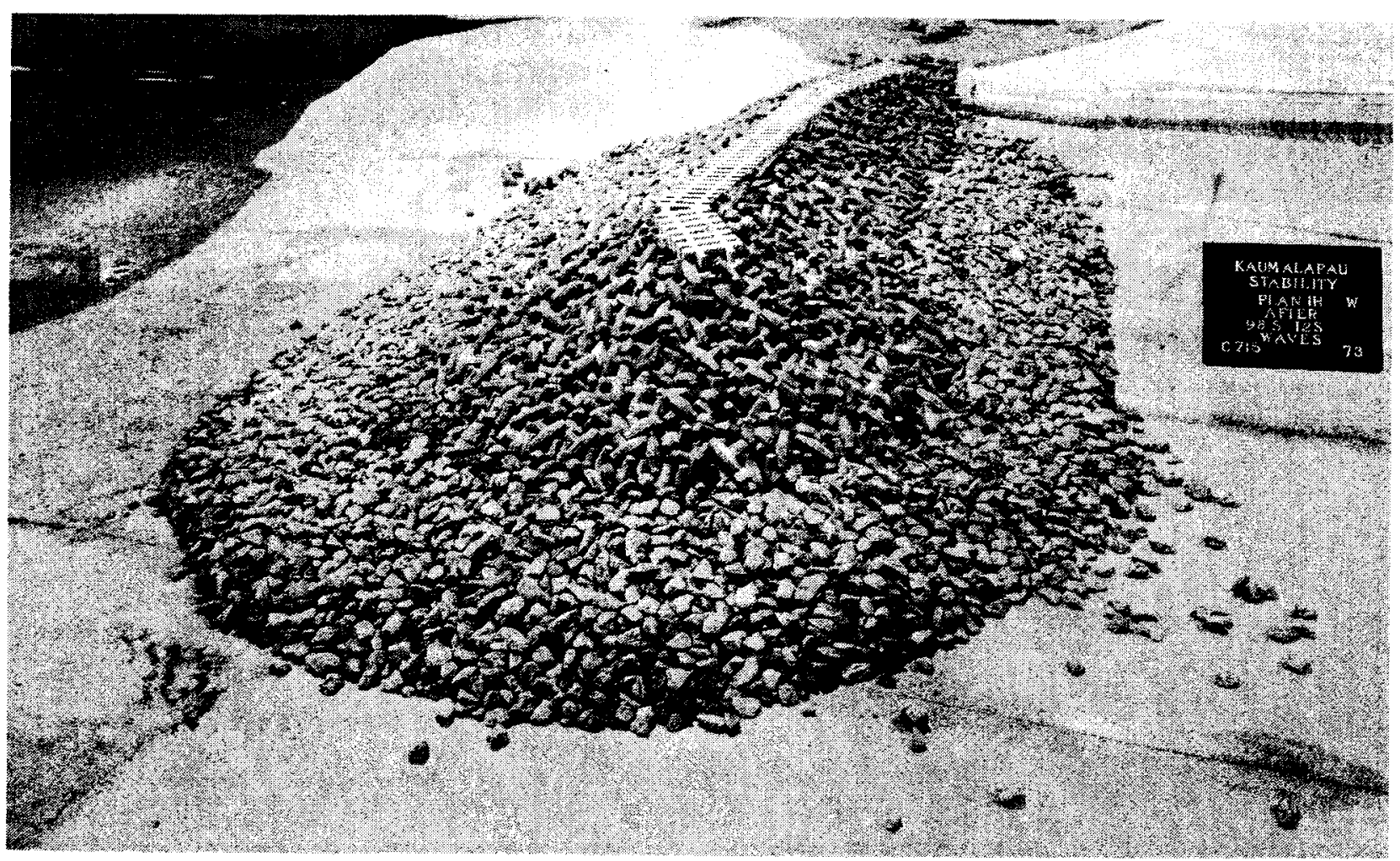

Photo B67. Plan 4H, breakwater head after 9.8- and 12-sec waves from 251-deg direction

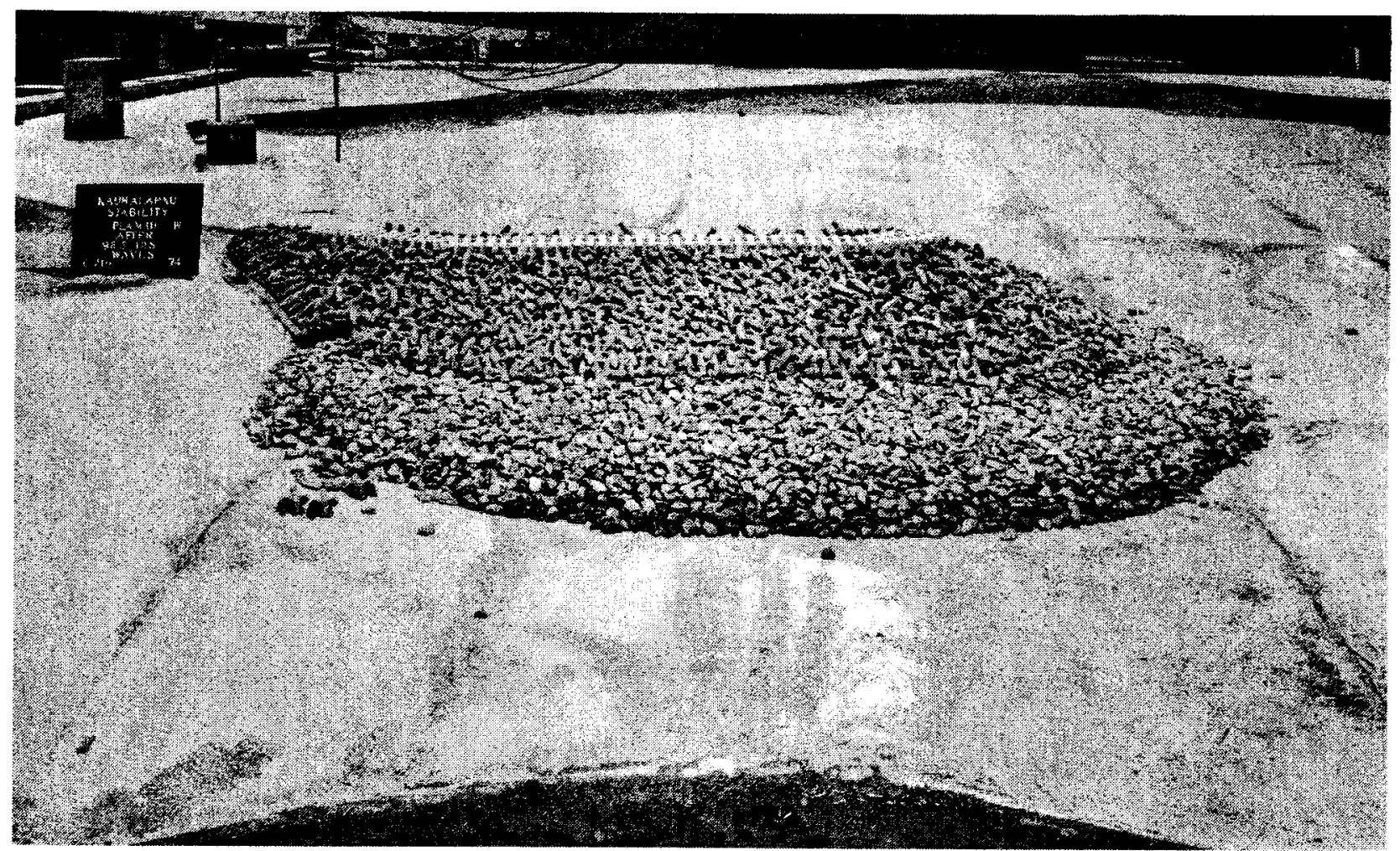

Photo B68. Sea-side view of Plan 4H after maximum 9.8- and 12-sec waves from 251-deg direction 


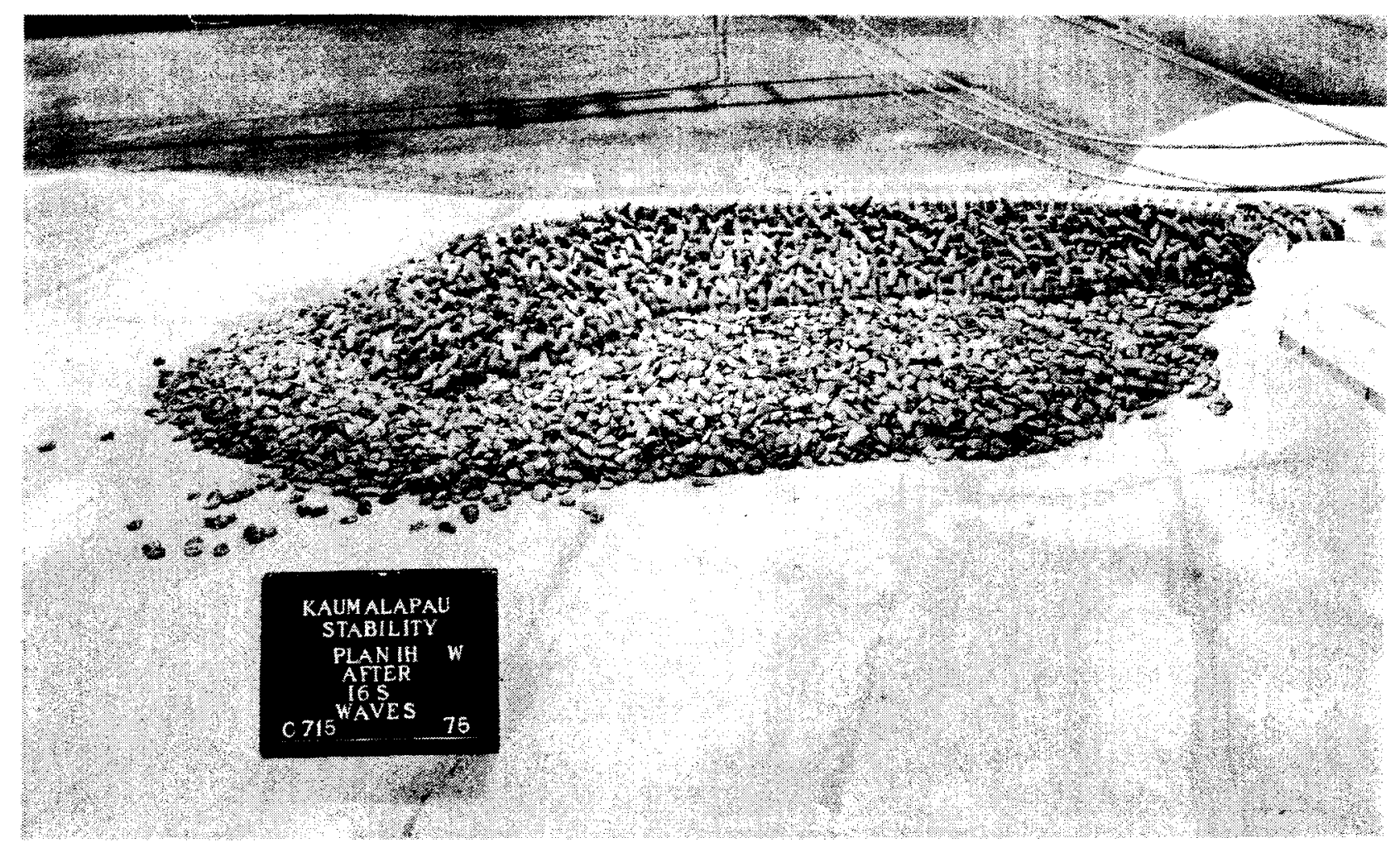

Photo B69. Leeside view of Plan 4H after 16-sec, 7.7-m waves from 251-deg direction

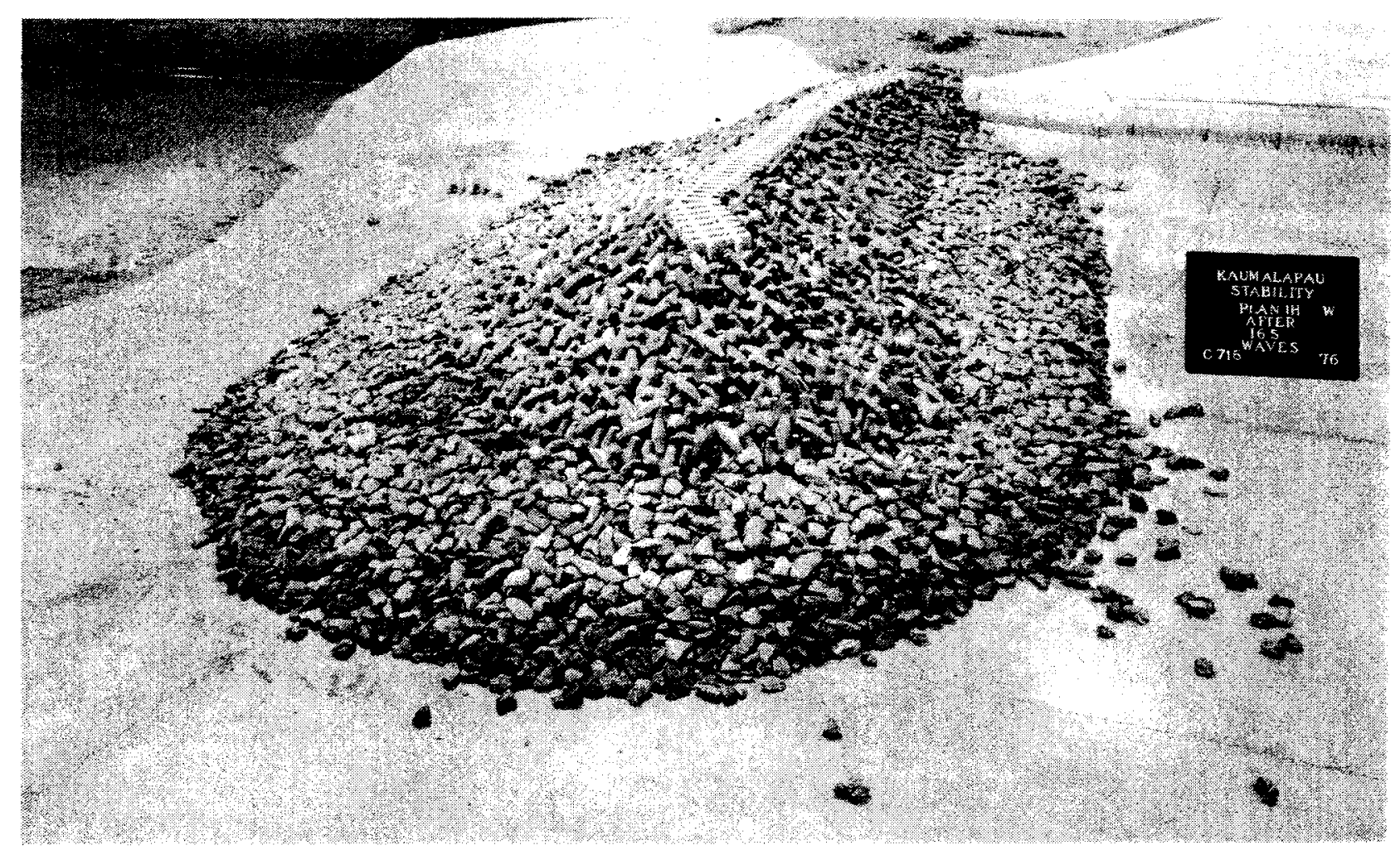

Photo B70. Plan 4H, breakwater head after 16-sec, 7.7-m waves from 251-deg direction 


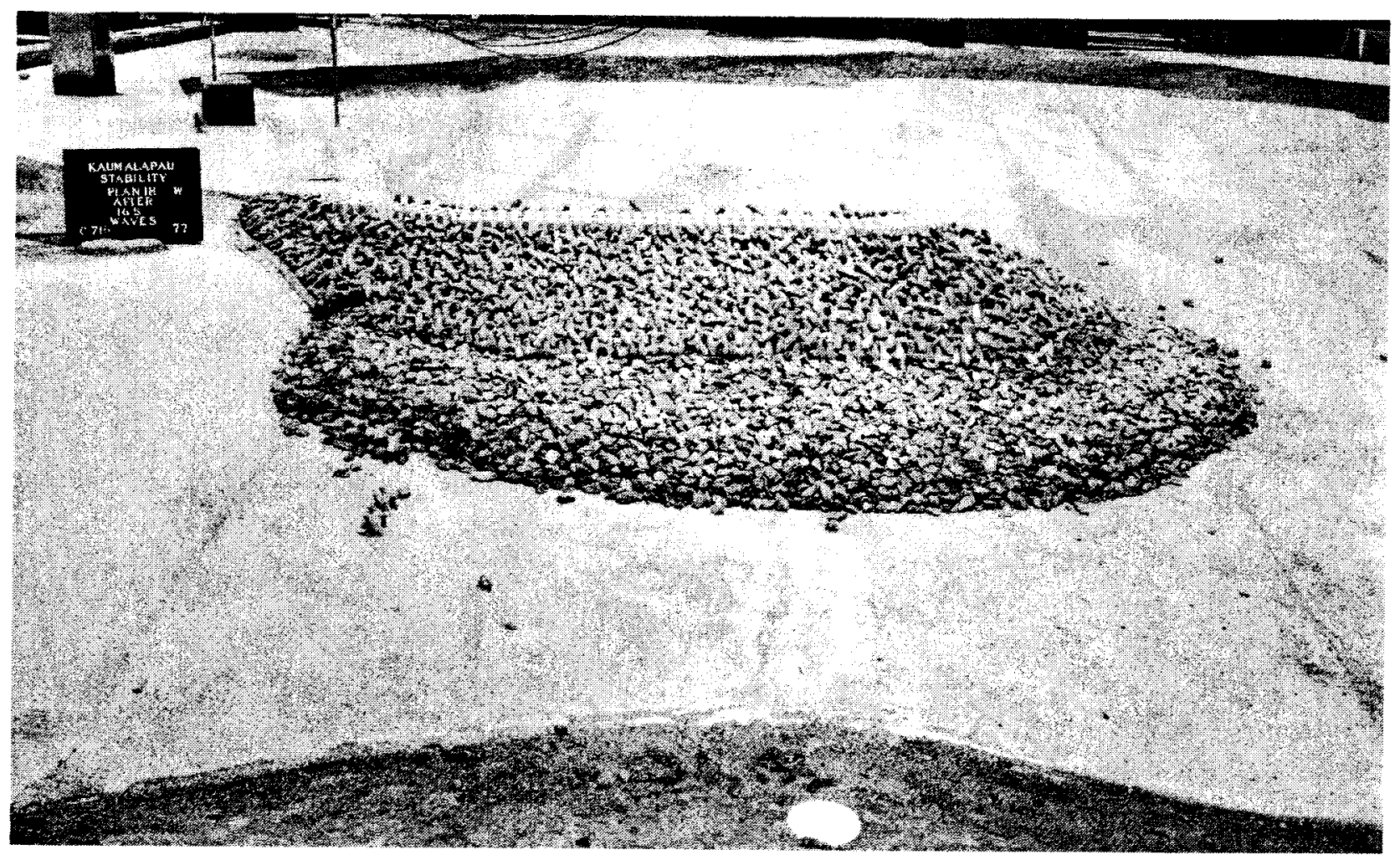

Photo B71. Sea-side view of Plan $4 \mathrm{H}$ after 16-sec, 7.7-m waves from 251-deg direction

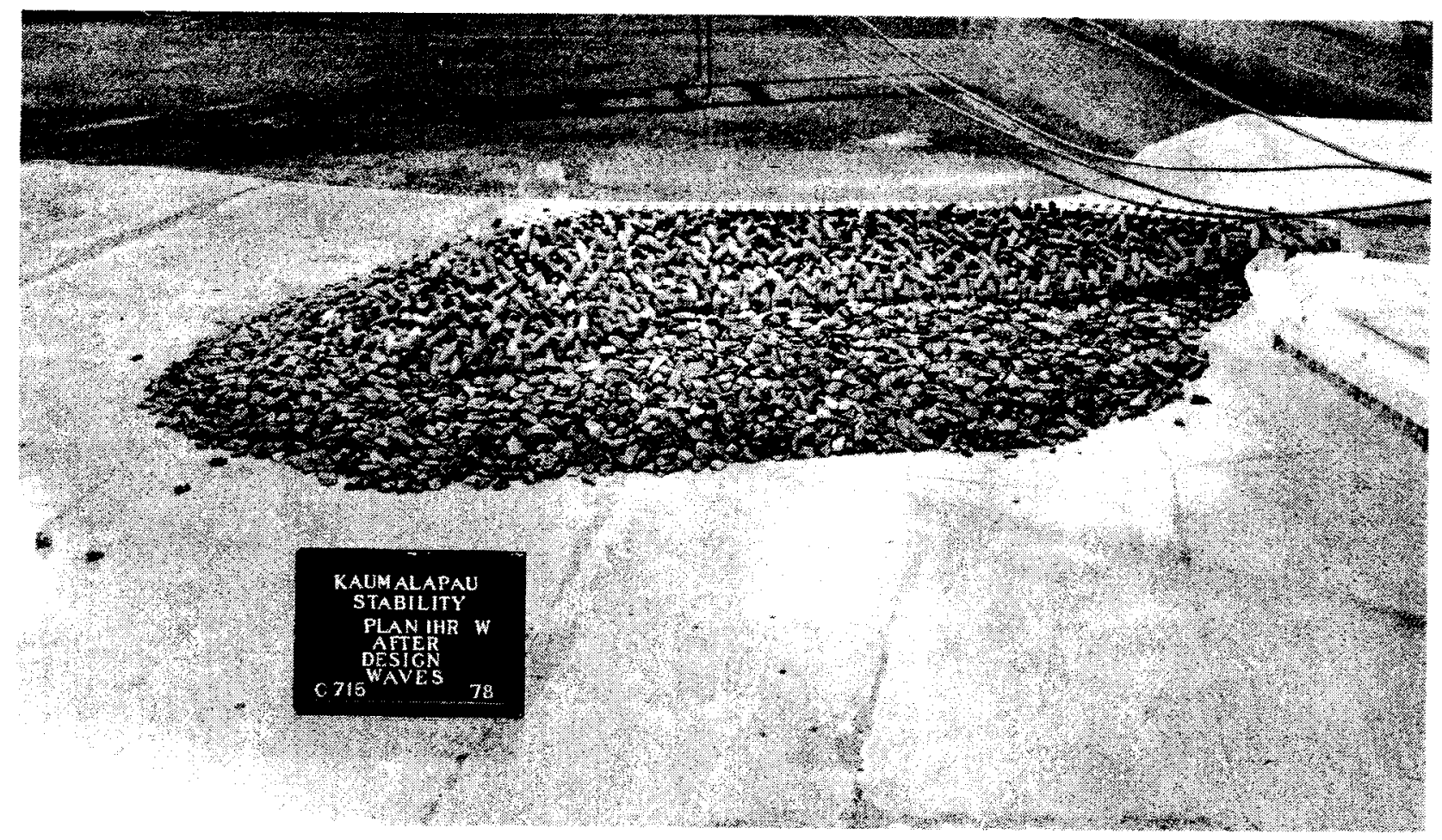

Photo B72. Leeside view of Plan 4H after 9.8- and 12-sec waves at design height and 16-sec waves up to $H_{o}=6.6 \mathrm{~m}$ from $251-\mathrm{deg}$ direction, repeat test 


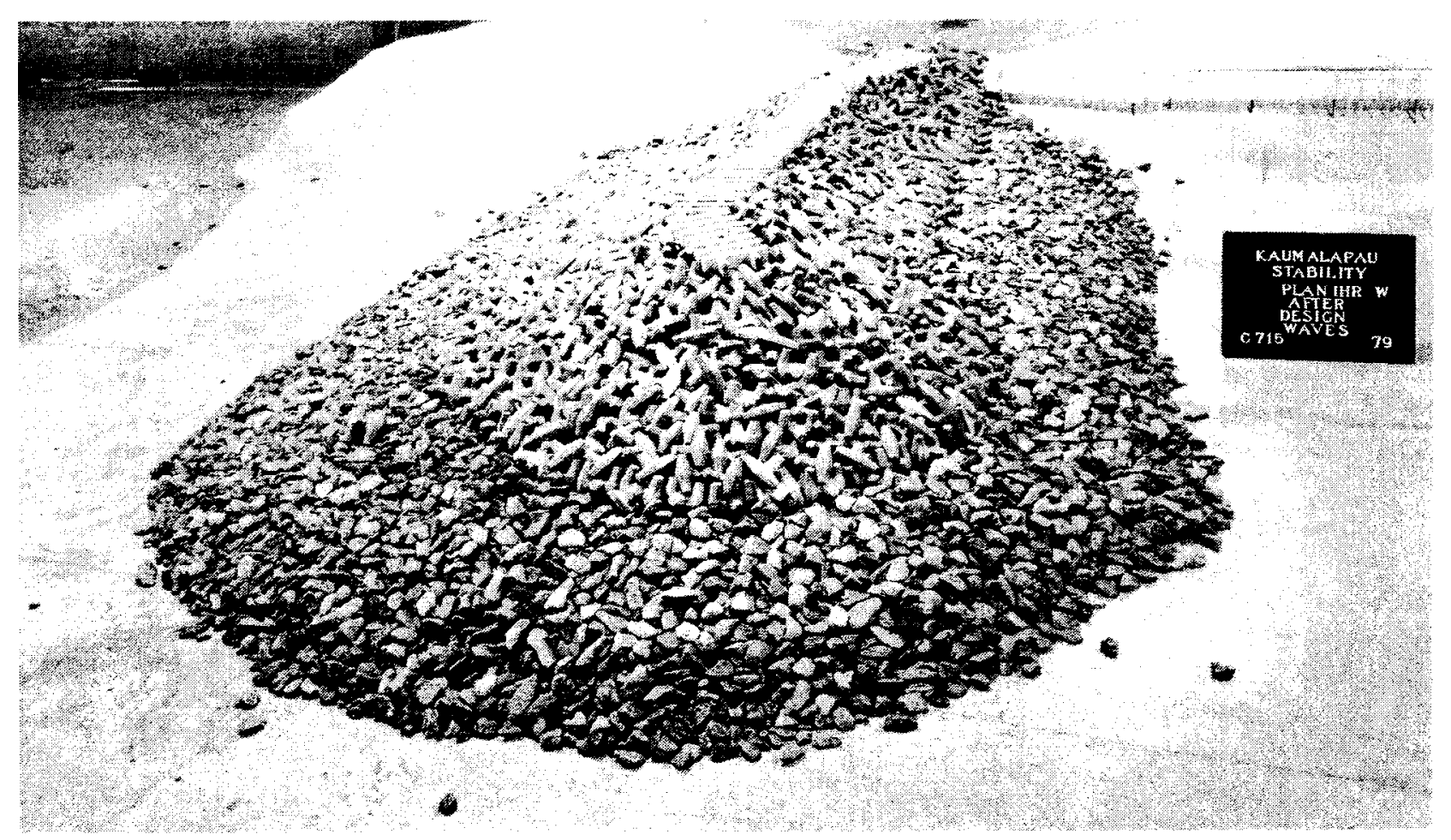

Photo B73. Plan $4 \mathrm{H}$, breakwater head after 9.8- and 12-sec waves at design height and 16-sec waves up to $H_{o}=6.6 \mathrm{~m}$ from 251 -deg direction, repeat test

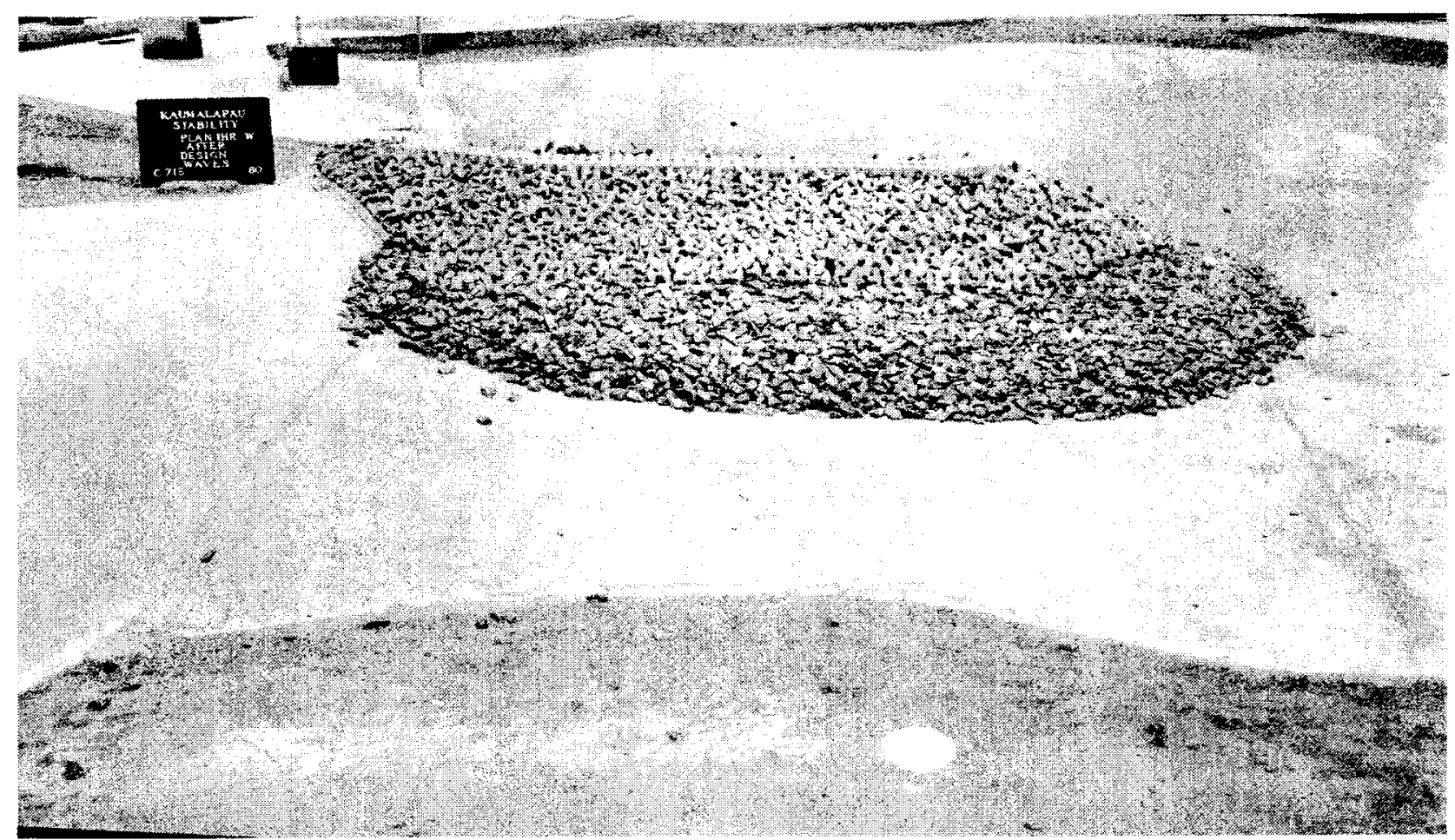

Photo B74. Sea-side view of Plan $4 \mathrm{H}$ after 9.8- and 12-sec waves at design height and 16-sec waves up to $H_{o}=6.6 \mathrm{~m}$ from $251-\mathrm{deg}$ direction, repeat test 


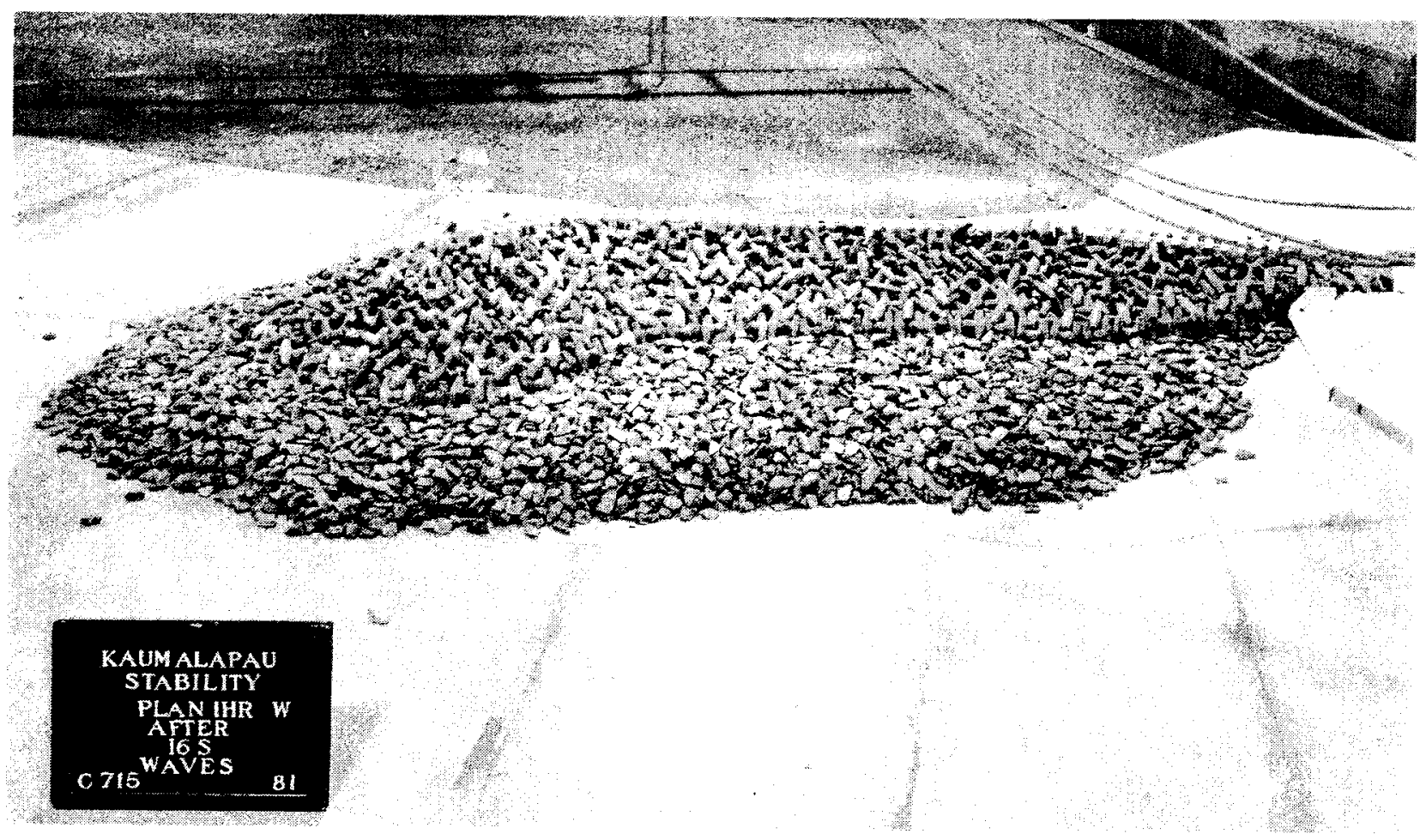

Photo B75. Leeside view of Plan $4 \mathrm{H}$ after maximum 9.8- and 12-sec waves and 16-sec waves up to $H_{0}=8.5 \mathrm{~m}$ from 251-deg direction, repeat test

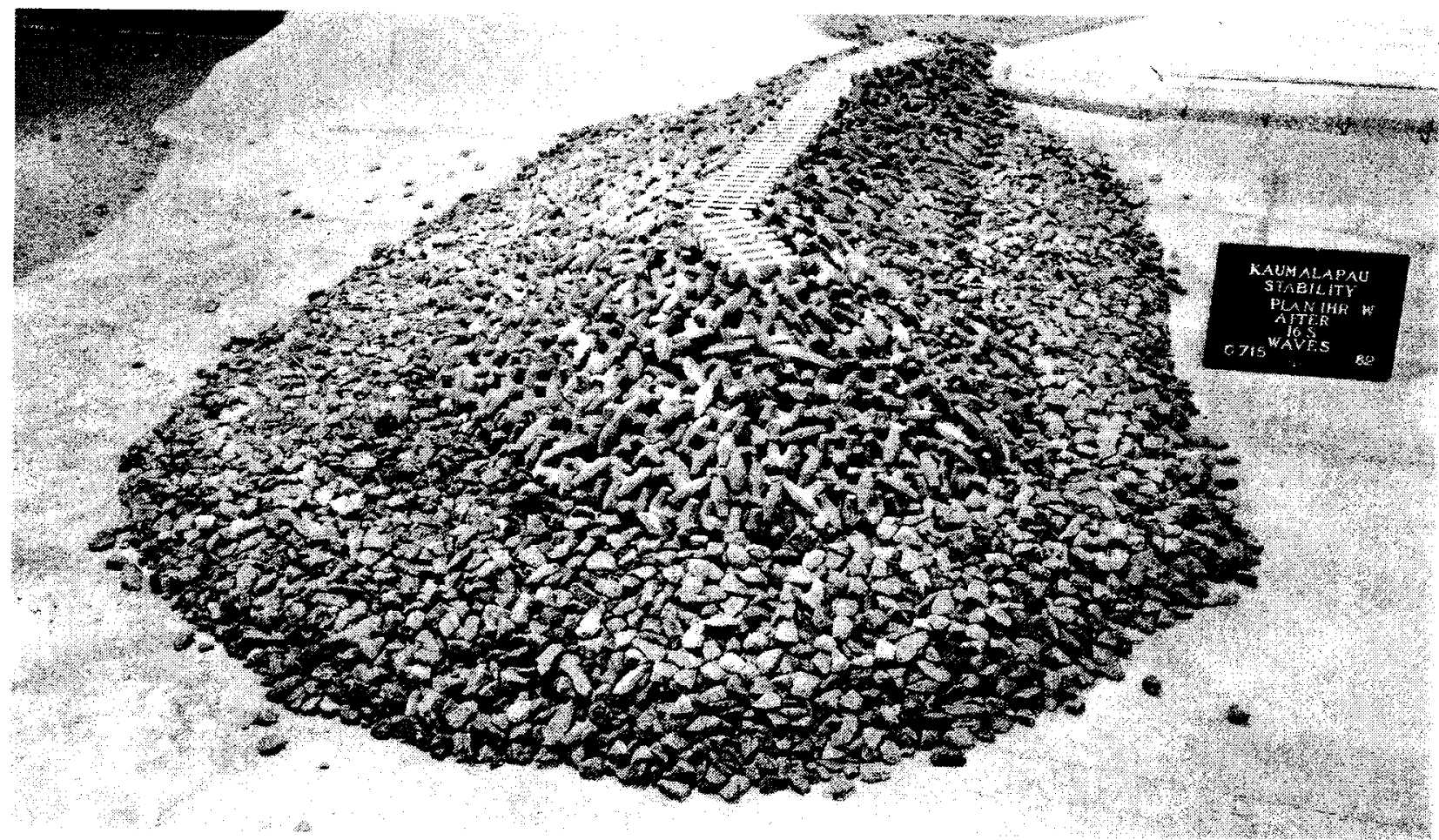

Photo B76. Plan $4 \mathrm{H}$, breakwater head after 9.8- and 12-sec waves and 16-sec waves up to $H_{0}=8.5 \mathrm{~m}$ from 251-deg direction, repeat test 


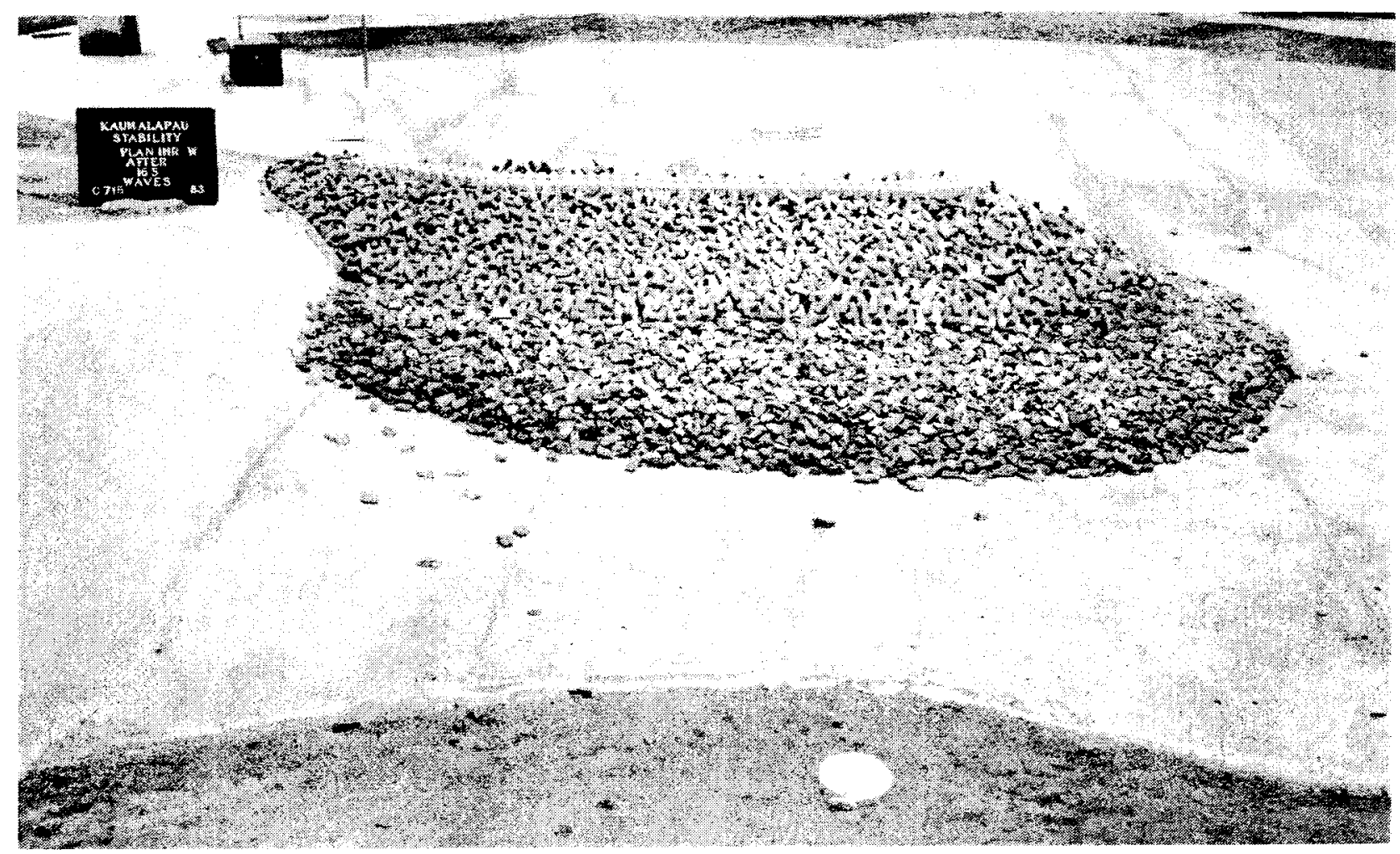

Photo B77. Sea-side view of Plan 4H after maximum 9.8- and 12-sec waves and 16-sec waves up to $H_{o}=8.5 \mathrm{~m}$ from 251-deg direction, repeat test 


\section{Appendix C Notation}

$a \quad$ Wave amplitude, $\mathrm{m}(\mathrm{ft})$

$a_{i} \quad$ Incident wave amplitude, $\mathrm{m}(\mathrm{ft})$

$A_{\text {amp }}$ Wave amplification factor

$\left(A_{\text {amp }}\right)_{\text {eff }}$ Effective, or spectral, wave amplification factor

$c \quad$ Wave phase speed, $\mathrm{m} / \mathrm{sec}(\mathrm{ft} / \mathrm{sec})$

$c_{g} \quad$ Wave group speed, $\mathrm{m} / \mathrm{sec}(\mathrm{ft} / \mathrm{sec})$

d Water depth, $\mathrm{m}(\mathrm{ft})$

$d_{\text {far }} \quad$ Water depth, $\mathrm{m}(\mathrm{ft})$

$f_{p} \quad$ Peak spectral frequency, $\sec ^{-1}$

$H \quad$ Wave height, $\mathrm{m}(\mathrm{ft})$

$H_{i} \quad$ Incident wave height, $\mathrm{m}(\mathrm{ft})$

$H_{\text {o }} \quad$ Deepwater wave height, $\mathrm{m}(\mathrm{ft})$

$H_{\mathrm{s}} \quad$ Significant wave height

$H_{m 0} \quad$ Energy-based, or zero-moment, estimate of significant wave height, $\mathrm{m}(\mathrm{ft})$

$i \quad(-1)^{1 / 2}$

I $\sqrt{-1}$

$\operatorname{Im}\{\phi\}$ Imaginary part of $\phi$

$K_{d} \quad$ Stability coefficient

$K_{r} \quad$ Reflection coefficient of a solid boundary, refraction coefficient

$K_{r, \text { coast }}$ Reflection coefficient of a solid boundary

$K_{\mathrm{s}} \quad$ Shoaling coefficient

$l \quad$ Length scale

$L \quad$ Wavelength

$l_{m} / l_{p} \quad$ Linear scale of the model

$L_{o} \quad$ Deepwater wave length

$L_{p} \quad$ Wavelength for waves at peak frequency

$m$ Model quantity (subscript)

$n \quad$ Unit normal vector directed into the solid region

$N \quad$ Number of units in a given area

$N_{a} \quad$ Normalized transmission coefficient

$N_{T} \quad$ Number of HARBD computational wave periods for spectral approximation

$p \quad$ Prototype quantity (subscript)

$r \quad$ Radial polar coordinate, $\mathrm{m}(\mathrm{ft})$

$\operatorname{Re}\{\phi\}$ Real part of $\phi$ 
$S_{a} \quad$ Specific gravity of an individual armor unit relative to the water in which it is placed, $S_{a}=\gamma_{d} / \gamma_{w}$

$S\left(f_{i}\right) \quad$ Spectral energy density at frequency, $f_{i}$

$T_{p} \quad$ Peak spectral wave period, sec

$u, v \quad$ Horizontal velocity components, $\mathrm{m} / \mathrm{sec}(\mathrm{ft} / \mathrm{sec})$

$V \quad$ Armor unit volume

$W_{a} \quad$ Weight of an individual armor unit

$w_{k} \quad$ Weighting factor for $k^{\prime}$ th HARBD computational frequency

$x, y \quad$ Horizontal coordinates, $\mathrm{m}(\mathrm{ft})$

$\beta \quad$ Dimensionless bottom friction coefficient

$\gamma \quad$ Spectral peak enhancement factor; phase shift between stress and flow velocity

$\gamma_{a} \quad$ Specific weight of an individual armor unit

$\gamma_{w} \quad$ Specific weight of water

$\Delta x \quad$ Element size

$\epsilon \quad$ Significant wave steepness

$\theta \quad$ Wave phase

$\theta \quad$ Angle of structure slope measured from horizontal in degrees

$K \quad$ Wave number

$\lambda \quad$ Complex bottom friction factor

$\phi \quad$ Velocity potential; packing density coefficient

$\phi^{s} \quad$ Velocity potential of the scattered wave

$\omega \quad$ Angular wave frequency, radians

$\nabla \quad$ Horizontal gradient operator

$\partial \quad$ Partial differentiation symbol 


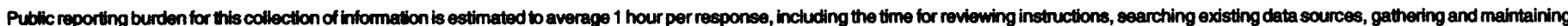
the data needed, and completing and reviewing the collection of information. Send comments reganding this burden estimate or any other aspect of this collection of information, inctuding suggestions

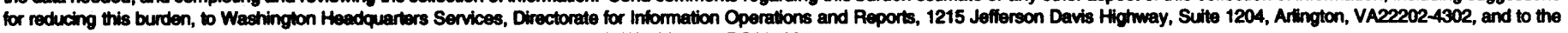
Office of Management and Budget, Papenwork Rectuction Project (0704-0188), Washington, DC20503.

\begin{tabular}{|l|l}
\hline 1.AGENCY USE ONLY (Loave blank) & $\begin{array}{l}\text { 2.REPORT DATE } \\
\text { May } 1998\end{array}$ \\
\hline
\end{tabular}

4.TITLE AND SUBTITLE

Wave Response of Kaumalapau Harbor, Lanai, Hawaii

6.AUTHOR(S)

Ernest R. Smith (Editor)

7.PERFORMING ORGANIZATION NAME(S) AND ADDRESS(ES)

U.S. Army Engineer Waterways Experiment Station

3909 Halls Ferry Road, Vicksburg, MS 39180-6199

3.REPORT TYPE AND DATES COVERED

Final report

9.SPONSORINGMONTORING AGENCY NAME(S) AND ADDRESS(ES)

U.S. Army Engineer Division, Pacific Ocean

10.SPONSORINGMONITORING

8.PERFORMING ORGANIZATION REPORT NUMBER

Fort Shafter, HI 96858-5440

\section{SUPPLEMENTARY NOTES}

Available from National Technical Information Service, 5285 Port Royal Road, Springfield, VA 22161.

\section{2a.DISTRIBUTIONAVALABIUTY STATEMENT}

12b.DISTRIBUTION CODE

Approved for public release; distribution is unlimited.

\section{ABSTRACT (Maximum 200 words)}

Kaumalapau Harbor, the main commercial harbor for Lanai, Hawaii, is being studied for development. This harbor is protected from the open ocean by a single rubble-mound breakwater. The U.S. Army Engineer Waterways Experiment Station (WES) was asked to carry out a wave response study for the harbor. WES collected field data to validate physical and numerical models and assess hindcast data. A numerical model study was used to assist in optimizing the placement of field wave gauges, to maximize efficiency of physical model experiments by identifying the most promising modification plans and most damaging incident wave directions, and to evaluate harbor oscillation characteristics of the proposed plan. An undistorted, three-dimensional physical model of Kaumalapau Harbor was used to evaluate harbor response to shortperiod waves for existing conditions and two alternative harbor layout configurations, straight and dogleg breakwater plans, respectively, for three incident wave directions as well as optimize the stability of the proposed breakwater design.

\begin{tabular}{|c|c|c|c|}
\hline \multirow{2}{*}{$\begin{array}{l}\text { Hindcast data } \\
\text { Kaumalapau Harbor }\end{array}$} & \multirow{2}{*}{\multicolumn{2}{|c|}{$\begin{array}{l}\text { Numerical models } \\
\text { Wave response studies }\end{array}$}} & $\begin{array}{l}\text { 15. NUMBER OF PAGES } \\
189\end{array}$ \\
\hline & & & 16.PRICE CODE \\
\hline $\begin{array}{l}\text { 17.SECURITY CLASSIFICATION } \\
\text { OF REPORT } \\
\text { UNCLASSIFIED }\end{array}$ & $\begin{array}{l}\text { 18.SECURITY CLASSIFICATION } \\
\text { OF THIS PAGE } \\
\text { UNCLASSIFIED }\end{array}$ & $\begin{array}{l}\text { 19.SECURITY CLASSIFICATION } \\
\text { OF ABSTRACT }\end{array}$ & 20.LAMITATION OF ABSTRACT \\
\hline
\end{tabular}

